\title{
Observations: Cryosphere
}

\section{Coordinating Lead Authors:}

David G. Vaughan (UK), Josefino C. Comiso (USA)

\section{Lead Authors:}

Ian Allison (Australia), Jorge Carrasco (Chile), Georg Kaser (Austria/ltaly), Ronald Kwok (USA), Philip Mote (USA), Tavi Murray (UK), Frank Paul (Switzerland/Germany), Jiawen Ren (China), Eric Rignot (USA), Olga Solomina (Russian Federation), Konrad Steffen (USA/Switzerland), Tingjun Zhang (USA/China)

\section{Contributing Authors:}

Anthony A. Arendt (USA), David B. Bahr (USA), Michiel van den Broeke (Netherlands), Ross Brown (Canada), J. Graham Cogley (Canada), Alex S. Gardner (USA), Sebastian Gerland (Norway), Stephan Gruber (Switzerland), Christian Haas (Canada), Jon Ove Hagen (Norway), Regine Hock (USA), David Holland (USA), Matthias Huss (Switzerland), Thorsten Markus (USA), Ben Marzeion (Austria), Rob Massom (Australia), Geir Moholdt (USA), Pier Paul Overduin (Germany), Antony Payne (UK), W. Tad Pfeffer (USA), Terry Prowse (Canada), Valentina Radić (Canada), David Robinson (USA), Martin Sharp (Canada), Nikolay Shiklomanov (USA), Sharon Smith (Canada), Sharon Stammerjohn (USA), Isabella Velicogna (USA), Peter Wadhams (UK), Anthony Worby (Australia), Lin Zhao (China)

\section{Review Editors:}

Jonathan Bamber (UK), Philippe Huybrechts (Belgium), Peter Lemke (Germany) 


\section{Table of Contents}

Executive Summary 319

4.1 Introduction 321

4.2 Sea Ice

4.2.1 Background 323

4.2.2 Arctic Sea Ice 323

4.2.3 Antarctic Sea Ice 330

4.3 Glaciers. 335

4.3.1 Current Area and Volume of Glaciers 335

4.3.2 Methods to Measure Changes in Glacier Length, Area and Volume/Mass

4.3.3 Observed Changes in Glacier Length, Area and Mass 338

4.4 Ice Sheets 344

4.4.1 Background 344

4.4.2 Changes in Mass of Ice Sheets.. 344

4.4.3 Total Ice Loss from Both Ice Sheets 353

4.4.4 Causes of Changes in Ice Sheets 353

4.4.5 Rapid Ice Sheet Changes 355
4.5 Seasonal Snow ............................................................. 358

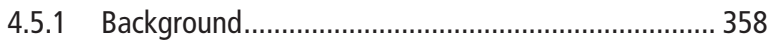

4.5.2 Hemispheric View......................................................... 358

4.5.3 Trends from In Situ Measurements............................ 359

4.5.4 Changes in Snow Albedo ........................................ 359

Box 4.1: Interactions of Snow within the Cryosphere 360

4.6 Lake and River Ice. 361

\subsection{Frozen Ground} 362

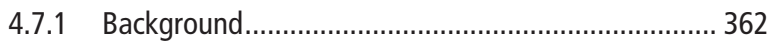

4.7.2 Changes in Permafrost.............................................. 362

4.7.3 Subsea Permafrost ................................................... 364

4.7.4 Changes in Seasonally Frozen Ground ...................... 364
4.8 Synthesis 367

References 369

Appendix 4.A: Details of Available and Selected Ice Sheet Mass Balance Estimates from 1992 to 2012 .......... 380

\section{Frequently Asked Questions}

FAQ 4.1 How Is Sea Ice Changing in the Arctic and Antarctic?

FAQ 4.2 Are Glaciers in Mountain Regions Disappearing?.

\section{Supplementary Material}

Supplementary Material is available in online versions of the report. 


\section{Executive Summary}

The cryosphere, comprising snow, river and lake ice, sea ice, glaciers, ice shelves and ice sheets, and frozen ground, plays a major role in the Earth's climate system through its impact on the surface energy budget, the water cycle, primary productivity, surface gas exchange and sea level. The cryosphere is thus a fundamental control on the physical, biological and social environment over a large part of the Earth's surface. Given that all of its components are inherently sensitive to temperature change over a wide range of time scales, the cryosphere is a natural integrator of climate variability and provides some of the most visible signatures of climate change.

Since AR4, observational technology has improved and key time series of measurements have been lengthened, such that our identification and measurement of changes and trends in all components of the cryosphere has been substantially improved, and our understanding of the specific processes governing their responses has been refined. Since the AR4, observations show that there has been a continued net loss of ice from the cryosphere, although there are significant differences in the rate of loss between cryospheric components and regions. The major changes occurring to the cryosphere are as follows.

\section{Sea Ice}

Continuing the trends reported in AR4, the annual Arctic sea ice extent decreased over the period 1979-2012. The rate of this decrease was very likely' ${ }^{1}$ between 3.5 and $4.1 \%$ per decade ( 0.45 to 0.51 million $\mathrm{km}^{2}$ per decade). The average decrease in decadal extent of Arctic sea ice has been most rapid in summer and autumn (high confidence ${ }^{2}$ ), but the extent has decreased in every season, and in every successive decade since 1979 (high confidence). $\{4.2 .2$, Figure 4.2$\}$

The extent of Arctic perennial and multi-year sea ice decreased between 1979 and 2012 (very high confidence). The perennial sea ice extent (summer minimum) decreased between 1979 and 2012 at $11.5 \pm 2.1 \%$ per decade ( 0.73 to 1.07 million $\mathrm{km}^{2}$ per decade) (very likely) and the multi-year ice (that has survived two or more summers) decreased at a rate of $13.5 \pm 2.5 \%$ per decade $(0.66$ to 0.98 million $\mathrm{km}^{2}$ per decade) (very likely). \{4.2.2, Figures 4.4, 4.6\}

The average winter sea ice thickness within the Arctic Basin decreased between 1980 and 2008 (high confidence). The average decrease was likely between 1.3 and $2.3 \mathrm{~m}$. High confidence in this assessment is based on observations from multiple sources: submarine, electro-magnetic (EM) probes, and satellite altimetry, and is consistent with the decline in multi-year and perennial ice extent $\{4.2 .2$, Figures
4.5, 4.6\} Satellite measurements made in the period 2010-2012 show a decrease in sea ice volume compared to those made over the period 2003-2008 (medium confidence). There is high confidence that in the Arctic, where the sea ice thickness has decreased, the sea ice drift speed has increased. \{4.2.2, Figure 4.6\}

It is likely that the annual period of surface melt on Arctic perennial sea ice lengthened by $5.7 \pm 0.9$ days per decade over the period 1979-2012. Over this period, in the region between the East Siberian Sea and the western Beaufort Sea, the duration of ice-free conditions increased by nearly 3 months. \{4.2.2, Figure 4.6\}

It is very likely that the annual Antarctic sea ice extent increased at a rate of between 1.2 and $1.8 \%$ per decade $(0.13$ to 0.20 million $\mathrm{km}^{2}$ per decade) between 1979 and 2012. There was a greater increase in sea ice area, due to a decrease in the percentage of open water within the ice pack. There is high confidence that there are strong regional differences in this annual rate, with some regions increasing in extent/area and some decreasing $\{4.2 .3$, Figure 4.7$\}$

\section{Glaciers}

Since AR4, almost all glaciers worldwide have continued to shrink as revealed by the time series of measured changes in glacier length, area, volume and mass (very high confidence). Measurements of glacier change have increased substantially in number since AR4. Most of the new data sets, along with a globally complete glacier inventory, have been derived from satellite remote sensing. $\{4.3 .1,4.3 .3$, Figures $4.9,4.10,4.11\}$

Between 2003 and 2009, most of the ice lost was from glaciers in Alaska, the Canadian Arctic, the periphery of the Greenland ice sheet, the Southern Andes and the Asian Mountains (very high confidence). Together these regions account for more than $80 \%$ of the total ice loss. \{4.3.3, Figure 4.11, Table 4.4\}

Total mass loss from all glaciers in the world, excluding those on the periphery of the ice sheets, was very likely $226 \pm 135$

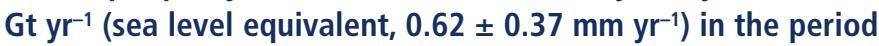
$1971-2009,275 \pm 135 \mathrm{Gt} \mathrm{yr}^{-1}\left(0.76 \pm 0.37 \mathrm{~mm} \mathrm{yr}^{-1}\right)$ in the period 1993-2009, and $301 \pm 135 \mathrm{Gt} \mathrm{yr}^{-1}\left(0.83 \pm 0.37 \mathrm{~mm} \mathrm{yr}^{-1}\right)$ between 2005 and 2009. \{4.3.3, Figure 4.12, Table 4.5\}

Current glacier extents are out of balance with current climatic conditions, indicating that glaciers will continue to shrink in the future even without further temperature increase (high confidence). $\{4.3 .3\}$

In this Report, the following terms have been used to indicate the assessed likelihood of an outcome or a result: Virtually certain 99-100\% probability, Very likely 90-100\%, Likely $66-100 \%$, About as likely as not 33-66\%, Unlikely 0-33\%, Very unlikely 0-10\%, Exceptionally unlikely 0-1\%. Additional terms (Extremely likely: 95-100\%, More likely than not $>50-100 \%$, and Extremely unlikely $0-5 \%$ ) may also be used when appropriate. Assessed likelihood is typeset in italics, e.g., very likely (see Section 1.4 and Box TS.1 for more details).

2 In this Report, the following summary terms are used to describe the available evidence: limited, medium, or robust; and for the degree of agreement: low, medium, or high. A level of confidence is expressed using five qualifiers: very low, low, medium, high, and very high, and typeset in italics, e.g., medium confidence. For a given evidence and agreement statement, different confidence levels can be assigned, but increasing levels of evidence and degrees of agreement are correlated with increasing confidence (see Section 1.4 and Box TS.1 for more details). 


\section{Ice Sheets}

The Greenland ice sheet has lost ice during the last two decades (very high confidence). Combinations of satellite and airborne remote sensing together with field data indicate with high confidence that the ice loss has occurred in several sectors and that large rates of mass loss have spread to wider regions than reported in AR4. \{4.4.2, 4.4.3, Figures 4.13, 4.15, 4.17\}

The rate of ice loss from the Greenland ice sheet has accelerated since 1992. The average rate has very likely increased from 34 [-6 to 74] Gt $\mathrm{yr}^{-1}$ over the period 1992-2001 (sea level equivalent, 0.09 [ -0.02 to 0.20 ] $\left.\mathrm{mm} \mathrm{yr}^{-1}\right)$, to 215 [157 to 274] $\mathrm{Gt} \mathrm{yr}^{-1}$ over the period 2002-2011 (0.59 [0.43 to 0.76] $\left.\mathrm{mm} \mathrm{yr}^{-1}\right)$. $\{4.4 .3$, Figures $4.15,4.17\}$

Ice loss from Greenland is partitioned in approximately similar amounts between surface melt and outlet glacier discharge (medium confidence), and both components have increased (high confidence). The area subject to summer melt has increased over the last two decades (high confidence). $\{4.4 .2\}$

The Antarctic ice sheet has been losing ice during the last two decades (high confidence). There is very high confidence that these losses are mainly from the northern Antarctic Peninsula and the Amundsen Sea sector of West Antarctica, and high confidence that they result from the acceleration of outlet glaciers. $\{4.4 .2,4.4 .3$, Figures $4.14,4.16,4.17\}$

The average rate of ice loss from Antarctica likely increased from 30 [-37 to 97] $\mathrm{Gt} \mathrm{yr}^{-1}$ (sea level equivalent, 0.08 [ -0.10 to 0.27 ] $\mathrm{mm} \mathrm{yr}^{-1}$ ) over the period 1992-2001, to 147 [72 to 221] $\mathrm{Gt} \mathrm{yr}^{-1}$ over the period 2002-2011 (0.40 [0.20 to 0.61$\left.] \mathrm{mm} \mathrm{yr}^{-1}\right)$. $\{4.4 .3$, Figures $4.16,4.17\}$

In parts of Antarctica, floating ice shelves are undergoing substantial changes (high confidence). There is medium confidence that ice shelves are thinning in the Amundsen Sea region of West Antarctica, and medium confidence that this is due to high ocean heat flux. There is high confidence that ice shelves round the Antarctic Peninsula continue a long-term trend of retreat and partial collapse that began decades ago. $\{4.4 .2,4.4 .5\}$

\section{Snow Cover}

Snow cover extent has decreased in the Northern Hemisphere, especially in spring (very high confidence). Satellite records indicate that over the period 1967-2012, annual mean snow cover extent decreased with statistical significance; the largest change, $-53 \%$ [very likely, $-40 \%$ to $-66 \%$ ], occurred in June. No months had statistically significant increases. Over the longer period, 1922-2012, data are available only for March and April, but these show a 7\% [very likely, $4.5 \%$ to $9.5 \%]$ decline and a strong negative $[-0.76]$ correlation with March-April $40^{\circ} \mathrm{N}$ to $60^{\circ} \mathrm{N}$ land temperature. $\{4.5 .2,4.5 .3\}$
Station observations of snow, nearly all of which are in the Northern Hemisphere, generally indicate decreases in spring, especially at warmer locations (medium confidence). Results depend on station elevation, period of record, and variable measured (e.g., snow depth or duration of snow season), but in almost every study surveyed, a majority of stations showed decreasing trends, and stations at lower elevation or higher average temperature were the most liable to show decreases. In the Southern Hemisphere, evidence is too limited to conclude whether changes have occurred. $\{4.5 .2,4.5 .3$, Figures $4.19,4.20,4.21\}$

\section{Freshwater Ice}

The limited evidence available for freshwater (lake and river) ice indicates that ice duration is decreasing and average seasonal ice cover shrinking (low confidence). For 75 Northern Hemisphere lakes, for which trends were available for 150-, 100- and 30-year periods ending in 2005, the most rapid changes were in the most recent period (medium confidence), with freeze-up occurring later (1.6 days per decade) and breakup earlier (1.9 days per decade). In the North American Great Lakes, the average duration of ice cover declined $71 \%$ over the period 1973-2010. \{4.6\}

\section{Frozen Ground}

Permafrost temperatures have increased in most regions since the early 1980s (high confidence) although the rate of increase has varied regionally. The temperature increase for colder permafrost was generally greater than for warmer permafrost (high confidence). $\{4.7 .2$, Table 4.8, Figure 4.24\}

Significant permafrost degradation has occurred in the Russian European North (medium confidence). There is medium confidence that, in this area, over the period 1975-2005, warm permafrost up to $15 \mathrm{~m}$ thick completely thawed, the southern limit of discontinuous permafrost moved north by up to $80 \mathrm{~km}$ and the boundary of continuous permafrost moved north by up to $50 \mathrm{~km}$. \{4.7.2\}

In situ measurements and satellite data show that surface subsidence associated with degradation of ice-rich permafrost occurred at many locations over the past two to three decades (medium confidence). $\{4.7 .4\}$

In many regions, the depth of seasonally frozen ground has changed in recent decades (high confidence). In many areas since the 1990s, active layer thicknesses increased by a few centimetres to tens of centimetres (medium confidence). In other areas, especially in northern North America, there were large interannual variations but few significant trends (high confidence). The thickness of the seasonally frozen ground in some non-permafrost parts of the Eurasian continent likely decreased, in places by more than $30 \mathrm{~cm}$ from 1930 to 2000 (high confidence) $\{4.7 .4\}$ 


\subsection{Introduction}

The cryosphere is the collective term for the components of the Earth system that contain a substantial fraction of water in the frozen state (Table 4.1). The cryosphere comprises several components: snow, river and lake ice; sea ice; ice sheets, ice shelves, glaciers and ice caps; and frozen ground which exist, both on land and beneath the oceans (see Glossary and Figure 4.1). The lifespan of each component is very different. River and lake ice, for example, are transient features that generally do not survive from winter to summer; sea ice advances and retreats with the seasons but especially in the Arctic can survive to become multi-year ice lasting several years. The East Antarctic ice sheet, on the other hand, is believed to have become relatively stable around 14 million years ago (Barrett, 2013). Nevertheless, all components of the cryosphere are inherently sensitive to changes in air temperature and precipitation, and hence to a changing climate (see Chapter 2).

Changes in the longer-lived components of the cryosphere (e.g., glaciers) are the result of an integrated response to climate, and the cryosphere is often referred to as a 'natural thermometer'. But as our understanding of the complexity of this response has grown, it is increasingly clear that elements of the cryosphere should rather be considered as a 'natural climate-meter', responsive not only to temperature but also to other climate variables (e.g., precipitation). However, it remains the case that the conspicuous and widespread nature of changes in the cryosphere (in particular, sea ice, glaciers and ice sheets) means these changes are frequently used emblems of the impact of changing climate. It is thus imperative that we understand the context of current change within the framework of past changes and natural variability.

The cryosphere is, however, not simply a passive indicator of climate change; changes in each component of the cryosphere have a significant and lasting impact on physical, biological and social systems. Ice sheets and glaciers exert a major control on global sea level (see Chapters 5 and 13), ice loss from these systems may affect global ocean circulation and marine ecosystems, and the loss of glaciers near populated areas as well as changing seasonal snow cover may have direct impacts on water resources and tourism (see WGII Chapters 3 and 24). Similarly, reduced sea ice extent has altered, and in the future may continue to alter, ocean circulation, ocean productivity and regional climate and will have direct impacts on shipping and mineral and oil exploration (see WGII, Chapter 28). Furthermore, decline in snow cover and sea ice will tend to amplify regional warming through snow and ice-albedo feedback effects (see Glossary and Chapter 9). In addition,

Table 4.1 | Representative statistics for cryospheric components indicating their general significance.

\begin{tabular}{|c|c|c|}
\hline Ice on Land & Percent of Global Land Surface & Sea Level Equivalent ${ }^{b}$ (metres) \\
\hline Antarctic ice sheet ${ }^{c}$ & 8.3 & 58.3 \\
\hline Greenland ice sheet ${ }^{d}$ & 1.2 & 7.36 \\
\hline Glacierse & 0.5 & 0.41 \\
\hline Terrestrial permafrost ${ }^{f}$ & $9-12$ & $0.02-0.10^{g}$ \\
\hline Seasonally frozen ground ${ }^{\mathrm{h}}$ & 33 & Not applicable \\
\hline $\begin{array}{l}\text { Seasonal snow cover } \\
\text { (seasonally variable) }\end{array}$ & $1.3-30.6$ & $0.001-0.01$ \\
\hline Northern Hemisphere freshwater (lake and river) ice & 1.1 & Not applicable \\
\hline Total $^{k}$ & $52.0-55.0 \%$ & $\sim 66.1$ \\
\hline Ice in the Ocean & Percent of Global Ocean Area ${ }^{a}$ & Volume $\left(10^{3} \mathrm{~km}^{3}\right)$ \\
\hline Antarctic ice shelves & $0.45^{\mathrm{m}}$ & $\sim 380$ \\
\hline Antarctic sea ice, austral summer (spring) ${ }^{n}$ & $0.8(5.2)$ & $3.4(11.1)$ \\
\hline Arctic sea ice, boreal autumn (winter/spring) ${ }^{n}$ & $1.7(3.9)$ & $13.0(16.5)$ \\
\hline Sub-sea permafrost ${ }^{\circ}$ & $\sim 0.8$ & Not available \\
\hline Totalp & $5.3-7.3$ & \\
\hline
\end{tabular}

Notes:

a Assuming a global land area of $147.6 \mathrm{Mkm}^{2}$ and ocean area of $362.5 \mathrm{Mkm}^{2}$.

b See Glossary. Assuming an ice density of $917 \mathrm{~kg} \mathrm{~m}^{-3}$, a seawater density of $1028 \mathrm{~kg} \mathrm{~m}^{-3}$, with seawater replacing ice currently below sea level.

c Area of grounded ice sheet not including ice shelves is $12.295 \mathrm{Mkm}^{2}$ (Fretwell et al., 2013).

d Area of ice sheet and peripheral glaciers is $1.801 \mathrm{Mkm}^{2}$ (Kargel et al., 2012). SLE (Bamber et al., 2013).

e Calculated from glacier outlines (Arendt et al., 2012), includes glaciers around Greenland and Antarctica. For sources of SLE see Table 4.2.

f Area of permafrost excluding permafrost beneath the ice sheets is 13.2 to $18.0 \mathrm{Mkm}^{2}$ (Gruber, 2012).

9 Value indicates the full range of estimated excess water content of Northern Hemisphere permafrost (Zhang et al., 1999).

h Long-term average maximum of seasonally frozen ground is $48.1 \mathrm{Mkm}^{2}$ (Zhang et al., 2003); excludes Southern Hemisphere.

Northern Hemisphere only (Lemke et al., 2007).

Areas and volume of freshwater (lake and river ice) were derived from modelled estimates of maximum seasonal extent (Brooks et al., 2012).

k To allow for areas of permafrost and seasonally frozen ground that are also covered by seasonal snow, total area excludes seasonal snow cover.

I Antarctic austral autumn (spring) (Kurtz and Markus, 2012); and Arctic boreal autumn (winter) (Kwok et al., 2009). For the Arctic, volume includes only sea ice in the Arctic Basin.

m Area is $1.617 \mathrm{Mkm}^{2}$ (Griggs and Bamber, 2011).

n Maximum and minimum areas taken from this assessment, Sections 4.2.2 and 4.2.3.

- Few estimates of the area of sub-sea permafrost exist in the literature. The estimate shown, $2.8 \mathrm{Mkm}^{2}$, has significant uncertainty attached and was assembled from other publications by Gruber (2012).

p Summer and winter totals assessed separately. 


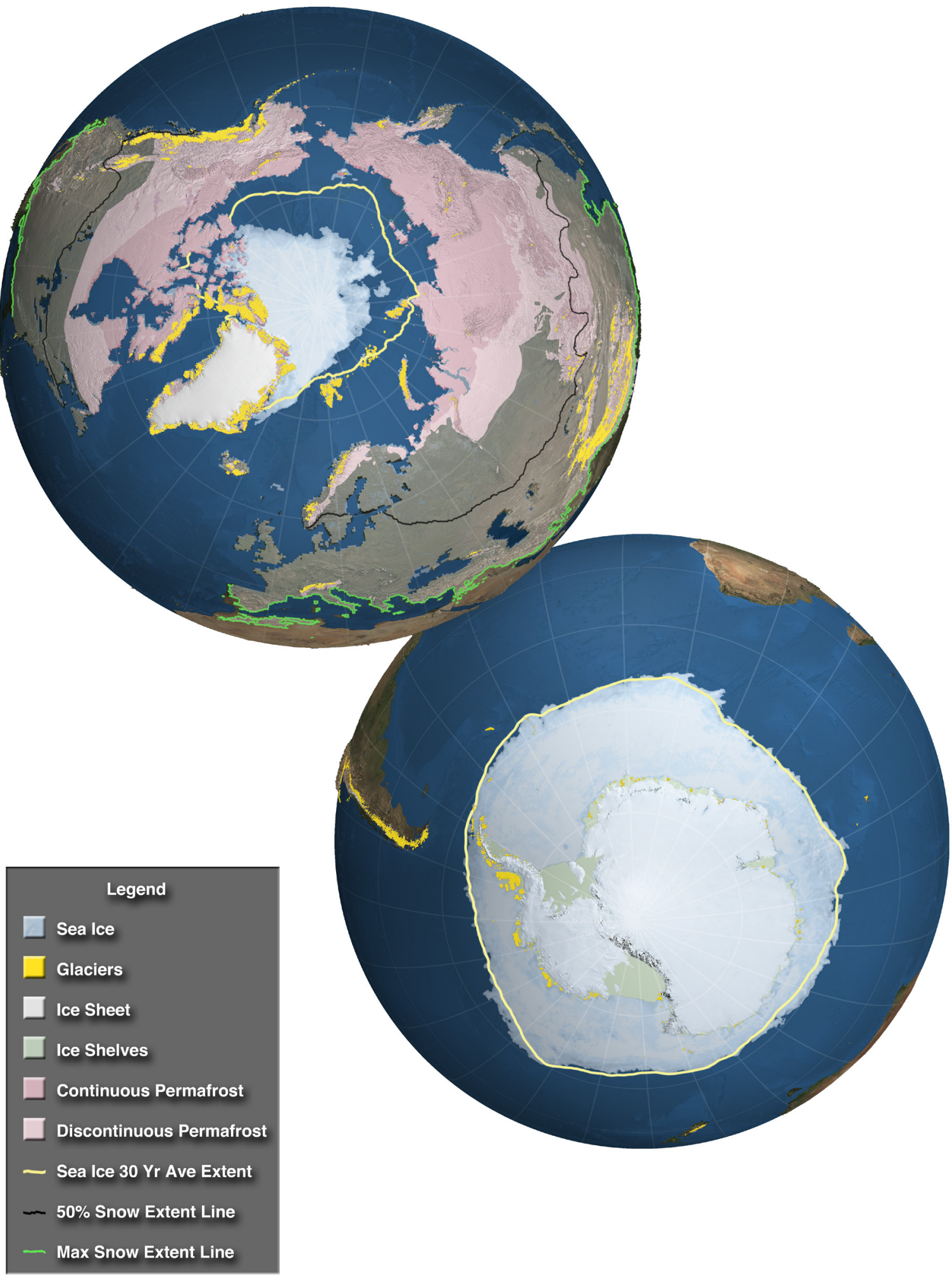

Figure 4.1 | The cryosphere in the Northern and Southern Hemispheres in polar projection. The map of the Northern Hemisphere shows the sea ice cover during minimum summer extent (13 September 2012). The yellow line is the average location of the ice edge (15\% ice concentration) for the yearly minima from 1979 to 2012 . Areas of continuous permafrost (see Glossary) are shown in dark pink, discontinuous permafrost in light pink. The green line along the southern border of the map shows the maximum snow extent while the black line across North America, Europe and Asia shows the 50\% contour for frequency of snow occurrence. The Greenland ice sheet (blue/grey) and locations of glaciers (small gold circles) are also shown. The map of the Southern Hemisphere shows approximately the maximum sea ice cover during an austral winter (13 September 2012). The yellow line shows the average ice edge (15\% ice concentration) during maximum extent of the sea ice cover from 1979 to 2012 . Some of the elements (e.g., some glaciers and snow) located at low latitudes are not visible in this projection (see Figure 4.8). The source of the data for sea ice, permafrost, snow and ice sheet are data sets held at the National Snow and Ice Data Center (NSIDC), University of Colorado, on behalf of the North American Atlas, Instituto Nacional de Estadística, Geografía e Informática (Mexico), Natural Resources Canada, U.S. Geological Survey, Government of Canada, Canada Centre for Remote Sensing and The Atlas of Canada. Glacier locations were derived from the multiple data sets compiled in the Randolph Glacier Inventory (Arendt et al., 2012). 
changes in frozen ground (in particular, ice-rich permafrost) will damage some vulnerable Arctic infrastructure (see WGII, Chapter 28), and could substantially alter the carbon budget through the release of methane (see Chapter 6).

Since AR4, substantial progress has been made in most types of cryospheric observations. Satellite technologies now permit estimates of regional and temporal changes in the volume and mass of the ice sheets. The longer time series now available enable more accurate assessments of trends and anomalies in sea ice cover and rapid identification of unusual events such as the dramatic decline of Arctic summer sea ice extent in 2007 and 2012. Similarly, Arctic sea ice thickness can now be estimated using satellite altimetry, allowing pan-Arctic measurements of changes in volume and mass. A new global glacier inventory includes nearly all glaciers (Arendt et al., 2012) (42\% in AR4) and allows for much better estimates of the total ice volume and its past and future changes. Remote sensing measurements of regional glacier volume change are also now available widely and modelling of glacier mass change has improved considerably. Finally, fluctuations in the cryosphere in the distant and recent past have been mapped with increasing certainty, demonstrating the potential for rapid ice loss, compared to slow recovery, particularly when related to sea level rise.

This chapter describes the current state of the cryosphere and its individual components, with a focus on recent improvements in understanding of the observed variability, changes and trends. Projections of future cryospheric changes (e.g., Chapter 13) and potential drivers (Chapter 10) are discussed elsewhere. Earlier IPCC reports used cryospheric terms that have specific scientific meanings (see Cogley et al., 2011), but have rather different meanings in everyday language. To avoid confusion, this chapter uses the term 'glaciers' for what was previously termed 'glaciers and ice caps' (e.g., Lemke et al., 2007). For the two largest ice masses of continental size, those covering Greenland and Antarctica, we use the term 'ice sheets'. For simplicity, we use units such as gigatonnes (Gt, $10^{9}$ tonnes, or $10^{12} \mathrm{~kg}$ ). One gigatonne is approximately equal to one cubic kilometre of freshwater $\left(1.1 \mathrm{~km}^{3}\right.$ of ice), and $362.5 \mathrm{Gt}$ of ice removed from the land and immersed in the oceans will cause roughly $1 \mathrm{~mm}$ of global sea level rise (Cogley, 2012).

\subsection{Sea Ice}

\subsubsection{Background}

Sea ice (see Glossary) is an important component of the climate system. A sea ice cover on the ocean changes the surface albedo, insulates the ocean from heat loss, and provides a barrier to the exchange of momentum and gases such as water vapour and $\mathrm{CO}_{2}$ between the ocean and atmosphere. Salt ejected by growing sea ice alters the density structure and modifies the circulation of the ocean. Regional climate changes affect the sea ice characteristics and these changes can feed back on the climate system, both regionally and globally. Sea ice is also a major component of polar ecosystems; plants and animals at all trophic levels find a habitat in, or are associated with, sea ice.

Most sea ice exists as pack ice, and wind and ocean currents drive the drift of individual pieces of ice (called floes). Divergence and shear in sea ice motion create areas of open water where, during colder months, new ice can quickly form and grow. On the other hand, convergent ice motion causes the ice cover to thicken by deformation. Two relatively thin floes colliding with each other can 'raft', stacking one on top of the other and thickening the ice. When thicker floes collide, thick ridges may be built from broken pieces, with a height above the surface (ridge sail) of $2 \mathrm{~m}$ or more, and a much greater thickness $(\sim 10 \mathrm{~m})$ and width below the ocean surface (ridge keel).

Sea ice thickness also increases by basal freezing during winter months. But the thicker the ice becomes the more it insulates heat loss from the ocean to the atmosphere and the slower the basal growth is. There is an equilibrium thickness for basal ice growth that is dependent on the surface energy balance and heat from the deep ocean below. Snow cover lying on the surface of sea ice provides additional insulation, and also alters the surface albedo and aerodynamic roughness. But also, and particularly in the Antarctic, a heavy snow load on thin sea ice can depress the ice surface and allow seawater to flood the snow. This saturated snow layer freezes quickly to form 'snow ice' (see FAQ 4.1).

Because sea ice is formed from seawater it contains sea salt, mostly in small pockets of concentrated brine. The total salt content in newly formed sea ice is only 25 to $50 \%$ of that in the parent seawater, and the residual salt rejected as the sea ice forms alters ocean water density and stability. The salinity of the ice decreases as it ages, and particularly during the Arctic summer when melt water (including from melt ponds that form on the surface) drains through and flushes the ice. The salinity and porosity of sea ice affect its mechanical strength, its thermal properties and its electrical properties - the latter being very important for remote sensing.

Geographical constraints play a dominant but not an exclusive role in determining the quite different characteristics of sea ice in the Arctic and the Antarctic (see FAQ 4.1). This is one of the reasons why changes in sea ice extent and thickness are very different in the north and the south. We also have much more information on Arctic sea ice thickness than we do on Antarctic sea ice thickness, and so discuss Arctic and Antarctic separately in this assessment.

\subsubsection{Arctic Sea Ice}

Regional sea ice observations, which span more than a century, have revealed significant interannual changes in sea ice coverage (Walsh and Chapman, 2001). Since the advent of satellite multichannel passive microwave imaging systems in 1979, which now provide more than 34 years of continuous coverage, it has been possible to monitor the entire extent of sea ice with a temporal resolution of less than a day. A number of procedures have been used to convert the observed microwave brightness temperature into sea ice concentration - the fractional area of the ocean covered by ice-and thence to derive sea ice extent and area (Markus and Cavalieri, 2000; Comiso and Nishio, 2008). Sea ice extent is defined as the sum of ice covered areas with concentrations of at least $15 \%$, while ice area is the product of the ice concentration and area of each data element within the ice extent. A brief description of the different techniques for deriving sea ice concentration is provided in the Supplementary Material. The trends in the sea ice concentration, ice extent and ice area, as inferred from data 
derived from the different techniques, are generally compatible. A comparison of derived ice extents from different sources is presented in the next section and in the Supplementary Material. Results presented in this assessment are based primarily on a single technique (Comiso and Nishio, 2008) but the use of data from other techniques would provide generally the same conclusions.

Arctic sea ice cover varies seasonally, with average ice extent varying between about $6 \times 10^{6} \mathrm{~km}^{2}$ in the summer and about $15 \times 10^{6} \mathrm{~km}^{2}$ in the winter (Comiso and Nishio, 2008; Cavalieri and Parkinson, 2012; Meier et al., 2012). The summer ice cover is confined to mainly the Arctic Ocean basin and the Canadian Arctic Archipelago, while winter sea ice reaches as far south as $44^{\circ} \mathrm{N}$, into the peripheral seas. At the end of summer, the Arctic sea ice cover consists primarily of the previously thick, old and ridged ice types that survived the melt period. Interannual variability is largely determined by the extent of the ice cover in the peripheral seas in winter and by the ice cover that survives the summer melt in the Arctic Basin.

\subsubsection{Total Arctic Sea Ice Extent and Concentration}

Figure 4.2 (derived from passive microwave data) shows both the seasonality of the Arctic sea ice cover and the large decadal changes that have occurred over the last 34 years. Typically, Arctic sea ice reaches its maximum seasonal extent in February or March whereas the minimum occurs in September at the end of summer melt. Changes in decadal averages in Arctic ice extent are more pronounced in summer than in winter. The change in winter extent between 1979-1988 and 1989-1998 was negligible. Between 1989-1998 and 1999-2008, there was a decrease in winter extent of around $0.6 \times 10^{6} \mathrm{~km}^{2}$. This can be contrasted to a decrease in ice extent at the end of the summer (September) of $0.5 \times 10^{6} \mathrm{~km}^{2}$ between 1979-1988 and 1989-1998, followed by a further decrease of $1.2 \times 10^{6} \mathrm{~km}^{2}$ between 1989-1998 and 1999-2008. Figure 4.2 also shows that the change in extent from 1979-1988 to 1989-1998 was statistically significant mainly in spring and summer while the change from 1989-1998 to 1999-2008 was statistically significant during winter and summer. The largest interannual changes occur during the end of summer when only the thick components of the winter ice cover survive the summer melt (Comiso et al., 2008; Comiso, 2012).

For comparison, the average extents during the 2009-2012 period are also presented: the extent during this period was considerably less than in earlier periods in all seasons, except spring. The summer minimum extent was at a record low in 2012 following an earlier record set in 2007 (Stroeve et al., 2007; Comiso et al., 2008). The minimum ice extent in 2012 was $3.44 \times 10^{6} \mathrm{~km}^{2}$ while the low in 2007 was 4.22 $\times 10^{6} \mathrm{~km}^{2}$. For comparison, the record high value was $7.86 \times 10^{6} \mathrm{~km}^{2}$ in 1980. The low extent in 2012 (which is 18.5\% lower than in 2007) was probably caused in part by an unusually strong storm in the Central Arctic Basin on 4 to 8 August 2012 (Parkinson and Comiso, 2013). The extents for 2007 and 2012 were almost the same from June until the storm period in 2012, after which the extent in 2012 started to trend considerably lower than in 2007. The error bars, which represent 1 standard deviation ( $1 \sigma$ ) of samples used to estimate each data point, are smallest in the first decade and get larger with subsequent decades indicating much higher interannual variability in recent years. The error bars are also comparable in summer and winter during the first decade but become progressively larger for summer compared to winter in subsequent decades. These results indicate that the largest interannual variability has occurred in the summer and in the recent decade.

Although relatively short as a climate record, the 34-year satellite record is long enough to allow determination of significant and consistent trends of the time series of monthly anomalies (i.e., difference between the monthly and the averages over the 34-year record) of ice extent, area and concentration. The trends in ice concentration for the winter, spring, summer and autumn for the period November 1978 to December 2012 are shown in Figure 4.2 (b, c, d and e). The seasonal trends for different regions, except the Bering Sea, are negative. Ice cover changes are relatively large in the eastern Arctic Basin and most peripheral seas in winter and spring, while changes are pronounced almost everywhere in the Arctic Basin, except at greater than $82^{\circ} \mathrm{N}$, in summer and autumn. In connection with a comprehensive observational research program during the International Polar Year 2007-2008, regional studies primarily on the Canadian side of the Arctic revealed very similar patterns of spatial and interannual variability of the sea ice cover (Derksen et al., 2012).

From the monthly anomaly data, the trend in sea ice extent in the Northern Hemisphere (NH) for the period from November 1978 to December 2012 is $-3.8 \pm 0.3 \%$ per decade (very likely) (see FAQ 4.1). The error quoted is calculated from the standard deviation of the slope of the regression line. The baseline for the monthly anomalies is the average of all data for each month from November 1978 to December 2012. The trends for different regions vary greatly, ranging from $+7.3 \%$ per decade in the Bering Sea to $-13.8 \%$ per decade in the Gulf of St. Lawrence. This large spatial variability is associated with the complexity of the atmospheric and oceanic circulation system as manifested in the Arctic Oscillation (Thompson and Wallace, 1998). The trends also differ with season (Comiso and Nishio, 2008; Comiso et al., 2011). For the entire $\mathrm{NH}$, the trends in ice extent are $-2.3 \pm 0.5 \%,-1.8 \pm 0.5 \%$, $-6.1 \pm 0.8 \%$ and $-7.0 \pm 1.5 \%$ per decade (very likely) in winter, spring, summer and autumn, respectively. The corresponding trends in ice area are $-2.8 \pm 0.5 \%,-2.2 \pm 0.5 \%,-7.2 \pm 1.0 \%$, and $-7.8 \pm 1.3 \%$ per decade (very likely). Similar results were obtained by (Cavalieri and Parkinson, 2012) but cannot be compared directly since their data are for the period from 1979 to 2010 (see Supplementary Material). The trends for ice extent and ice area are comparable except in the summer and autumn, when the trend in ice area is significantly more than that in ice extent. This is due in part to increasing open water areas within the pack that may be caused by more frequent storms and more divergence in the summer (Simmonds et al., 2008). The trends are larger in the summer and autumn mainly because of the rapid decline in the multi-year ice cover (Comiso, 2012), as discussed in Section 4.2.2.3. The trends in $\mathrm{km}^{2} \mathrm{yr}^{-1}$ were estimated as in Comiso and Nishio (2008) and Comiso (2012) but the percentage trends presented in this chapter were calculated differently. Here the percentage is calculated as a difference from the first data point on the trend line whereas the earlier estimations used the difference from the mean value. The new percentage trends are only slightly different from the previous ones and the conclusions about changes are the same. 


\subsubsection{Longer Records of Arctic Ice Extent}

For climate analysis, the variability of the sea ice cover prior to the commencement of the satellite record in 1979 is also of interest. There are a number of pre-satellite records, some based on regional observations taken from ships or aerial reconnaissance (e.g., Walsh and Chapman, 2001; Polyakov et al., 2003) while others were based on
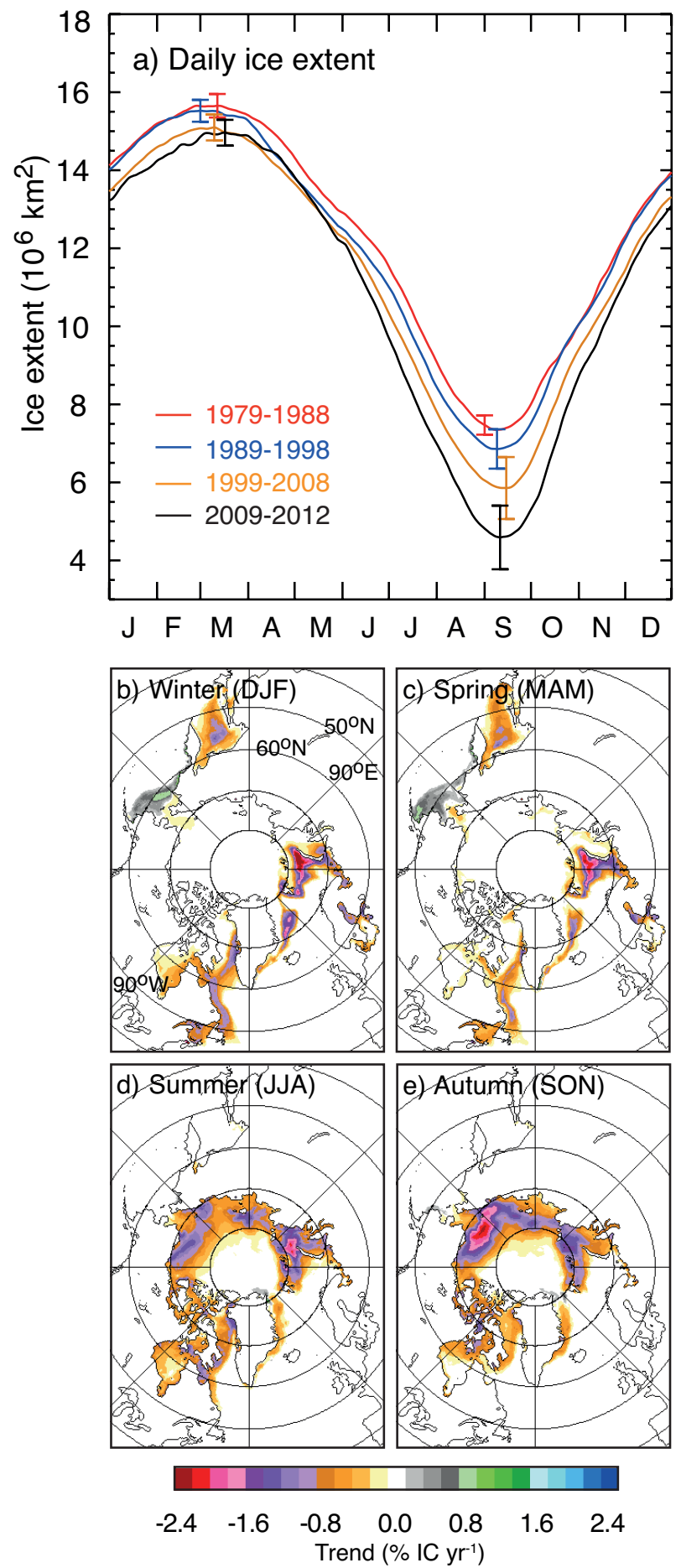

Figure 4.2 | (a) Plots of decadal averages of daily sea ice extent in the Arctic (1979 to 1988 in red, 1989 to 1998 in blue, 1999 to 2008 in gold) and a 4-year average daily ice extent from 2009 to 2012 in black. Maps indicate ice concentration trends (19792012) in (b) winter, (c) spring, (d) summer and (e) autumn (updated from Comiso, 2010). terrestrial proxies (e.g., Macias Fauria et al., 2010; Kinnard et al., 2011). The records constructed by Kinnard et al. (2011) and Macias Fauria et al. (2010) suggest that the decline of sea ice over the last few decades has been unprecedented over the past 1450 years (see Section 5.5.2). In a study of the marginal seas near the Russian coastline using ice extent data from 1900 to 2000, Polyakov et al. (2003) found a low frequency multi-decadal oscillation near the Kara Sea that shifted to a dominant decadal oscillation in the Chukchi Sea.

A more comprehensive basin-wide record, compiled by Walsh and Chapman (2001), showed very little interannual variability until the last three to four decades. For the period 1901 to 1998, their results show a summer mode that includes an anomaly of the same sign over nearly the entire Arctic and that captures the sea-ice trend from recent satellite data. Figure 4.3 shows an updated record of the Walsh and Chapman data set with longer time coverage (1870 to 1978) that is more robust because it includes additional historical sea ice observations (e.g., from Danish meteorological stations). A comparison of this updated data set with that originally reported by Walsh and Chapman (2001) shows similar interannual variability that is dominated by a nearly constant extent of the winter (January-February-March) and autumn (October-November-December) ice cover from 1870 to the 1950s. The absence of interannual variability during that period is due to the use of climatology to fill gaps, potentially masking the natural signal. Sea ice data from 1900-2011 as compiled by Met Office Hadley Centre are also plotted for comparison. In this data set, the 1979-2011 values were derived from various sources, including satellite data, as described by Rayner et al. (2003). Since the 1950s, more in situ data are available and have been homogenized with the satellite record (Meier et al., 2012). These data show a consistent decline in the sea ice cover that is relatively moderate during the winter but more dramatic during the summer months. Satellite data from other sources are also plotted in Figure 4.3, including Scanning Multichannel Microwave Radiometer (SMMR) and Special Sensor Microwave/lmager (SSM/I) data using the Bootstrap Algorithm (SBA) as described by Comiso and Nishio (2008) and National Aeronautics and Space Administration (NASA) Team Algorithm (NT1) as described by Cavalieri et al. (1984) (see Supplementary Material). Data from the Advanced Microwave Scanning Radiometer - Earth Observing System (AMSR-E) using the Bootstrap Algorithm (ABA) and the NASA Team Algorithm Version 2 (NT2) are also presented. The error bars represent one standard deviation of the interannual variability during the satellite period. Because of the use of climatology to fill data gaps from 1870 to 1953 , the error bars in the Walsh and Chapman data were set to twice that of the satellite period and 1.5 times higher for 1954 to 1978 . The apparent reduction of the sea ice extent from 1978 to 1979 is in part due to the change from surface observations to satellite data. Generally, the temporal distributions from the various sources are consistent with some exceptions that may be attributed to possible errors in the data (e.g., Screen, 2011 and Supplementary Material). Taking this into account, the various sources provide similar basic information and conclusions about the changing extent and variability of the Arctic sea ice cover.

\subsubsection{Multi-year/Seasonal Ice Coverage}

The winter extent and area of the perennial and multi-year ice cover in the Central Arctic (i.e., excluding Greenland Sea multi-year ice) for 

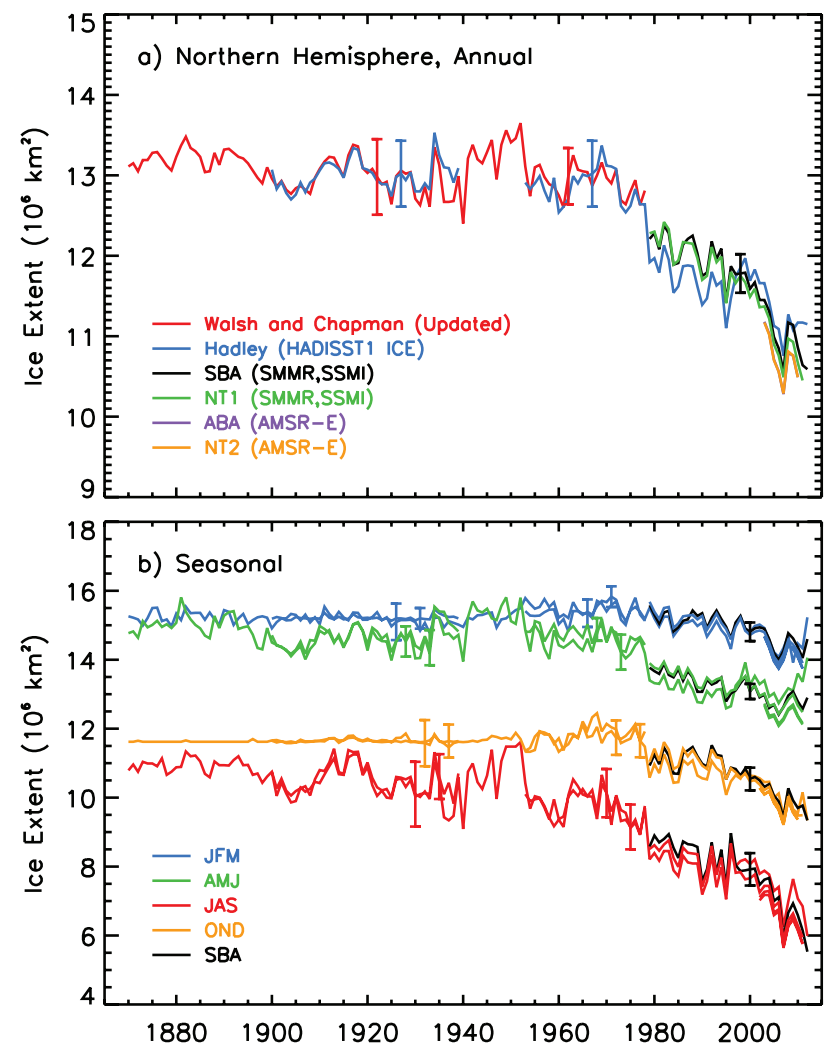

Figure 4.3 I Ice extent in the Arctic from 1870 to 2011. (a) Annual ice extent and (b) seasonal ice extent using averages of mid-month values derived from in situ and other sources including observations from the Danish meteorological stations from 1870 to 1978 (updated from, Walsh and Chapman, 2001). Ice extent from a joint Hadley and National Oceanic and Atmospheric Administration (NOAA) project (called HADISST1_ Ice) from 1900 to 2011 is also shown. The yearly and seasonal averages for the period from 1979 to 2011 are shown as derived from Scanning Multichannel Microwave Radiometer (SMMR) and Special Sensor Microwave/Imager (SSM/I) passive microwave data using the Bootstrap Algorithm (SBA) and National Aeronautics and Space Administration (NASA) Team Algorithm, Version 1 (NT1), using procedures described in Comiso and Nishio (2008), and Cavalieri et al. (1984), respectively; and from Advanced Microwave Scanning Radiometer, Version 2 (AMSR2) using algorithms called AMSR Bootstrap Algorithm (ABA) and NASA Team Algorithm, Version 2 (NT2), described in Comiso and Nishio (2008) and Markus and Cavalieri (2000). In (b), data from the different seasons are shown in different colours to illustrate variation between seasons, with SBA data from the procedure in Comiso and Nishio (2008) shown in black.

1979-2012 are shown in Figure 4.4. Perennial ice is that which survives the summer, and the ice extent at summer minimum has been used as a measure of its coverage (Comiso, 2002). Multi-year ice (as defined by World Meteorological Organization) is ice that has survived at least two summers. Generally, multi-year ice is less saline and has a distinct microwave signature that differs from the seasonal ice, and thus can be discriminated and monitored with satellite microwave radiometers (Johannessen et al., 1999; Zwally and Gloersen, 2008; Comiso, 2012).

Figure 4.4 shows similar interannual variability and large trends for both perennial and multi-year ice for the period 1979 to 2012. The extent of the perennial ice cover, which was about $7.9 \times 10^{6} \mathrm{~km}^{2}$ in 1980 , decreased to as low as $3.5 \times 10^{6} \mathrm{~km}^{2}$ in 2012 . Similarly, the multi-year ice extent decreased from about $6.2 \times 10^{6} \mathrm{~km}^{2}$ in 1981 to about $2.5 \times 10^{6} \mathrm{~km}^{2}$ in 2012. The trends in perennial ice extent and ice area were strongly negative at $-11.5 \pm 2.1$ and $-12.5 \pm 2.1 \%$ per decade (very likely) respectively. These values indicate an increased rate of decline from the $-6.4 \%$ and $-8.5 \%$ per decade, respectively, reported for the 1979 to 2000 period by Comiso (2002). The trends in multi-year ice extent and area are even more negative, at $-13.5 \pm 2.5$ and $-14.7 \pm 3.0 \%$ per decade (very likely), respectively, as updated for the period 1979 to 2012 (Comiso, 2012). The more negative trend in ice area than in ice extent indicates that the average ice concentration of multi-year ice in the Central Arctic has also been declining. The rate of decline in the extent and area of multi-year ice cover is consistent with the observed decline of old ice types from the analysis of ice drift and ice age by Maslanik et al. (2007), confirming that older and thicker ice types in the Arctic have been declining significantly. The more negative trend for the thicker multi-year ice area than that for the perennial ice area implies that the average thickness of the ice, and hence the ice volume, has also been declining.

Drastic changes in the multi-year ice coverage from QuikScat (satellite radar scatterometer) data, validated using high-resolution Synthetic Aperture Radar data (Kwok, 2004; Nghiem et al., 2007), have also been reported. Some of these changes have been attributed to the near zero replenishment of the Arctic multi-year ice cover by ice that survives the summer (Kwok, 2007).
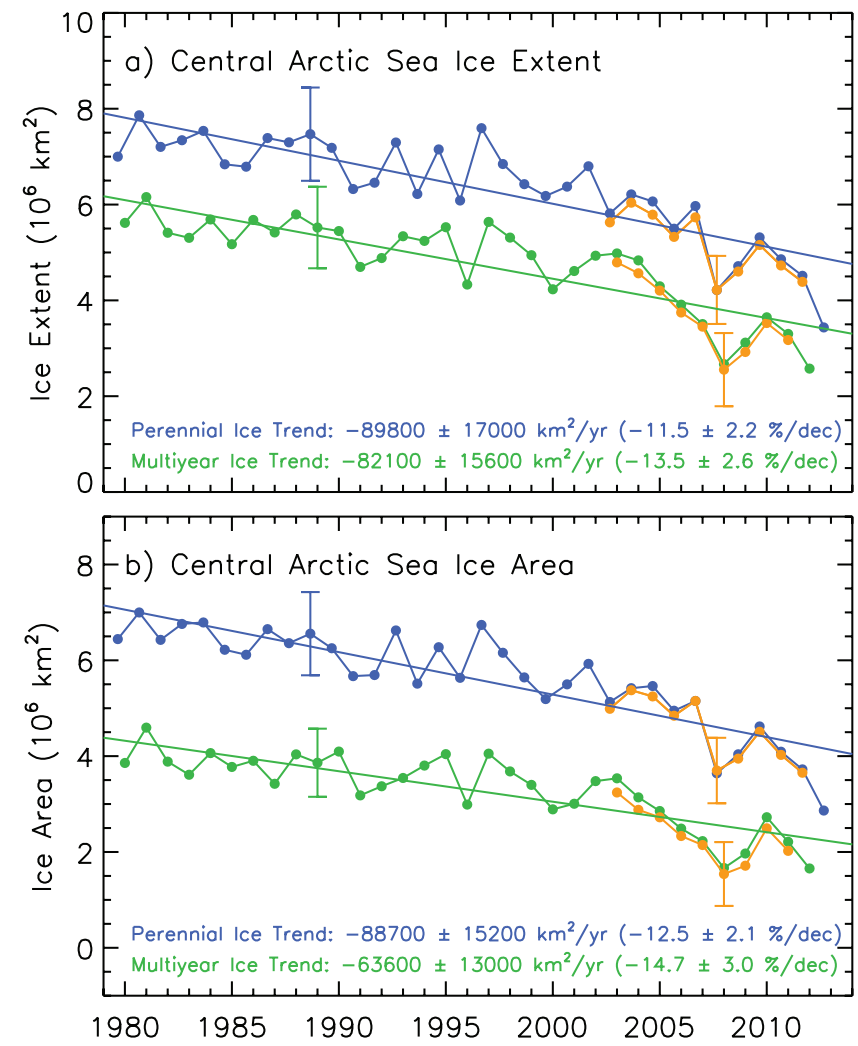

Figure 4.4 | Annual perennial (blue) and multi-year (green) sea ice extent (a) and sea ice area (b) in the Central Arctic from 1979 to 2012 as derived from satellite passive microwave data (updated from Comiso, 2012). Perennial ice values are derived from summer minimum ice extent, while the multi-year ice values are averages of those from December, January and February. The gold lines (after 2002) are from AMSR-E data. Uncertainties in the observations (very likely range) are indicated by representative error bars, and uncertainties in the trends are given (very likely range). 


\subsubsection{Ice Thickness and Volume}

For the Arctic, there are several techniques available for estimating the thickness distribution of sea ice. Combined data sets of draft and thickness from submarine sonars, satellite altimetry and airborne electromagnetic sensing provide broadly consistent and strong evidence of decrease in Arctic sea ice thickness in recent years (Figure 4.6c).

Data collected by upward-looking sonar on submarines operating beneath the Arctic pack ice provided the first evidence of 'basin-wide' decreases in ice thickness (Wadhams, 1990). Sonar measurements are of average draft (the submerged portion of sea ice), which is converted to thickness by assuming an average density for the measured floe including its snow cover. With the then available submarine records, Rothrock et al. (1999) found that ice draft in the mid-1990s was less than that measured between 1958 and 1977 in each of six regions within the Arctic Basin. The change was least $(-0.9 \mathrm{~m})$ in the Beaufort and Chukchi seas and greatest $(-1.7 \mathrm{~m})$ in the Eurasian Basin. The decrease averaged about $42 \%$ of the average 1958 to 1977 thickness. This decrease matched the decline measured in the Eurasian Basin between 1976 and 1996 using UK submarine data (Wadhams and Davis, 2000), which was $43 \%$.

A subsequent analysis of US Navy submarine ice draft (Rothrock et al., 2008) used much richer and more geographically extensive data from 34 cruises within a data release area that covered almost $38 \%$ of the area of the Arctic Ocean. These cruises were equally distributed in spring and autumn over a 25-year period between 1975 and 2000. Observational uncertainty associated with the ice draft from these is $0.5 \mathrm{~m}$ (Rothrock and Wensnahan, 2007). Multiple regression analysis was used to separate the interannual changes (Figure 4.6c), the annual cycle and the spatial distribution of draft in the observations. Results of that analysis show that the annual mean ice thickness declined from a peak of $3.6 \mathrm{~m}$ in 1980 to $2.4 \mathrm{~m}$ in 2000 , a decrease of $1.2 \mathrm{~m}$. Over the period, the most rapid change was $-0.08 \mathrm{~m} \mathrm{yr}^{-1}$ in 1990 .

The most recent submarine record, Wadhams et al. (2011), found that tracks north of Greenland repeated between the winters of 2004 and 2007 showed a continuing shift towards less multi-year ice.

Satellite altimetry techniques are now capable of mapping sea ice freeboard to provide relatively comprehensive pictures of the distribution of Arctic sea ice thickness. Similar to the estimation of sea ice thickness from ice draft, satellite measured freeboard (the height of sea ice above the water surface) is converted to thickness, assuming an average density of ice and snow. The principal challenges to accurate thickness estimation using satellite altimetry are in the discrimination of ice and open water, and in estimating the thickness of the snow cover.

Since 1993, radar altimeters on the European Space Agency (ESA), European Remote Sensing (ERS) and Envisat satellites have provided Arctic observations south of $81.5^{\circ} \mathrm{N}$. With the limited latitudinal reach of these altimeters, however, it has been difficult to infer basin-wide changes in thickness. The ERS-1 estimates of ice thickness show a downward trend but, because of the high variability and short time series (1993-2001), Laxon et al. (2003) concluded that the trend in a region of mixed seasonal and multi-year ice (i.e., below $81.5^{\circ} \mathrm{N}$ ) cannot be considered as significant. Envisat observations showed a large decrease in thickness $(0.25 \mathrm{~m})$ following September 2007 when ice extent was the second lowest on record (Giles et al., 2008b). This was associated with the large retreat of the summer ice cover, with thinning regionally confined to the Beaufort and Chukchi seas, but with no significant changes in the eastern Arctic. These results are consistent with those from the NASA Ice, Cloud and land Elevation Satellite (ICESat) laser altimeter (see comment on ICESat data in Section 4.4.2.1), which show thinning in the same regions between 2007 and 2008 (Kwok, 2009) (Figure 4.5). Large decreases in thickness due to the 2007 minimum in summer ice are clearly seen in both the radar and laser altimeter thickness estimates.

The coverage of the laser altimeter on ICESat (which ceased operation in 2009) extended to $86^{\circ} \mathrm{N}$ and provided a more complete spatial pattern of the thickness distribution in the Arctic Basin (Figure 4.6c). Thickness estimates are consistently within $0.5 \mathrm{~m}$ of sonar measurements from near-coincident submarine tracks and profiles from sonar moorings in the Chukchi and Beaufort seas (Kwok, 2009). Ten ICESat campaigns between autumn 2003 and spring 2008 showed seasonal differences in thickness and thinning and volume losses of the Arctic Ocean ice cover (Kwok, 2009). Over these campaigns, the multi-year sea ice thickness in spring declined by $\sim 0.6 \mathrm{~m}$ (Figure 4.5), while the average thickness of the first-year ice $(\sim 2 \mathrm{~m})$ had a negligible trend. The average sea ice volume inside the Arctic Basin in spring (February/ March) was $\sim 14,000 \mathrm{~km}^{3}$. Between 2004 and 2008, the total multi-year ice volume in spring (February/March) experienced a net loss of 6300 $\mathrm{km}^{3}(>40 \%)$. Residual differences between sonar mooring and satellite thicknesses suggest basin-scale volume uncertainties of approximately $700 \mathrm{~km}^{3}$. The rate of volume loss $\left(-1237 \mathrm{~km}^{3} \mathrm{yr}^{-1}\right)$ during autumn (October/November), while highlighting the large changes during the short ICESat record compares with a more moderate loss rate $(-280$ $\left.\pm 100 \mathrm{~km}^{3} \mathrm{yr}^{-1}\right)$ over a 31-year period (1979-2010) estimated from a sea ice reanalysis study using the Pan-Arctic Ice-Ocean Modelling and Assimilation system (Schweiger et al., 2011).

The CryoSat-2 radar altimeter (launched in 2010), which provides coverage up to $89^{\circ} \mathrm{N}$, has provided new thickness and volume estimates of Arctic Ocean sea ice (Laxon et al., 2013). These show that the ice volume inside the Arctic Basin decreased by a total of $4291 \mathrm{~km}^{3}$ in autumn (October/November) and $1479 \mathrm{~km}^{3}$ in winter (February/March) between the ICESat (2003-2008) and CryoSat-2 (2010-2012) periods. Based on ice thickness estimates from sonar moorings, an inter-satellite bias between ICESat and CryoSat-2 of $700 \mathrm{~km}^{3}$ can be expected. This is much less than the change in volume between the two periods.

Airborne electro-magnetic (EM) sounding measures the distance between an EM instrument near the surface or on an aircraft and the ice/water interface, and provides another method to measure ice thickness. Uncertainties in these thickness estimates are $0.1 \mathrm{~m}$ over level ice. Comparison with drill-hole measurements over a mix of level and ridged ice found differences of $0.17 \mathrm{~m}$ (Haas et al., 2011).

Repeat EM surveys in the Arctic, though restricted in time and space, have provided a regional view of the changing ice cover. From repeat ground-based and helicopter-borne EM surveys, Haas et al. (2008) found significant thinning in the region of the Transpolar Drift (an 


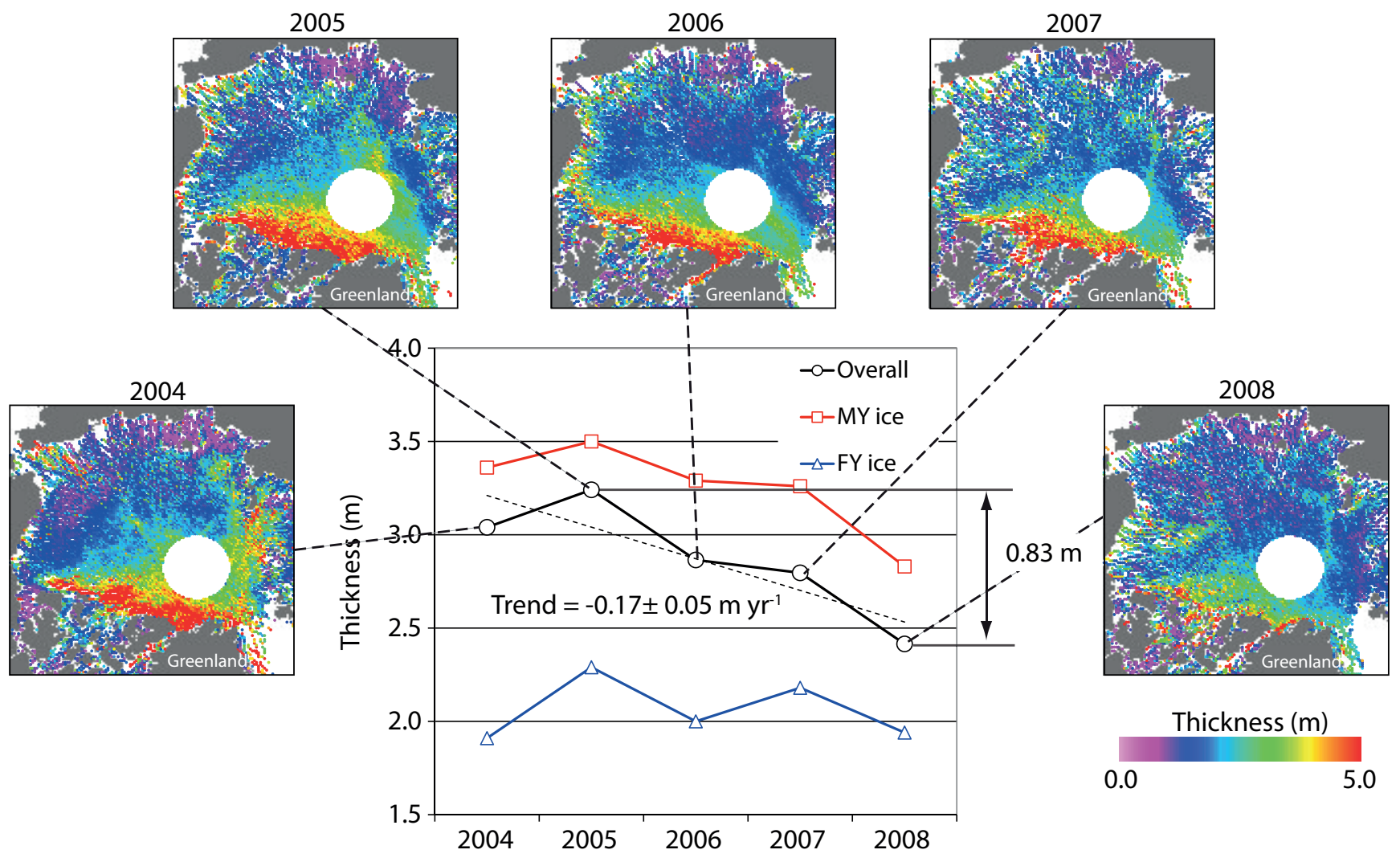

Figure 4.5 | The distribution of winter sea ice thickness in the Arctic and the trends in average, first-year (FY and multi-year (MY) ice thickness derived from ICESat data between 2004 and 2008 (Kwok, 2009).

average wind-driven drift pattern that transports sea ice from the Siberian coast of Russia across the Arctic Basin to Fram Strait). Between 1991 and 2004, the modal ice thickness decreased from $2.5 \mathrm{~m}$ to 2.2 $\mathrm{m}$, with a larger decline to $0.9 \mathrm{~m}$ in 2007. Mean ice thicknesses also decreased strongly. This thinning was associated with reduction of the age of the ice, and replacement of second-year ice by first-year ice in 2007 (following the large decline in summer ice extent in 2007) as seen in satellite observations. Ice thickness estimates from EM surveys near the North Pole can be compared to submarine estimates (Figure 4.6c). Airborne EM measurements from the Lincoln Sea between $83^{\circ} \mathrm{N}$ and $84^{\circ} \mathrm{N}$ since 2004 (Haas et al., 2010) showed some of the thickest ice in the Arctic, with mean and modal thicknesses of more than $4.5 \mathrm{~m}$ and $4 \mathrm{~m}$, respectively. Since 2008, the modal thickness in this region has declined to $3.5 \mathrm{~m}$, which is most likely related to the narrowing of the remaining band of old ice along the northern coast of Canada.

\subsubsection{Arctic Sea Ice Drift}

Ice motion influences the distribution of sea ice thickness in the Arctic Basin: locally, through deformation and creation of open water areas; regionally, through advection of ice from one area to another; and basin-wide, through export of ice from polar seas to lower latitudes where it melts. The drift and deformation of sea ice is forced primarily by winds and surface currents, but depends also on ice strength, top and bottom surface roughness, and ice concentration. On time scales of days to weeks, winds are responsible for most of the variance in sea ice motion.
Drifting buoys have been used to measure Arctic sea ice motion since 1979. From the record of buoy drift archived by the International Arctic Buoy Programme, Rampal et al. (2009) found an increase in average drift speed between 1978 and 2007 of $17 \pm 4.5 \%$ per decade in winter and $8.5 \pm 2.0 \%$ per decade in summer. Using daily satellite ice motion fields, which provide a basin-wide picture of the ice drift, Spreen et al. (2011) found that, between 1992 and 2008, the spatially averaged winter ice drift speed increased by $10.6 \pm 0.9 \%$ per decade, but varied regionally between -4 and $+16 \%$ per decade (Figure $4.6 \mathrm{~d}$ ). Increases in drift speed are seen over much of the Arctic except in areas with thicker ice (Figure 4.6b, e.g., north of Greenland and the Canadian Archipelago). The largest increases occurred during the second half of the period (2001-2009), coinciding with the years of rapid ice thinning discussed in Section 4.2.2.4. Both Rampal et al. (2009) and Spreen et al. (2011) suggest that, since atmospheric reanalyses do not show stronger winds, the positive trend in drift speed is probably due to a weaker and thinner ice cover, especially during the period after 2003.

In addition to freezing and melting, sea ice export through Fram Strait is a major component of the Arctic Ocean ice mass balance. Approximately $10 \%$ of the area of Arctic Ocean ice is exported annually. Over a 32-year satellite record (1979-2010), the mean annual outflow of ice area through Fram Strait was $699 \pm 112 \times 10^{3} \mathrm{~km}^{2}$ with a peak during the 1994-1995 winter (updated from , Kwok, 2009), but with no significant decadal trend. Decadal trends in ice volume export-a more definitive measure of change-is far less certain owing to the lack of an extended record of the thickness of sea ice exported through Fram 
Strait. Comparison of volume outflow using ICESat thickness estimates (Spreen et al., 2009) with earlier estimates by Kwok and Rothrock (1999) and Vinje (2001) using thicknesses from moored upward looking sonars shows no discernible change.

Between 2005 and 2008, more than a third of the thicker and older sea ice loss occurred by transport of thick, multi-year ice, typically found west of the Canadian Archipelago, into the southern Beaufort Sea, where it melted in summer (Kwok and Cunningham, 2010). Uncertainties remain in the relative contributions of in-basin melt and export to observed changes in Arctic ice volume loss, and it has also been shown that export of thicker ice through Nares Strait could account for a small fraction of the loss (Kwok, 2005).

\subsubsection{Timing of Sea Ice Advance, Retreat and Ice Season Duration; Length of Melt Season}

Importantly from both physical and biological perspectives, strong regional changes have occurred in the seasonality of sea ice in both polar regions (Massom and Stammerjohn, 2010; Stammerjohn et al., 2012). However, there are distinct regional differences in when seasonally the change is strongest (Stammerjohn et al., 2012).

Seasonality collectively describes the annual time of sea ice advance and retreat, and its duration (the time between day of advance and retreat). Daily satellite ice-concentration records (1979-2012) are used to determine the day to which sea ice advanced, and the day from which it retreated, for each satellite pixel location. Maps of the timing of sea ice advance, retreat and duration are derived from these data (see Parkinson (2002) and Stammerjohn et al. (2008) for detailed methods).

Most regions in the Arctic show trends towards shorter ice season duration. One of the most rapidly changing areas (showing greater than 2 days $\mathrm{yr}^{-1}$ change) extends from the East Siberian Sea to the western Beaufort Sea. Here, between 1979 and 2011, sea ice advance occurred $41 \pm 6$ days later (or $1.3 \pm 0.2$ days $\mathrm{yr}^{-1}$ ), sea ice retreat $49 \pm 7$ days earlier $\left(-1.5 \pm 0.2\right.$ days $\left.\mathrm{yr}^{-1}\right)$, and duration became $90 \pm 16$ days shorter $\left(-2.8 \pm 0.5\right.$ days $\mathrm{yr}^{-1}$ ) (Stammerjohn et al., 2012). This 3-month lengthening of the summer ice-free season places Arctic summer sea ice extent loss into a seasonal perspective and underscores impacts to the marine ecosystem (e.g., Grebmeier et al., 2010).

The timing of surface melt onset in spring, and freeze-up in autumn, can be derived from satellite microwave data as the emissivity of the surface changes significantly with snow melt (Smith, 1998; Drobot and Anderson, 2001; Belchansky et al., 2004). The amount of solar energy absorbed by the ice cover increases with the length of the melt season. Longer melt seasons with lower albedo surfaces (wet snow, melt ponds and open water) increase absorption of incoming shortwave radiation and ice melt (Perovich et al., 2007). Hudson (2011) estimates that the observed reduction in Arctic sea ice has contributed approximately $0.1 \mathrm{~W} \mathrm{~m}^{-2}$ of additional global radiative forcing, and that an ice-free summer Arctic Ocean will result in a forcing of about $0.3 \mathrm{~W} \mathrm{~m}^{-2}$. The satellite record (Markus et al., 2009) shows a trend toward earlier melt and later freeze-up nearly everywhere in the Arctic (Figure 4.6e). Over the last 34 years, the mean melt season over the Arctic ice cover has increased at a rate of $5.7 \pm 0.9$ days per decade. The largest and most significant trends (at the $99 \%$ level) of more than 10 days per decade are seen in the coastal margins and peripheral seas: Hudson Bay, the East Greenland Sea, the Laptev/East Siberian seas, and the Chukchi/ Beaufort seas.

\subsubsection{Arctic Polynyas}

High sea ice production in coastal polynyas (anomalous regions of open water or low ice concentration) over the continental shelves of the Arctic Ocean is responsible for the formation of cold saline water, which contributes to the maintenance of the Arctic Ocean halocline (see Glossary). A new passive microwave algorithm has been used to estimate thin sea ice thicknesses $(<0.15 \mathrm{~m})$ in the Arctic Ocean (Tamura and Ohshima, 2011), providing the first circumpolar mapping of sea ice production in coastal polynyas. High sea ice production is confined to the most persistent Arctic coastal polynyas, with the highest ice production rate being in the North Water Polynya. The mean annual sea ice production in the 10 major Arctic polynyas is estimated to be $2942 \pm$ $373 \mathrm{~km}^{3}$ and decreased by $462 \mathrm{~km}^{3}$ between 1992 and 2007 (Tamura and Ohshima, 2011).

\subsubsection{Arctic Land-Fast Ice}

Shore- or land-fast ice is sea ice attached to the coast. Land-fast ice along the Arctic coast is usually grounded in shallow water, with the seaward edge typically around the 20 to $30 \mathrm{~m}$ isobath (Mahoney et al., 2007). In fjords and confined bays, land-fast ice extends into deeper water.

There are no reliable estimates of the total area or interannual variability of land-fast ice in the Arctic. However, both significant and non-significant trends have been observed regionally. Long-term monitoring near Hopen, Svalbard, revealed thinning of land-fast ice in the Barents Sea region by $11 \mathrm{~cm}$ per decade between 1966 and 2007 (Gerland et al., 2008). Between 1936 and 2000, the trends in land-fast ice thickness (in May) at four Siberian sites (Kara Sea, Laptev Sea, East Siberian Sea, Chukchi Sea) are insignificant (Polyakov et al., 2003). A more recent composite time series of land-fast ice thickness between the mid 1960s and early 2000s from 15 stations along the Siberian coast revealed an average rate of thinning of $0.33 \mathrm{~cm} \mathrm{yr}^{-1}$ (Polyakov et al., 2010). End-of-winter ice thickness for three stations in the Canadian Arctic reveal a small downward trend at Eureka, a small positive trend at Resolute Bay, and a negligible trend at Cambridge Bay (updated from Brown and Coté, 1992; Melling, 2012), but these trends are small and not statistically significant. Even though the trend in the land-fast ice extent near Barrow, Alaska has not been significant (Mahoney et al., 2007), relatively recent observations by Mahoney et al. (2007) and Druckenmiller et al. (2009) found longer ice-free seasons and thinner land-fast ice compared to earlier records (Weeks and Gow, 1978; Barry et al., 1979). As freeze-up happens later, the growth season shortens and the thinner ice breaks up and melts earlier.

\subsubsection{Decadal Trends in Arctic Sea Ice}

The average decadal extent of Arctic sea ice has decreased in every season and in every successive decade since satellite observations 
commenced. The data set is robust with continuous and consistent global coverage on a daily basis thereby providing very reliable trend results (very high confidence). The annual Arctic sea ice cover very likely declined within the range 3.5 to $4.1 \%$ per decade $(0.45$ to 0.51 million $\mathrm{km}^{2}$ per decade) during the period 1979-2012 with larger changes occurring in summer and autumn (very high confidence). Much larger changes apply to the perennial ice (the summer minimum extent) which very likely decreased in the range from $9.4 \%$ to $13.6 \%$ per decade ( 0.73 to 1.07 million $\mathrm{km}^{2}$ per decade) and multiyear sea ice (more than 2 years old) which very likely declined in the range from $11.0 \%$ to $16.0 \%$ per decade ( 0.66 to 0.98 million $\mathrm{km}^{2}$ per decade) (very high confidence; Figure 4.4b). The rate of decrease in ice area has been greater than that in extent (Figure 4.4b) because the ice concentration has also decreased. The decline in multiyear ice cover as observed by QuikScat from 1992 to 1910 is presented in Figure 4.6b and shown to be consistent with passive microwave data (Figure 4.4b)

The decrease in perennial and multi-year ice coverage has resulted in a strong decrease in ice thickness, and hence in ice volume. Declassified submarine sonar measurements, covering $\sim 38 \%$ of the Arctic Ocean, indicate an overall mean winter thickness of $3.64 \mathrm{~m}$ in 1980, which likely decreased by 1.8 [1.3 to 2.3] m by 2008 (high confidence, Figure 4.6c). Between 1975 and 2000, the steepest rate of decrease was 0.08 $\mathrm{m} \mathrm{yr}^{-1}$ in 1990 compared to a slightly higher winter/summer rate of $0.10 / 0.20 \mathrm{~m} \mathrm{yr}^{-1}$ in the 5-year ICESat record (2003-2008). This combined analysis (Figure 4.6c) shows a long-term trend of sea ice thinning that spans five decades. Satellite measurements made in the period 2010-2012 show a decrease in basin-scale sea ice volume compared to those made over the period 2003-2008 (medium confidence). The Arctic sea ice is becoming increasingly seasonal with thinner ice, and it will take several years for any recovery.

The decreases in both concentration and thickness reduces sea ice strength reducing its resistance to wind forcing, and drift speed has increased (Figure 4.6d) (Rampal et al., 2009; Spreen et al., 2011). Other significant changes to the Arctic Ocean sea ice include lengthening in the duration of the surface melt on perennial ice of 6 days per decade (Figure 4.6e) and a nearly 3-month lengthening of the ice-free season in the region from the East Siberian Sea to the western Beaufort Sea.

\subsubsection{Antarctic Sea Ice}

The Antarctic sea ice cover is largely seasonal, with average extent varying from a minimum of about $3 \times 10^{6} \mathrm{~km}^{2}$ in February to a maximum of about $18 \times 10^{6} \mathrm{~km}^{2}$ in September (Zwally et al., 2002a; Comiso et al., 2011). The relatively small fraction of Antarctic sea ice that survives the summer is found mostly in the Weddell Sea, but with some perennial ice also surviving on the western side of the Antarctic Peninsula and in small patches around the coast. As well as being mostly first-year ice, Antarctic sea ice is also on average thinner, warmer, more saline and more mobile than Arctic ice (Wadhams and Comiso, 1992). These characteristics, which reduce the capabilities of some remote sensing techniques, together with its more distant location from inhabited continents, result in far less being known about the properties of Antarctic sea ice than of that in the Arctic.

\subsubsection{Total Antarctic Sea Ice Extent and Concentration}

Figure 4.7a shows the seasonal variability of Antarctic sea ice extent using 34 years of satellite passive microwave data updated from Comiso and Nishio (2008). In contrast to the Arctic, decadal monthly averages almost overlap with each other, and the seasonal variability of the total Antarctic sea ice cover has not changed much over the period. In winter, the values for the 1999-2008 decade were slightly higher than those of the other decades; whereas in autumn the values for 1989-1998 and 1999-2008 decades were higher than those of 1979-1988. There was more seasonal variability in the period 20092012 than for earlier decadal periods, with relatively high values in late autumn, winter and spring.

Trend maps for winter, spring, summer and autumn extent are presented in Figure 4.7 (b, c, $d$ and e respectively). The seasonal trends are significant mainly near the ice edge, with the values alternating between positive and negative around Antarctica. Such an alternating pattern is similar to that described previously as the Antarctic Circumpolar Wave (ACW) (White and Peterson, 1996) but the ACW may not be associated with the trends because the trends have been strongly positive in the Ross Sea and negative in the Bellingshausen/Amundsen seas but with almost no trend in the other regions (Comiso et al., 2011). In the winter, negative trends are evident at the tip of the Antarctic Peninsula and the western part of the Weddell Sea, while positive trends are prevalent in the Ross Sea. The patterns in spring are very similar to those of winter, whereas in summer and autumn negative trends are mainly confined to the Bellingshausen/Amundsen seas, while positive trends are dominant in the Ross Sea and the Weddell Sea.

The regression trend in the monthly anomalies of Antarctic sea ice extent from November 1978 to December 2012 (updated from Comiso and Nishio, 2008) is slightly positive, at $1.5 \pm 0.3 \%$ per decade, or 0.13 to 0.20 million $\mathrm{km}^{2}$ per decade (very likely) (see FAQ 4.1). The seasonal trends in ice extent are $1.2 \pm 0.5 \%, 1.0 \pm 0.5 \%, 2.5 \pm 2.0 \%$ and 3.0 $\pm 2.0 \%$ per decade (very likely) in winter, spring, summer and autumn, respectively, as updated from Comiso et al. (2011). The corresponding trends in ice area (also updated) are $1.9 \pm 0.7 \%, 1.6 \pm 0.5 \%, 3.0 \pm$ $2.1 \%$, and $4.4 \pm 2.3 \%$ per decade (very likely). The values are all positive, with the largest trends occurring in the autumn. The trends are consistently higher for ice area than ice extent, indicating less open water (possibly due to less storms and divergence) within the pack in later years. Trends reported by Parkinson and Cavalieri (2012) using data from 1978 to 2010 are slightly different, in part because they cover a different time period (see Supplementary Material). The overall interannual trends for various sectors around Antarctica are given in FAQ 4.1, and show large regional variability. Changes in ice drift and wind patterns as reported by Holland and Kwok (2012) may be related to this phenomenon.

\subsubsection{Antarctic Sea Ice Thickness and Volume}

Since AR4, some advances have been made in determining the thickness of Antarctic sea ice, particularly in the use of ship-based observations and satellite altimetry. However, there is still no information on large-scale Antarctic ice thickness change. Worby et al. (2008) compiled 25 years of ship-based data from 83 Antarctic voyages on 
a) Annual ice extent
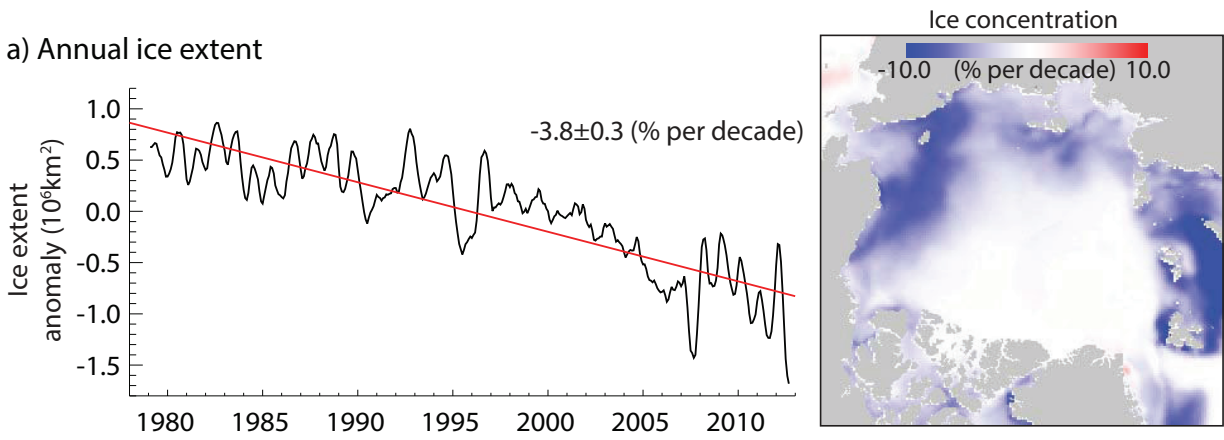

b) Multiyear ice coverage (Jan-1)
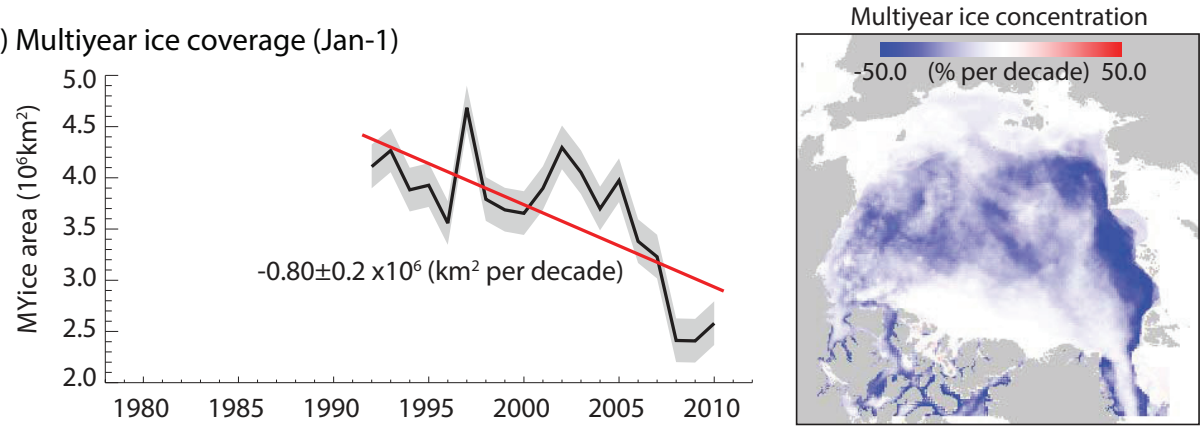

c) Ice thickness
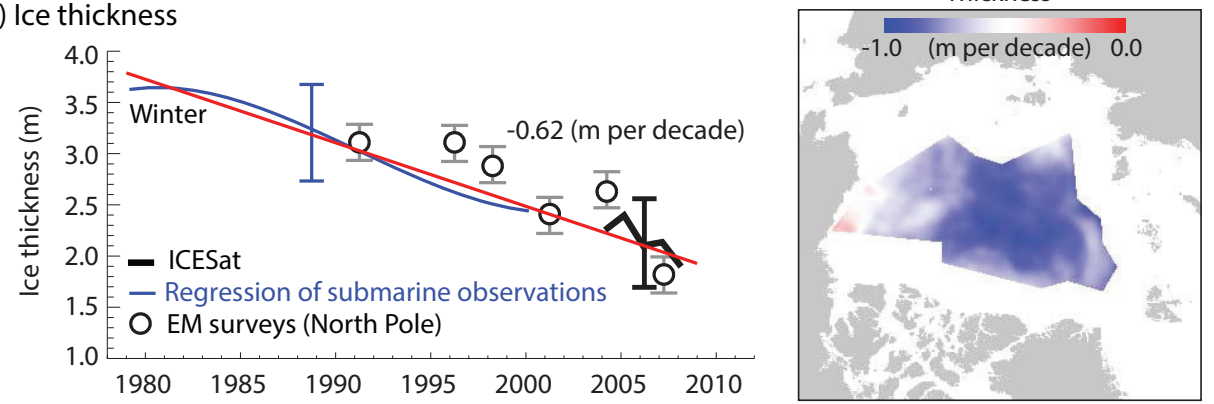

d) Sea ice drift speed
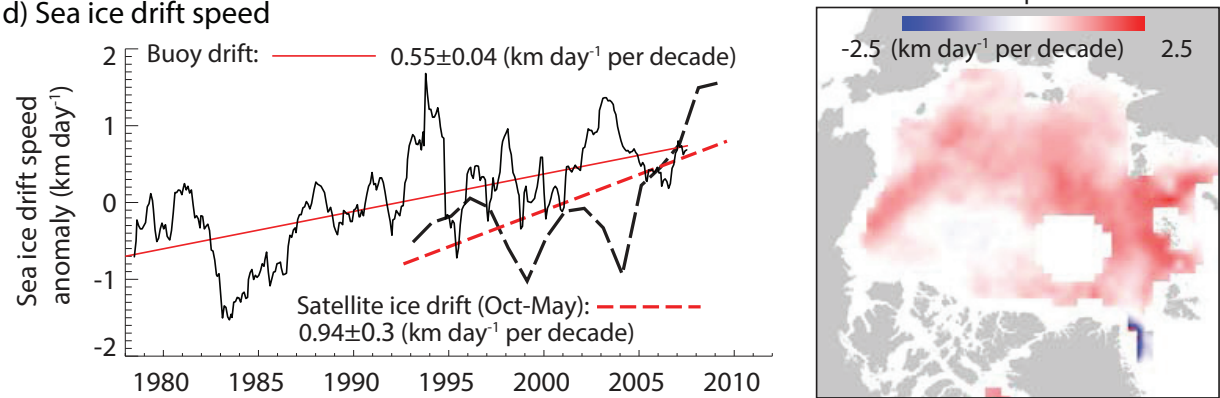

e) Average length of melt season
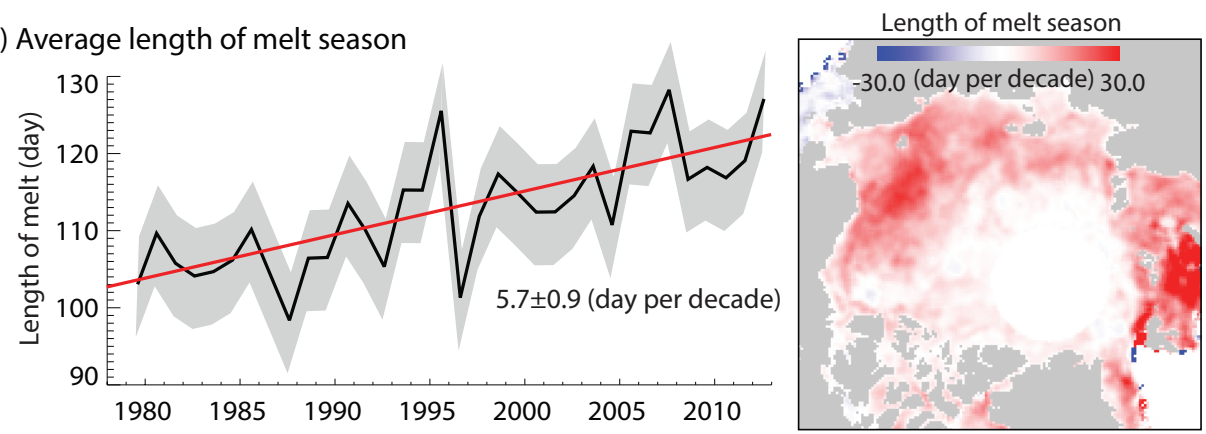

Figure 4.6 | Summary of linear decadal trends (red lines) and pattern of changes in the following: (a) Anomalies in Arctic sea ice extent from satellite passive microwave observations (Comiso and Nishio, 2008, updated to include 2012). Uncertainties are discussed in the text. (b) Multi-year sea ice coverage on January 1st from analysis of the QuikSCAT time series (Kwok, 2009); grey band shows uncertainty in the retrieval. (c) Sea ice thickness from submarine (blue), satellites (black) (Kwok and Rothrock, 2009), and in situ/electromagnetic (EM) surveys (circles) (Haas et al., 2008); trend in submarine ice thickness is from multiple regression of available observations within the data release area (Rothrock et al., 2008). Error bars show uncertainties in observations. (d) Anomalies in buoy (Rampal et al., 2009) and satellite-derived sea ice drift speed (Spreen et al., 2011). (e) Length of melt season (updated from Markus et al., 2009); grey band shows the basin-wide variability. 

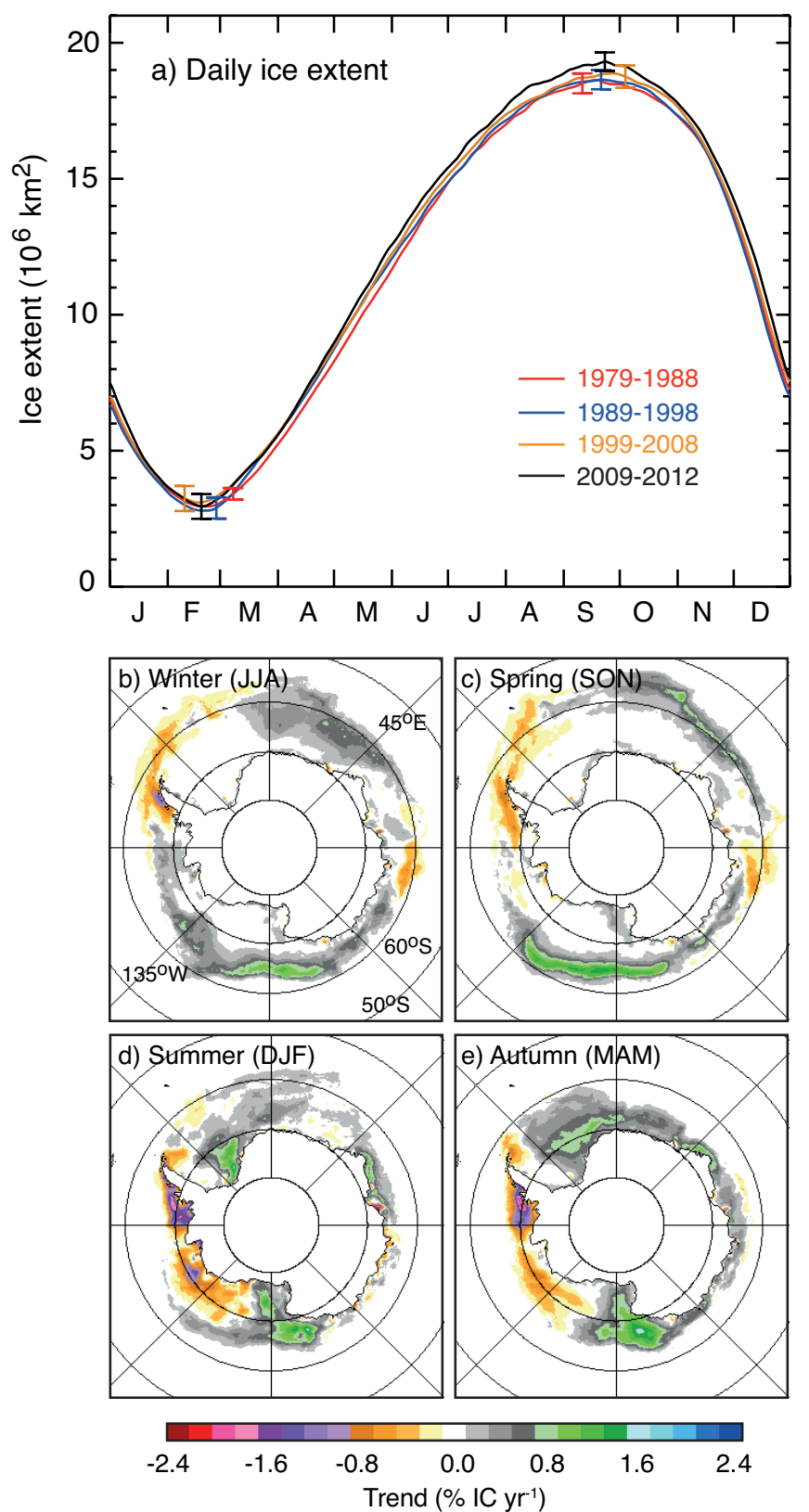

Figure 4.7 | (a) Plots of decadal averages of daily sea ice extent in the Antarctic (1979-1988 in red, 1989-1998 in blue, 1999- 2008 in gold) and a 4-year average daily ice extent from 2009 to 2012 in black. Maps indicate ice concentration trends (1979-2012) in (b) winter, (c) spring, (d) summer and (e) autumn (updated from Comiso, 2010).

which routine observations of sea ice and snow properties were made. Their compilation included a gridded data set that reflects the regional differences in sea ice thickness. A subset of these ship observations, and ice charts, was used by DeLiberty et al. (2011) to estimate the annual cycle of sea ice thickness and volume in the Ross Sea, and to investigate the relationship between ice thickness and extent. They found that maximum sea ice volume was reached later than maximum extent. While ice is advected to the northern edge and melts, the interior of the sea ice zone is supplied with ice from higher latitudes and continues to thicken by thermodynamic growth and deformation. Satellite retrievals of sea ice freeboard and thickness in the Antarctic (Mahoney et al., 2007; Zwally et al., 2008; Xie et al., 2011) are under development but progress is limited by knowledge of snow thickness and the paucity of suitable validation data sets. A recent analysis of the ICESat record by Kurtz and Markus (2012), assuming zero ice freeboard, found negligible trends in ice thickness over the 5-year record.

\subsubsection{Antarctic Sea Ice Drift}

Using a 19-year data set (1992-2010) of satellite-tracked sea ice motion, Holland and Kwok (2012) found large and statistically significant decadal trends in Antarctic ice drift that in most sectors are caused by changes in local winds. These trends suggest acceleration of the wind-driven Ross Gyre and deceleration of the Weddell Gyre. The changes in meridional ice transport affect the freshwater budget near the Antarctic coast. This is consistent with the increase of $30,000 \mathrm{~km}^{2}$ $\mathrm{yr}^{-1}$ in the net area export of sea ice from the Ross Sea shelf coastal polynya region between 1992 and 2008 (Comiso et al., 2011). Assuming an annual average thickness of $0.6 \mathrm{~m}$, Comiso et al. (2011) estimated an increase in volume export of $20 \mathrm{~km}^{3} \mathrm{yr}^{-1}$ which is similar to the rate of production in the Ross Sea coastal polynya region for the same period discussed in Section 4.2.3.5.

\subsubsection{Timing of Sea Ice Advance, Retreat and Ice Season Duration}

In the Antarctic there are regionally different patterns of strong change in ice duration $\left(>2\right.$ days $\left.\mathrm{yr}^{-1}\right)$. In the northeast and west Antarctic Peninsula and southern Bellingshausen Sea region, later ice advance (+61 \pm 15 days), earlier retreat $(-39 \pm 13$ days) and shorter duration $\left(+100 \pm 31\right.$ days, a trend of $-3.1 \pm 1.0$ days $\left.\mathrm{yr}^{-1}\right)$ occurred over the period 1979/1980-2010/2011 (Stammerjohn et al., 2012). These changes have strong impacts on the marine ecosystem (MontesHugo et al., 2009; Ducklow et al., 2011). The opposite is true in the adjacent western Ross Sea, where substantial lengthening of the ice season of $79 \pm 12$ days has occurred $\left(+2.5 \pm 0.4\right.$ days $\left.\mathrm{yr}^{-1}\right)$ due to earlier advance $(+42 \pm 8$ days) and later retreat $(-37 \pm 8$ days $)$. Patterns of change in the relatively narrow East Antarctic sector are generally of a lower magnitude and zonally complex, but in certain regions involve changes in the timing of sea ice advance and retreat of the order of \pm 1 to 2 days $\mathrm{yr}^{-1}$ (for the period 1979-2009) (Massom et al., 2013).

\subsubsection{Antarctic Polynyas}

Polynyas are commonly found along the coast of Antarctica. There are two different processes that cause a polynya. Warm water upwelling keeps the surface water near the freezing point and reduces ice production (sensible heat polynya), and wind or ocean currents move ice away and increase further ice production (latent heat polynya).

An increase in the extent of coastal polynyas in the Ross Sea caused increased ice production (latent heat effect) that is primarily responsible for the positive trend in ice extent in the Antarctic (Comiso et al., 2011). Drucker et al. (2011) show that in the Ross Sea, the net ice export equals the annual ice production in the Ross Sea polynya (approximately $400 \mathrm{~km}^{3}$ in 1992), and that ice production increased by $20 \mathrm{~km}^{3} \mathrm{yr}^{-1}$ from 1992 to 2008. However, the ice production in the Weddell Sea, which is three times less, has had no statistically significant 
Frequently Asked Questions

\section{FAQ 4.1 | How Is Sea Ice Changing in the Arctic and Antarctic?}

The sea ice covers on the Arctic Ocean and on the Southern Ocean around Antarctica have quite different characteristics, and are showing different changes with time. Over the past 34 years (1979-2012), there has been a downward trend of 3.8\% per decade in the annual average extent of sea ice in the Arctic. The average winter thickness of Arctic Ocean sea ice has thinned by approximately $1.8 \mathrm{~m}$ between 1978 and 2008, and the total volume (mass) of Arctic sea ice has decreased at all times of year. The more rapid decrease in the extent of sea ice at the summer minimum is a consequence of these trends. In contrast, over the same 34-year period, the total extent of Antarctic sea ice shows a small increase of $1.5 \%$ per decade, but there are strong regional differences in the changes around the Antarctic. Measurements of Antarctic sea ice thickness are too few to be able to judge whether its total volume (mass) is decreasing, steady, or increasing.

A large part of the total Arctic sea ice cover lies above $60^{\circ} \mathrm{N}$ (FAQ 4.1, Figure 1) and is surrounded by land to the south with openings to the Canadian Arctic Archipelago, and the Bering, Barents and Greenland seas. Some of the ice within the Arctic Basin survives for several seasons, growing in thickness by freezing of seawater at the base and by deformation (ridging and rafting). Seasonal sea ice grows to only $\sim 2 \mathrm{~m}$ in thickness but sea ice that is more than 1 year old (perennial ice) can be several metres thicker. Arctic sea ice drifts within the basin, driven by wind and ocean currents: the mean drift pattern is dominated by a clockwise circulation pattern in the western Arctic and a Transpolar Drift Stream that transports Siberian sea ice across the Arctic and exports it from the basin through the Fram Strait.

Satellites with the capability to distinguish ice and open water have provided a picture of the sea ice cover changes. Since 1979, the annual average extent of ice in the Arctic has decreased by $3.8 \%$ per decade. The decline in extent at the end of summer (in late September) has been even greater at $11 \%$ per decade, reaching a record minimum in 2012. The decadal average extent of the September minimum Arctic ice cover has decreased for each decade since satellite records began. Submarine and satellite records suggest that the thickness of Arctic ice, and hence the total volume, is also decreasing. Changes in the relative amounts of perennial and seasonal ice are contributing to the reduction in ice volume. Over the 34-year record, approximately $17 \%$ of this type of sea ice per decade has been lost to melt and export out of the basin since 1979 and $40 \%$ since 1999. Although the area of Arctic sea ice coverage can fluctuate from year to year because of variable seasonal production, the proportion of thick perennial ice, and the total sea ice volume, can recover only slowly.

Unlike the Arctic, the sea ice cover around Antarctica is constrained to latitudes north of $78^{\circ} \mathrm{S}$ because of the presence of the continental land mass. The Antarctic sea ice cover is largely seasonal, with an average thickness of only $\sim 1 \mathrm{~m}$ at the time of maximum extent in September. Only a small fraction of the ice cover survives the summer minimum in February, and very little Antarctic sea ice is more than 2 years old. The ice edge is exposed to the open ocean and the snowfall rate over Antarctic sea ice is higher than in the Arctic. When the snow load from snowfall is sufficient to depress the ice surface below sea level, seawater infiltrates the base of the snow pack and snow-ice is formed when the resultant slush freezes. Consequently, snow-to-ice conversion (as well as basal freezing as in the Arctic) contributes to the seasonal growth in ice thickness and total ice volume in the Antarctic. Snow-ice formation is sensitive to changes in precipitation and thus changes in regional climate. The consequence of changes in precipitation on Antarctic sea ice thickness and volume remains a focus for research.

Unconstrained by land boundaries, the latitudinal extent of the Antarctic sea ice cover is highly variable. Near the Antarctic coast, sea ice drift is predominantly from east to west, but further north, it is from west to east and highly divergent. Distinct clockwise circulation patterns that transport ice northward can be found in the Weddell and Ross seas, while the circulation is more variable around East Antarctica. The northward extent of the sea ice cover is controlled in part by the divergent drift that is conducive in winter months to new ice formation in persistent open water areas (polynyas) along the coastlines. These zones of ice formation result in saltier and thus denser ocean water and become one of the primary sources of the deepest water found in the global oceans.

Over the same 34-year satellite record, the annual extent of sea ice in the Antarctic increased at about $1.5 \%$ per decade. However, there are regional differences in trends, with decreases seen in the Bellingshausen and Amundsen seas, but a larger increase in sea ice extent in the Ross Sea that dominates the overall trend. Whether the smaller overall increase in Antarctic sea ice extent is meaningful as an indicator of climate is uncertain because the extent 
FAQ 4.1 (continued)

varies so much from year to year and from place to place around the continent. Results from a recent study suggest that these contrasting trends in ice coverage may be due to trends in regional wind speed and patterns. Without better ice thickness and ice volume estimates, it is difficult to characterize how Antarctic sea ice cover is responding to changing climate, or which climate parameters are most influential.

There are large differences in the physical environment and processes that affect the state of Arctic and Antarctic sea ice cover and contribute to their dissimilar responses to climate change. The long, and unbroken, record of satellite observations have provided a clear picture of the decline of the Arctic sea ice cover, but available evidence precludes us from making robust statements about overall changes in Antarctic sea ice and their causes.
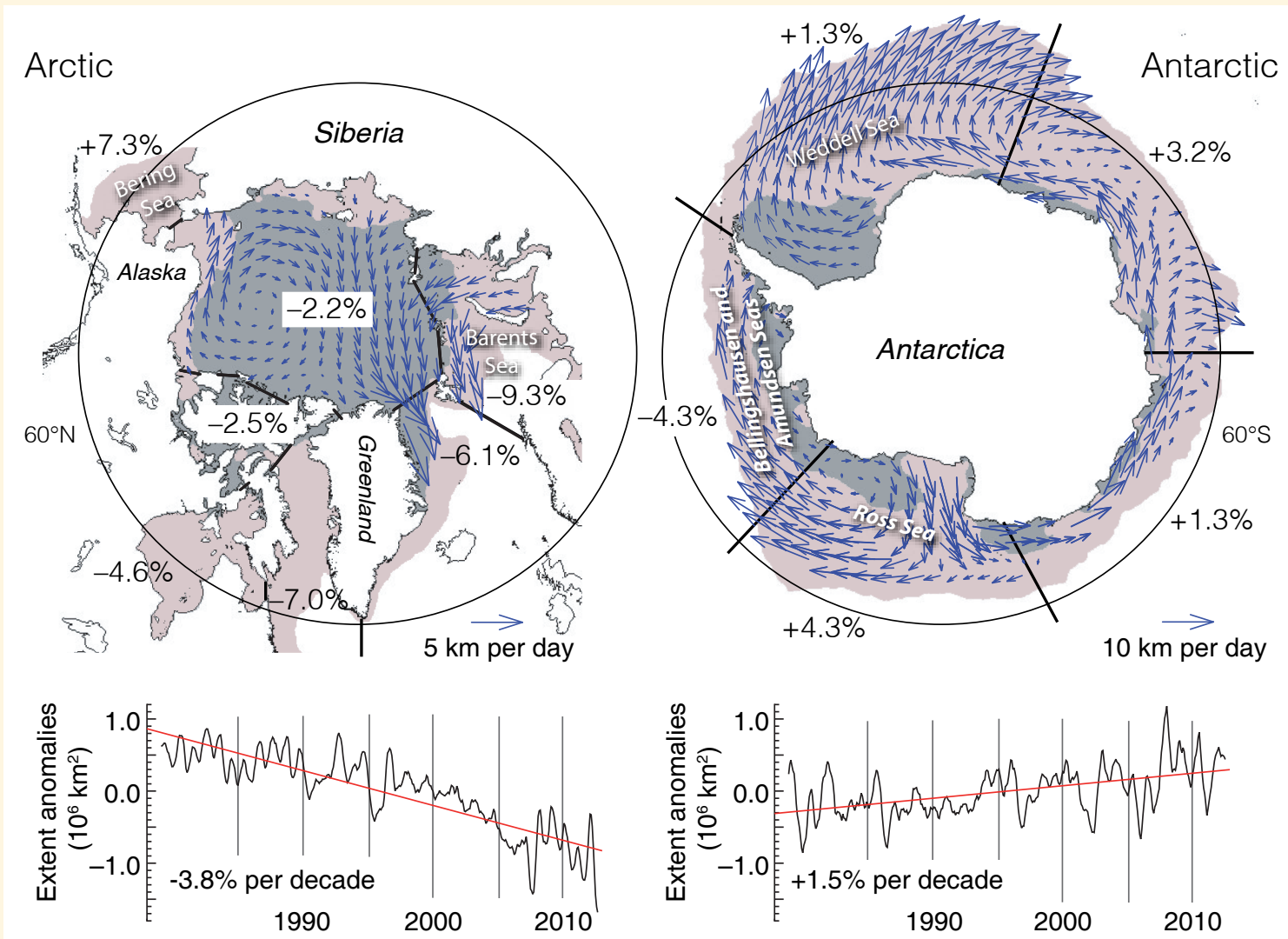

FAQ 4.1, Figure 1 | The mean circulation pattern of sea ice and the decadal trends (\%) in annual anomalies in ice extent (i.e., after removal of the seasonal cycle), in different sectors of the Arctic and Antarctic. Arrows show the average direction and magnitude of ice drift. The average sea ice cover for the period 1979 through 2012, from satellite observations, at maximum (minimum) extent is shown as orange (grey) shading.

trend over the same period. Variability in the ice cover in this region is linked to changes in the Southern Annular Mode (SAM). Between 1974 and 1976, the large Weddell Sea Polynya, which is a sensible heat polynya, was created by the injection of relatively warm deep water into the surface layer due to sustained deep-ocean convection (sensible heat effect) during negative SAM, but since the late 1970s the SAM has been mainly positive, resulting in warmer and wetter condition forestalling any reoccurrence of the Weddell Sea Polynya (Gordon et al., 2007).

\subsubsection{Antarctic Land-Fast Ice}

Land-fast ice forms around the coast of Antarctica, typically in narrow coastal bands of varying width up to $150 \mathrm{~km}$ from the coast and in water depths of up to 400 to $500 \mathrm{~m}$. Around East Antarctica, it comprises generally between $5 \%$ (winter) and $35 \%$ (summer) of the overall sea ice area (Fraser et al., 2012), and a greater fraction of ice volume (Giles et al., 2008a).

Variability in the distribution and extent of land-fast ice is sensitive to processes of ice formation and to processes such as ocean swell and 
waves, and strong wind events that cause the ice to break-up. Historical records of Antarctic land-fast ice extent, such as that of Kozlovsky et al. (1977) covering $0^{\circ}$ to $160^{\circ} \mathrm{E}$, were limited by sparse and sporadic sampling. Recently, using cloud-free Moderate Resolution Imaging Spectrometer (MODIS) composite images, Fraser et al. (2012) derived a high-resolution time series of land-fast sea ice extent along the East Antarctic coast, showing a statistically significant increase (1.43 $\pm 0.30 \% \mathrm{yr}^{-1}$ ) between March 2000 and December 2008. There is a strong increase in the Indian Ocean sector $\left(20^{\circ} \mathrm{E}\right.$ to $90^{\circ} \mathrm{E}, 4.07 \pm 0.42 \%$ $\left.\mathrm{yr}^{-1}\right)$, and a non-significant decrease in the sector from $90^{\circ} \mathrm{E}$ to $160^{\circ} \mathrm{E}$ $\left(-0.40 \pm 0.37 \% \mathrm{yr}^{-1}\right)$. An apparent shift from a negative to a positive trend was noted in the Indian Ocean sector from 2004, which coincided with greater interannual variability. Although significant changes are observed, this record is only 9 years in length.

\subsubsection{Decadal Trends in Antarctic Sea Ice}

For the Antarctic, any changes in many sea ice characteristics are unknown. There has been a small but significant increase in total annual mean sea ice extent that is very likely in the range of 1.2 to $1.8 \%$ per decade between 1979 and 2012 (0.13 to 0.20 million $\mathrm{km}^{2}$ per decade) (very high confidence). There was also a greater increase in ice area associated with an increase in ice concentration. But there are strong regional differences within this total, with some regions increasing in extent/area and some decreasing (high confidence). Similarly, there are contrasting regions around the Antarctic where the ice-free season has lengthened, and others where it has decreased over the satellite period (high confidence). There are still inadequate data to make any assessment of changes to Antarctic sea ice thickness and volume.

\subsection{Glaciers}

This section considers all perennial surface land ice masses (defined in 4.1 and Glossary) outside of the Antarctic and Greenland ice sheets. Glaciers occur where climate conditions and topographic characteristics allow snow to accumulate over several years and to transform gradually into firn (snow that persists for at least one year) and finally to ice. Under the force of gravity, this ice flows downwards to elevations with higher temperatures where various processes of ablation (loss of snow and ice) dominate over accumulation (gain of snow and ice). The sum of all accumulation and ablation processes determines the mass balance of a glacier. Accumulation is in most regions due mainly to solid precipitation (in general snow), but also results from refreezing of liquid water, especially in polar regions or at high altitudes where firn remains below melting temperature. Ablation is, in most regions, mainly due to surface melting with subsequent runoff, but loss of ice by calving (on land or in water; see Glossary) or sublimation (important in dry regions) can also dominate. Re-distribution of snow by wind and avalanches can contribute to both accumulation and ablation. The energy and mass fluxes governing the surface mass balance are directly linked to atmospheric conditions and are modified by topography (e.g., due to shading). Glaciers are sensitive climate indicators because they adjust their size in response to changes in climate (e.g., temperature and precipitation) (FAQ 4.2). Glaciers are also important seasonal to long-term hydrologic reservoirs (WGII, Chapter 3 ) on a regional scale and a major contributor to sea level rise on a global scale (see
Section 4.3.3.4 and Chapter 13). In the following, we report global glacier coverage (Section 4.3.1), how changes in length, area, volume and mass are determined (Section 4.3.2) and the observed changes in these parameters through time (Section 4.3.3).

\subsubsection{Current Area and Volume of Glaciers}

The total area covered by glaciers was only roughly known in AR4, resulting in large uncertainties for all related calculations (e.g., overall glacier volume or mass changes). Since AR4, the world glacier inventory (WGMS, 1989) was gradually extended by Cogley (2009a) and Radić and Hock (2010); and for AR5, a new globally complete data set of glacier outlines (Randolph Glacier Inventory (RGI)) was compiled from a wide range of data sources from the 1950s to 2010 with varying levels of detail and quality (Arendt et al., 2012). Regional glacier-covered areas for 19 regions were extracted from the RGI and supplemented with the percentage of the area covered by glaciers terminating in tidewater (Figure 4.8 and Table 4.2). The areas covered by glaciers that are in contact with freshwater lakes are only locally available. The separation of so-called peripheral glaciers from the ice sheets in Greenland and Antarctica is not easy. A new detailed inventory of the glaciers in Greenland (Rastner et al., 2012) allows for estimation of their area, volume, and mass balance separately from those of the ice sheet. This separation is still incomplete for Antarctica, and values discussed here (Figures 4.1, 4.8 to 4.11, Tables 4.2 and 4.4) refer to the glaciers on the islands in the Antarctic and Sub-Antarctic (Bliss et al., 2013) but exclude glaciers on the mainland of Antarctica that are separate from the ice sheet. Regionally variable accuracy of the glacier outlines leads to poorly quantified uncertainties. These uncertainties, along with the regional variation in the minimum size of glaciers included in the inventory, and the subdivision of contiguous ice masses, also makes the total number of glaciers uncertain; the current best estimate is around 170,000 covering a total area of about $730,000 \mathrm{~km}^{2}$. When summed up, nearly $80 \%$ of the glacier area found in regions Antarctic and Subantarctic (region 19), Canadian Arctic (regions 3 and 4), High Mountain Asia (regions 13, 14 and 15), Alaska (region 5), and Greenland (region 17) (Table 4.2).

From the glacier areas in the new inventory, total glacier volumes and masses have been determined by applying both simple scaling relations and ice-dynamical considerations (Table 4.2, and references therein), however, both methods are calibrated with only a few hundred glacier thickness measurements. This small sample means that uncertainties are large and difficult to quantify. The range of values as derived from four global-scale studies for each of the 19 RGI regions is given in Table 4.2, suggesting a global glacier mass that is likely between 114,000 and $192,000 \mathrm{Gt}$ (314 to $529 \mathrm{~mm}$ SLE). The numbers and areas of glaciers reported in Table 4.2 are directly taken from RGI 2.0 (Arendt et al., 2012), with updates for the Low Latitudes (region 16) and the Southern Andes (region 17).

\subsubsection{Methods to Measure Changes in Glacier Length, Area and Volume/Mass}

To measure changes in glacier length, area, mass and volume, a wide range of observational techniques has been developed. Each technique has individual benefits over specific spatial and temporal scales; their 
main characteristics are summarized in Table 4.3. Monitoring programs include complex climate-related observations at a few glaciers, index measurements of mass balance at about a hundred glaciers, annual length changes for a few hundred glaciers, and repeat geodetic estimates of area and volume changes at regional scales using remote sensing methods (e.g., Haeberli et al., 2007). Although in situ measurements of glacier changes are biased towards glaciers that are easily accessible, comparatively small and simple to interpret, a large proportion of all glaciers in the world is debris covered or tidewater calving (see Table 4.2) and changes of such glaciers are more difficult to interpret in climatic terms (Yde and Pasche, 2010). In addition, many of the remote-sensing based assessments do not discriminate these types.

\subsubsection{Length Change Measurements}

For the approximately 500 glaciers worldwide that are regularly observed, front variations (commonly called length changes) are usually obtained through annual measurements of the glacier terminus position. Globally coordinated observations were started in 1894, providing one of the longest available time series of environmental change (WGMS, 2008). More recently, particularly in regions that are difficult to access, aerial photography and satellite imaging have been used to determine glacier length changes over the past decades. For selected glaciers globally, historic terminus positions have been reconstructed from maps, photographs, satellite imagery, also paintings, dated moraines and other sources (e.g., Masiokas et al., 2009; Lopez et al., 2010; Nussbaumer et al., 2011; Davies and Glasser, 2012; Leclerca and Oerlemans, 2012; Rabatel et al., 2013). Early reconstructions are sparsely distributed in both space and time, generally at intervals of decades. The terminus fluctuations of some individual glaciers have been reconstructed for periods of more than 3000 years (Holzhauser et al., 2005), with a much larger number of records available as far back as the 16th or 17th centuries (Zemp et al., 2011, and references therein). The reconstructed glacier length records are globally well distributed and were used, for example, to determine the contribution of glaciers to global sea level rise (Leclercq et al., 2011) (Section 4.3.3.4), and for an independent temperature reconstruction at a hemispheric scale (Leclercq and Oerlemans, 2012).

Table 4.2 The 19 regions used throughout this chapter and their respective glacier numbers and area (absolute and in percent) are derived from the RGI 2.0 (Arendt et al., 2012 ); the tidewater fraction is from Gardner et al. (2013). The minimum and maximum values of glacier mass are the minimum and maximum of the estimates given in four studies: Grinsted (2013), Huss and Farinotti (2012), Marzeion et al. (2012) and Radić et al. (2013). The mean sea level equivalent (SLE) of the mean glacier mass is the mean of estimates from the same four studies, using an ocean area of $362.5 \times 10^{6} \mathrm{~km}^{2}$ for conversion. All values were derived with globally consistent methods; deviations from more precise national data sets are thus possible. Ongoing improvements may lead to revisions of these (RGI 2.0) numbers in future releases of the RGI.

\begin{tabular}{|c|c|c|c|c|c|c|c|c|}
\hline Region & Region Name & $\begin{array}{l}\text { Number of } \\
\text { Glaciers }\end{array}$ & $\begin{array}{l}\text { Area } \\
\left(\mathrm{km}^{2}\right)\end{array}$ & $\begin{array}{l}\text { Percent of } \\
\text { total area }\end{array}$ & $\begin{array}{c}\text { Tidewater } \\
\text { fraction }(\%)\end{array}$ & $\begin{array}{c}\text { Mass } \\
\text { (minimum) } \\
(\mathrm{Gt})\end{array}$ & $\begin{array}{c}\text { Mass } \\
\underset{(\text { maximum) }}{(\mathrm{Gt})}\end{array}$ & $\begin{array}{c}\text { Mean SLE } \\
\quad(\mathrm{mm})\end{array}$ \\
\hline 1 & Alaska & 23,112 & 89,267 & 12.3 & 13.7 & 16,168 & 28,021 & 54.7 \\
\hline 2 & $\begin{array}{l}\text { Western Canada } \\
\text { and USA }\end{array}$ & 15,073 & $14,503.5$ & 2.0 & 0 & 906 & 1148 & 2.8 \\
\hline 3 & Arctic Canada North & 3318 & $103,990.2$ & 14.3 & 46.5 & 22,366 & 37,555 & 84.2 \\
\hline 4 & Arctic Canada South & 7342 & $40,600.7$ & 5.6 & 7.3 & 5510 & 8845 & 19.4 \\
\hline 5 & Greenland & 13,880 & $87,125.9$ & 12.0 & 34.9 & 10,005 & 17,146 & 38.9 \\
\hline 6 & Iceland & 290 & $10,988.6$ & 1.5 & 0 & 2390 & 4640 & 9.8 \\
\hline 7 & Svalbard & 1615 & $33,672.9$ & 4.6 & 43.8 & 4821 & 8700 & 19.1 \\
\hline 8 & Scandinavia & 1799 & 2833.7 & 0.4 & 0 & 182 & 290 & 0.6 \\
\hline 9 & Russian Arctic & 331 & $51,160.5$ & 7.0 & 64.7 & 11,016 & 21,315 & 41.2 \\
\hline 10 & North Asia & 4403 & 3425.6 & 0.4 & 0 & 109 & 247 & 0.5 \\
\hline 11 & Central Europe & 3920 & 2058.1 & 0.3 & 0 & 109 & 125 & 0.3 \\
\hline 12 & Caucasus & 1339 & 1125.6 & 0.2 & 0 & 61 & 72 & 0.2 \\
\hline 13 & Central Asia & 30,200 & 64,497 & 8.9 & 0 & 4531 & 8591 & 16.7 \\
\hline 14 & South Asia (West) & 22,822 & 33,862 & 4.7 & 0 & 2900 & 3444 & 9.1 \\
\hline 15 & South Asia (East) & 14,006 & $21,803.2$ & 3.0 & 0 & 1196 & 1623 & 3.9 \\
\hline 16 & Low Latitudes ${ }^{\mathrm{a}}$ & 2601 & 2554.7 & 0.6 & 0 & 109 & 218 & 0.5 \\
\hline 17 & Southern Andes ${ }^{\mathrm{a}}$ & 15,994 & $29,361.2$ & 4.5 & 23.8 & 4241 & 6018 & 13.5 \\
\hline 18 & New Zealand & 3012 & 1160.5 & 0.2 & 0 & 71 & 109 & 0.2 \\
\hline \multirow[t]{2}{*}{19} & $\begin{array}{l}\text { Antarctic and } \\
\text { Sub-Antarctic }\end{array}$ & 3274 & $13,2267.4$ & 18.2 & 97.8 & 27,224 & 43,772 & 96.3 \\
\hline & Total & 168,331 & $726,258.3$ & & 38.5 & 113,915 & 191,879 & 412.0 \\
\hline
\end{tabular}

Notes:

a For regions 10, 16 and 17 the number and area of glaciers are corrected to allow for over-inclusion of seasonal snow in the glacierized extent of RGI 2.0 and for improved outlines (region 10) compared to RGI 2.0 (updated from, Arendt et al., 2012). 


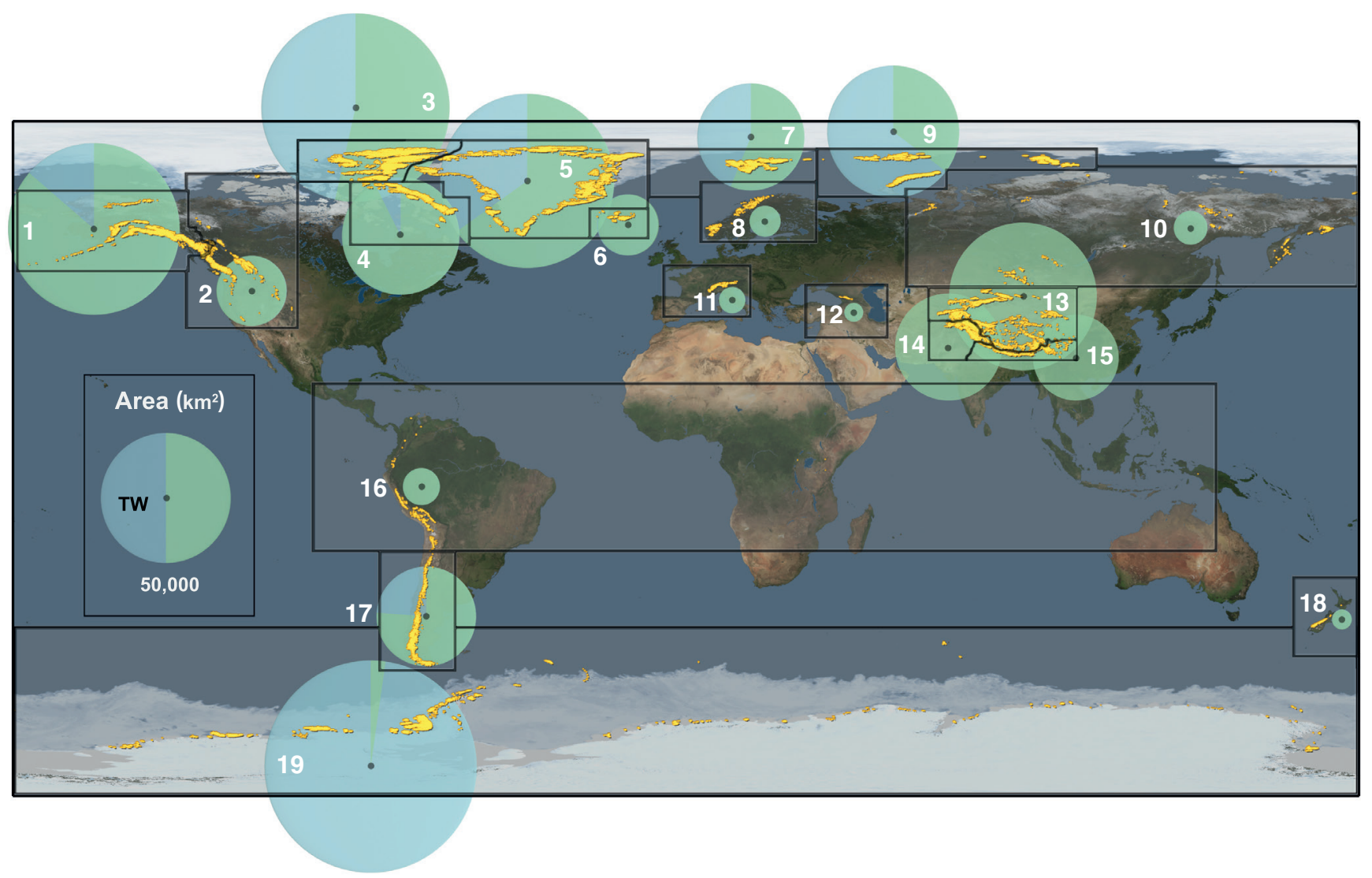

Figure 4.8 Global distribution of glaciers (yellow, area increased for visibility) and area covered (diameter of the circle), sub-divided into the 19 RGI regions (white number) referenced in Table 4.2. The area percentage covered by tidewater (TW) glaciers in each region is shown in blue. Data from Arendt et al. (2012) and Gardner et al. (2013).

\subsubsection{Area Change Measurements}

Glacier area changes are reported in increasing number and coverage based on repeat satellite imagery (WGMS, 2008). Although satellite-based observations are available only for the past four decades, studies using aerial photography, old maps, as well as mapped and dated moraines and trim lines show glacier areas back to the end of the so-called Little Ice Age (LIA, see Glossary) about 150 years ago (cf. Figure 6 in Rabatel et al., 2008) and beyond (e.g., Citterio et al., 2009; Davies and Glasser, 2012). The observed area changes depend (in most regions) on glacier size (with smaller glaciers shrinking at faster percentage rates) and tend to vary greatly within any one mountain range. Moreover, the time spans of the measurements of change vary from study to study and regional or global-scale estimates are therefore difficult to generate. The focus here is thus on the comparison of mean annual relative area changes averaged over entire mountain regions.

\subsubsection{Volume and Mass Change Measurements}

Several methods are in use for measuring mass changes of glaciers. Traditionally, the annual surface mass balance is derived from repeated snow density and snow/ice stake readings on individual glaciers. Estimates over larger regions are obtained by extrapolating from the measured glaciers. This labour-intensive method is generally restricted to a limited number of accessible glaciers, which are unevenly distributed over glacier regions and types. Annual measurements began in the 1940 s on a few glaciers, with about 100 glaciers being measured since the 1980s - and only 37 glaciers have been measured without interruption for more than 40 years (WGMS, 2009). Potential mass loss from calving or from basal ablation is not included in the surface measurements. At present, it is not possible to quantify all sources of uncertainty in mass budgets extrapolated from measurements of individual glaciers (Cogley, 2009b).

A second method determines the volume change of all glaciers in a region by measurement of surface-elevation changes (Section 4.3.3.3 and Figure 4.11). The information is derived by subtracting digital terrain models from two points in time, including those from repeat airborne or satellite altimetry (particularly suitable for larger and flatter ice surfaces). The conversion from volume to mass change can cause a major uncertainty, in particular over short periods, as density information is required, but is generally available only from field measurements (Gardner et al., 2013, and references therein).

Since 2003, a third method used to estimate overall mass change is through measurement of the changing gravity field from satellites (GRACE mission). The coarse spatial resolution (about $300 \mathrm{~km}$ ) and the difficulties of separating different mass change signals such as hydrological storage and glacial isostatic adjustment limit this method to regions with large continuous ice extent (Gardner et al., 2013). 
A fourth method calculates the mass balance of individual glaciers, or a glacier region, with models that either convert particular glacier variables such as length changes or the altitude of the equilibrium line (see Glossary) (e.g., Rabatel et al., 2005; Luethi et al., 2010; Leclercq et al., 2011) into mass changes, or use time series of atmospheric temperature and other meteorological variables to simulate glacier mass balances at different levels of complexity (e.g., Hock et al., 2009; Machguth et al., 2009; Marzeion et al., 2012; Hirabayashi et al., 2013). The models improve fidelity and physical completeness, and add value to the scarce direct measurements.

A fifth method determines glacier mass changes as residuals of the water balance for hydrological basins rather than for glacier regions. Results from all but this last method are used in the following regional and global assessment of glacier mass changes (Sections 4.3.3.3 and 4.3.3.4).

\subsubsection{Observed Changes in Glacier Length, Area and Mass}

\subsubsection{Length Changes}

Despite their variability due to different response times and local conditions (see FAQ 4.2), the annually measured glacier terminus fluctuations from about 500 glaciers worldwide reveal a largely homogeneous trend of retreat (WGMS, 2008). In Figure 4.9, a selection of the available long-term records of field measurements is shown for 14 out of the $19 \mathrm{RGI}$ regions. Cumulative values of retreat for large, land-terminating valley glaciers typically reach a few kilometres over the 120 year period of observation. For mid-latitude mountain and valley glaciers, typical retreat rates are of the order of 5 to $20 \mathrm{~m} \mathrm{yr}^{-1}$. Rates of up to $100 \mathrm{~m} \mathrm{yr}^{-1}$ (or even more) are seen to occur under special conditions, such as the complete loss of a tongue on a steep slope (see FAQ 4.2, Figure $1 \mathrm{c}$ ), or the disintegration of a very flat tongue. A non-calving valley glacier in Chile had reported mean annual retreat rates of $125 \mathrm{~m}$ from 1961 to 2011 (Rivera et al., 2012). The general tendency of retreat in the 20th century was interrupted in several regions (e.g., regions $2,8,11$ and 17) by phases of stability lasting one or two decades, or even advance, for example in the 1920s, 1970s and 1990s (regionally variable). In regions for which long-term field measurements of several glaciers of different sizes are available, the terminus fluctuations typically show a pattern with the largest (flatter) glaciers tending to retreat continuously and by large cumulative distances, medium-sized (steeper) glaciers showing decadal fluctuations, and smaller glaciers showing high variability superimposed on smaller cumulative retreats (Figure 4.9).

The exceptional terminus advances of a few individual glaciers in Scandinavia and New Zealand in the 1990s may be related to locally specific climatic conditions such as increased winter precipitation (Nesje et al., 2000; Chinn et al., 2005; Lemke et al., 2007). In other regions, such as Iceland, the Karakoram and Svalbard, observed advances were often related to dynamical instabilities (surging) of glaciers (e.g., Murray et al., 2003; Quincey et al., 2011; Bolch et al., 2012; Björnsson et al., 2013). Glaciers with calving instabilities can retreat exceptionally rapidly (Pfeffer, 2007), while those with heavily debris-covered tongues are often close to stationary (Scherler et al., 2011). More regionallyfocused studies of length change over different time periods (e.g., Citterio et al., 2009; Masiokas et al., 2009; Lopez et al., 2010; Bolch et al., 2012) justify high confidence about the trend of glacier length variations shown in Figure 4.9.

\subsubsection{Area Changes}

From the large number of published studies on glacier area changes in all parts of the world since AR4 (see Table 4.SM.1) a selection with examples from 16 out of the $19 \mathrm{RGI}$ regions is shown in Figure 4.10. The studies reveal that (1) total glacier area has decreased in all regions, (2) the rates of change cover a similar range of values in all regions, (3) there is considerable variability of the rates of change within each region, (4) highest loss rates are found in regions 2, 11 and 16, and (5) the rates of loss have a tendency to be higher over more recent time periods. The last point (5) requires studies comparing the same sample of glaciers over multiple similar time periods. For 14 out of 19 regions listed in Table 4.SM.1 (see Supplementary Material) with such an analysis, higher loss rates were found for the more recent period.

While points (1) and (2) give high confidence in the global-scale shrinkage in glacier area, (3) points to a considerable regional to local-scale scatter of observed change rates. The shorter the period of investigation and the smaller the sample of glaciers analysed, the more variable

Table 4.3 Overview of methods used to determine changes in glacier length, area and volume mass along with some typical characteristics. The techniques are not exclusive. The last three columns provide only indicative values.

\begin{tabular}{|c|c|c|c|c|c|c|}
\hline Parameter & Method & Technique & Typical Accuracy & $\begin{array}{c}\text { Number of } \\
\text { Glaciers }\end{array}$ & $\begin{array}{l}\text { Repeat } \\
\text { Interval }\end{array}$ & Earliest Data \\
\hline \multirow{3}{*}{ Length change } & Various & Reconstruction & $10 \mathrm{~m}$ & Dozens & $\begin{array}{l}\text { Decadal - } \\
\text { centuries }\end{array}$ & Holocene \\
\hline & Field & In situ measurement & $1 \mathrm{~m}$ & Hundreds & Annual & 19th century \\
\hline & Remote sensing & Photogrammetric survey & Two image pixels (depending on resolution) & Hundreds & Annual & 20th century \\
\hline \multirow{2}{*}{ Area change } & Maps & Cartographic & $5 \%$ of the area & Hundreds & Decadal & 19th century \\
\hline & Remote sensing & Image processing & $5 \%$ of the area & Thousands & Sub-decadal & 20th century \\
\hline \multirow{2}{*}{ Volume change } & Remote sensing & Laser and radar profiling & $0.1 \mathrm{~m}$ & Hundreds & Annual & 21 st century \\
\hline & Remote sensing & DEM differencing & $0.5 \mathrm{~m}$ & Thousands & Decadal & 20th century \\
\hline \multirow{2}{*}{ Mass change } & Field & Direct mass balance measurement & $0.2 \mathrm{~m}$ & Hundreds & Seasonal & 20th century \\
\hline & Remote sensing & Gravimetry (GRACE) & Dependent on the region & Global & Seasonal & 21st century \\
\hline
\end{tabular}



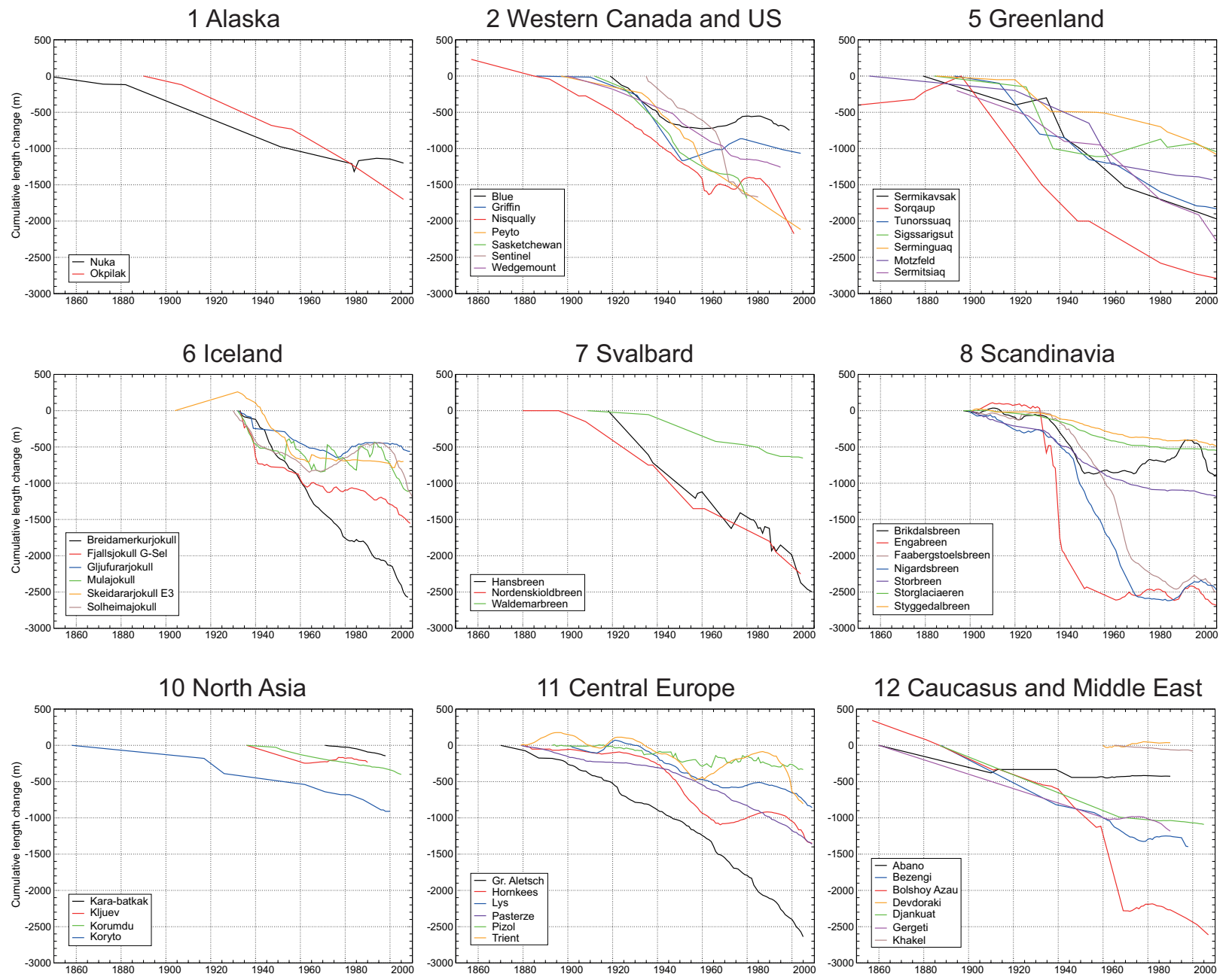

\section{Caucasus and Middle East}

13 Central Asia

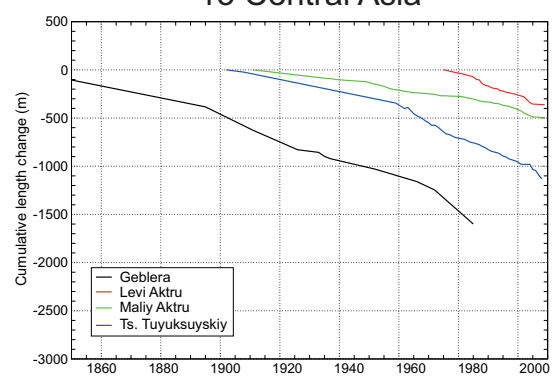

16 Low Latitudes
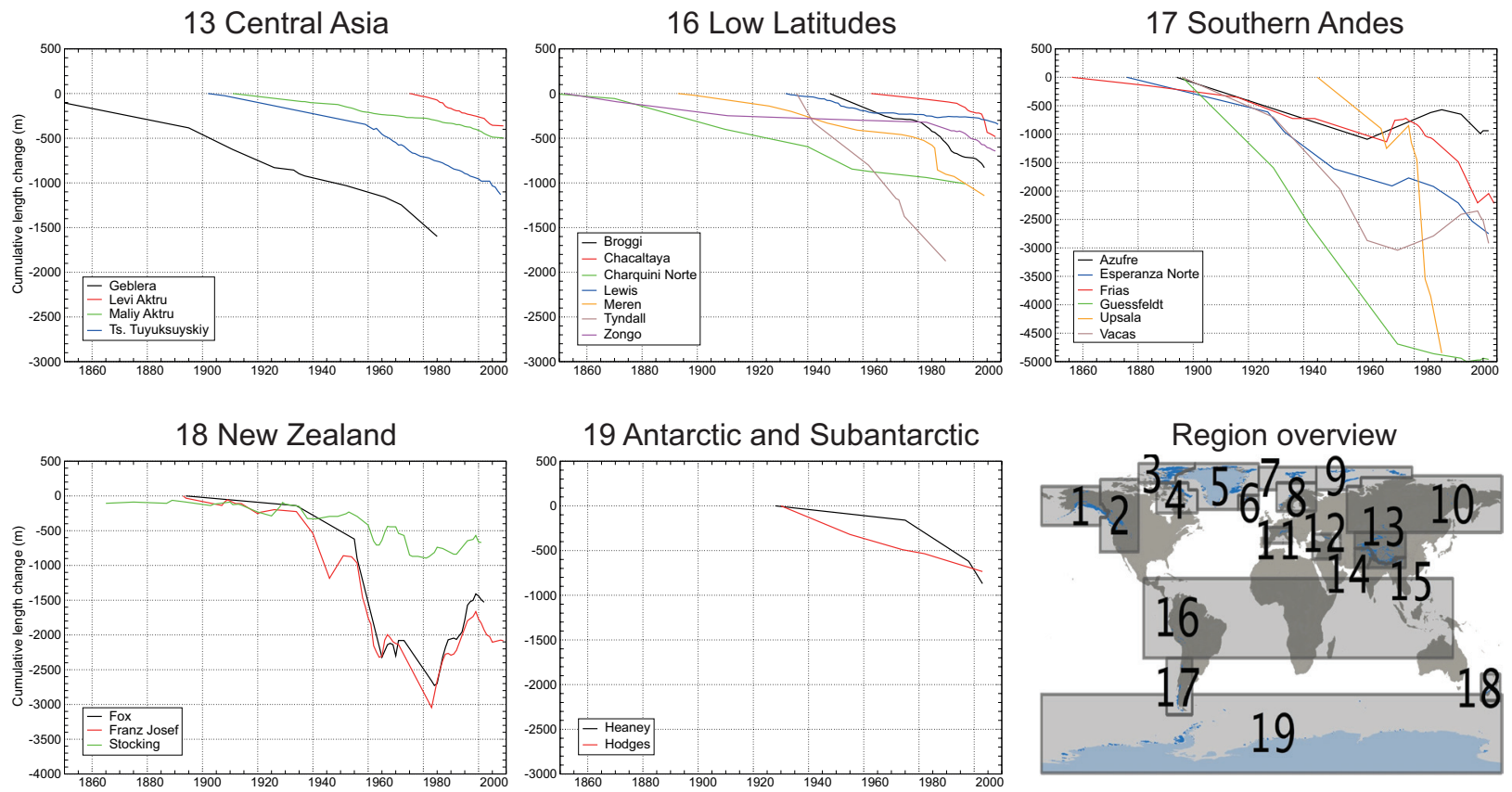

Figure 4.9 | Selection of long-term cumulative glacier length changes as compiled from in situ measurements (WGMS, 2008), reconstructed data points added to measured time series (region 5) from Leclercq et al. (2012), and additional time series from reconstructions (regions 1, 2, 7, 10, 12, 16, 17 and 18) from Leclercq and Oerlemans (2012). Independent of their (highly variable) temporal density, all measurement points are connected by straight lines. The glacier Mulajokull (region 6) is of surge type and some of the glaciers showing strong retreat either terminate (Guessfeldt and Upsala in region 17) or terminated (Engabreen and Nigardsbreen in region 8) in lakes. For region 11, many more time series are available (see WGMS, 2008), but are not shown for graphical reasons. 
are the rates of change reported for a specific region (Table 4.SM.1). In many regions of the world, rates of area loss have increased (Table 4.SM.1), confirming that glaciers are still too large for the current climate and will continue to shrink (see FAQ 4.2 and Section 4.3.3.3).

Several studies have reported the disappearance of glaciers, among others in Arctic Canada (Thomson et al., 2011), the Rocky Mountains (Bolch et al., 2010; Tennant et al., 2012) and North Cascades (Pelto, 2006), Patagonia (Bown et al., 2008; Davies and Glasser, 2012), several tropical mountain ranges (Coudrain et al., 2005; Klein and Kincaid, 2006; Cullen et al., 2013), the European Alps (Citterio et al., 2007; Knoll and Kerschner, 2009; Diolaiuti et al., 2012), the Tien Shan (Hagg et al., 2012; Kutuzov and Shahgedanova, 2009) in Asia and on James Ross Island in Antarctica (Carrivick et al., 2012). In total, the disappearance of more than 600 glaciers has been reported, but the real number is certainly higher. Also some of the glaciers, whose annual mass balance has been measured over several years or even decades, have disappeared or started to disintegrate (Ramirez et al., 2001; Carturan and Seppi, 2007; Thibert et al., 2008). Though the number of glaciers that have disappeared is difficult to compare directly (e.g., the time periods analysed or the disappearance-criteria applied differ), glaciers that have disappeared provide robust evidence that the ELA (see Glossary) has risen above the highest peaks in many mountain ranges (see FAQ 4.2).

\subsubsection{Regional Scale Glacier Volume and Mass Changes}

In AR4, global and regional scale glacier mass changes were extrapolated from in situ measurements of mass balance on individual glaciers (Kaser et al., 2006; Lemke et al., 2007). In some regions, such as Alaska, Patagonia and the Russian Arctic, very few if any such records were available. Since AR4, geodetically derived ice volume changes have been assimilated (Cogley, 2009b), providing more consistent regional coverage and better representation of the proportion of calving glaciers. In addition, the new near complete inventory (RGI) of glacier-covered areas (Arendt et al., 2012) has improved knowledge about regional and global glacier volume and mass changes.

Figure 4.11 shows a compilation of available mean mass-balance rates for 1960-2010 for each of the 19 RGI regions. Where error estimates are reported, the $90 \%$ confidence bounds are shown. Most results shown are calculated using a single method, some merge multiple methods; those from Gardner et al. (2013) are reconciled estimates for 2003-2009 obtained by selecting the most reliable results of different observation methods, after region-by-region reanalysis and comparison.

Despite the great progress made since AR4, uncertainties inherent to specific methods, and arising from the differences between methods (cf.

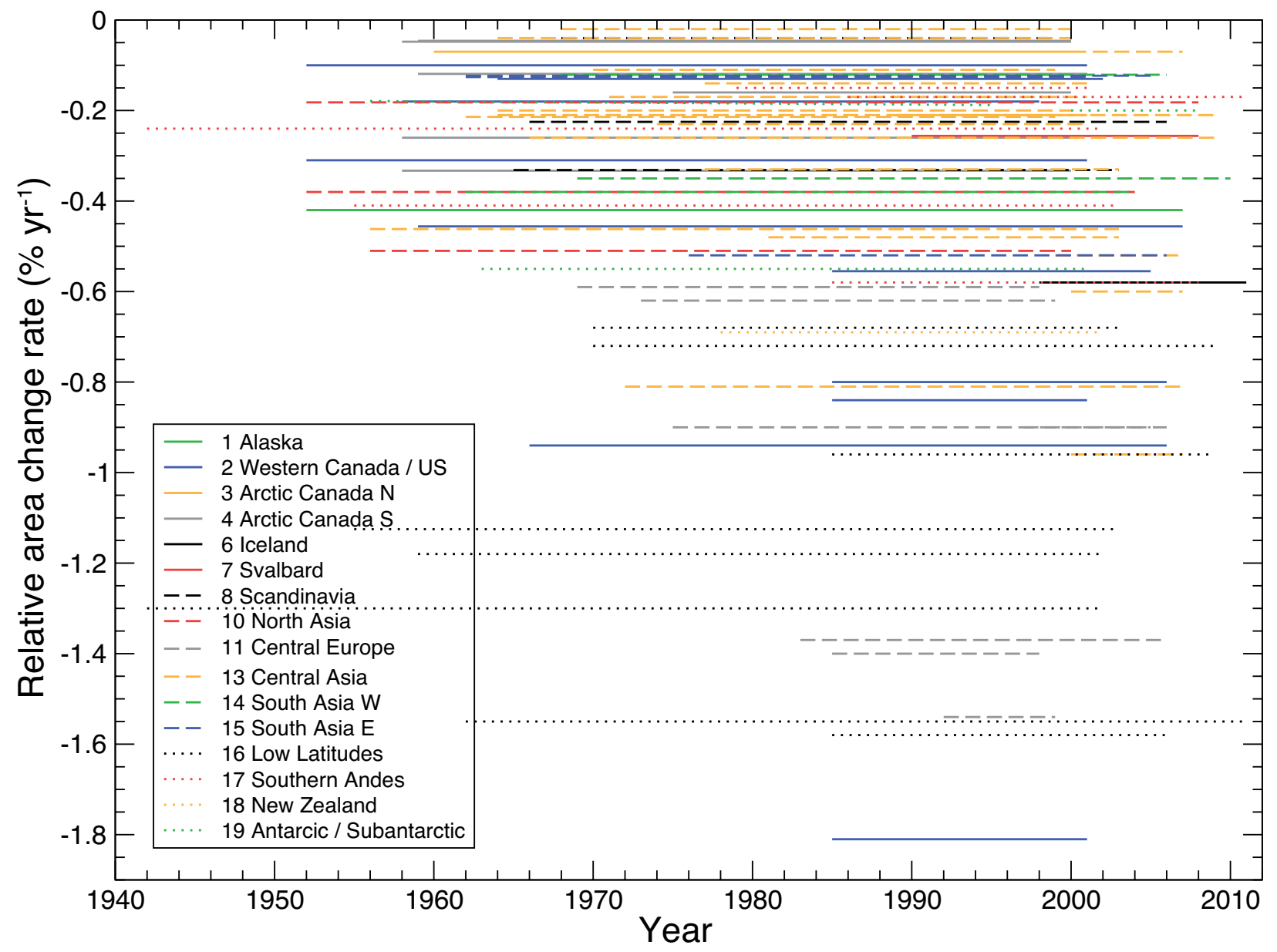

Figure 4.10 Mean annual relative area loss rates for 16 out of the 19 RGI regions of Figure 4.8. Each line shows a measurement of the rate of percentage change in area over a mountain range from a specific publication (for sources see Table 4.SM.1), the length of the line shows the period used for averaging. 
Box 2.1), remain large, and confidence about the absolute value of mass loss is medium at both regional and global scales (Figure 4.11). The highest density of measurement and best time resolution are available for Scandinavia (region 8) and Central Europe (region 11). The least coverage and some of the highest uncertainties are in the Arctic (regions 3 , $4,5,9)$ and the Antarctic and Sub-Antarctic (region 19).
Gardner et al. (2013) discussed inconsistencies among, and differences between, methods and their respective results for 2003-2009. They found that results from the GRACE gravimetric mission agree well with results from ICESat laser altimetry in regions of extensive ice cover (see comment on ICESat data in Section 4.4.2.1), but show much more variable and uncertain mass changes in regions with small or scattered ice
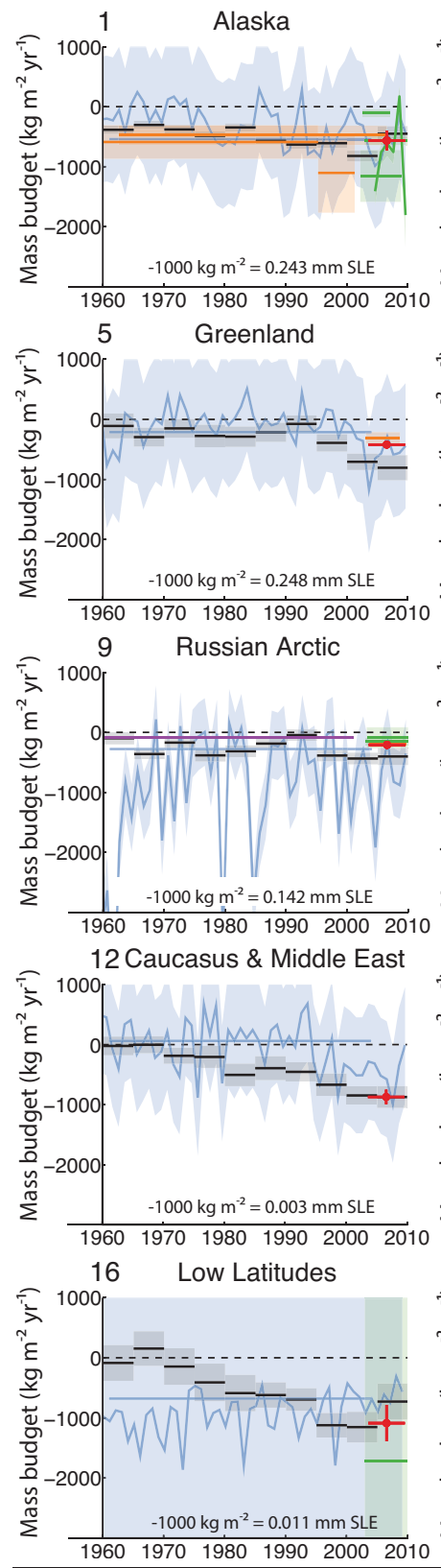

2 Western Canada/US

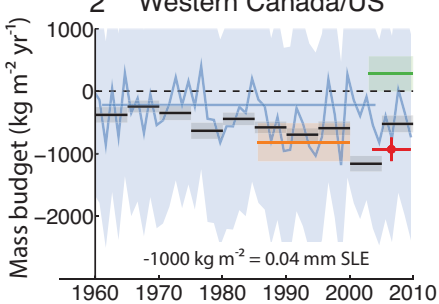

$6 \quad$ Iceland
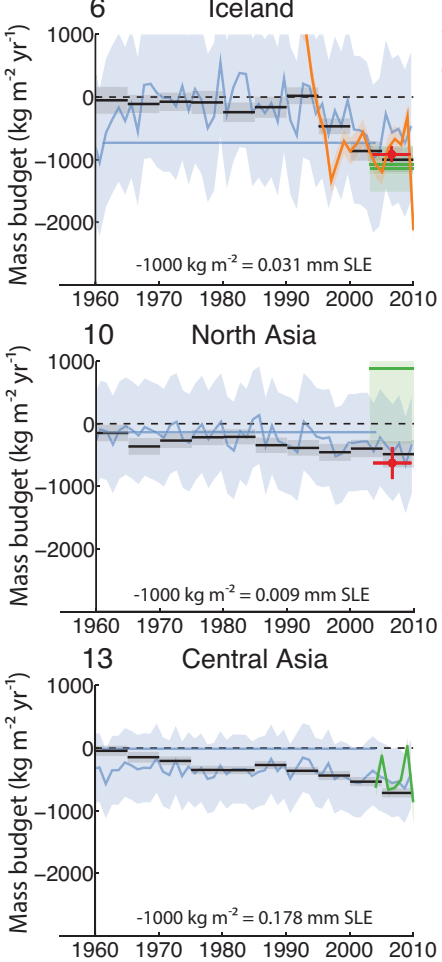

17 Southern Andes

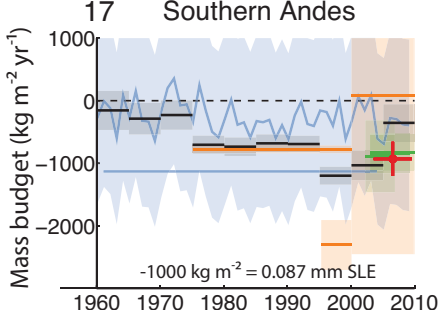

3 Arctic Canada North
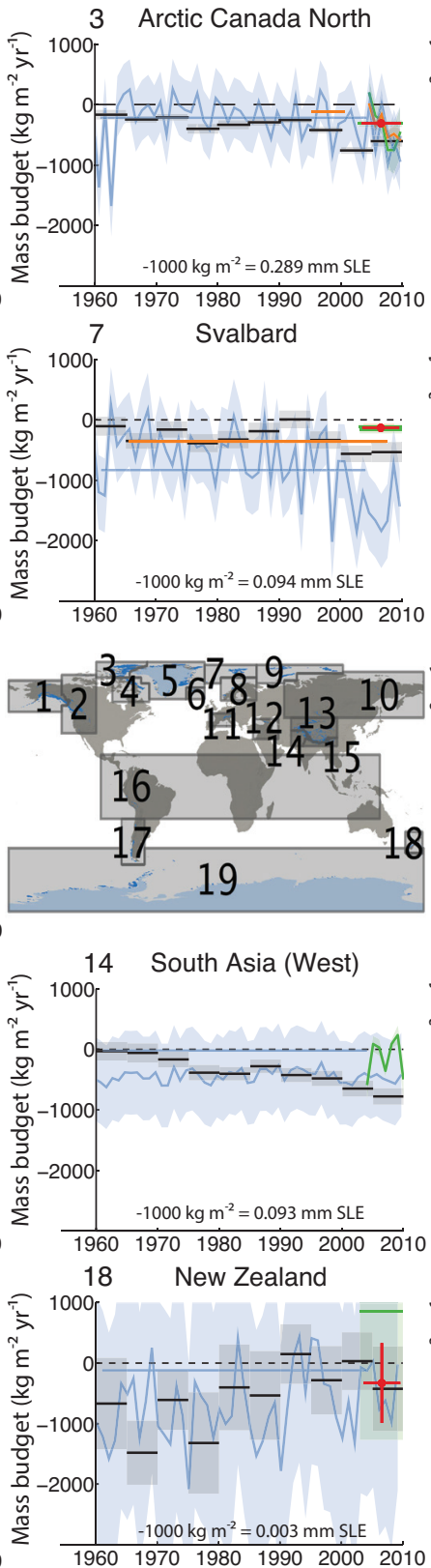
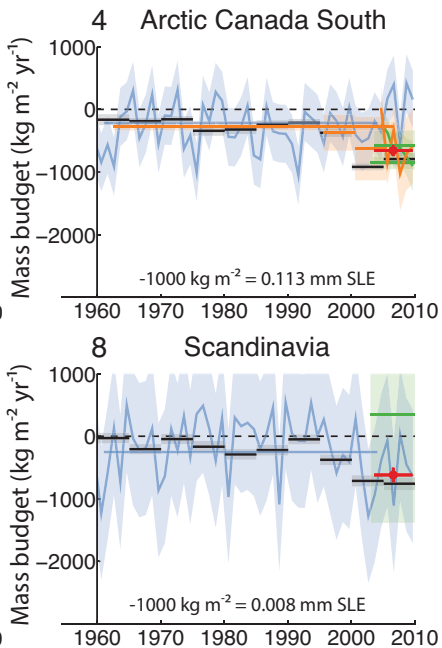

11 Central Europe

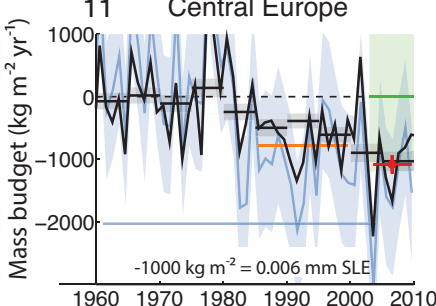

15 South Asia (East)

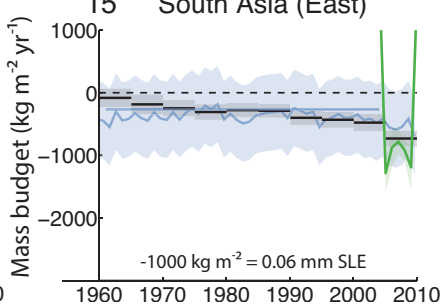

19 Antarctic \& Subantarctic

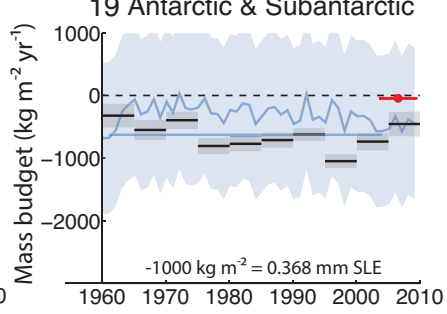

— modeled with climate data — repeat volume area scaling — repeat topography

_ repeat gravimetry _ interpolated local records _ Gardner et al. 2013 [mixed]

Figure 4.11 Regional glacier mass budgets in units of $\mathrm{kg} \mathrm{m}^{-2} \mathrm{yr}^{-1}$ for the world's 19 glacierized regions (Figure 4.8 and Table 4.2). Estimates are from modelling with climate data (blue: Hock et al., 2009; Marzeion et al., 2012), repeat gravimetry (green: Chen et al., 2007; Luthcke et al., 2008; Peltier, 2009; Matsuo and Heki, 2010; Wu et al., 2010; Gardner et al., 2011; Ivins et al., 2011; Schrama and Wouters, 2011; Jacob et al., 2012, updated for RGI regions), repeat volume area scaling (magenta: Glazovsky and Macheret, 2006), interpolation of local glacier records (black: Cogley, 2009a; Huss, 2012), or airborne and/or satellite repeat topographic mapping (orange: Arendt et al., 2002; Rignot et al., 2003; Abdalati et al., 2004; Schiefer et al., 2007; Paul and Haeberli, 2008; Berthier et al., 2010; Moholdt et al., 2010, 2012; Nuth et al., 2010; Gardner et al., 2011, 2012; Willis et al., 2012; Björnsson et al., 2013; Bolch et al., 2013). Mass-budget estimates are included only for study domains that cover about 50\% or more of the total regional glacier area. Mass-budget estimates include $90 \%$ confidence envelopes (not available from all studies). Conversions from specific mass budget in $\mathrm{kg} \mathrm{m}^{-2}$ to $\mathrm{mm} \mathrm{SLE}$ are given for each region. Gravimetric estimates are often not accompanied by estimates of glacierized area (required for conversion from $\mathrm{Gt} \mathrm{yr}^{-1}$ to $\mathrm{kg} \mathrm{m}^{-2} \mathrm{yr}^{-1}$ ); in such cases the RGI regional glacier areas were used. 
cover such as Western Canada/USA (region 2) and the Qinghai-Xizang (Tibet) Plateau (e.g., Yao et al., 2012, and references therein). Based on ICESat measurements, Gardner et al. (2013) also found that glaciers with in situ measurements tend to be located in sub-regions that are thinning more rapidly than the region as a whole. Thus, extrapolation from in situ measurements has a negative bias in regions with sparse measurements. Based on this analysis, Gardner et al. (2013) excluded GRACE results for regions with small or scattered glacier coverage and excluded results based on extrapolation of local records for remote, sparsely sampled regions.

The 2003-2009 regionally differentiated results are given in Table 4.4. There is very high confidence that, between 2003 and 2009, most mass loss was from glaciers in the Canadian Arctic (regions 3 and 4), Alaska (region 1), Greenland (region 5), the Southern Andes (region 17) and the Asian Mountains (region 13 to 15), which together account for more than $80 \%$ of the global ice loss.

Despite the considerable scatter, Figure 4.11 shows mass losses in all 19 regions over the past five decades that, together with their consistency with length (Section 4.3.3.1) and area changes (Section 4.3.3.2), provide robust evidence and very high confidence in global glacier shrinkage. In many regions, ice loss has likely increased during the last two decades, with slightly smaller losses in some regions during the most recent years, since around 2005. In Central Europe (region 11), the increase of loss rates was earliest and strongest. In the Russian Arctic (region 9) and in the Antarctic and Sub-Antarctic (region 19), the signal is highly uncertain and trends are least clear. Gardner et al. (2013) present values close to balance for the Antarctic and Subantarctic (region 19) that result from complex regional patterns, for exam-

Table 4.4 Regional mass change rates in units of $\mathrm{kg} \mathrm{m}^{-2} \mathrm{yr}^{-1}$ and $\mathrm{Gt} \mathrm{y}^{\mathrm{r}-1}$ for the period 2003-2009 from Gardner et al. (2013). Central Asia (region 13), South Asia West (region 14), and South Asia East (region 15) are merged into a single region. For the division of regions see Figure 4.8.

\begin{tabular}{|c|c|c|c|}
\hline No. & Region Name & $\left(\mathrm{kg} \mathrm{m}^{-2} \mathrm{yr}^{-1}\right)$ & $\left(G t y^{-1}\right)$ \\
\hline 1 & Alaska & $-570 \pm 200$ & $-50 \pm 17$ \\
\hline 2 & Western Canada and USA & $-930 \pm 230$ & $-14 \pm 3$ \\
\hline 3 & Arctic Canada North & $-310 \pm 40$ & $-33 \pm 4$ \\
\hline 4 & Arctic Canada South & $-660 \pm 110$ & $-27 \pm 4$ \\
\hline 5 & Greenland periphery & $-420 \pm 70$ & $-38 \pm 7$ \\
\hline 6 & Iceland & $-910 \pm 150$ & $-10 \pm 2$ \\
\hline 7 & Svalbard & $-130 \pm 60$ & $-5 \pm 2$ \\
\hline 8 & Scandinavia & $-610 \pm 140$ & $-2 \pm 0$ \\
\hline 9 & Russian Arctic & $-210 \pm 80$ & $-11 \pm 4$ \\
\hline 10 & North Asia & $-630 \pm 310$ & $-2 \pm 1$ \\
\hline 11 & Central Europe & $-1060 \pm 170$ & $-2 \pm 0$ \\
\hline 12 & Caucasus and Middle East & $-900 \pm 160$ & $-1 \pm 0$ \\
\hline $13-15$ & High Mountain Asia & $-220 \pm 100$ & $-26 \pm 12$ \\
\hline 16 & Low Latitudes & $-1080 \pm 360$ & $-4 \pm 1$ \\
\hline 17 & Southern Andes & $-990 \pm 360$ & $-29 \pm 10$ \\
\hline 18 & New Zealand & $-320 \pm 780$ & $0 \pm 1$ \\
\hline \multirow[t]{2}{*}{19} & Antarctic and Sub-Antarctic & $-50 \pm 70$ & $-6 \pm 10$ \\
\hline & Total & $-350 \pm 40$ & $-259 \pm 28$ \\
\hline
\end{tabular}

ple, with losses on Antarctic Peninsula islands and gains on Ellsworth Land islands. The picture is also heterogeneous in High Mountain Asia (region 13 to 15) (e.g., Bolch et al., 2012; Yao et al., 2012), where glaciers in the Himalaya and the Hindu Kush have been losing mass (Kääb et al., 2012) while those in the Karakoram are close to balance (Gardelle et al., 2012).

Several studies of recent glacier velocity change (Heid and Kääb, 2012; Azam et al., 2012) and of the worldwide present-day sizes of accumulation areas (Bahr et al., 2009) indicate that the world's glaciers are out of balance with the present climate and thus committed to losing considerable mass in the future, even without further changes in climate. Increasing ice temperatures recorded at high elevation sites in the tropical Andes (Gilbert et al., 2010) and in the European Alps (Col du Dome on Mont Blanc and Monte Rosa) (Vincent et al., 2007; Hoelzle et al., 2011), as well as the ongoing thinning of the cold surface layer on Storglaciären in northern Sweden (Gusmeroli et al., 2012), support this conclusion and give it high confidence.

\subsubsection{Global Scale Glacier Mass Changes-The Contribution to Sea Level}

Global time series are required to assess the continuing contribution of glacier mass changes to sea level (see Section 13.4.2 for discussion of the small proportion of ice loss from glaciers that does not contribute to sea level rise). A series of recent studies, some updated to RGI areas for this report by their respective authors, provides very high confidence in a considerable and continuous mass loss, despite only medium agreement on the specific rates (Figure 4.12 and Table 4.5). Cogley (updated from, 2009b) compiled 4,817 directly measured annual mass budgets, and 983 volume change measurements by extending the data set of WGMS (2009, and earlier issues ). Global 5-year averages for 1961-2010, with uncertainties, were estimated from these using an inverse-distance-weighted interpolation. Newly available volume change measurements increased the proportion of observations from calving glaciers from $3 \%$ to $16 \%$ compared to earlier estimates reported by Lemke et al. (2007). This proportion is more realistic, but may still underestimate the relative importance of calving glaciers (Figure 4.8 and Section 4.3.3.3).

Leclercq et al. (updated from 2011) used length variations from 382 glaciers worldwide as a proxy for glacier mass loss since 1800 . The length/mass change conversion was calibrated against mass balance observations for 1950-2005 from Cogley (2009b) and provide one estimate based on the arithmetic mean and another based on area-weighted extrapolation of regional averages. Uncertainty was estimated from upper and lower bounds of the calibration parameter assumptions, and cumulatively propagated backward in time. For the 19th century, the information was constrained by a limited number of observations, particularly in extensively glacierized regions that contribute most to the global mass budget.

Two global-scale time series are obtained from mass-balance modelling based on temperature and precipitation data (Marzeion et al., 2012; Hirabayashi et al., 2013). Glacier size adjustments are simulated by using area-volume power-law relations as proposed by Bahr et al. (1997) for the approximately 170,000 individual glaciers delineated in 

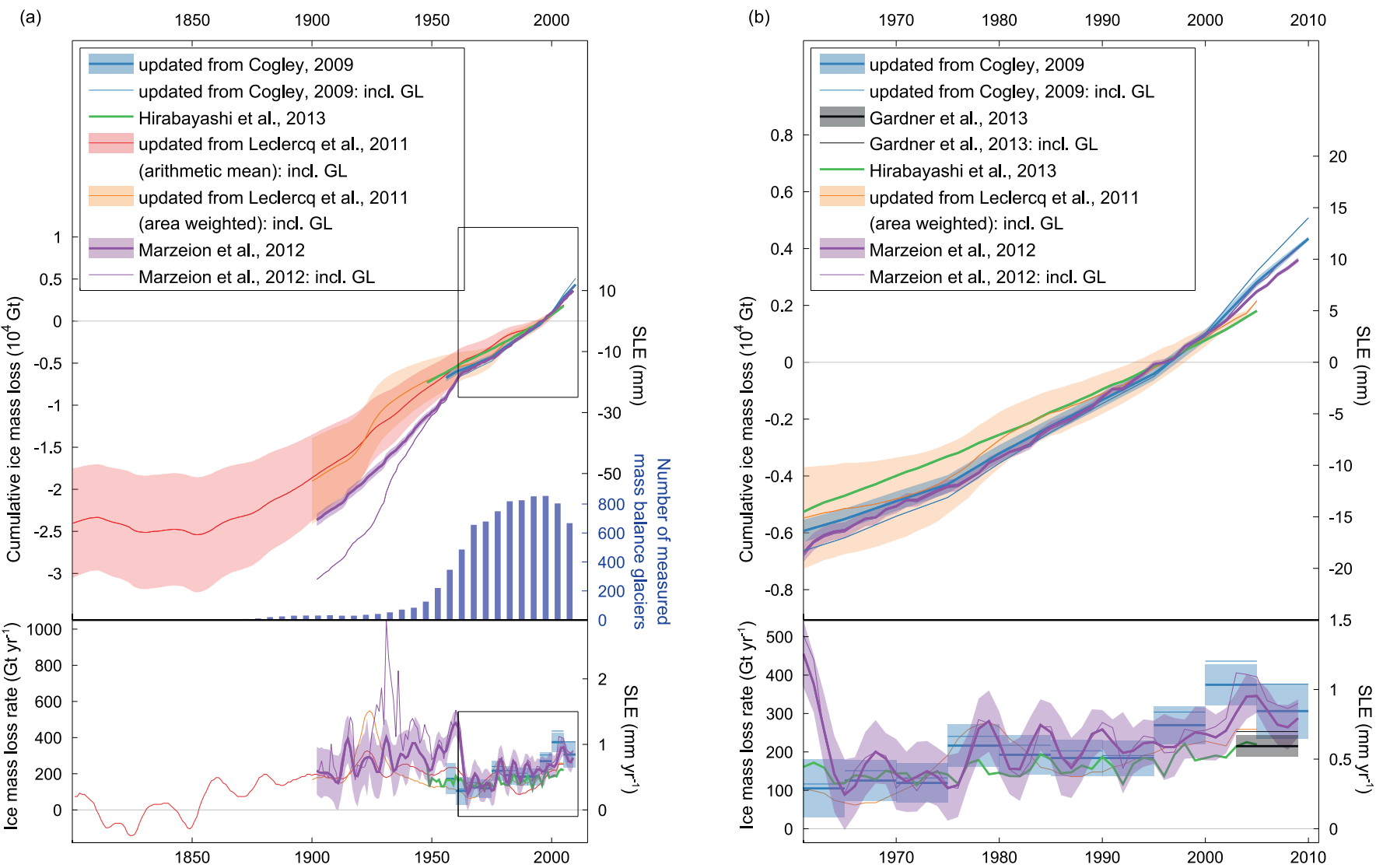

Figure 4.12 | Global cumulative (top graphs) and annual (lower graphs) glacier mass change for (a) 1801-2010 and (b) 1961-2010. The cumulative estimates are all set to zero mean over 1986-2005. Estimates are based on glacier length variations (updated from Leclercq et al., 2011), from area-weighted extrapolations of individual directly and geodetically measured glacier mass budgets (updated from Cogley, 2009b), and from modelling with atmospheric variables as input (Marzeion et al., 2012; Hirabayashi et al., 2013). Uncertainties are based on comprehensive error analyses in Cogley (2009b) and Marzeion et al. (2012) and on assumptions about the representativeness of the sampled glaciers in Leclercq et al. (2011). Hirabayashi et al. (2013) give a bulk error estimate only. For clarity in the bottom panels, uncertainties are shown only for the Cogley and Marzeion curves excluding Greenland (GL). The blue bars ( $\mathrm{a}$, top) show the number of measured single-glacier mass balances per pentad in the updated Cogley (2009b) time series. The mean 2003-2009 estimate of Gardner et al. (2013) is added to b, bottom.

the RGI. Marzeion et al. (2012) derive mass balances for 1902-2009 from monthly mean temperature and precipitation obtained from Mitchell and Jones (2005). The model is calibrated against measured time series and validated against independent measurements. Uncertainty estimates are obtained from comprehensive error propagation, first accumulated temporally for each glacier, and then regionally and globally. The model does not account for the subsurface mass balance or calving, but reproduces geodetically measured volume changes for land-based glaciers within the uncertainties; however, it underestimates volume loss slightly for calving glaciers. Hirabayashi et al. (2013) force an extended positive degree-day model with data from an observation-based global set of daily precipitation and near-surface temperature as updated from earlier work (Hirabayashi et al., 2008). Annual mass balance is provided for 1948-2005 with a constant root mean square error of $500 \mathrm{~km}^{3} \mathrm{yr}^{-1}$, estimated from comparison of modelled with measured mass balances.

For the Antarctic and Sub-Antarctic (region 19) observational information is limited and difficult to incorporate into this assessment. For some studies the time spans do not match (e.g., Gardner et al., 2013 give only mean mass change for 2003-2009). Some estimates have been made simply by extrapolating the global mean to region 19 (Cogley, 2009a; Marzeion et al., 2012). One (1961-2004) mean glacier mass loss estimate based on an ECMWF 40-year reanalysis (ERA-40) driven simulation (Hock et al., 2009), is for a glacier area differing from the RGI region 19. For these reasons, the Antarctic and Sub-Antarctic (region 19) is excluded from this global glacier mass change assessment. The contribution of region 19 to sea level is assumed to be within the uncertainty bounds of the Antarctic ice sheet assessment (Section 4.4.2). Whereas Hirabayashi et al. (2013) exclude the Antarctic and Greenland from their simulations and Leclercq et al. (2011) implicitly include Greenland, both Cogley (2009a) and Marzeion et al. (2012) explicitly estimate mass changes in Greenland. In Figure 4.12, cumulative mass changes and corresponding rates are shown for global glaciers excluding regions 5 and 19 (bold lines), and also for global glaciers excluding only region 19 (thin lines). The cumulative curves are normalized such that their 1986-2005 averages are all zero.

The arithmetic-mean estimate of Leclercq et al. (2011) indicates continuous mass loss from glaciers after about 1850 (Figure 4.12a, top). During the 1920s their area-weighted extrapolation reaches consid- 
erably higher rates (Figure 4.12a, bottom) than the other estimates, but the reasons remain unclear. After 1950, mass loss rates including Greenland are all within the uncertainty bounds of those that exclude Greenland, except for the 2001-2005 period when the Greenland contribution was slightly outside the uncertainty bounds for both the Cogley and the Marzeion et al. estimates. Most notable is the rapid loss from Greenland glaciers in the Marzeion et al. simulations during the 1930s. Other studies support rapid Greenland mass loss around this time (Zeeberg and Forman, 2001; Yde and Knudsen, 2007, and references therein; Bjørk et al., 2012; Zdanowicz et al., 2012); however, the neighbouring regions in the Canadian Arctic (south and north) and Iceland have mass loss anomalies an order of magnitude lower than predicted for Greenland in the same simulation. This discrepancy may be an artefact of the uncertainties in the forcing and methods of Marzeion et al. that are considerably larger in the first than in the second half of the 20th century, so that the rates may well be overestimated. The Marzeion et al. rates are also considerably greater in the 1950 s and 1960s than in the other studies; during this period, the most rapid losses are in Arctic Canada and the Russian Arctic (Marzeion et al., 2012).

Overall, there is very high confidence that globally, the mass loss from glaciers has increased since the 1960s, and this is evident in regional-scale estimates (Figure 4.11). For 2003-2009, Gardner et al. (2013) indicate that some regional (Section 4.3.3.3 and Figure 4.11) and also the global time series may overestimate mass loss (Figure 4.12b, bottom). That glaciers with measured mass balances are concentrated in sub-regions with higher mass losses definitely biases the estimates of Cogley (2009a) (Section 4.3.3.3), but this explanation cannot hold for the Marzeion et al. (2012) time series, for which mass changes are simulated separately for every single glacier in the inventory. It also remains unclear whether the 2003-2009 inconsistency identified by Gardner et al. (2013) applies to earlier times, and if so how it should be reconciled. Neither the evidence nor our level of understanding warrants any simple correction of the longer time series at present.

Table 4.5 summarizes global-scale glacier mass losses for different periods relevant to discussions on sea level change (Chapter 13) and the global energy budget (Chapter 3). Values are given separately for the Greenland glaciers alone (region 5) and for all glaciers excluding those in regions 5 and 19, which are included in the assessment of ice sheets (Section 4.4.2). For the more recent periods, the time series of Cogley (2009a) and Marzeion et al. (2012) are combined, while for 1901-1990 the Leclercq et al. (2011) series were separated by area-weighting and combined with the Marzeion et al. (2012) values. Each rate in Table 4.5 is thus the arithmetic mean of two series, with a confidence bound calculated from their difference, and assessed to represent the $90 \%$ likelihood range. Because differences between the two time series vary considerably, the average confidence bound of 1971-2009 is also applied uniformly to the two sub-periods 19932009 and 2005-2009. The 2003-2009 estimate of Gardner et al. (2013) is lower than the Cogley and Marzeion averages but those for all glaciers excluding regions 5 and 19 are within the 2005-2009 90\% confidence bound. The 1991-2009 assessment is shown as a cumulative time series in Section 4.8 (see Figure 4.25). Earlier studies of the long-term contribution of glaciers to sea level change (Meier, 1984; Zuo and Oerlemans, 1997; Gregory and Oerlemans, 1998; Kaser et al., 2006; Lemke et al., 2007; Oerlemans et al., 2007; Hock et al., 2009, with removal of Antarctic glacier contribution) all give smaller estimates than those assessed here.

\subsection{Ice Sheets}

\subsubsection{Background}

Since AR4, satellite, airborne and in situ observations have greatly improved our ability to identify and quantify change in the vast polar ice sheets of Antarctica and Greenland. As a direct consequence, our understanding of the underlying drivers of ice-sheet change is also much improved. These observations and the insights they yield are discussed throughout Section 4.4, while the attribution of recent ice sheet change, projection of future changes in ice sheets and their future contribution to sea level rise are discussed in Chapter 10 and Chapter 13 respectively.

\subsubsection{Changes in Mass of Ice Sheets}

The current state of mass balance of the Greenland and Antarctic ice sheets is assessed in sections 4.4.2.2 and 4.4.2.3, but is introduced by

Table 4.5 Average annual rates of global mass change in $\mathrm{Gt} \mathrm{yr}^{-1}$ and in sea level equivalents (mm SLE yr-1) for different time periods (Chapter 13) for (a) glaciers around the Greenland ice sheet (region 5 as defined by Rastner et al., 2012) and (b) all glaciers globally, excluding peripheral glaciers around the Antarctic and Greenland ice sheets (see discussion in Section 4.4.2). The values are derived by averaging the results from the references listed and uncertainty ranges give $90 \%$ confidence level. The uncertainty calculated for 1971-2009 is also applied for the sub-periods 1993-2009 and 2005-2009. The global values for 2003-2009 from Gardner et al. (2013) are within this likelihood range (italics).

\begin{tabular}{|c|c|c|c|c|c|}
\hline & \multirow{2}{*}{ Reference } & \multicolumn{2}{|c|}{ (a) Greenland glaciers (region 5) } & \multicolumn{2}{|c|}{ (b) All glaciers excluding ice sheet peripheries } \\
\hline & & Gt $\mathrm{yr}^{-1}$ & $\mathrm{~mm}$ SLE yr-1 & Gt $\mathrm{yr}^{-1}$ & $\mathrm{~mm}$ SLE $\mathrm{yr}^{-1}$ \\
\hline 1901-1990 & $\begin{array}{l}\text { Marzeion et al. (2012); Leclercq } \\
\text { et al. (2011), updated }\end{array}$ & $-54 \pm 16$ & $0.15 \pm 0.05$ & $-197 \pm 24$ & $0.54 \pm 0.07$ \\
\hline 1971-2009 & Cogley (2009a); Marzeion et al. (2012) & $-21 \pm 10$ & $0.06 \pm 0.03$ & $-226 \pm 135$ & $0.62 \pm 0.37$ \\
\hline 1993-2009 & Cogley (2009a); Marzeion et al. (2012) & $-37 \pm 10$ & $0.10 \pm 0.03$ & $-275 \pm 135$ & $0.76 \pm 0.37$ \\
\hline $2005-2009$ & Cogley (2009a); Marzeion et al. (2012) & $-56 \pm 10$ & $0.15 \pm 0.03$ & $-301 \pm 135$ & $0.83 \pm 0.37$ \\
\hline
\end{tabular}

Notes:

a Isolation of (a) from (b) made by applying the respective annual ratios in Marzeion et al. (2012). 
Frequently Asked Questions

\section{FAQ 4.2 | Are Glaciers in Mountain Regions Disappearing?}

In many mountain ranges around the world, glaciers are disappearing in response to the atmospheric temperature increases of past decades. Disappearing glaciers have been reported in the Canadian Arctic and Rocky Mountains; the Andes; Patagonia; the European Alps; the Tien Shan; tropical mountains in South America, Africa and Asia and elsewhere. In these regions, more than 600 glaciers have disappeared over the past decades. Even if there is no further warming, many more glaciers will disappear. It is also likely that some mountain ranges will lose most, if not all, of their glaciers.

In all mountain regions where glaciers exist today, glacier volume has decreased considerably over the past 150 years. Over that time, many small glaciers have disappeared. With some local exceptions, glacier shrinkage (area and volume reduction) was globally widespread already and particularly strong during the 1940s and since the 1980s. However, there were also phases of relative stability during the 1890s, 1920s and 1970s, as indicated by longterm measurements of length changes and by modelling of mass balance. Conventional in situ measurements-and increasingly, airborne and satellite measurements-offer robust evidence in most glacierized regions that the rate of reduction in glacier area was higher over the past two decades than previously, and that glaciers continue to shrink. In a few regions, however, individual glaciers are behaving differently and have advanced while most others were in retreat (e.g., on the coasts of New Zealand, Norway and Southern Patagonia (Chile), or in the Karakoram range in Asia). In general, these advances are the result of special topographic and/or climate conditions (e.g., increased precipitation).

It can take several decades for a glacier to adjust its extent to an instantaneous change in climate, so most glaciers are currently larger than they would be if they were in balance with current climate. Because the time required for the adjustment increases with glacier size, larger glaciers will continue to shrink over the next few decades, even if temperatures stabilise. Smaller glaciers will also continue to shrink, but they will adjust their extent faster and many will ultimately disappear entirely.

Many factors influence the future development of each glacier, and whether it will disappear: for instance, its size, slope, elevation range, distribution of area with elevation, and its surface characteristics (e.g., the amount of debris cover). These factors vary substantially from region to region, and also between neighbouring glaciers. External factors, such as the surrounding topography and the climatic regime, are also important for future glacier evolution. Over shorter time scales (one or two decades), each glacier responds to climate change individually and differently in detail.

Over periods longer than about 50 years, the response is more coherent and less dependent on local environmental details, which means that long-term trends in glacier development can be well modelled. Such models are built on an understanding of basic physical principles. For example, an increase in local mean air temperature, with no change in precipitation, will cause an upward shift of the equilibrium line altitude (ELA; see Glossary) by about 150 $m$ for each degree Celsius of atmospheric warming. Such an upward shift and its consequences for glaciers of different size and elevation range are illustrated in FAQ 4.2, Figure 1.

Initially, all glaciers have an accumulation area (white) above and an ablation area (light blue) below the ELA (FAQ 4.2, Figure 1a). As the ELA shifts upwards, the accumulation area shrinks and the ablation area expands, thus increasing the area over which ice is lost through melt (FAQ 4.2, Figure 1b). This imbalance results in an overall loss of ice. After several years, the glacier front retreats, and the ablation area shrinks until the glacier has adjusted its extent to the new climate (FAQ 4.2, Figure 1c). Where climate change is sufficiently strong to raise the ELA permanently above the glacier's highest point (FAQ 4.2, Figure 1b, right) the glacier will eventually disappear entirely (FAQ 4.2, Figure 1c, right). Higher glaciers, which retain their accumulation areas, will shrink but not disappear (FAQ 4.2, Figure 1C, left and middle). A large valley glacier might lose much of its tongue, probably leaving a lake in its place (FAQ 4.2, Figure 1C, left). Besides air temperature, changes in the quantity and seasonality of precipitation influence the shift of the ELA as well. Glacier dynamics (e.g., flow speed) also plays a role, but is not considered in this simplified scheme.

Many observations have confirmed that different glacier types do respond differently to recent climate change. For example, the flat, low-lying tongues of large valley glaciers (such as in Alaska, Canada or the Alps) currently show the strongest mass losses, largely independent of aspect, shading or debris cover. This type of glacier is slow in 
adjusting its extent to new climatic conditions and reacts mainly by thinning without substantial terminus retreat. In contrast, smaller mountain glaciers, with fairly constant slopes, adjust more quickly to the new climate by changing the size of their ablation area more rapidly (FAQ 4.2, Figure 1c, middle).

The long-term response of most glacier types can be determined very well with the approach illustrated in FAQ 4.2, Figure 1. However, modelling short-term glacier response, or the longterm response of more complex glacier types (e.g., those that are heavily debris-covered, fed by avalanche snow, have a disconnected accumulation area, are of surging type, or calve into water), is difficult. These cases require detailed knowledge of other glacier characteristics, such as mass balance, ice thickness distribution, and internal hydraulics. For the majority of glaciers worldwide, such data are unavailable, and their response to climate change can thus only be approximated with the simplified scheme shown in FAQ 4.2, Figure 1.

The Karakoram-Himalaya mountain range, for instance, has a large variety of glacier types and climatic conditions, and glacier characteristics are still only poorly known. This makes determining their future evolution particularly uncertain. However, gaps in knowledge are expected to decrease substantially in coming years, thanks to increased use of satellite data (e.g., to compile glacier inventories or derive flow velocities) and extension of the groundbased measurement network.

In summary, the fate of glaciers will be variable, depending on both their specific characteristics and future climate conditions. More glaciers will disappear; others will lose most of their low-lying portions and others might not change substantially. Where the ELA is already above the highest elevation on a particular glacier, that glacier is destined to disappear entirely unless climate cools. Similarly, all glaciers will disappear in those regions where the ELA rises above their highest elevation in the future.

a discussion of the improvements in techniques of measurement and understanding of the change made since AR4 (e.g., Lemke et al., 2007; Cazenave et al., 2009; Chen et al., 2011).

\subsubsection{Techniques}

The three broad techniques for measuring ice-sheet mass balance are the mass budget method, repeated altimetry and measurement of a) Before climate change

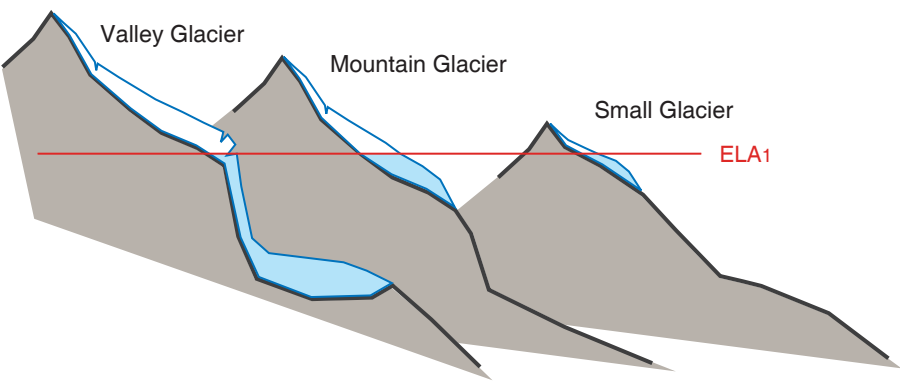

b) After climate change but before glacier readjustment

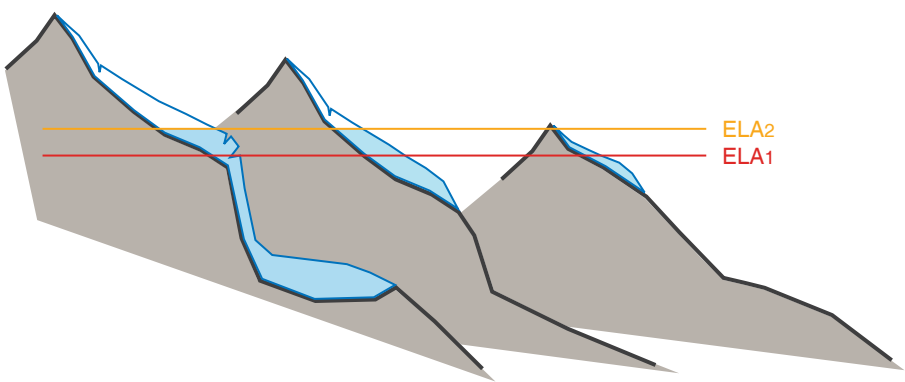

c) After readjustment to climate change

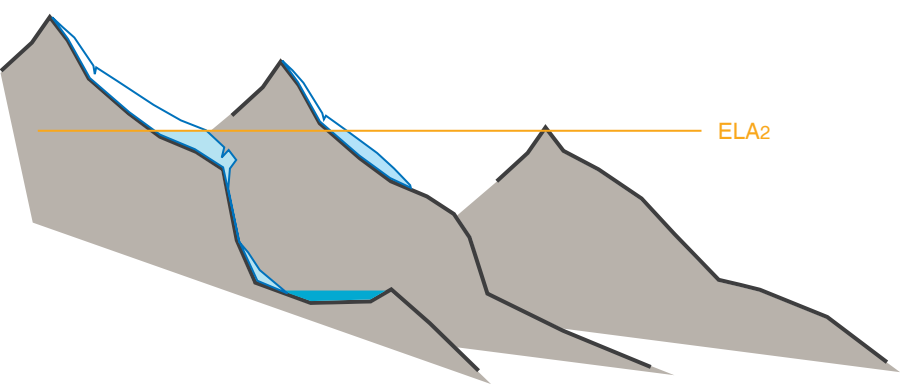

FAQ 4.2, Figure 1 | Schematic of three types of glaciers located at different elevations, and their response to an upward shift of the equilibrium line altitude (ELA). (a) For a given climate, the ELA has a specific altitude (ELA1), and all glaciers have a specific size. (b) Due to a temperature increase, the ELA shifts upwards to a new altitude (ELA2), initially resulting in reduced accumulation and larger ablation areas for all glaciers. (c) After glacier size has adjusted to the new ELA, the valley glacier (left) has lost its tongue and the small glacier (right) has disappeared entirely. temporal variations in the Earth's gravity field. Each method has been applied to both ice sheets by multiple groups, and over time scales ranging from multiple years to decades (Figures 4.13 and 4.14). The peripheral glaciers, surrounding but not strictly a part of the ice sheets, are not treated in the same manner by each technique. Peripheral glaciers are generally excluded from estimates using the mass budget method, they are sometimes, but not always, included in altimetric estimates, and they are almost always included in gravity estimates. 


\subsection{Mass budget method}

The mass budget method (see Glossary) relies on estimating the difference between net surface balance over the ice sheet (input) and perimeter ice discharge flux (output). This method requires comparison of two very large numbers, and even small percentage errors in either may result in large errors in total mass balance. For ice discharge, perimeter fluxes are calculated from measurements of ice velocity and ice thickness at the grounding line. Knowledge of perimeter fluxes has improved significantly since AR4 for both ice sheets (Rignot et al., $2011 \mathrm{~b})$ as a result of more complete ice-thickness data (Bamber et al., 2013; Fretwell et al., 2013) and velocity data from satellite radar interferometry and other techniques (Joughin et al., 2010b; Rignot et al., 2011a). However, incomplete ice thickness mapping still causes uncertainties in ice discharge of 2 to $15 \%$ in Antarctica (Rignot et al., 2008b) and 10\% in Greenland (Howat et al., 2011; Rignot et al., 2011c).

Regional atmospheric climate models (see Glossary) verified using independent in situ data are increasingly preferred to produce estimates of surface mass balance over models that are recalibrated or corrected with in situ data (Box et al., 2009), downscaling of global re-analysis data (see Glossary) (Hanna et al., 2011), or interpolation of
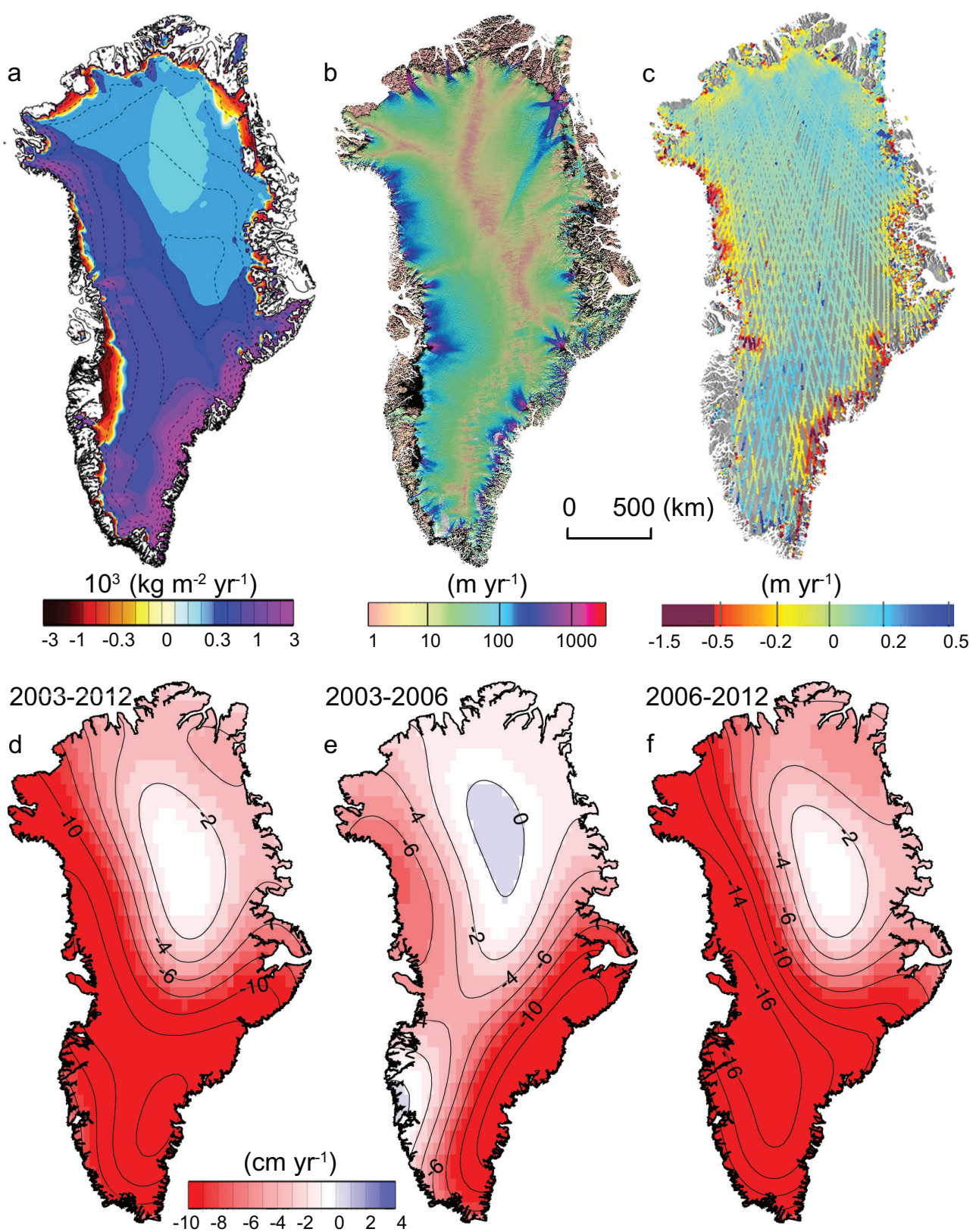

Figure 4.13 Key variable related to the determination of the Greenland ice sheet mass changes. (a) Mean surface mass balance for 1989-2004 from regional atmospheric climate modelling (Ettema et al., 2009). (b) Ice sheet velocity for 2007-2009 determined from satellite data, showing fastest flow in red, fast flow in blue and slower flow in green and yellow (Rignot and Mouginot, 2012). (c) Changes in ice sheet surface elevation for 2003-2008 determined from ICESat altimetry, with elevation decrease in red to increase in blue (Pritchard et al., 2009). (d, e) Temporal evolution of ice loss determined from GRACE time-variable gravity, shown in centimetres of water per year for the periods (a) 2003-2012, (b) 2003-2006 and (c) 2006-2012, colour coded red (loss) to blue (gain) (Velicogna, 2009). Fields shown in (a) and (b) are used together with ice thickness (see Figure 4.18) in the mass budget method. 

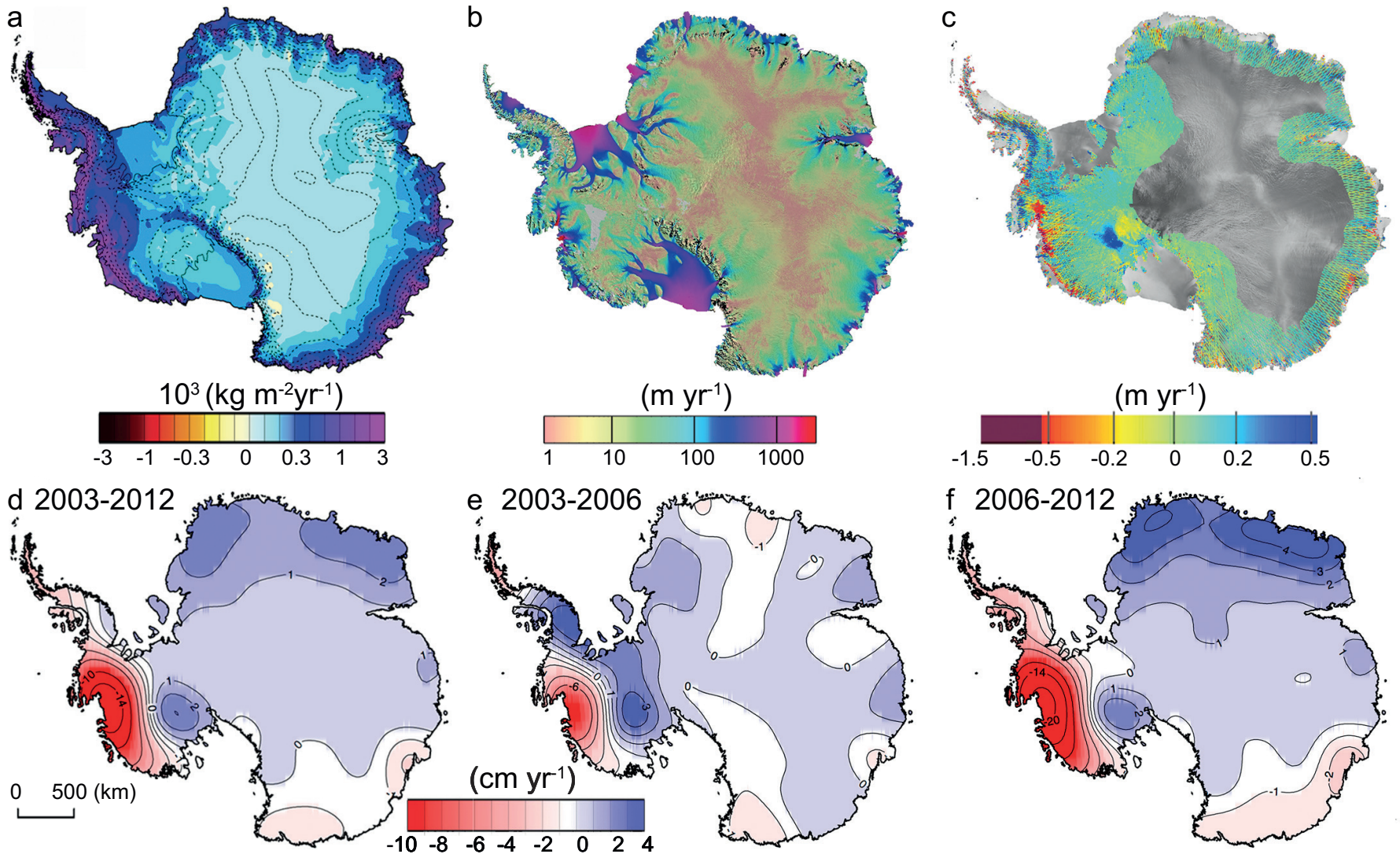

Figure 4.14 | Key fields relating to the determination of Antarctica ice sheet mass changes. (a) Mean surface mass balance for 1989-2004 from regional atmospheric climate modelling (van den Broeke et al., 2006). (b) Ice sheet velocity for 2007-2009 determined from satellite data, showing fastest flow in red, fast flow in blue, and slower flow in green and yellow (Rignot et al., 2011a). (c) Changes in ice sheet surface elevation for 2003-2008 determined from ICESat altimetry, with elevation decrease in red to increase in blue (Pritchard et al., 2009). (d, e) Temporal evolution of ice loss determined from GRACE time-variable gravity, shown in centimetres of water per year for the periods (a) 2003-2012, (b) 2003-2006 and (c) 2006-2012, colour coded red (loss) to blue (gain) (Velicogna, 2009). Fields shown in (a) and (b) are used together with ice thickness (see Figure 4.18) in the mass budget method.

in situ measurements (Arthern et al., 2006; Bales et al., 2009). In Antarctica, surface mass balance (excluding ice shelves) for 1979-2010 is estimated at $1983 \pm 122 \mathrm{Gt} \mathrm{yr}^{-1}$ (van de Berg et al., 2006; Lenaerts et

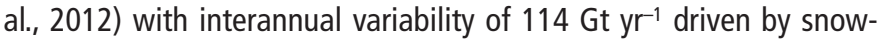
fall variability (Figure 4.14). Comparison with 750 in situ observations indicates an overall uncertainty of $6 \%$ for total ice sheet mass balance, ranging from 5 to $20 \%$ for individual drainage basins (van de Berg et al., 2006; Rignot et al., 2008b; Lenaerts et al., 2012; Shepherd et al., 2012). In Greenland, total snowfall (697 Gt $\mathrm{yr}^{-1}$ ) and rainfall (46 Gt $\left.\mathrm{yr}^{-1}\right)$ minus runoff $\left(248 \mathrm{Gt}^{\mathrm{yr}} \mathrm{r}^{-1}\right.$ ) and evaporation/sublimation (26 Gt $\mathrm{yr}^{-1}$ ) yield a surface mass balance of $469 \pm 82 \mathrm{Gt} \mathrm{yr}^{-1}$ for 1958-2007 (Ettema et al., 2009). The 17\% uncertainty is based on a comparison of model outputs with 350 in situ accumulation observations and, in the absence of runoff data, an imposed 20\% uncertainty in runoff (Howat et al., 2011). Interannual variability in surface mass balance is large (107 $\mathrm{Gt}_{\mathrm{r}^{-1}}$ ) due to the out-of-phase relationship between the variability in precipitation $\left(78 \mathrm{Gt} \mathrm{yr}^{-1}\right)$ and runoff $\left(67 \mathrm{Gt}_{\mathrm{yr}}{ }^{-1}\right)$.

\subsection{Repeated altimetry}

Repeated altimetric survey allows measurement of rates of surface-elevation change, and after various corrections (for changes in snow density and bed elevation; or if the ice is floating, for tides and sea level) reveals changes in ice sheet mass. Satellite radar altimetry (SRALT) has been widely used (Thomas et al., 2008b; Wingham et al., 2009), as has laser altimetry from airplanes (Krabill et al., 2002; Thomas et al., 2009) and satellites (Pritchard et al., 2009; Abdalati et al., 2010; Sorensen et al., 2011; Zwally et al., 2011). Both radar and laser methods have significant challenges. The field-of-view of early SRALT sensors was $\sim 20 \mathrm{~km}$ in diameter, and as a consequence, interpretation of the data they acquired over ice sheets with undulating surfaces or significant slopes was complex. Also, for radar altimeters, estimates are affected by penetration of the radar signal below the surface, which depends on characteristics such as snow density and wetness, and by wide orbit separation (Thomas et al., 2008b). Errors in surface-elevation change are typically determined from the internal consistency of the measurements, often after iterative removal of surface elevation-change values that exceed some multiple of the local value of their standard deviation; this results in very small error estimates (Zwally et al., 2005).

Laser altimeters have been used from aircraft for many years, but satellite laser altimetry, available for the first time from NASA's ICESat satellite launched in 2003, has provided many new results since AR4. Laser 
altimetry is easier to validate and interpret than radar data; the field of view is small (1 $\mathrm{m}$ diameter for airborne lasers, $60 \mathrm{~m}$ for ICESat), and there is negligible penetration below the surface. However, clouds limit data acquisition, and accuracy is affected by atmospheric conditions, laser-pointing errors, and data scarcity.

Knowledge of the density of the snow and firn in the upper layers of an ice sheet is required to convert altimetric measurements to mass change. However, snow densification rates are sensitive to snow temperature and wetness. Warm conditions favour more rapid densification (Arthern et al., 2010; Li and Zwally, 2011). Consequently, recent Greenland warming has probably caused surface lowering simply from this effect. Corrections are inferred from models that are difficult to validate and are typically less than $2 \mathrm{~cm} \mathrm{yr}^{-1}$. ICESat derived surface elevation changes supplemented with differenced ASTER (Advanced Spaceborne Thermal Emission and Reflection Radiometer) satellite digital elevation models were used for outlet glaciers in southeast Greenland (Howat et al., 2008) and for the northern Antarctic Peninsula (Shuman et al., 2011). Laser surveys from airborne platforms over Greenland yield elevation estimates accurate to $10 \mathrm{~cm}$ along reference targets (Krabill et al., 1999; Thomas et al., 2009) and $15 \mathrm{~cm}$ for ICESat using ground-based high-resolution GPS measurements (Siegfried et al., 2011). For a 5 -year separation between surveys, this is an uncertainty of $2.0 \mathrm{~cm} \mathrm{yr}^{-1}$ for airborne platforms and $3 \mathrm{~cm} \mathrm{yr}^{-1}$ for ICESat.

Early in 2013, NASA released an elevation correction for ICESat (National Snow and Ice Data Center, 2013) that is relevant to several studies cited in this chapter, but was provided too late to be included in those studies. This correction improves shot-to-shot variability in ICESat elevations, although spatial averaging and application of inter-campaign bias corrections derived from calibration data and used in many studies already mitigates the impact of the higher variability. The correction also changes elevation trend estimates over the 20032009 ICESat mission period by up to $-1.4 \mathrm{~cm} \mathrm{yr}^{-1}$.

To date, a thorough treatment of the impact of this finding has not been published in the peer-reviewed literature, but the overall magnitude of the effect is reported to be at the level of $1.4 \mathrm{~cm} \mathrm{yr}^{-1}$. For many studies of glaciers, ice sheets and sea ice this is substantially lower (in some cases, an order of magnitude lower) than the signal of change, but elsewhere (e.g, for elevation changes in East Antarctica) it may have an impact. However, multiple lines of evidence, of which ICESat is only one, are used to arrive at the conclusions presented in this chapter. To the degree to which it can be assessed, there is high confidence that the substantive conclusions this chapter will not be affected by revisions of the ICESat data products.

\subsection{Temporal variations in Earth gravity field}

Since 2002, the GRACE (Gravity Recovery and Climate Experiment) satellite mission has surveyed the Earth's time-variable gravity field. Time-variable gravity provides a direct estimate of the ice-mass change at a spatial resolution of about $300 \mathrm{~km}$ (Wahr, 2007). GRACE data yielded early estimates of trends in ice-mass changes over the Greenland and Antarctic ice sheets and confirmed regions of ice loss in coastal Greenland and West Antarctica (Luthcke et al., 2006; Velicogna and Wahr, 2006a, 2006b). With extended time series, now more than
10 years, estimates of ice sheet mass change from GRACE have lower uncertainties than in AR4 (e.g., Harig and Simons, 2012; King et al., 2012). The ice-loss signal from the last decade is also more distinct because the numbers have grown significantly higher (e.g., Wouters et al., 2008; Cazenave et al., 2009; Chen et al., 2009; Velicogna, 2009). The estimates of ice loss based on data from GRACE vary between published studies due to the time-variable nature of the signal, along with other factors that include (1) data-centre specific processing, (2) specific methods used to calculate the mass change, and (3) contamination by other signals within the ice sheet (e.g., glacial isostatic adjustment or GIA, see Glossary) or outside the ice sheet (continental hydrology, ocean circulation). Many of these differences have been reduced in studies published since AR4, resulting in greater agreement between GRACE estimates (Shepherd et al., 2012).

In Antarctica, the GIA signal is similar in magnitude to the ice-loss

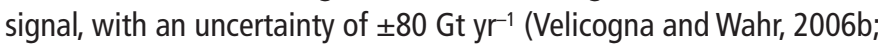
Riva et al., 2009; Velicogna, 2009). Correction for the GIA signal is addressed using numerical models (e.g., Ivins and James, 2005; Paulson et al., 2007; Peltier, 2009). A comparison of recent GIA models (Tarasov and Peltier, 2002; Fleming and Lambeck, 2004; Peltier, 2004; Ivins and James, 2005; Simpson et al., 2009; Whitehouse et al., 2012) with improved constraints on ice-loading history, indicate better agreement with direct observations of vertical land movements (Thomas et al., 2011a), despite a potential discrepancy between far-field sea level records and common NH deglaciation models. In Greenland, the GIA correction is less than $10 \%$ of the GRACE signal with an error of \pm 19 $\mathrm{Gt}_{\mathrm{yr}} \mathrm{r}^{-1}$. However, because the GIA rate is constant over the satellite's lifetime, GIA uncertainty does not affect the estimate of any change in the rate of ice mass loss (acceleration/deceleration). In Antarctica, the adoption of new GIA models has resulted in a lowering of estimated ice-sheet mass loss (King et al., 2012; Shepherd et al., 2012).

In addition to GRACE, the elastic response of the crustal deformation shown in GPS measurements of uplift rates confirms increasing rates of ice loss in Greenland (Khan et al., 2010b; Khan et al., 2010a) and Antarctica (Thomas et al., 2011a). Analysis of a 34-year time series of the Earth's oblateness (J2) by satellite laser ranging also suggests that ice loss from Greenland and Antarctica has progressively dominated the change in oblateness trend since the 1990s (Nerem and Wahr, 2011).

\subsubsection{Greenland}

There is very high confidence that the Greenland ice sheet has lost ice and contributed to sea level rise over the last two decades (Ewert et al., 2012; Sasgen et al., 2012; Shepherd et al., 2012). Recent GRACE results are in better agreement than in AR4 as discussed in Section 4.4.2.1 (Baur et al., 2009; Velicogna, 2009; Pritchard et al., 2010; Wu et al., 2010; Chen et al., 2011; Schrama and Wouters, 2011). Altimetry missions report losses comparable to those from the mass budget method and from the time-variable gravity method (Thomas et al., 2006; Zwally et al., 2011) (Figure 4.13f).

Figure 4.15 shows the cumulative ice mass loss from the Greenland ice sheet over the period 1992-2012 derived from 18 recent studies made by 14 different research groups (Baur et al., 2009; Cazenave et 
al., 2009; Slobbe et al., 2009; Velicogna, 2009; Pritchard et al., 2010; Wu et al., 2010; Chen et al., 2011; Rignot et al., 2011c; Schrama and Wouters, 2011; Sorensen et al., 2011; Zwally et al., 2011; Ewert et al., 2012; Harig and Simons, 2012; Sasgen et al., 2012). These studies do not include earlier estimates from the same researchers when those have been updated by more recent analyses using extended data. They include estimates made from satellite gravimetry, satellite altimetry and the mass budget method. Details of the studies used for Greenland are listed in Appendix Table 4.A.1 (additional studies not selected are listed in Table 4.A.2).

The mass balance for each year is estimated as a simple average of all the selected estimates available for that particular year. Figure 4.15 shows an accumulation of these estimates since an arbitrary zero on 1 January 1992. The number of estimates available varies with time, with as few as two estimates per year in the 1990s and up to 18 per year from 2004. The cumulative uncertainty in Figure 4.15 is based on the uncertainty cited in the original studies which, when the confidence level is not specifically given, is assumed to be at the 1 standard deviation $(1 \sigma)$ level. However, the annual estimates from different studies often do not overlap within the original uncertainties, and hence the error limits used in this assessment are derived from the absolute maximum and minimum mass balance estimate for each year. These have been converted to the $90 \%$ confidence interval ( 5 to $95 \%$, or $1.65 \sigma$ ). The cumulative error is weighted by $1 / \sqrt{n}$, where $n$ is the number of years accumulated.

Despite year-to-year differences between the various original analyses, this multi-study assessment yields very high confidence that Greenland has lost mass over the last two decades and high confidence that the rate of loss has increased. The increase is also shown in several individual studies (Velicogna, 2009; Chen et al., 2011; Rignot et al., 2011c; Zwally et al., 2011) (Figure 4.13a-c). The average ice mass change to Greenland from the present assessment has been -121 [-149 to -94] Gt yr-1 (a sea level equivalent of 0.33 [0.41 to 0.26 ] $\mathrm{mm} \mathrm{yr}^{-1}$ ) over the period 1993 to 2010 , and -229 [-290 to -169$] \mathrm{Gt}$ $\mathrm{yr}^{-1}(0.63$ [0.80 to 0.47$] \mathrm{mm} \mathrm{yr}^{-1}$ sea level equivalent) over the period 2005-2010.

Greenland changes that include and exclude peripheral glaciers cannot be cleanly separated from the mixture of studies and techniques in this assessment, but for the post 2003 period there is a prevalence of gravity studies, which do include the peripheral glaciers. Hence, although the estimated mass change in Greenland peripheral glaciers of $-38 \pm 7$ Gt $\mathrm{yr}^{-1}$ over the period 2003-2009 (Gardner et al., 2013) is discussed in Section 4.3.3 (Table 4.5), these changes are included within the values for ice-sheet change quoted in this section, and not as part of the total mass change for glaciers.

A reconciliation of apparent disparities between the different satellite methods was made by the Ice-sheet Mass Balance Intercomparison Experiment (IMBIE) (Shepherd et al., 2012). This intercomparison combined an ensemble of satellite altimetry, interferometry, airborne radio-echo sounding and airborne gravimetry data and regional atmospheric climate model output products, for common geographical regions and for common time intervals. Good agreement was obtained between the estimates from the different methods and, whereas the uncertainties of any method are sometimes large, the combination of methods considerably improves the overall certainty. (Note that Shepherd et al. (2012) also cannot cleanly separate estimates including or excluding peripheral glaciers). For Greenland, Shepherd et al. (2012) estimate a change in mass over the period 1992-2011, averaged

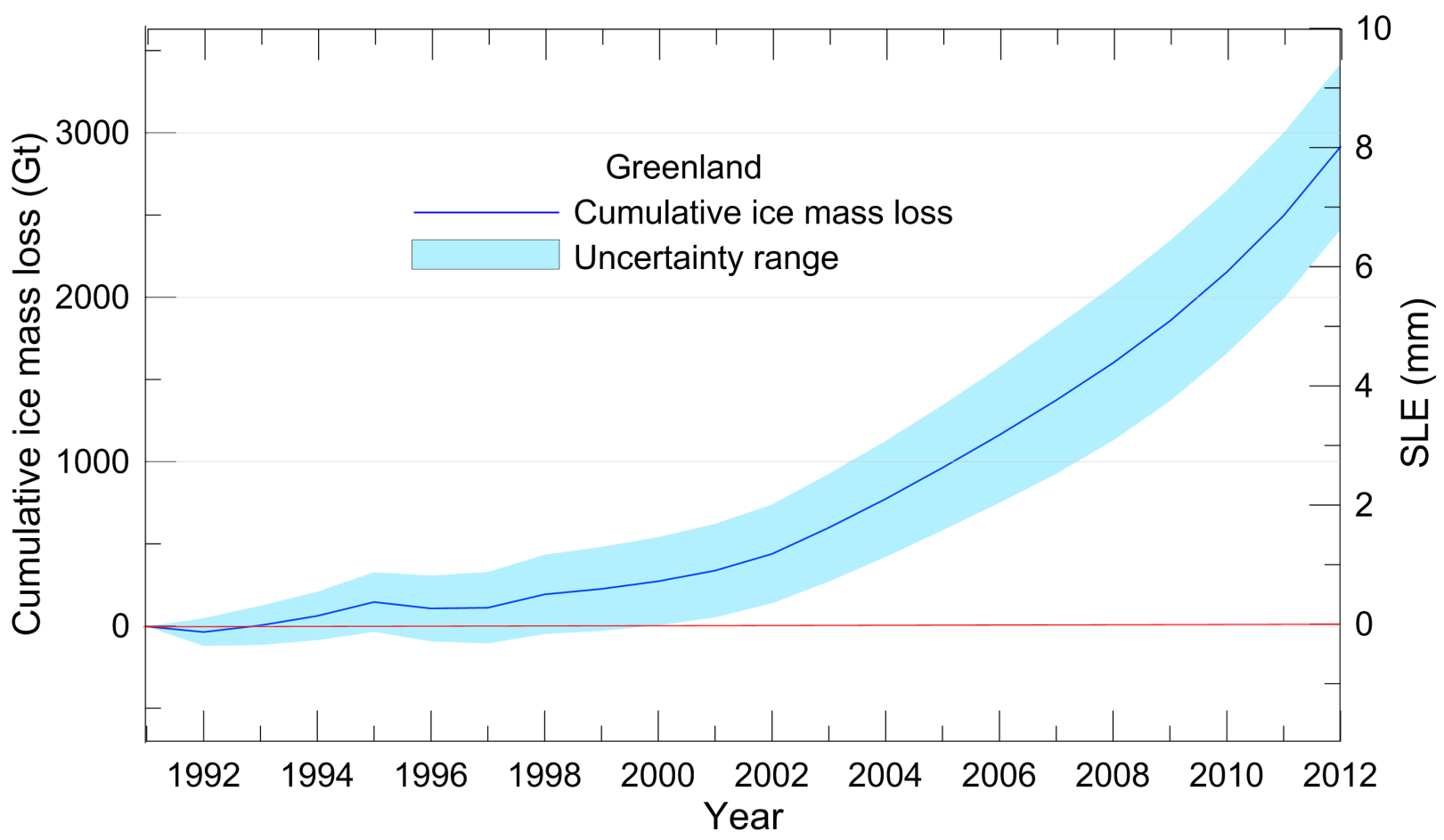

Figure 4.15 C Cumulative ice mass loss (and sea level equivalent, SLE) from Greenland derived as annual averages from 18 recent studies (see main text and Appendix 4.A for details). 
across the ensemble for each method, of $-142 \pm 49 \mathrm{Gt} \mathrm{yr}^{-1}(0.39 \pm$ $0.14 \mathrm{~mm} \mathrm{yr}^{-1}$ of sea level rise). For the same period, this present assessment, which averages across individual studies, yields a slightly slower loss, with a rate of mass change of $-125 \pm 25 \mathrm{Gt} \mathrm{yr}^{-1}$ at the $90 \%$ confidence level $\left(0.34 \pm 0.07 \mathrm{~mm} \mathrm{yr}^{-1} \mathrm{SLE}\right)$. Averaging across technique ensembles in the present assessment yields a loss at a rate of $-129 \mathrm{Gt}$ $\mathrm{yr}^{-1}(0.36 \mathrm{~mm})$. Shepherd et al. (2012) confirm an increasing mass loss from Greenland, although they also identify mass balance variations over intermediate (2- to 4-year) periods.

The mass budget method shows that ice loss from the Greenland ice sheet is partitioned in approximately similar amounts between surface mass balance (i.e., runoff) and discharge from ice flow across the grounding line (van den Broeke et al., 2009) (medium confidence). However, there are significant differences in the relative importance of ice discharge and surface mass balance in various regions of Greenland (Howat et al., 2007; Pritchard et al., 2009; van den Broeke et al., 2009; Sasgen et al., 2012). Dynamic losses dominate in southeast and central west regions, and also influence losses in northwest Greenland, whereas in the central north, southwest and northeast sectors, changes in surface mass balance appear to dominate.

There is high confidence that over the last two decades, surface mass balance has become progressively more negative as a result of an increase in surface melt and runoff, and that ice discharge across the grounding line has also been enhanced due to the increased speed of some outlet glaciers. Altimetric measurements of surface height suggest slight inland thickening in 1994-2006 (Thomas et al., 2006, 2009), but this is not confirmed by regional atmospheric climate model outputs for the period 1957-2009 (Ettema et al., 2009), nor recent ice core (see Glossary) data (Buchardt et al., 2012), hence there is low confidence in an increase in precipitation in Greenland in recent decades. Probable changes in accumulation are, however, exceeded by the increased runoff especially since 2006 (van den Broeke et al., 2009). The four highest runoff years over the last 140 years occurred since 1995 (Hanna et al., 2011).

The total surface melt area has continued to increase since AR4 and has accelerated in the past few years (Fettweis et al., 2011; Tedesco et al., 2011), with an extreme melt event covering more than $90 \%$ of the ice sheet for a few days in July 2012 (Nghiem et al., 2012; Tedesco et al., 2013). Annual surface mass balance in 2011-2012 was 2 stand-

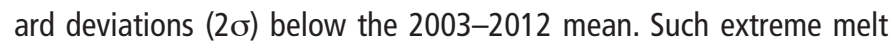
events are rare and have been observed in ice core records only twice, once in 1889, and once more, seven centuries earlier in the Medieval Warm Period (Meese et al., 1994; Alley and Anandakrishnan, 1995). Over the past decade, the surface albedo of the Greenland ice sheet has decreased by up to $18 \%$ in coastal regions, with a statistically significant increase over $87 \%$ of the ice sheet due to melting and snow metamorphism, allowing more solar energy to be absorbed for surface melting (Box et al., 2012).

GRACE results show ice loss was largest in southeast Greenland during 2005 and increased in the northwest after 2007 (Khan et al., 2010a; Chen et al., 2011; Schrama and Wouters, 2011; Harig and Simons, 2012). Subsequent to 2005, ice loss decreased in the southeast. These GRACE results agree with measurements of ice discharge from the major outlet glaciers that confirm the dominance of dynamic losses in these regions (van den Broeke et al., 2009). In particular, major outlet glacier speed-up reported in AR4 occurred in west Greenland between 1996 and 2000 (Rignot and Kanagaratnam, 2006) and in southeast Greenland from 2001 to 2006 (Rignot and Kanagaratnam, 2006: Joughin et al., 2010b). In the southeast, many outlet glaciers slowed after 2005 (Howat et al., 2007; Howat et al., 2011), with many flow speeds decreasing back towards those of the early 2000s (Murray et al., 2010; Moon et al., 2012), although most are still flowing faster and discharging more ice into the ocean than they did in 1996 (Rignot and Kanagaratnam, 2006; Howat et al., 2011).

In the northwest, the increase in the rate of ice loss from 1996-2006 to 2006-2010 was probably caused partially by a higher accumulation in the late 1990s compared to earlier and later years (Sasgen et al., 2012), but ice dynamic changes also played a role as outlet glaciers in the northwest showed an increase in speed from 2000 to 2010, with the greatest increase from 2007 to 2010 (Moon et al., 2012). Longer-term observations of surface topography in the northwest sector confirm the dynamic component of this mass loss and suggest two periods of loss in 1985-1993 and 2005-2010 separated by limited mass changes (Kjaer et al., 2012). In the southeast, an 80-year long record reveals that many land-terminating glaciers retreated more rapidly in the 1930 s compared to the 2000 s, but marine-terminating glaciers retreated more rapidly during the recent warming (Bjørk et al., 2012).

\subsubsection{Antarctica}

Antarctic results from the gravity method are also now more numerous and consistent than in AR4 (Figure 4.14a-c). Methods combining GPS and GRACE at the regional level indicate with high confidence that the Antarctic Peninsula is losing ice (Ivins et al., 2011; Thomas et al., 2011a). In other areas, large uncertainties remain in the global GRACEGPS solutions (Wu et al., 2010).

The SMB reconstructions used in the mass budget method have improved considerably since AR4 (e.g., Rignot et al. 2008b; van den Broeke et al., 2006; Lenaerts et al., 2012; Shepherd et al., 2012). Reconstructed snowfall from regional atmospheric climate models indicates higher accumulation along the coastal sectors than in previous estimates, but little difference in total snowfall. There is medium confidence that there has been no long-term trend in the total accumulation over the continent over the past few decades (Monaghan et al., 2006; van den Broeke et al., 2006; Bromwich et al., 2011; Frezzotti et al., 2012; Lenaerts et al., 2012). Although anomalies in accumulation have been noted in recent decades in Eastern Wilkes Land (Boening et al., 2012; Shepherd et al., 2012) and Law Dome (Van Ommen and Morgan, 2010) in East Antarctica, their overall impact on total mass balance is not significant. Satellite laser altimetry indicates that ice volume changes are concentrated on outlet glaciers and ice streams (see Glossary), as illustrated by the strong correspondence between areas of thinning (Figure 4.14f) and areas of fast flow (Figure 4.14e) (Pritchard et al., 2009).

Figure 4.16 shows the cumulative ice mass loss from the Antarctic ice sheet over the period 1992-2012 derived from recent studies made by 10 different research groups (Cazenave et al., 2009; Chen et al., 2009; E et al., 2009; Horwath and Dietrich, 2009; Velicogna, 2009; Wu 


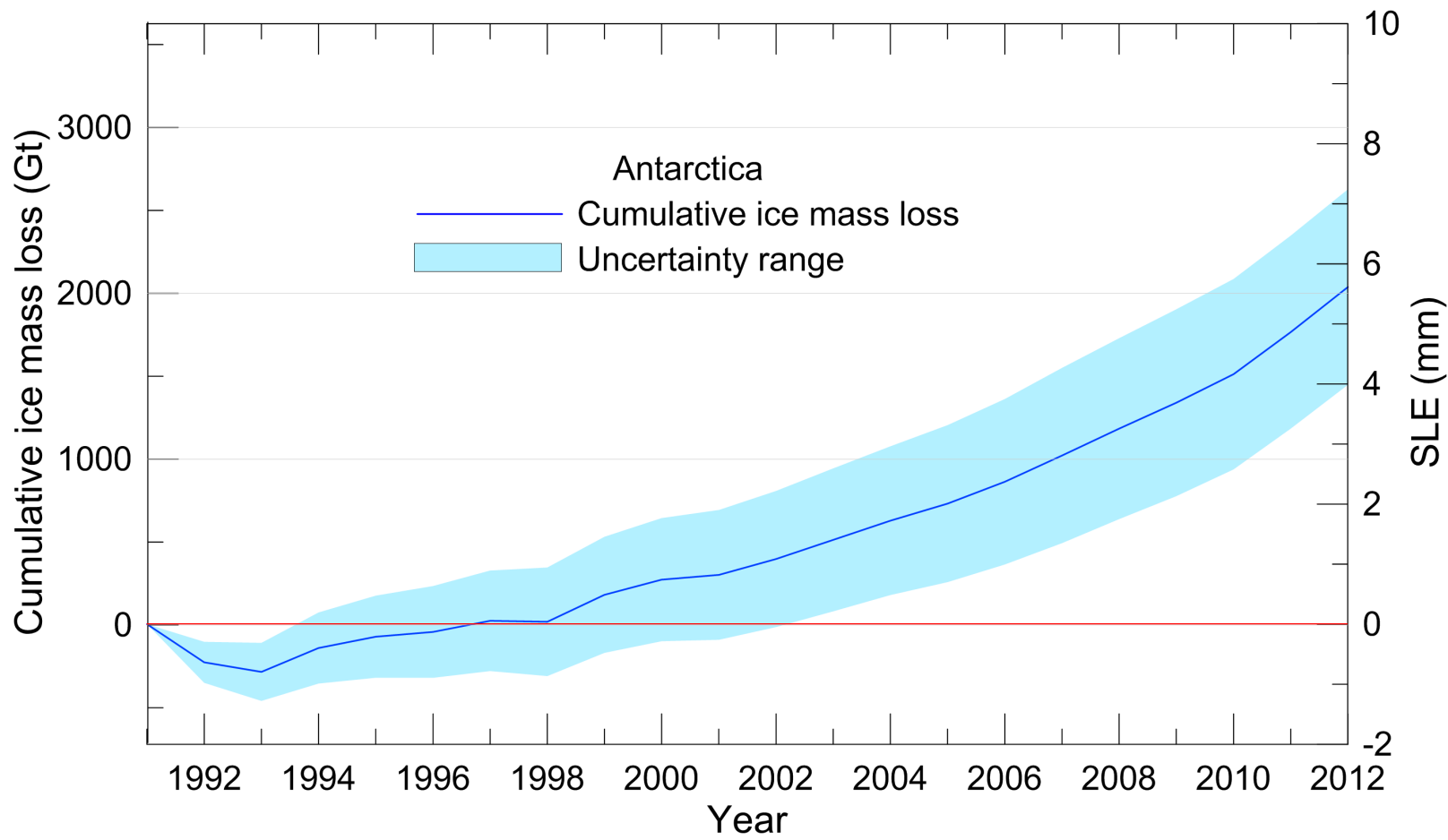

Figure 4.16 Cumulative ice mass loss (and sea level equivalent, SLE) from Antarctica derived as annual averages from 10 recent studies (see main text and Appendix 4.A for details).

et al., 2010; Rignot et al., 2011c; Shi et al., 2011; King et al., 2012; Tang et al., 2012). These studies do not include earlier estimates from the same researchers when those have been updated by more recent analyses using extended data. They include estimates made from satellite gravimetry, satellite altimetry and the mass balance method. Details of the studies used for Antarctica are listed in Table 4.A.3 (additional studies not selected are listed in Table 4.A.4). The number of estimates available varies with time, with only one estimate per year in the 1990s and up to 10 per year from 2003. The cumulative curves and associated errors are derived in the same way as those for Figure 4.15 (see Section 4.4.2.2).

Overall, there is high confidence that the Antarctic ice sheet is currently losing mass. The average ice mass change to Antarctica from the present assessment has been $-97[-135$ to -58$] \mathrm{Gt} \mathrm{yr}^{-1}$ (a sea level equivalent of $0.27 \mathrm{~mm} \mathrm{yr}^{-1}$ [0.37 to 0.16$] \mathrm{mm} \mathrm{yr}^{-1}$ ) over the period 1993-2010, and -147 [ -221 to -74$] \mathrm{Gt} \mathrm{yr}^{-1}$ (0.41 [0.61 to 0.20$] \mathrm{mm}$ $\mathrm{yr}^{-1}$ ) over the period 2005-2010. These assessments include the Antarctic peripheral glaciers.

The recent IMBIE intercomparison (Shepherd et al., 2012) for Antarctica, where the GIA signal is less well known than in Greenland, used two new GIA models (an updated version of Ivins and James (2005), for details see Shepherd et al. (2012); and Whitehouse et al. (2012)). These new models had the effect of reducing the estimates of East Antarctic ice mass loss from GRACE data, compared with some previous estimates. For Antarctica, Shepherd et al. (2012) estimate an average change in mass for 1992-2011 of $-71 \pm 53 \mathrm{Gt} \mathrm{yr}^{-1}(0.20 \pm 0.15 \mathrm{~mm}$ $\mathrm{yr}^{-1}$ of sea level equivalent). For the same period this present assessment estimates a loss of $88 \pm 35 \mathrm{Gt} \mathrm{yr}^{-1}$ at the $90 \%$ confidence level (0.24 $\left.\pm 0.10 \mathrm{~mm} \mathrm{yr}^{-1} \mathrm{SLE}\right)$. Averaging across technique ensembles in the present assessment, rather than individual estimates, yields no significant difference.

There is low confidence that the rate of Antarctic ice loss has increased over the last two decades (Chen et al., 2009; Velicogna, 2009; Rignot et al., 2011c; Shepherd et al., 2012); however, GRACE data gives medium confidence of increasing loss over the last decade (Chen et al., 2009; Velicogna, 2009) (Figure 4.16). For GRACE, this conclusion is independent of the GIA signal, which is constant over the measurement period. The mass budget method suggests that the increase in loss from the mass budget method is caused by an increase in glacier flow-speed in the eastern part of the Pacific sector of West Antarctica (Rignot, 2008; Joughin et al., 2010a) and the Antarctic Peninsula (Scambos et al., 2004; Pritchard and Vaughan, 2007; Rott et al., 2011). Comparison of GRACE and the mass budget method for 1992-2010 indicates an increase in the rate of ice loss of, on average, $14 \pm 2 \mathrm{Gt} \mathrm{yr}^{-1}$ per year compared with $21 \pm 2 \mathrm{Gt} \mathrm{yr}^{-1}$ per year on average for Greenland during the same time period (Rignot et al., 2011c). The recent IMBIE analysis (Shepherd et al., 2012) shows that the West Antarctic ice sheet and the Antarctic Peninsula are losing mass at an increasing rate, but that East Antarctica gained an average of $21 \pm 43 \mathrm{Gt} \mathrm{yr}^{-1}$ between 1992 and 2011. Zwally and Giovinetto (2011) also estimate a mass gain for East Antarctica (+16 Gt yr-1 between 1992 and 2001). Their reassessment of total Antarctic change made a correction for the ice discharge estimates from regions of the ice sheet not observed in the mass budget method (see Section 4.4.2.1.1). The analysis of Shepherd et al. (2012) indicated that the missing regions contribute little to the total mass change.

In the near-absence of surface runoff and, as discussed in this section, with no evidence of multi-decadal change in total snowfall, there is 
high confidence that Antarctic multi-decadal changes in grounded ice mass must be due to increased ice discharge, although the observational record of ice dynamics extends only from the 1970s and is spatially incomplete for much of this period. Over shorter time scales, however, the interannual to decadal variability in snowfall has an important impact on ice sheet mass balance (Rignot et al., 2011c).

The three techniques are in excellent agreement as to the spatial pattern of ice loss (thinning) and gain (thickening) over Antarctica (Figure 4.14). There is very high confidence that the largest ice losses are located along the northern tip of the Antarctic Peninsula where the collapse of several ice shelves in the last two decades triggered the acceleration of outlet glaciers, and in the Amundsen Sea, in West Antarctica (Figure 4.14).. On the Antarctic Peninsula, there is evidence that precipitation has increased (Thomas et al., 2008a) but the resulting ice-gain is insufficient to counteract the losses (Wendt et al., 2010; Ivins et al., 2011). There is medium confidence that changes in the Amundsen Sea region are due to the thinning of ice shelves (Pritchard et al., 2012), and medium confidence that this is due to high ocean heat flux (Jacobs et al., 2011), which caused grounding line retreat $\left(1 \mathrm{~km} \mathrm{yr}^{-1}\right)$ (Joughin et al., 2010a) and glacier thinning (Wingham et al., 2009). Indications of dynamic change are also evident in East Antarctica, primarily around Totten Glacier, from GRACE (Chen et al., 2009), altimetry (Wingham et al., 2006; Shepherd and Wingham, 2007; Pritchard et al., 2009; Flament and Remy, 2012), and satellite radar interferometry (Rignot et al., 2008b). The contribution to the total ice loss from these areas is, however, small and not well understood.

\subsubsection{Ice Shelves and Floating Ice Tongues}

As much as $74 \%$ of the ice discharged from the grounded ice sheet in Antarctica passes through ice shelves and floating ice tongues (Bindschadler et al., 2011). Ice shelves help to buttress and restrain flow of the grounded ice (Rignot et al., 2004; Scambos et al., 2004; Hulbe et al., 2008), and so changes in thickness (Shepherd et al., 2003, 2010; Fricker and Padman, 2012), and extent (Doake and Vaughan, 1991; Scambos et al., 2004) of ice shelves influence current ice sheet change. Indeed, nearly all of the outlet glaciers and ice streams that are experiencing high rates of ice loss flow into thinning or disintegrated ice shelves (Pritchard et al., 2012). Many of the larger ice shelves however, exhibit stable conditions (King et al., 2009; Shepherd et al., 2010; Pritchard et al., 2012).

Around the Antarctic Peninsula, the reduction in ice-shelf extent has been ongoing for several decades (Cook and Vaughan, 2010; Fricker and Padman, 2012), and has continued since AR4 with substantial collapse of a section of Wilkins Ice Shelf (Humbert et al., 2010), which had been retreating since the late1990s (Scambos et al., 2000). Overall, 7 of 12 ice shelves around the Peninsula have retreated in recent decades with a total loss of $28,000 \mathrm{~km}^{2}$, and a continuing rate of loss of around $6000 \mathrm{~km}^{2}$ per decade (Cook and Vaughan, 2010). There is high confidence that this retreat of ice shelves along the Antarctic Peninsula has been related to changing atmospheric temperatures (e.g., Scambos et al., 2000; Morris and Vaughan, 2003; Marshall et al., 2006; Holland et al., 2011). There is low confidence that changes in the ocean have also contributed (e.g., Shepherd et al., 2003; Holland et al., 2011; Nicholls et al., 2012; Padman et al., 2012).

\subsubsection{Total Ice Loss from Both Ice Sheets}

The total ice loss from both ice sheets for the 20 years 1992-2011 (inclusive) has been 4260 [3060 to 5460] Gt, equivalent to 11.7 [8.4 to 15.1$] \mathrm{mm}$ of sea level. However, the rate of change has increased with time and most of this ice has been lost in the second decade of the 20-year period. From the data presented in Figure 4.17, the average loss in Greenland has very likely increased from 34 [-6 to 74] Gt yr ${ }^{-1}$ over the decade 1992-2001 (sea level equivalent, 0.09 [ -0.02 to 0.20$]$ $\mathrm{mm} \mathrm{yr}^{-1}$ ), to 215 [157 to 274] $\mathrm{Gt} \mathrm{yr}^{-1}$ over the decade 2002-2011 (0.59 [0.43 to 0.76] $\mathrm{mm} \mathrm{yr}^{-1}$ ). In Antarctica, the loss has likely increased 30 [-37 to 97] $\mathrm{Gt} \mathrm{yr}^{-1}$ (sea level equivalent, 0.08 [ -0.10 to 0.27$] \mathrm{mm} \mathrm{yr}^{-1}$ ) for 1992-2001, to 147 [72 to 221] Gt yr ${ }^{-1}$ for 2002-2011 (0.40 [0.20 to 0.61$\left.] \mathrm{mm} \mathrm{yr}^{-1}\right)$. Over the last five years (2007-2011), the loss from both ice sheets combined has been equivalent to $1.2 \pm 0.4 \mathrm{~mm} \mathrm{yr}^{-1}$ of sea level (Figure 4.17 and Table 4.6).

\subsubsection{Causes of Changes in Ice Sheets}

\subsubsection{Climatic Forcing}

Changes in ice sheet mass balance are the result of an integrated response to climate, and it is imperative that we understand the context of current change within the framework of past changes and natural variability.

\subsection{Snowfall and surface temperature}

Ice sheets experience large interannual variability in snowfall, and local trends may deviate significantly from the long-term trend in integrated snowfall. However, as in AR4, the available data do not suggest any significant long-term change in accumulation in Antarctica, except for the Antarctic Peninsula (Monaghan et al., 2006; Ettema et al., 2009; van den Broeke et al., 2009; Bromwich et al., 2011).

Increasing air temperature will (when above the freezing point) increase the amount of surface melt, and can also increase the moisture bearing capacity of the air, and hence can increase snowfall. Over Greenland, temperature has risen significantly since the early 1990s, reaching values similar to those in the 1930s (Box et al., 2009). The

Table 4.6 | Average rates of ice sheet loss given as $\mathrm{mm}$ of sea level equivalent, derived as described for Figure 4.15 and Figure 4.16 using estimates listed in Appendix Tables 4.A. 1 and 4.A.3.

\begin{tabular}{|l|c|c|}
\hline \multicolumn{1}{|c|}{ Period } & \multicolumn{2}{c|}{$\begin{array}{l}\text { Ice sheet loss } \\
\text { (mm yr }{ }^{-1} \text { SLE) }\end{array}$} \\
\hline Greenland & 0.63 & \pm 0.17 \\
\hline 2005-2010 (6-year) & 0.33 & \pm 0.08 \\
1993-2010 (18-year) & 0.41 & \pm 0.20 \\
\hline Antarctica & 0.27 & \pm 0.11 \\
\hline 2005-2010 (6-year) & 1.04 & \pm 0.37 \\
1993-2010 (18-year) & 0.60 & \pm 0.18 \\
\hline Combined &
\end{tabular}




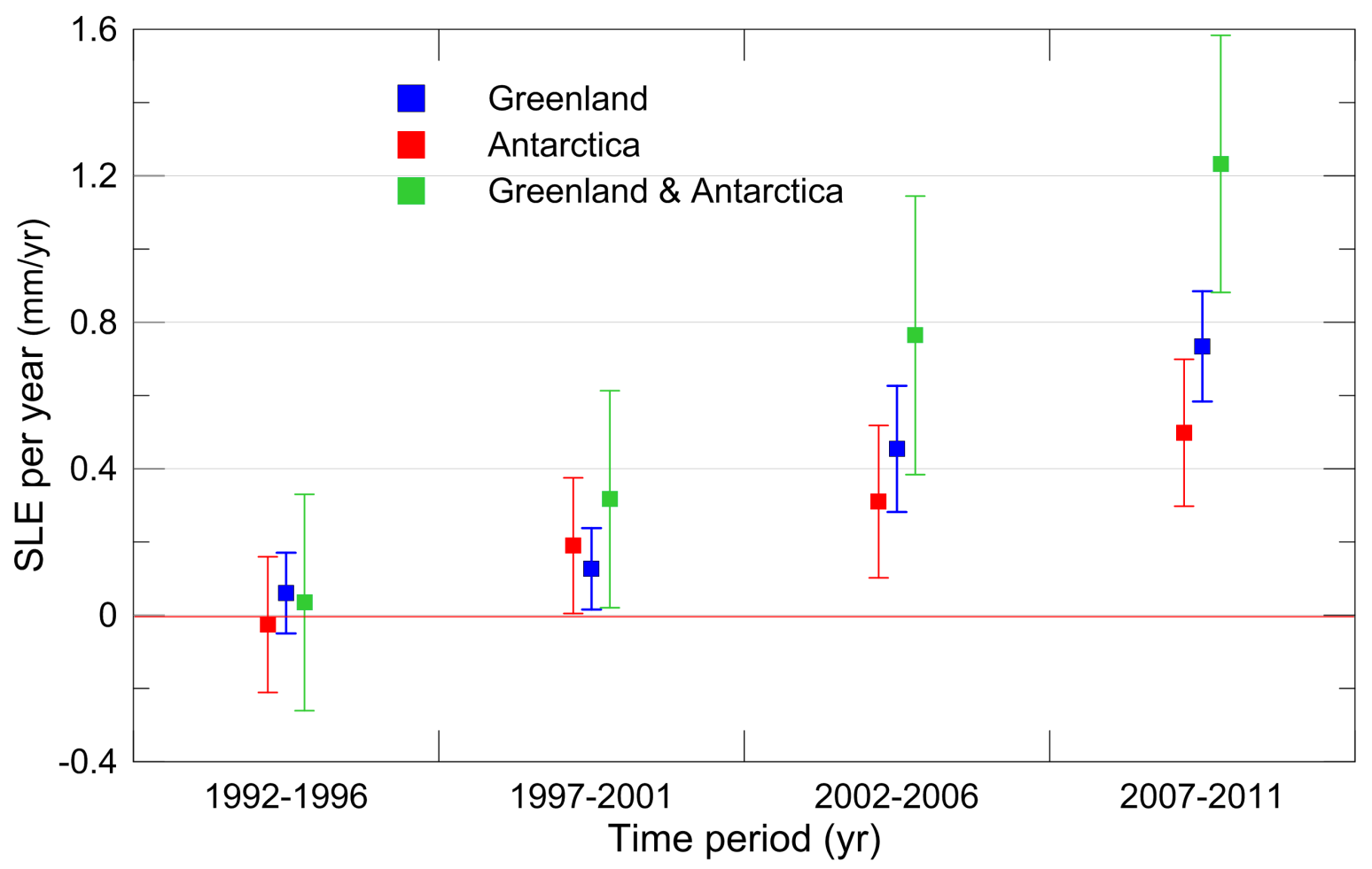

Figure 4.17| Rate of ice sheet loss in sea level equivalent averaged over 5-year periods between 1992 and 2011. These estimates are derived from the data in Figures 4.15 and 4.16.

year 2010 was an exceptionally warm year in west Greenland with Nuuk having the warmest year since the start of the temperature record in 1873 (Tedesco et al., 2011). In West Antarctica, the warming since the 1950s (Steig et al., 2009; Ding et al., 2011; Schneider et al., 2012; Bromwich et al., 2013), the magnitude and seasonality of which are still debated, has not manifested itself in enhanced surface melting (Tedesco and Monaghan, 2009; Kuipers Munneke et al., 2012) nor in increased snowfall (Monaghan et al., 2006; Bromwich et al., 2011; Lenaerts et al., 2012). Statistically significant summer warming has been observed on the east coast of the northern Antarctic Peninsula (Marshall et al., 2006; Chapman and Walsh, 2007), with extension of summer melt duration (Barrand et al., 2013), while East Antarctica has showed summer cooling (Turner et al., 2005). In contrast, the significant winter warming at Faraday/Vernadsky station on the western Antarctic Peninsula is attributable to a reduction of sea ice extent (Turner et al., 2005).

\subsection{Ocean thermal forcing}

Since AR4, observational evidence has contributed to medium confidence that the interaction between ocean waters and the periphery of large ice sheets plays a major role in present ice sheet changes (Holland et al., 2008; Pritchard et al., 2012). Ocean waters provide the heat that can drive high melt rates beneath ice shelves (Jacobs et al., 1992; Holland and Jenkins, 1999; Rignot and Jacobs, 2002; Pritchard et al., 2012) and at marine-terminating glacier fronts (Holland et al., 2008; Rignot et al., 2010; Jacobs et al., 2011).
Ocean circulation delivers warm waters to ice sheets. Variations in wind patterns associated with the North Atlantic Oscillation (Jacobs et al., 1992; Hurrell, 1995), and tropical circulations influencing West Antarctica (Ding et al., 2011; Steig et al., 2012), are probable drivers of increasing melt at some ice-sheet margins. In some parts of Antarctica, changes in the Southern Annular Mode (Thompson and Wallace, 2000, see Glossary) may also be important. Observations have established that warm waters of subtropical origin are present within several fjords in Greenland (Holland et al., 2008; Myers et al., 2009; Straneo et al., 2010; Christoffersen et al., 2011; Daniault et al., 2011).

Satellite records and in situ observations indicate warming of the Southern Ocean (see Chapter 3) since the 1950s (Gille, 2002, 2008). This warming is confirmed by data from robotic ocean buoys (Argo floats) (Boening et al., 2008) but the observational record remains short and, close to Antarctica, there are only limited observations from ships (Jacobs et al., 2011), short-duration moorings and data from instrumented seals (Charrassin et al., 2008; Costa et al., 2008).

\subsubsection{Ice Sheet Processes}

\subsection{Basal lubrication}

Ice flows in part by sliding over the underlying rock and sediment, which is lubricated by water at the ice base: a process known as basal lubrication (see Glossary). In many regions close to the Greenland ice sheet margin, abundant summer meltwater on the surface of the ice sheet forms large lakes. This surface water can drain to the ice sheet 
bed, thus increasing basal water pressure, reducing basal friction and increasing ice flow speed (Zwally et al., 2002b).

Such drainage events are common in southwest and northeast Greenland, but rare in the most rapidly changing southeast and northwest regions (Selmes et al., 2011). The effect can be seen in diurnal flow variations of some land-terminating regions (Das et al., 2008; Shepherd et al., 2009), and after lake-drainage events, when 50 to $110 \%$ short-term speed-up of flow has been observed. However, the effect is temporally and spatially restricted (Das et al., 2008). The summer increase in speed over the annual mean is only 10-20\%, the increase is less at higher elevations (Bartholomew et al., 2011), and observations suggest most lake drainages do not affect ice sheet velocity (Hoffman et al., 2011). Theory and field studies suggest an initial increase in flow rate with increased surface meltwater supply (Bartholomew et al., 2011; Palmer et al., 2011), but if the supply of surface water continues to increase and subglacial drainage becomes more efficient, basal water pressure, and thus basal motion, is reduced (van de Wal et al., 2008; Schoof, 2010; Sundal et al., 2011; Shannon et al., 2012). Overall, there is high confidence that basal lubrication is important in modulating flow in some regions, especially southwest Greenland, but there is also high confidence that it does not explain recent dramatic regional speed-ups that have resulted in rapid increases in ice loss from calving glaciers.

\subsection{Cryo-hydrologic warming}

Percolation and refreezing of surface meltwater that drains through the ice column may alter the thermal regime of the ice sheet on decadal time scales (Phillips et al., 2010). This process is known as cryo-hydrologic warming, and it could affect ice rheology and hence ice flow.

\subsection{Ice shelf buttressing}

Recent changes in marginal regions of the Greenland and Antarctic ice sheets include some thickening and slowdown of outlet glaciers, but mostly thinning and acceleration (e.g., Pritchard et al., 2009; Sorensen et al., 2011), with some glacier speeds increasing two- to eight-fold (Joughin et al., 2004; Rignot et al., 2004; Scambos et al., 2004; Luckman and Murray, 2005; Rignot and Kanagaratnam, 2006; Howat et al., 2007). Many of the largest and fastest glacier changes appear to be at least partly a response to thinning, shrinkage or loss of ice shelves or floating ice tongues (MacGregor et al., 2012; Pritchard et al., 2012). This type of glacier response is consistent with classical models of ice shelf buttressing proposed 40 years ago (Hughes, 1973; Weertman, 1974; Mercer, 1978; Thomas and Bentley, 1978).

\subsection{Ice-ocean interaction}

Since AR4 it has become far more evident that the rates of submarine melting can be very large (e.g., Motyka et al., 2003). The rate of melting is proportional to the product of ocean thermal forcing (difference between ocean temperature and the in situ freezing point of seawater) and water flow speed at the ice-ocean interface (Holland and Jenkins, 1999). Melt rates along marine-terminating glacier margins are one-to-two orders of magnitude greater than for ice shelves because of the additional buoyancy forces provided by the discharge of sub-glacial melt water at the glacier base (Motyka et al., 2003; Jenkins, 2011; Straneo et al., 2012; Xu et al., 2012). In South Greenland, there is medium confidence that the acceleration of glaciers from the mid-1990s to mid-2000s was due to the intrusion of ocean waters of subtropical origin into glacial fjords (Holland et al., 2008; Howat et al., 2008; Murray et al., 2010; Straneo et al., 2010; Christoffersen et al., 2011; Motyka et al., 2011; Straneo et al., 2011; Rignot and Mouginot, 2012). Models suggest that the increase in ice melting by the ocean contributed to the reduction of backstress experienced by glaciers and subsequent acceleration (Payne et al., 2004; Schoof, 2007; Nick et al., 2009; Nick et al., 2013; O'Leary and Christoffersen, 2013): changes in the floating mixture of sea ice, iceberg debris and blown snow in front of the glacier may also play a part (Amundson et al., 2010).

\subsection{Iceberg calving}

Calving of icebergs from marine-terminating glaciers and ice shelves is important in their overall mass balance, but the processes that initiate calving range from seasonal melt-driven processes (Benn et al., 2007) to ocean swells and tsunamis (MacAyeal et al., 2006; Brunt et al., 2011), or the culmination of a response to gradual change (Doake et al., 1998; Scambos et al., 2000). Some of these processes show strong climate influence, while others do not. Despite arguments of rather limited progress in this area (Pfeffer, 2011), there have been some recent advances (Joughin et al., 2008a; Blaszczyk et al., 2009; Amundson et al., 2010; Nick et al., 2010, 2013), and continental-scale ice sheet models currently rely on improved parameterisations (Alley et al., 2008; Pollard and DeConto, 2009; Levermann et al., 2012). Recently more realistic models have been developed allowing the dependence of calving and climate to be explicitly investigated (e.g., Nick et al., 2013).

\subsubsection{Rapid Ice Sheet Changes}

The projections of sea level rise presented in AR4 explicitly excluded future rapid dynamical changes (see Glossary) in ice flow, and stated that 'understanding of these processes is limited and there is no consensus on their magnitude'. Considerable efforts have been made since AR4 to fill this knowledge gap. Chapter 13 discusses observed and likely future sea level, including model projections of changes in the volume stored in the ice sheets: in this section we summarise the processes thought to be potential causes of rapid changes in ice flow and emphasise new observational evidence that these processes are already underway.

'Rapid ice sheet changes' are defined as changes that are of sufficient speed and magnitude to impact on the mass budget and hence rate of sea level rise on time scales of several decades or shorter. A further consideration is whether and under what circumstances any such changes are 'irreversible', that is, would take several decades to centuries to reverse under a different climate forcing. For example, an effectively irreversible change might be the loss of a significant fraction of the Greenland ice sheet, because at its new lower (and therefore warmer) surface elevation, the ice sheet would be able to grow thicker only slowly even in a cooler climate (Ridley et al., 2010) (Section 13.4.3.3). 
Observations suggest that some observed changes in ice shelves and glaciers on the Antarctic Peninsula are irreversible. These ice bodies continue to experience rapid and irreversible retreat, coincident with air temperatures rising at four to six times the global average rate at some stations (Vaughan et al., 2003), and with warm Circumpolar Deep Water becoming widespread on the western continental shelf (Martinson et al., 2008). Collapse of floating ice shelves on the Antarctic Peninsula, such as the 2002 collapse of the Larsen B Ice Shelf which is unprecedented in the last 10,000 years, has resulted in speed up of tributary glaciers by 300 to $800 \%$ (De Angelis and Skvarca, 2003; Rignot et al., 2004; Scambos et al., 2004; Rott et al., 2011). Even if iceberg calving was to cease entirely, regrowth of the Larsen B ice shelf to its pre-collapse state would take centuries based on the ice-shelf speed and size prior to its collapse (Rignot et al., 2004).

Surface melt that becomes runoff is a major contributor to mass loss from the Greenland ice sheet, which results in a lower (hence warmer) ice sheet surface and a lower surface albedo (allowing the surface to absorb more solar radiation); both processes further increase melt. The warm summers of the last two decades (van den Broeke et al., 2009; Hanna et al., 2011), and especially in 2012 (Hall et al., 2013), are unusual in the multi-centennial record. Exceptionally high melt events have affected even the far north of Greenland, for example, with the partial collapse of the floating ice tongues of Ostenfeld Gletscher and Zachariae Isstrom in 2000-2006 (Moon and Joughin, 2008).

The importance that subsurface warm waters play in melting the periphery of ice sheets in Greenland and Antarctica, and the evolution of these ice sheets, has become much clearer since AR4 (see Sections 4.4.3.1 and 4.4.3.2). New observations in Greenland and Antarctica, as well as advances in theoretical understanding, show that regions of ice sheets that are grounded well below sea level are most likely to experience rapid ice mass loss, especially if the supply of heat to the ice margin increases (Schoof, 2007; Holland et al., 2008; Joughin and Alley, 2011; Motyka et al., 2011; Young et al., 2011a; Joughin et al., 2012; Ross et al., 2012) (See also Figure 4.18.) Where this ice meets the
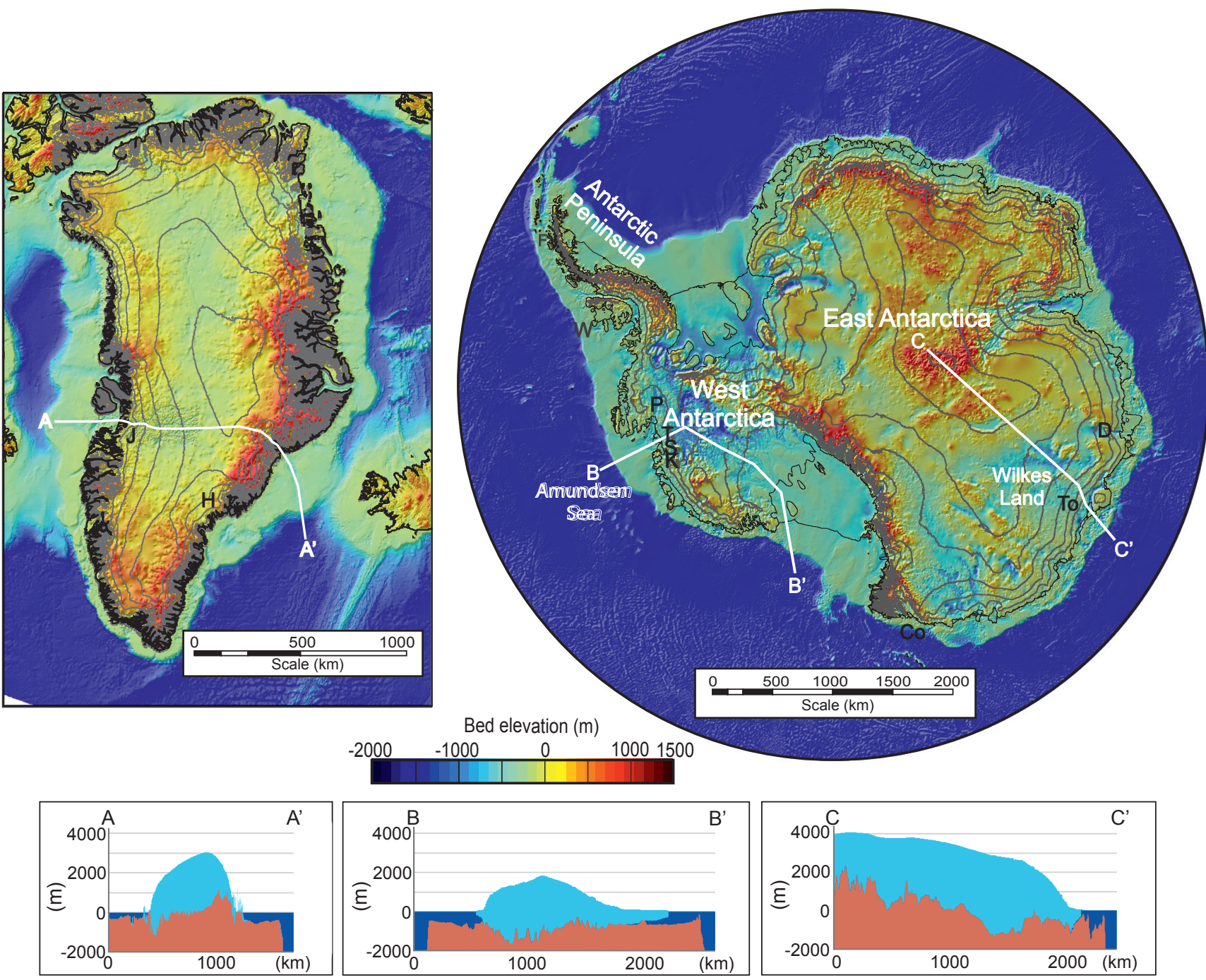

Figure 4.18 Subglacial and seabed topography for Greenland and Antarctica derived from digital compilations (Bamber et al., 2013; Fretwell et al., 2013). Blue areas highlight the marine-based parts of the ice sheets, which are extensive in Antarctica, but in Greenland, relate to specific glacier troughs. Selected sections through the ice sheet show reverse bed gradients that exist beneath some glaciers in both ice sheets. 
ocean and does not form an ice shelf, warm waters can increase melting at the ice front, causing undercutting, higher calving rates, ice-front retreat (Motyka et al., 2003; Benn et al., 2007; Thomas et al., 2011a) and consequent speed-up and thinning. Surface runoff also increases subglacial water discharge at the grounding line, which enhances ice melting at the ice front (Jenkins, 2011; Xu et al., 2012). Where an ice shelf is present, ice melt by the ocean may cause thinning of the shelf as well as migration of the grounding line further inland into deep basins, with a major impact on buttressing, flow speed and thinning rate (Thomas et al., 2011a).

The influence of the ocean on the ice sheets is controlled by the delivery of heat to the ice sheet margins, particularly to ocean cavities beneath ice shelves and to calving fronts (Jenkins and Doake, 1991; Jacobs et al., 2011). The amount of heat delivered is a function of the temperature and salinity of ocean waters; ocean circulation; and the bathymetry of continental shelves, in fjords near glacier fronts and beneath ice shelves, most of which are not known in sufficient detail (Jenkins and Jacobs, 2008; Holland et al., 2010; Dinniman et al., 2012; Galton-Fenzi et al., 2012; Padman et al., 2012). Changes in any of these parameters would have a direct and rapid impact on melt rates and potentially on calving fluxes (see Chapter 13).

Ice grounded on a reverse bed-slope, deepening towards the ice sheet interior, is potentially subject to the marine ice sheet instability (Weertman, 1974; Schoof, 2007) (see Box 13.2). Much of the bed of the West Antarctic Ice Sheet (WAIS) lies below sea level and on a reverse bed-slope, with basins extending to depths greater than $2 \mathrm{~km}$ (Figure 4.18). The marine parts of the WAIS contain $\sim 3.4 \mathrm{~m}$ of equivalent sea level rise (Bamber et al., 2013; Fretwell et al., 2013), and a variety of evidence strongly suggests that the ice sheet volume has been much smaller than present in the last 1 million years, during periods with temperatures similar to those predicted in the next century (see also Chapter 5) (Kopp et al., 2009). Potentially unstable marine ice sheets also exist in East Antarctica, for example, in Wilkes Land (Young et al., 2011a), and these contain more ice than WAIS (9 m sea level equivalent for Wilkes Land). In northern Greenland, ice is also grounded below sea level, with reverse slopes (Figure 4.18; Joughin et al., 1999).

Observations since AR4 confirm that rapid changes are indeed occurring at the marine margins of ice sheets, and that these changes have been observed to penetrate hundreds of kilometres inland (Pritchard et al., 2009; Joughin et al., 2010b).

The Amundsen Sea sector of West Antarctica is grounded significantly below sea level and is the region of Antarctica changing most rapidly at present. Pine Island Glacier has sped up 73\% since 1974 (Rignot, 2008) and has thinned throughout 1995-2008 at increasing rates (Wingham et al., 2009) due to grounding line retreat. There is medium confidence that retreat was caused by the intrusion of warm ocean water into the sub-ice shelf cavity (Jenkins et al., 2010; Jacobs et al., 2011; Steig et al., 2012). The neighbouring Thwaites, Smith and Kohler glaciers are also speeding-up, thinning and contributing to increasing mass loss (Figure 4.14). The present rates of thinning are more than one order of magnitude larger than millennial-scale thinning rates in this area (Johnson et al., 2008). Changes in velocity, elevation, thickness and grounding line position observed in the past two to three decades in the Pine Island/
Thwaites Glacier sector are not inconsistent with the development of a marine ice sheet instability triggered by a change in climate forcing, but neither are they inconsistent solely with a response to external environmental (probably oceanic) forcing.

In Greenland, there is medium confidence that the recent rapid retreat of Jakobshavn Isbrae was caused by the intrusion of warm ocean water beneath the floating ice tongue (Holland et al., 2008; Motyka et al., 2011) combined with other factors, such as weakening of the floating mixture of sea ice, iceberg debris and blown snow within ice rifts (Joughin et al., 2008b; Amundson et al., 2010). There is medium confidence that recent variations in southeast Greenland's glaciers have been caused by intrusion of warm waters of subtropical origin into glacial fjords. Since AR4 it has become clear that the mid-2000s speed up of southeast Greenland glaciers, which caused a doubling of ice loss from the Greenland ice sheet (Luthcke et al., 2006; Rignot and Kanagaratnam, 2006; Howat et al., 2008; Wouters et al., 2008), was a pulse that was followed by a partial slow down (Howat et al., 2008; Murray et al., 2010). Although changes in elevation in the north are not as large as in the south, marine sectors were thinning in 2003-2008 (Pritchard et al., 2009; Sorensen et al., 2011).

In contrast to the rapidly changing marine margins of the ice sheets, land-terminating regions of the Greenland ice sheet are changing more slowly, and these changes are explained largely by changes in the input of snow and loss of meltwater (Sole et al., 2011). Surface meltwater, although abundant on the Greenland ice sheet, does not seem to be driving significant changes in basal lubrication that impact on ice sheet flow (Joughin et al., 2008b; Selmes et al., 2011; Sundal et al., 2011).

In Greenland, the observed changes are not all irreversible. The Helheim Glacier in southeast Greenland accelerated, retreated and increased its calving flux during the period 2002-2005 (Howat et al., 2011; Andresen et al., 2012), but its calving flux similarly increased during the late 1930s - early 1940s (Andresen et al., 2012): an episode from which the glacier subsequently recovered and re-advanced (Joughin et al., $2008 \mathrm{~b})$. The collapse of the floating tongue of Jakobshavn Isbrae in 2002 and consequent loss of buttressing has considerably increased ice flow speeds and discharge from the ice sheet. At present, the glacier grounding line is retreating $0.5-0.6 \mathrm{~km} \mathrm{yr}^{-1}$ (Thomas et al., $2011 \mathrm{~b}$; Rosenau et al., 2013), with speeds in excess of $11 \mathrm{~km} \mathrm{yr}^{-1}$ (Moon et al., 2012), and the glacier is retreating on a bed that deepens further inland, which could be conducive to a marine instability. However, there is evidence that Jakobshavn Isbrae has undergone significant margin changes over the last approximately 8000 years which may have been both more and less extensive than the recent ones (Young et al., 2011b).

Since AR4, many new observations indicate that changes in ice sheets can happen more rapidly than was previously recognised. Similarly, evidence presented since AR4 indicates that interactions with both the atmosphere and ocean are key drivers of decadal ice-sheet change. So, although our understanding of the detailed processes that control the evolution of ice sheets in a warming climate remains incomplete, there is no indication in observations of a slowdown in the mass loss from ice sheets; instead, recent observations suggest an ongoing increase in mass loss. 


\subsection{Seasonal Snow}

\subsubsection{Background}

Snowfall is a component of total precipitation and, in that context, is discussed in Chapter 2 (See Section 2.5.1.3); here we discuss accumulated snow as a climatological indicator. Snow is measured using a variety of instruments and techniques, and reported using several metrics, including snow cover extent (SCE; see Glossary); the seasonal sum of daily snowfall; snow depth (SD); snow cover duration (SCD), that is, number of days with snow exceeding a threshold depth; or snow water equivalent (SWE; see Glossary).

Long-duration, consistent records of snow are rare owing to many challenges in making accurate and representative measurements. Although weather stations in snowy inhabited areas often report snow depth, records of snowfall are often patchy or use techniques that change over time (e.g., Kunkel et al., 2007). The density of stations and the choice of metric also varies considerably from country to country. The longest satellite-based record of SCE is the visible-wavelength weekly product of the National Oceanic and Atmospheric Administration (NOAA) dating to 1966 (Robinson et al., 1993), but this covers only the NH. Satellite mapping of snow depth and SWE has lower accuracy than SCE, especially in mountainous and heavily forested areas. Measurement challenges are particularly acute in the Southern Hemisphere (SH), where only about 11 long-duration in situ records continue to recent times: seven in the central Andes and four in southeast Australia. Owing to concerns about quality and duration, global satellite microwave retrievals of SWE are of less use in the data-rich NH than in the data-poor SH.

\subsubsection{Hemispheric View}

By blending in situ and satellite records, Brown and Robinson (2011) have updated a key indicator of climate change, namely the time series of NH SCE (Figure 4.19). This time series shows significant reductions over the past 90 years with most of the reductions occurring in the $1980 \mathrm{~s}$, and is an improvement over that presented in AR4 in several ways, not least because the uncertainty estimates are explicitly derived through the statistical analysis of multiple data sets, which leads to very high confidence. Snow cover decreases are largest in spring (Table 4.7), and the rate of decrease increases with latitude in response to larger albedo feedbacks (Déry and Brown, 2007). Averaged March and April NH SCE decreased $0.8 \%$ [0.5 to 1.1\%] per decade over the 1922-2012 period, $1.6 \%$ [0.8 to $2.4 \%$ ] per decade over the 1967-2012 period, and $2.2 \%$ [1.1 to 3.4\%] per decade over the 1979-2012 period. In a new development since AR4, both absolute and relative losses in June SCE now exceed the losses in March-April SCE: $11.7 \%$ [8.8 to $14.6 \%$ ] per decade or $53 \%$ [40 to 66\%] total over the 1967-2012 period and $14.8 \%$ [10.3 to 19.3\%] per decade over the 1979-2012 period (all ranges very likely). Note that these percentages differ from those given by Brown and Robinson (2011) which were calculated relative to the mean over the 1979-2000 period, rather than relative to the starting point. The loss rate of June SCE exceeds the loss rate for Coupled Model Intercomparison Project Phase 5 (CMIP5) model projections of June SCE and also exceeds the well-known loss of September sea ice extent (Derksen and Brown, 2012). Viewed another way, the NOAA SCE data indicate that, owing to earlier spring snowmelt, the duration of the snow season averaged over NH grid points declined by 5.3 days per decade since winter 1972-1973 (Choi et al., 2010).

Over Eurasia, in situ data show significant increases in winter snow accumulation but a shorter snowmelt season (Bulygina et al., 2009). From analysis of passive microwave satellite data since 1979, significant trends toward a shortening of the snowmelt season have been identified over much of Eurasia (Takala et al., 2009) and the pan-Arctic region (Tedesco et al., 2009), with a trend toward earlier melt of about 5 days per decade for the beginning of the melt season, and a trend of about 10 days per decade later for the end of the melt season.

The correlation between spring temperature and SCE (Figure 4.20) demonstrates that trends in spring SCE are linked to rising temperature, and for a well-understood reason: The spring snow cover-albedo feedback. This feedback contributes substantially to the hemispheric response to rising greenhouse gases and provides a useful test of global

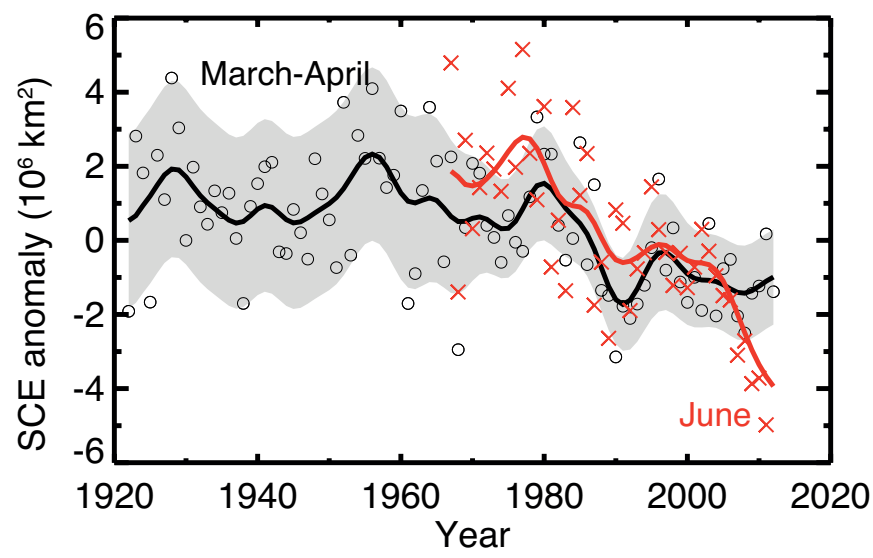

Figure 4.19 | March-April NH snow cover extent (SCE, circles) over the period of available data, filtered with a 13 -term smoother and with shading indicating the $95 \%$ confidence interval; and June SCE (red crosses, from satellite data alone), also filtered with a 13-term smoother. The width of the smoothed $95 \%$ confidence interval is influenced by the interannual variability in SCE. Updated from Brown and Robinson (2011). For both time series the anomalies are calculated relative to the 1971-2000 mean.

Table 4.7 | Least-squares linear trend in Northern Hemisphere snow cover extent (SCE) in $10^{6} \mathrm{~km}^{2}$ per decade for 1967-2012. The equivalent trends for $1922-2012$ (available only for March and April) are $-0.19^{*}$ March and $-0.40 *$ April.

\begin{tabular}{|c|c|c|c|c|c|c|c|c|c|c|c|c|}
\hline Annual & Jan & Feb & March & April & May & June & July & Aug & Sep & Oct & Nov & Dec \\
\hline$-0.40^{*}$ & 0.03 & -0.13 & $-0.50^{*}$ & $-0.63^{*}$ & $-0.90^{*}$ & $-1.31^{*}$ & $\mathrm{n} / \mathrm{a}$ & $\mathrm{n} / \mathrm{a}$ & $\mathrm{n} / \mathrm{a}$ & $\mathrm{n} / \mathrm{a}$ & 0.17 & 0.34 \\
\hline
\end{tabular}

Notes:

${ }^{*}$ Denotes statistical significance at $p=0.05$. 


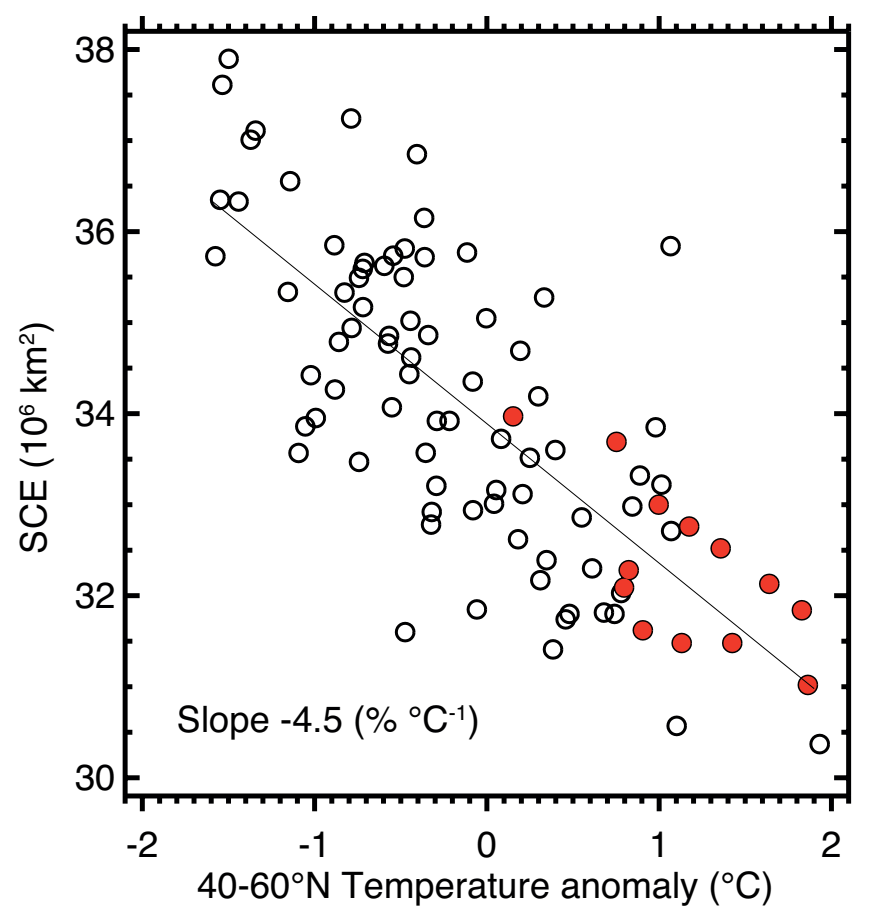

Figure 4.20| Relationship between NH April SCE and corresponding land air temperature anomalies over $40^{\circ} \mathrm{N}$ to $60^{\circ} \mathrm{N}$ from the CRUtem 4 data set (Jones et al., 2012). Red circles indicate the years 2000-2012. The correlation is 0.76. Updated from Brown and Robinson (2011).

climate models (Fernandes et al., 2009) (see also Chapter 9). Indeed, the observed declines in land snow cover and sea ice have contributed roughly the same amount to changes in the surface energy fluxes, and the albedo feedback of the $\mathrm{NH}$ cryosphere is likely in the range 0.3 to $1.1 \mathrm{~W} \mathrm{~m}^{-2} \mathrm{~K}^{-1}$ (Flanner et al., 2011). Brown et al. (2010) used satellite, reanalyses and in situ observations to document variability and trend in Arctic spring (May-June) SCE over the 1967-2008 period. In June, with Arctic albedo feedback at a maximum, SCE decreased $46 \%$ (as of 2012, now 53\%) and air temperature explains $56 \%$ of the variability.

For the $\mathrm{SH}$, as noted above (see Section 4.5.1), there are no correspondingly long visible-wavelength satellite records, but microwave data date from 1979. Foster et al. (2009) presented the first satellite study of variability and trends in any measure of snow for South America, in this case SWE from microwave data. They focused on the May-September period and noted large year-to-year variability and some lower frequency variability - the July with most extensive snow cover had almost six times as much as the July with the least extensive snow cover-but identified no trends.

\subsubsection{Trends from In Situ Measurements}

AR4 stimulated a review paper (Brown and Mote, 2009) that synthesized modelling results as well as observations from many countries. They showed that decreases in various metrics of snow are most likely to be observed in spring and at locations where air temperatures are close to the freezing point, because changes in air temperature there are most effective at reducing snow accumulation, increasing snowmelt, or both. However, unravelling the competing effects of rising temperatures and changing precipitation remains an important challenge in understanding and interpreting observed changes. Figure 4.21 shows a compilation of many published trends observed at individual locations; data were obtained either from tables in the published papers, or (when the numerical results in the figures were not tabulated) directly from the author, in some cases including updates to the published data sets. The figure shows that in most studies, a majority of sites experienced declines during the varying periods of record, and where data on site mean temperature or elevation were available, warmer/lower sites (red circles) were more likely to experience declines.

Some in situ studies in addition to those in Figure 4.21 deserve discussion. Ma and Qin (2012) described trends by season at 754 stations aggregated by region in China over 1951-2009; they found statistically significant trends: positive in winter SD in northwest China, and negative in SD and SWE in spring for China as a whole and spring SWE for the Qinghai-Xizang (Tibet) Plateau. Marty and Meister (2012) noted changes at six high-elevation $(>2200 \mathrm{~m}$ ) sites in the European Alps of Switzerland, Austria, and Germany, consistent with Figure 4.21: no change in SD in midwinter, shortening of SCD in spring and reduction in spring SWE and SD coincident with warming. For the Pyrenees, Lopez-Moreno and Vicente-Serrano (2007) derived proxy SD for 106 sites since 1950 from actual SD measurements since 1985 and weather measurements; they noted declines in spring SD that were related to changes in atmospheric circulation. In the $\mathrm{SH}$, of seven records in the Andes, none have significant trends in maximum SWE (Masiokas et al., 2010) over their periods of record. Of four records in Australia discussed in AR4, all show decreases in spring SWE over their respective periods of record (Nicholls, 2005), and the only one that has been updated since the Nicholls (2005) paper shows a statistically significant decrease of 37\% (Sanchez-Bayo and Green, 2013).

\subsubsection{Changes in Snow Albedo}

In addition to reductions in snow cover extent, which will reduce the mean reflectivity of particular regions, the reflectivity (albedo) of the snow itself may also be changing in response to human activities. Unfortunately, there are extremely limited data on the changes of albedo over time, and we must rely instead on analyses from ice cores, direct recent observations, and modelling. Flanner et al. (2007), using a detailed snow radiative model coupled to a global climate model and estimates of biomass burning, estimated that the human-induced radiative forcing by deposition of black carbon on snow cover is +0.054 $(0.007-0.13) \mathrm{W} \mathrm{m}^{-2}$ globally, of which $80 \%$ is from fossil fuels. However, spatially comprehensive surveys of impurities in Arctic snow in the late 2000s and mid-1980s suggested that impurities decreased between those two periods (Doherty et al., 2010) and hence albedo changes have probably not made a significant contribution to recent reductions in Arctic ice and snow. 


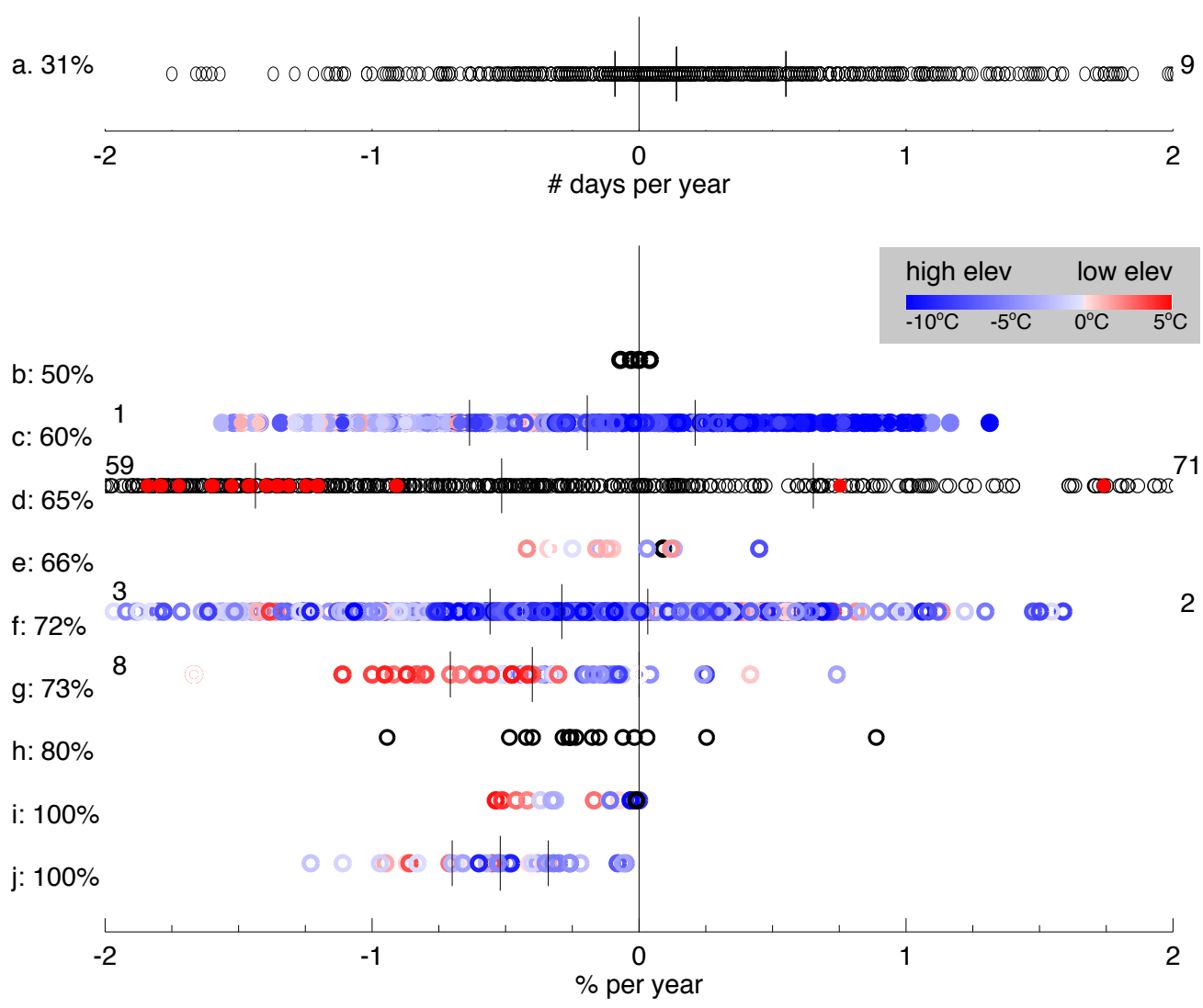

Figure 4.21 | Compilation of studies (rows) showing trends at individual stations (symbols in each row, with percentage of trends that are negative) showing that most sites studied show decreases in snow, especially at lower and/or warmer locations. For each study, if more than one quantity was presented, only the one representing spring conditions is shown. (a) Number of days per year with SD $>20 \mathrm{~cm}$ at 675 sites in northern Eurasia, 1966-2010 (Bulygina et al., 2011). (b) March-April-May snowfall for 500 stations in California, aggregated into four regions (Christy, 2012). (c) maximum SWE at 393 sites in Norway, 1961-2009 (Skaugen et al., 2012); statistically significant trends are denoted by solid circles. (d) SD at 560 sites in China, 1957-2012 (Ma and Qin, 2012); statistically significant trends are denoted by solid red circles. (e) Snow cover duration at 15 sites in the Romanian Carpathians, 1961-2003 (Micu, 2009). (f) 1 April SWE at 799 sites, 1950-2000, in western North America (Mote, 2006). (g) Difference between 1990s and 1960s March SD at 89 sites in Japan (Ishizaka, 2004). (h) SCD at 15 sites for starting years near 1931, ending 2000 (Petkova et al., 2004). (i) SCD at 18 sites in Italy, $1950-2009$ (Valt and Cianfarra, 2010). (j) SCD at 34 sites in Switzerland, 1948-2007, from Marty (2008). See text for definitions of abbreviations. For (b) through ( j), the quantity plotted is the percentage change of a linear fit divided by the number of years of the fit. For studies with more than 50 sites, the median, upper and lower quartiles are shown with vertical lines. In a few cases, some trends lie beyond the edges of the graph; these are indicated by a numeral at the corresponding edge of the graph, for example, two sites $>2 \%$ yr- 1 in row (f). Colours indicate temperature or, for studies e) and i), elevation using the lowest and highest site in the respective data set to set the colour scale. Note the prevalence of negative trends at lower/warmer sites.

\section{Box 4.1 | Interactions of Snow within the Cryosphere}

Snow is just one component of the cryosphere, but snow also sustains ice sheets and glaciers, and has strong interactions with all the other cryospheric components, except sub-sea permafrost. For example, snow can affect the rate of sea-ice production, and can alter frozen ground through its insulating effect. Snowfall and the persistence of snow cover are strongly dependent on atmospheric temperature and precipitation, and are thus likely to change in complex ways in a changing climate (e.g, Brown and Mote, 2009).

For the Earth's climate in general, and more specifically, the cryospheric components on which snow falls, the two most important physical properties of snow are its high albedo (reflectivity of solar radiation) and its low thermal conductivity, which results because its high air content makes it an excellent thermal insulator. Both factors substantially alter the flux of energy between the atmosphere and the material beneath the snow cover. Snow also has a major impact on the total energy balance of the Earth's surface because large regions in the NH are seasonally covered by snow (e.g., Barry and Gran, 2011). When seasonal snow melts it is also an important fresh water resource.

The high albedo of snow has a strong impact on the radiative energy balance of all surfaces on which it lies, most of which (including glaciers and sea ice) are much less reflective. For example, the albedo of bare glacier or sea ice is typically only 20 to $30 \%$, and hence 
Box 4.1 (continued)

70 to $80 \%$ of solar radiation is absorbed at the surface. For ice at the melting point, this energy melts the ice. With a fresh snow cover over ice, the albedo changes to $80 \%$ or even higher and melting is greatly reduced (e.g., Oerlemans, 2001). The effect is similar for other land surfaces-bare soil, frozen ground, low-lying vegetation - but here the thermal properties of the snow cover also play an important role by insulating the ground from changes in ambient air temperature.

While an insulating snow cover can reduce the growth of sea ice, a heavy snow load, particularly in the Antarctic, often depresses the sea ice surface below sea level and this leads to faster transformation of snow to ice (see FAQ 4.1). Even without flooding, the basal snow layer on Antarctic sea ice tends to be moist and saline because brine is wicked up through the snow cover. In regions of heavily ridged and deformed sea ice, snow redistributed by wind smoothes the ice surface, reducing the drag of the air on the ice and thus slowing ice drift and reducing heat exchange (Massom et al., 2001) .

For frozen ground, the insulation characteristics of snow cover are particularly important. If the air above is colder than the material on which it lies, the presence of snow will reduce heat transfer upwards, especially for fresh snow with a low density. This could, for example, reduce the seasonal freezing of soil, slow down the freezing of the active layer (seasonally thawed layer) or protect permafrost from cooling. Alternatively, if the air is warmer than the material beneath the snow, heat transfer downwards from the air is reduced and the presence of snow cover can increase the thickness of seasonal soil freeze and protect permafrost from warming. Which process applies depends on the timing of the snowfall, its thickness, and its duration (e.g., Zhang, 2005; Smith et al., 2012).

For the preceding reasons, the timing of snowfall and the persistence of snow cover are of major importance. Whereas snow falling on glaciers and ice sheets in summer has a strongly positive (sustaining) effect on the mass budget, early snow cover can reduce radiative and conductive cooling and freezing of the active layer. During winter, snowfall is the most important source of nourishment for most glaciers, but radiative cooling of frozen ground is strongly reduced by thick snow cover (Zhang, 2005).

\subsection{Lake and River Ice}

The assessment of changes in lake and river ice is made more difficult by several factors. Until the satellite era, some nations collected data from numerous lakes and rivers and others none; many published studies focus on a single lake or river. Many records have been discontinued (Prowse et al., 2011), and consistency of observational methods is a challenge, especially for date of ice break-up of ice on rivers when the process of break-up can take as long as 3 months (Beltaos and Prowse, 2009).

The most comprehensive description is the analysis of 75 lakes, mostly in Scandinavia and the northern USA, but with one each in Switzerland and Russia (Benson et al., 2012). Examining 150-, 100-, and 30-year periods ending in spring 2005, they found the most rapid changes in the most recent 30-year period (medium confidence) with trends in freeze-up 1.6 days per decade later and breakup 1.9 days per decade earlier. Wang et al. (2012) found a total ice cover reduction on the north American Great Lakes of 71\% over the 1973-2010 period of record, using weekly ice charts derived from satellite observations (medium confidence). Jensen et al. (2007) examined data from 65 water bodies in the Great Lakes region between Minnesota and New York (not including the Great Lakes themselves) and found trends in freeze-up 3.3 days per decade later, trends in breakup 2.1 days per decade earlier, and rates of change over 1975-2004 that were bigger than those over 1846-1995. Spatial patterns in trends are ambiguous: Latifovic and Pouliot (2007) found larger trends in higher latitudes over Canada, but Hodgkins et al. (2002) found larger trends in lower latitudes in the northeastern USA.
In the only reported study since the 1990s of ice on SH lakes, Green (2011) suggested on the basis of available evidence that break-up of ice cover on Blue Lake in the Snowy Mountains of Australia had shifted from November to October between observation periods 1970-1972 and 1998-2010.

Several studies made quantitative connections between ice cover and temperature. For instance, Benson et al. (2012) found significant correlations between mean ice duration and mean $\mathrm{NH}$ land air temperature in fall-winter-spring $\left(r^{2}=0.48\right)$ and between spring air temperature and breakup $\left(r^{2}=0.36\right)$; see also the review by Prowse et al. (2011).

Studies of changes in river ice have used both disparate data and time intervals, ranging in duration from multi-decade to more than two centuries, and most focus on a single river. Beltaos and Prowse (2009), summarizing most available information for northern rivers, noted an almost universal trend towards earlier break-up dates but considerable spatial variability in those for freeze-up, and noted too that changes were often more pronounced during the last few decades of the 20th century. They noted that the 20th century increase in mean air temperature in spring and autumn has produced in many areas a change of about 10 to 15 days toward earlier break-up and later freeze-up, although the relationship with air temperatures is complicated by the roles of snow accumulation and spring runoff.

In summary, the limited evidence available for freshwater (lake and river) ice indicates that ice duration is decreasing and average seasonal ice cover shrinking (low confidence), and the following general patterns (each of which has exceptions): rates of change in timing are 
generally, but not universally, (1) higher for spring breakup than fall freeze-up; (2) higher for more recent periods; (3) higher at higher elevations (Jensen et al., 2007) and (4) quantitatively related to temperature changes.

\subsection{Frozen Ground}

\subsubsection{Background}

Frozen ground occurs across the world at high latitudes, in mountain regions, beneath glacial ice and beneath lakes and seas. It is a product of cold weather and climate, and can be diurnal, seasonal or perennial. Wherever the ground remains at or below $0^{\circ} \mathrm{C}$ for at least two consecutive years, it is called permafrost (Van Everdingen, 1998), and this too can occur beneath the land surface (terrestrial permafrost) and beneath the seafloor (subsea permafrost). In this chapter, the term permafrost refers to terrestrial permafrost unless specified.

Both the temperature and extent of permafrost are highly sensitive to climate change, but the responses may be complex and highly heterogeneous (e.g., Osterkamp, 2007). Similarly, the annual freezing and thawing of seasonally frozen ground is coupled to the land surface energy and moisture fluxes, and thus to climate. Since, permafrost and seasonally frozen ground, can contain significant fractions of ice, changes in landscapes, ecosystems and hydrological processes can occur when it forms or degrades (Jorgenson et al., 2006; Gruber and Haeberli, 2007; White et al., 2007). Furthermore, frozen organic soils contain considerable quantities of carbon, more than twice the amount currently in the atmosphere (Tarnocai et al., 2009), and permafrost thawing exposes previously frozen carbon to microbial degradation and releases radiatively active gases, such as carbon dioxide $\left(\mathrm{CO}_{2}\right)$ and methane $\left(\mathrm{CH}_{4}\right)$, into the atmosphere (Zimov et al., 2006; Schuur et al., 2009; Schaefer et al., 2011) (for a detailed assessment of this issue, see Chapter 6). Similarly, recent evidence suggests that degradation of permafrost may also permit the release of nitrous oxide $\left(\mathrm{N}_{2} \mathrm{O}\right)$, which is also radiatively active (Repo et al., 2009; Marushchak et al., 2011). Finally, permafrost degradation may directly affect the lives of people, both in northern and high-mountain areas, through impacts on the landscape, vegetation and infrastructure (WGIl, Chapter 28).

\subsubsection{Changes in Permafrost}

\subsubsection{Permafrost Temperature}

The ice content and temperature of permafrost are the key parameters that determine its physical state. Permafrost temperature is a key parameter used to document changes to permafrost. Permafrost temperature measured at a depth where seasonal variations cease to occur is generally used as an indicator of long-term change and to represent the mean annual ground temperature (Romanovsky et al., 2010a). For most sites this depth occurs in the upper $20 \mathrm{~m}$.

In the $\mathrm{SH}$, permafrost temperatures as low as $-23.6^{\circ} \mathrm{C}$ have been observed in the Antarctic (Vieira et al., 2010), but in the $\mathrm{NH}$, permafrost temperatures generally range from $-15^{\circ} \mathrm{C}$ to close to the freezing point (Figure 4.22) (Romanovsky et al., 2010a). They are usually coldest in high Arctic regions and gradually increase southwards, but substantial differences do occur at the same latitude. For example, as a result of the proximity to warm ocean currents, the southern limit of permafrost is farther north, and permafrost temperature is higher in Scandinavia and north-western Russia than it is in Arctic regions of Siberia and North America (Romanovsky et al., 2010a).

In Russia, permafrost temperature measurements reach back to the early 1930s (Romanovsky et al., 2010b), in North America to the late 1940s (Brewer, 1958) and in China to the early 1960s (Zhou et al., 2000; Zhao et al., 2010). Systematic measurements, however, began mostly in the late 1970s and early 1980s (Zhou et al., 2000; Osterkamp, 2007; Smith et al., 2010). In addition, since the AR4, considerable effort (especially during the International Polar Year) has gone into enhancing the observation network and establishing a baseline against which future changes in permafrost can be measured (Romanovsky et al., 2010a). However, it should be noted that there still exist comparatively few measurements of permafrost temperature in the SH (Vieira et al., 2010).

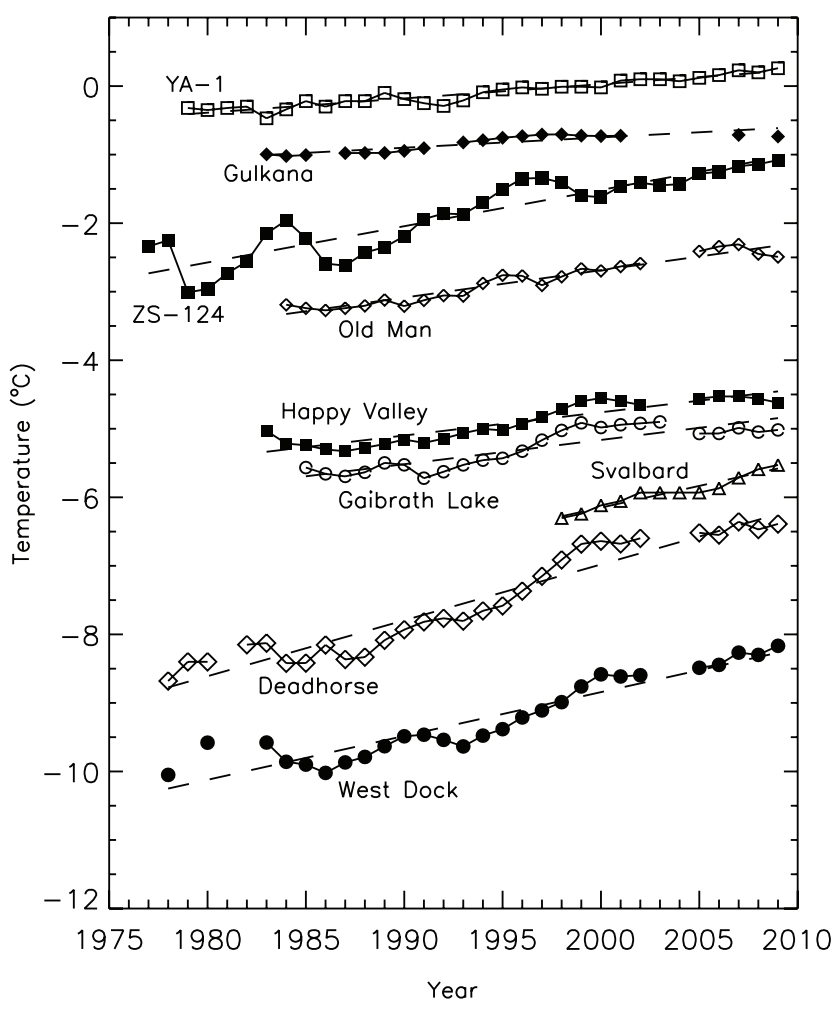

Figure 4.22 | Time series of mean annual ground temperatures at depths between 10 and $20 \mathrm{~m}$ for boreholes throughout the circumpolar northern permafrost regions (Romanovsky et al., 2010a). Data sources are from Romanovsky et al. (2010b) and Christiansen et al. (2010). Measurement depth is $10 \mathrm{~m}$ for Russian boreholes, $15 \mathrm{~m}$ for Gulkana and Oldman, and $20 \mathrm{~m}$ for all other boreholes. Borehole locations are: ZS-124, 67.48 $\mathrm{N} 063.48^{\circ} \mathrm{E} ; 85-8 \mathrm{~A}, 61.68^{\circ} \mathrm{N} 121.18^{\circ} \mathrm{W}$; Gulkana, $62.28^{\circ} \mathrm{N} 145.58^{\circ} \mathrm{W}$; YA-1, 67.58 $\mathrm{N} 648^{\circ} \mathrm{E}$; Oldman, $66.48^{\circ} \mathrm{N} 150.68^{\circ} \mathrm{W}$; Happy Valley, $69.18^{\circ} \mathrm{N} 148.88^{\circ} \mathrm{W}$; Svalbard, $78.28^{\circ} \mathrm{N} 016.58^{\circ} \mathrm{E}$; Deadhorse, $70.28^{\circ} \mathrm{N} 148.58^{\circ} \mathrm{W}$ and West Dock, $70.48^{\circ} \mathrm{N}$ $148.58^{\circ} \mathrm{W}$. The rate of change (degrees Celsius per decade) in permafrost temperature over the period of each site record is: ZS-124: $0.53 \pm 0.07$; YA-1: $0.21 \pm 0.02$; West Dock: $0.64 \pm 0.08$; Deadhorse: $0.82 \pm 0.07$; Happy Valley: $0.34 \pm 0.05$; Gaibrath Lake: $0.35 \pm 0.07$; Gulkana: $0.15 \pm 0.03$; Old Man: $0.40 \pm 0.04$ and Svalvard: $0.63 \pm 0.09$. (The trends are very likely range, $90 \%$.) 
In most regions, and at most sites, permafrost temperatures have increased during the past three decades (high confidence): at rather fewer sites, permafrost temperatures show little change, or a slight decrease (Figure 4.22; Table 4.8). However, it is important to discriminate between cold permafrost, with mean annual ground temperatures below $-2{ }^{\circ} \mathrm{C}$, and warm permafrost at temperatures above $-2^{\circ} \mathrm{C}$ (Cheng and Wu, 2007; Smith et al., 2010; Wu and Zhang, 2010). Warm permafrost is found mostly in the discontinuous permafrost zone, while cold permafrost exists in the continuous permafrost zone and only occasionally in the discontinuous permafrost zone (Romanovsky et al., 2010a).

Overall, permafrost temperature increases are greater in cold permafrost than they are in warm permafrost (high confidence). This is especially true for warm ice-rich permafrost, due to heat absorbed by partial melting of interstitial ice, slowing and attenuating temperature change (Romanovsky et al., 2010a). The temperatures of cold permafrost across a range of regions have increased by up to $2^{\circ} \mathrm{C}$ since the 1970s (Table 4.8 and Callaghan et al., 2011); however, the timing of warming events has shown considerable spatial variability (Romanovsky et al., 2010a).

Temperatures of warm permafrost have also increased over the last three decades, but generally by less than $1{ }^{\circ} \mathrm{C}$. Warm permafrost is sometimes nearly isothermal with depth; as is observed in mountain regions such as the European Alps (Noetzli and Vonder Muehll, 2010), Scandinavia (Christiansen et al., 2010), the Western Cordillera of North America (Smith et al., 2010; Lewkowicz et al., 2011), the Qinghai-Xizang (Tibet) Plateau (Zhao et al., 2010; Wu et al., 2012) and in the northern high latitudes in the southern margins of discontinuous permafrost regions (Romanovsky et al., 2010b; Smith et al., 2010). In such areas, permafrost temperatures have shown little or no change, indicating that permafrost is thawing internally but remaining very close to the melting point (Smith et al., 2010). Cooling of permafrost due to atmospheric temperature fluctuations has been observed; for example, in the eastern Canadian Arctic until the mid-1990s (Smith et al., 2010); but some examples have been short-lived and others controlled by site-specific conditions (Marchenko et al., 2007; Wu and Zhang, 2008; Noetzli and Vonder Muehll, 2010; Zhao et al., 2010). In at least one case in the Antarctic, permafrost warming has been observed in a region with almost stable air temperatures (Guglielmin and Cannone, 2012).

Permafrost warming is mainly in response to increased air temperature and changing snow cover (see Box 4.1). In cold permafrost regions, especially in tundra regions with low ice content (such as bedrock) where permafrost warming rates have been greatest, changes in snow cover may play an important role (Zhang, 2005; Smith et al., 2010).

Table 4.8 Permafrost temperatures during the International Polar Year (2007-2009) and their recent changes. Each line may refer to one or more measurements sites.

\begin{tabular}{|c|c|c|c|c|c|}
\hline Region & $\begin{array}{c}\text { Permafrost } \\
\text { Temperature } \\
\text { During IPY }\left({ }^{\circ} \mathrm{C}\right)\end{array}$ & $\begin{array}{l}\text { Permafrost } \\
\text { Temperature } \\
\text { Change }\left({ }^{\circ} \mathrm{C}\right)\end{array}$ & $\begin{array}{l}\text { Depth } \\
(\mathrm{m})\end{array}$ & Period of Record & Source \\
\hline \multicolumn{6}{|l|}{ North America } \\
\hline Northern Alaska & -5.0 to -10.0 & $0.6-3$ & $10-20$ & Early 1980s-2009 & $\begin{array}{l}\text { Osterkamp }(2005,2007) ; \text { Smith et al. } \\
\text { (2010); Romanovsky et al. (2010a) }\end{array}$ \\
\hline $\begin{array}{l}\text { Mackenzie Delta and Beau- } \\
\text { fort coastal region }\end{array}$ & -0.5 to -8.0 & $1.0-2.0$ & $12-20$ & Late 1960s-2009 & $\begin{array}{l}\text { Burn and Kokelj (2009); Burn and Zhang } \\
\text { (2009); Smith et al. (2010) }\end{array}$ \\
\hline Interior of Alaska, & 0.0 to -5.0 & $0.0-0.8$ & $15-20$ & 1985-2009 & $\begin{array}{l}\text { Osterkamp (2008); Smith et al. (2010); } \\
\text { Romanovsky et al. (2010a) }\end{array}$ \\
\hline Central and Southern Mackenzie Valley & $>-2.2$ & $0.0-0.5$ & $10-12$ & 1984-2008 & Smith et al. (2010) \\
\hline Northern Quebec & $>-5.6$ & $0.0-1.8$ & $12-20$ & $1993-2008$ & Allard et al. (1995); Smith et al. (2010) \\
\hline \multicolumn{6}{|l|}{ Europe } \\
\hline Nordic Countries & -0.1 to -5.6 & $0.0-1.0$ & $2-15$ & 1999-2009 & Christiansen et al. (2010); Isaksen et al. (2011) \\
\hline \multicolumn{6}{|l|}{ Northern and Central Asia } \\
\hline Northern Yakutia & -4.3 to -10.8 & $0.5-1.5$ & $14-25$ & early 1950s-2009 & Romanovsky et al. (2010b) \\
\hline Trans-Baykal region & -4.7 to -5.1 & $0.5-0.8$ & $19-20$ & late 1980s-2009 & Romanovsky et al. (2010b) \\
\hline Qinghai-Xizang Plateau & -0.2 to -3.4 & $0.2-0.7$ & 6 & $1996-2010$ & $\begin{array}{l}\text { Cheng and Wu (2007); Li et al. (2008); Wu } \\
\text { and Zhang (2008); Zhao et al. (2010) }\end{array}$ \\
\hline Tian Shan & -0.4 to -1.1 & $0.3-0.9$ & $10-25$ & 1974-2009 & (Marchenko et al. (2007); Zhao et al. (2010) \\
\hline Mongolia & 0.0 to $<-2.0$ & $0.2-0.6$ & $10-15$ & 1970-2009 & $\begin{array}{l}\text { Sharkhuu et al. (2007); Zhao et al. } \\
\text { (2010); Ishikawa et al. (2012) }\end{array}$ \\
\hline \multicolumn{6}{|l|}{ Others } \\
\hline
\end{tabular}


In forested areas, especially in warm ice-rich permafrost, changes in permafrost temperature are reduced by the effects of the surface insulation (Smith et al., 2012; Throop et al., 2012) and latent heat (Romanovsky et al., 2010a).

\subsubsection{Permafrost Degradation}

Permafrost degradation refers to a decrease in thickness and/or areal extent. In particular, the degradation can be manifested by a deepening of summer thaw, or top-down or bottom-up permafrost thawing, and a development of taliks (see Glossary). Other manifestations of degradation include geomorphologic changes such as the formation of thermokarst terrain (see Glossary and Jorgenson et al., 2006), expansion of thaw lakes (Sannel and Kuhry, 2011) active-layer detachment slides along slopes, rock falls (Ravanel et al., 2010), and destabilized rock glaciers (Kääb et al., 1997; Haeberli et al., 2006; Haeberli et al., 2010). Although most permafrost has been degrading since the Little Ice Age (Halsey et al., 1995), the trend was relatively modest until the past two decades, during which the rate of degradation has increased in some regions (Romanovsky et al., 2010b).

Significant permafrost degradation has been reported in the Russian European North (medium confidence). Warm permafrost with a thickness of 10 to $15 \mathrm{~m}$ thawed completely in the period 1975-2005 in the Vorkuta area (Oberman, 2008). And although boundaries between permafrost types are not easy to map, the southern permafrost boundary in this region is reported to have moved north by about $80 \mathrm{~km}$ and the boundary of continuous permafrost has moved north by 15 to 50 $\mathrm{km}$ (Oberman, 2008) (medium confidence). Taliks have also developed in relatively thick permafrost during the past several decades. In the Vorkuta region, the thickness of existing closed taliks increased by 0.6 to $6.7 \mathrm{~m}$ over the past 30 years (Romanovsky et al., 2010b). Permafrost thawing and talik formation has occurred in the Nadym and Urengoy regions in north- western Russian (Drozdov et al., 2010). Long-term permafrost thawing has been reported around the city of Yakutsk, but this in this case, the thawing may have been caused mainly by forest fires or human disturbance (Fedorov and Konstantinov, 2008). Permafrost degradation has also been reported on the Qinghai-Xizang (Tibet) Plateau (Cheng and Wu, 2007; Li et al., 2008).

Coastal erosion and permafrost degradation appear to be evident along many Arctic coasts in recent years, with complex interactions between them (Jones et al., 2009). In part, these interactions arise from the thermal and chemical impact of sea water on cold terrestrial permafrost (Rachold et al., 2007). Similar impacts arise for permafrost beneath new thaw lakes, which have been formed in recent years (e.g., Sannel and Kuhry, 2011). In northern Alaska, estimates of permafrost thawing under thaw lakes are in the range 0.9 to $1.7 \mathrm{~cm} \mathrm{a}^{-1}$ (Ling and Zhang, 2003).

Since AR4, destabilized rock glaciers have received increased attention from researchers. A rock glacier is a mass of perennially frozen rock fragments on a slope, that contains ice in one or more forms and shows evidence of past or present movement (Van Everdingen, 1998; Haeberli et al., 2006). Time series acquired over recent decades by terrestrial surveys indicate acceleration of some rock glaciers as well as seasonal velocity changes related to ground temperatures (Bodin et al., 2009;
Noetzli and Vonder Muehll, 2010; Schoeneich et al., 2010; Delaloye et al., 2011). Similarly, photo-comparison and photogrammetry have indicated collapse-like features on some rock glaciers (Roer et al., 2008). The clear relationship between mean annual air temperature at the rock glacier front and rock glacier velocity points to a likely temperature influence and a plausible causal connection to climate (Kaab et al., 2007). Strong surface lowering of rock glaciers has been reported in the Andes (Bodin et al., 2010), indicating melting of ground ice in rock glaciers and permafrost degradation.

\subsubsection{Subsea Permafrost}

Subsea permafrost is similar to its terrestrial counterpart, but lies beneath the coastal seas. And as with terrestrial permafrost, subsea permafrost is a substantial reservoir and/or a confining layer for gas hydrates (Koch et al., 2009). It is roughly estimated that subsea permafrost contains 2 to $65 \mathrm{Pg}$ of $\mathrm{CH}_{4}$ hydrate (McGuire et al., 2009). Observations of gas release on the East Siberian Shelf and high methane concentrations in water-column and air above (Shakhova et al., 2010a, $2010 \mathrm{~b})$ have led to the suggestion that permafrost thawing creates pathways for gas release.

Subsea permafrost in the Arctic is generally relict terrestrial permafrost (Vigdorchik, 1980), inundated after the last glaciation and now degrading under the overlying shelf sea. Permafrost may, however, also form when the sea is shallow, permitting sediment freezing through bottom-fast winter sea ice (Solomon et al., 2008; Stevens et al., 2010). A 76-year record of bottom water temperature in the Laptev Sea (Dmitrenko et al., 2011) showed warming of $2.1^{\circ} \mathrm{C}$ since 1985 in the nearshore zone ( $<10 \mathrm{~m}$ water depth), as lengthening summers reduced sea ice extent and increased solar heating. Degradation rates of the ice-bearing permafrost following inundation have been estimated to be 1 to $20 \mathrm{~cm} \mathrm{a}^{-1}$ on the East Siberian Shelf (Overduin et al., 2007) and 1 to $4 \mathrm{~cm} \mathrm{a}^{-1}$ in the Alaskan Beaufort Sea (Overduin et al., 2012).

\subsubsection{Changes in Seasonally Frozen Ground}

Seasonally frozen ground is a soil layer that freezes and thaws annually, which may or may not overlie terrestrial permafrost, and also includes some portions of the Arctic seabed that freeze in winter. A key parameter regarding seasonally frozen ground overlying permafrost is the active-layer thickness (ALT; see Glossary), which indicates the depth of the seasonal freeze-thaw cycle, and which is dependent on climate and other factors; for example, vegetation cover (Smith et al., 2009). Many observations across many regions have revealed trends in the thickness of the active laver (high confidence).

\subsubsection{Changes in Active-Layer Thickness}

Many observations have revealed a general positive trend in the thickness of the active layer (see Glossary) for discontinuous permafrost regions at high latitudes (medium confidence). Based on measurements from the International Permafrost Association (IPA) Circumpolar Active Layer Monitoring (CALM) programme, active-layer thickening has been observed since the 1970s and has accelerated since 1995 in northern Europe (Akerman and Johansson, 2008; Callaghan et al., 2010), and on Svalbard and Greenland since the late-1990s (Christiansen et 
al., 2010). The ALT has increased significantly in the Russian European North (Mazhitova, 2008), East Siberia (Fyodorov-Davydov et al., 2008), and Chukotka (Zamolodchikov, 2008) since the mid-1990s. Burn and Kokelj (2009) found, for a site in the Mackenzie Delta area, that ALT increased by $8 \mathrm{~cm}$ between 1983 and 2008, although the record does exhibit high interannual variability as has been observed at other sites in the region (Smith et al., 2009). ALT has increased since the mid1990s in the eastern portion of the Canadian Arctic, with the largest increase occurring at bedrock sites in the discontinuous permafrost zone (Smith et al., 2010).

The interannual variations and trends of the active-layer thickness in Northern America, Northern Europe and Northern Asia from 1990 to 2012 are presented in Figure 4.23. Large regional variations in the yearly variability patterns and trends are apparent. While increases in ALT are occurring in the Eastern Canadian Region (Smith et al., 2009), a slightly declining trend is observed in the Western Canadian Region (Figure 4.23a). In Northern Europe, the trends in the study areas are similar and consistently positive (Figure 4.23b). On the other hand, in Northern Asia, trends are generally strongly positive with the exception of West Siberia, where the trend is slightly negative (Figure 4.23c). On the interior of Alaska, slightly increasing ALT from 1990 to 2010 was followed by anomalous increases in 2011 and in 2012. Overall, a general increase in ALT since the 1990s has been observed at many stations in many regions (medium confidence). The general increase is shown in Figure $4.23 \mathrm{~d}$, which shows the results of analysis of data from about 44 stations in Russia indicating a change of almost $0.2 \mathrm{~m}$ from 1950 to 2008.

At some measurement sites on the Qinghai-Xizang (Tibet) Plateau, ALT was reported to be increasing at $7.8 \mathrm{~cm} \mathrm{yr}^{-1}$ over a period from 1995 through 2010 (Wu and Zhang, 2010). The high rates may have been the result of local disturbances since more recent studies indicate rates of $1.33 \mathrm{~cm} \mathrm{yr}^{-1}$ for the period $1981-2010$ and $3.6 \mathrm{~cm} \mathrm{yr}^{-1}$ for the period 1998-2010 (e.g., Zhao et al., 2010; Li et al., 2012a).

During the past decade, increases in ALT up to $4.0 \mathrm{~cm} \mathrm{yr}^{-1}$ were observed in Mongolian sites characterized as a warm permafrost region (Sharkhuu et al., 2007). Changes in ALT were also detected in Tian Shan (Marchenko et al., 2007; Zhao et al., 2010), and in the European Alps, where increases in ALT were largest during years of hot summers but a strong dependence on surface and subsurface characteristics was noted (Noetzli and Vonder Muehll, 2010).

In several areas, across North America and in West Siberia, large-inter annual variations obscure any trends in ALT (high confidence, Figure 4.23). No trend in ALT was observed on the Alaskan North Slope from 1993 to 2010 (Streletskiy et al., 2008; Shiklomanov et al., 2010) and also in the Mackenzie Valley (Smith et al., 2009) and in West Siberia (Vasiliev et al., 2008) since the mid-1990s (Figure 4.23). At some sites, such as at Western Canada (C5) and Western Siberia (R1) (Figure 4.23), the active layer thickness was actually decreasing.

The penetration of thaw into ice-rich permafrost at the base of the active layer is often accompanied by loss of volume due to consolidation. At several sites, this has been shown to cause surface subsidence (medium confidence). Results from ground-based measurements at
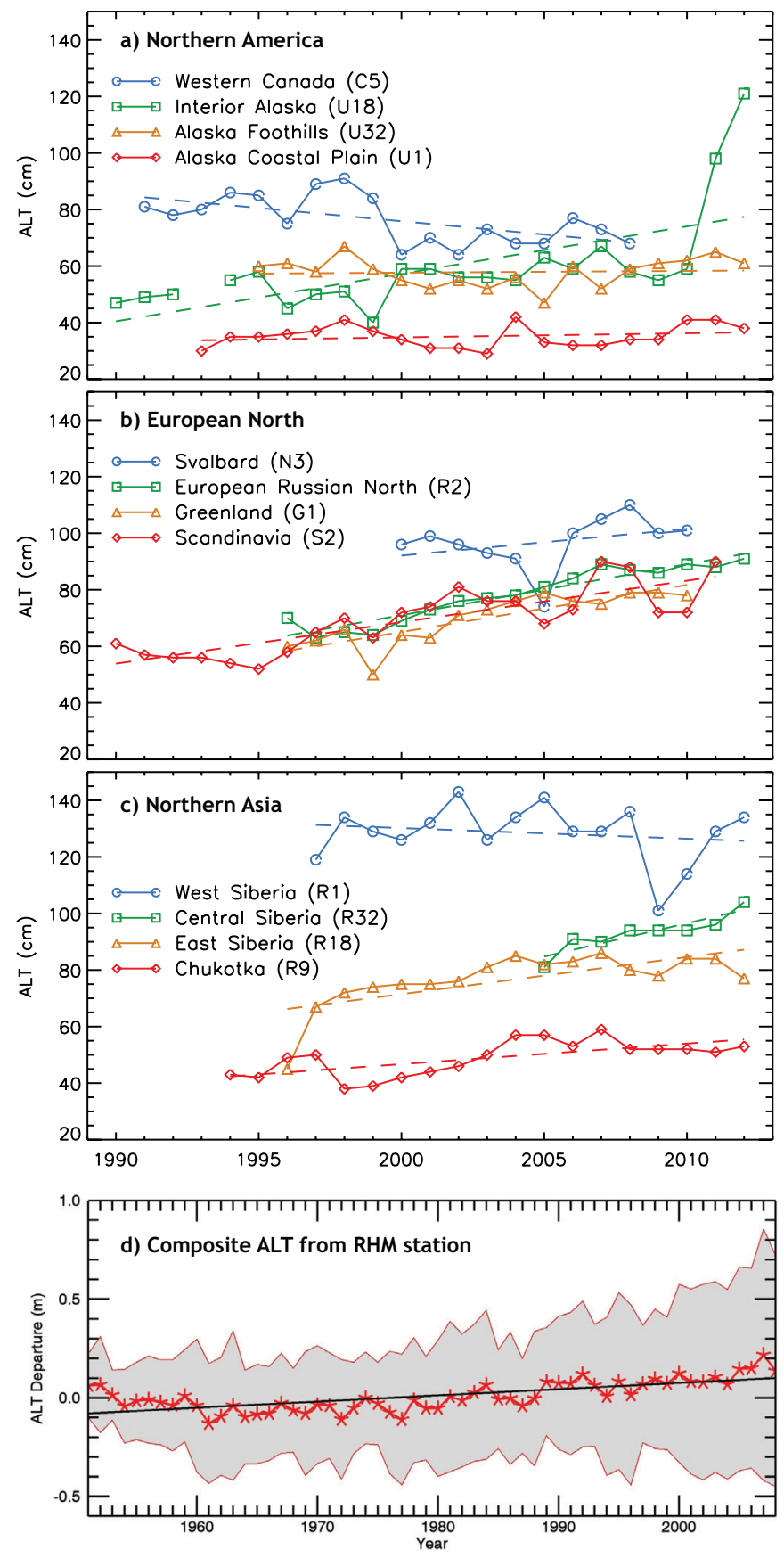

Figure 4.23 Active layer thickness from different locations for slightly different periods between 1990 and 2012 in (a) Northern America, (b) Northern Europe, and (c) Northern Asia. The dashed lines represents linear fit to each set of data. ALT data for Northern America, Northern Asia and Northern Europe were obtained from the International Permafrost Association (IPA) CALM website (http://www.udel.edu/Geography/ calm/about/permafrost.html). The number of Russian Hydrometeorological Stations (RHM) stations has expanded from 31 stations as reported from Frauenfeld et al. (2004) and Zhang et al. (2005) to 44 stations and the time series has extended from 1990 to 2008. (d) Departures from the mean of active layer thickness in Siberia from 1950 to 2008. The red asterisk represents the mean composite value, the shaded area indicates the standard deviation and the black line is the trend. Data for Siberia stations were obtained from the Russian Hydrometeorological Stations (RHM). 
selected sites on the North Slope of Alaska indicate 11 to $13 \mathrm{~cm}$ in surface subsidence over the period 2001-2006 (Streletskiy et al., 2008), 4 to $10 \mathrm{~cm}$ from 2003 to 2005 in the Brooks Range (Overduin and Kane, 2006) and up to $20 \mathrm{~cm}$ in the Russian European North (Mazhitova and Kaverin, 2007). Subsidence has also been identified using space-borne interferometric synthetic aperture radar (InSAR) data. Surface deformation was detected using InSAR over permafrost on the North Slope of Alaska during the 1992-2000 thaw seasons and a long-term surface subsidence of 1 to $4 \mathrm{~cm}$ per decade (Liu et al., 2010). Such subsidence could explain why in situ measurements at some locations reveal negligible trends in ALT changes during the past two decades, despite the fact that atmospheric and permafrost temperatures increased during that time.

\subsubsection{Changes in Seasonally Frozen Ground in Areas Not Underlain by Permafrost}

An estimate based on monthly mean soil temperatures from 387 stations across part of the Eurasian continent suggested that the thickness of seasonally frozen ground decreased by about $0.32 \mathrm{~m}$ during the period 1930-2000 (high confidence, Figure 4.24) (Frauenfeld and Zhang, 2011). Inter-decadal variability was such that no trend could be identified until the late 1960s, after which seasonal freeze depths decreased significantly until the early 1990s. From then, until about 2008, no further change was evident. Such changes are closely linked with the freezing index, but also with mean annual air temperatures and snow depth (Frauenfeld and Zhang, 2011).

Thickness of seasonally frozen ground in western China decreased by 20 to $40 \mathrm{~cm}$ since the early 1960s (Li et al., 2008), whereas on the Qinghai-Xizang (Tibet) Plateau, the seasonally frozen depth decreased by up to $33 \mathrm{~cm}$ since the middle of 1980s (Li et al., 2009). Evidence from the satellite record indicates that the onset dates of spring thaw advanced by 14 days, whereas the autumn freeze date was delayed by 10 days on the Qinghai-Xizang (Tibet) Plateau from 1988 through 2007 (Li et al., 2012b)

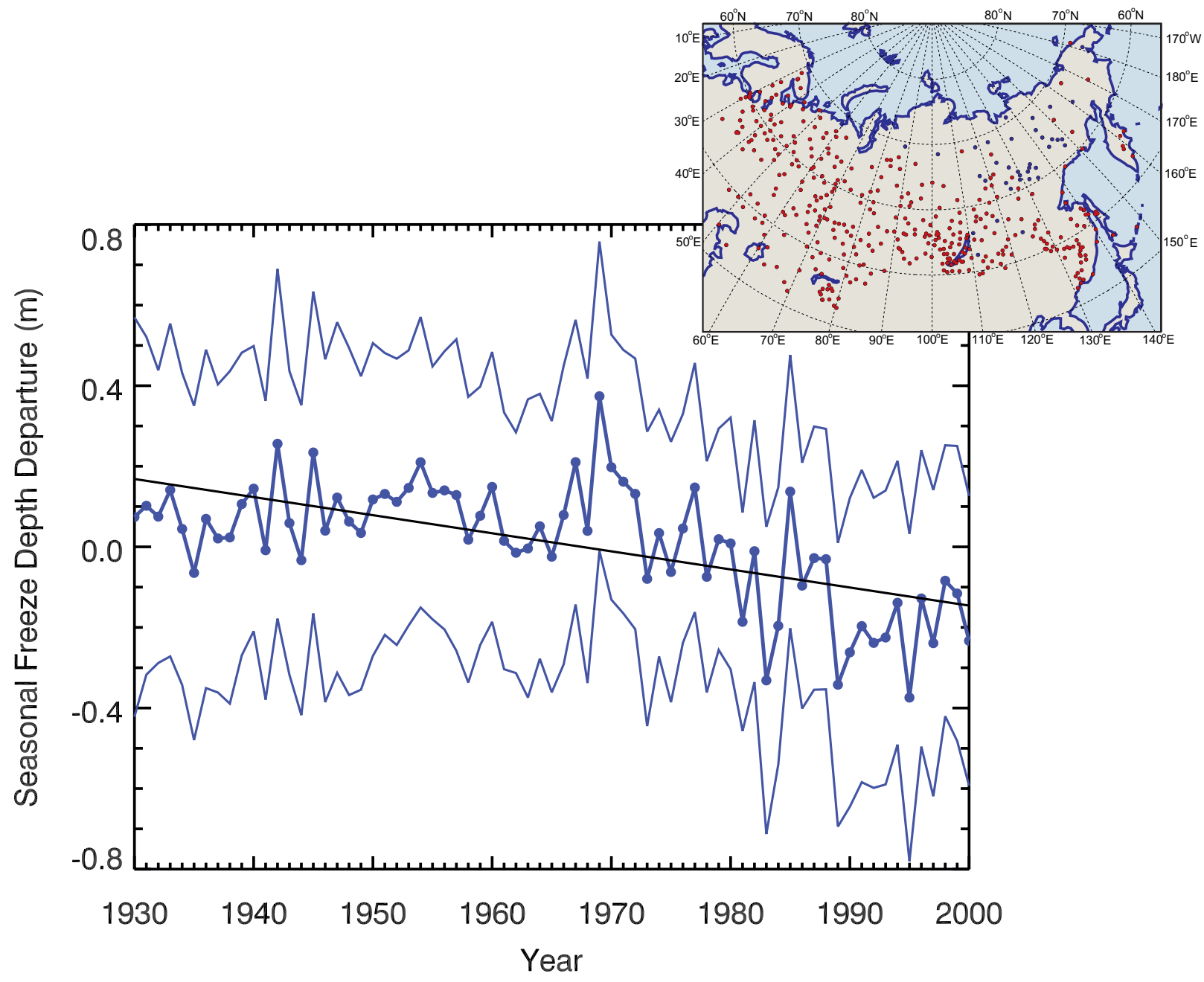

Figure 4.24 | Annual anomalies of the average thickness of seasonally frozen depth in Russia from 1930 to 2000. Each data point represents a composite from 320 stations as compiled at the Russian Hydrometeorological Stations (RHM) (upper right inset). The composite was produced by taking the sum of the thickness measurements from each station and dividing the result by the number of stations operating in that year. Although the total number of stations is 320, the number providing data may be different for each year but the minimum was 240 . The yearly anomaly was calculated by subtracting the 1971-2000 mean from the composite for each year. The thin lines indicate the 1 standard deviation $(1 \sigma)($ likely) uncertainty range. The line shows a negative trend of $-4.5 \mathrm{~cm}$ per decade or a total decrease in the thickness of seasonally frozen ground of $31.9 \mathrm{~cm}$ from 1930 to 2000 (Frauenfeld and Zhang, 2011). 


\subsection{Synthesis}

Observations show that the cryosphere has been in transition during the last few decades and that the strong and significant changes reported in AR4 have continued, and in many cases accelerated. The number of in situ and satellite observations of cryospheric parameters has increased considerably since AR4 and the use of the new data in trend analyses, and also in process studies, has enabled increased confidence in the quantification of most of the changes. A graphical depiction and a text summary of observed changes in the various components of the cryosphere are provided in Figure 4.25. They reveal a general decline in all components of the cryosphere, but the magnitude of the decline varies regionally and there are isolated cases where an increase is observed.

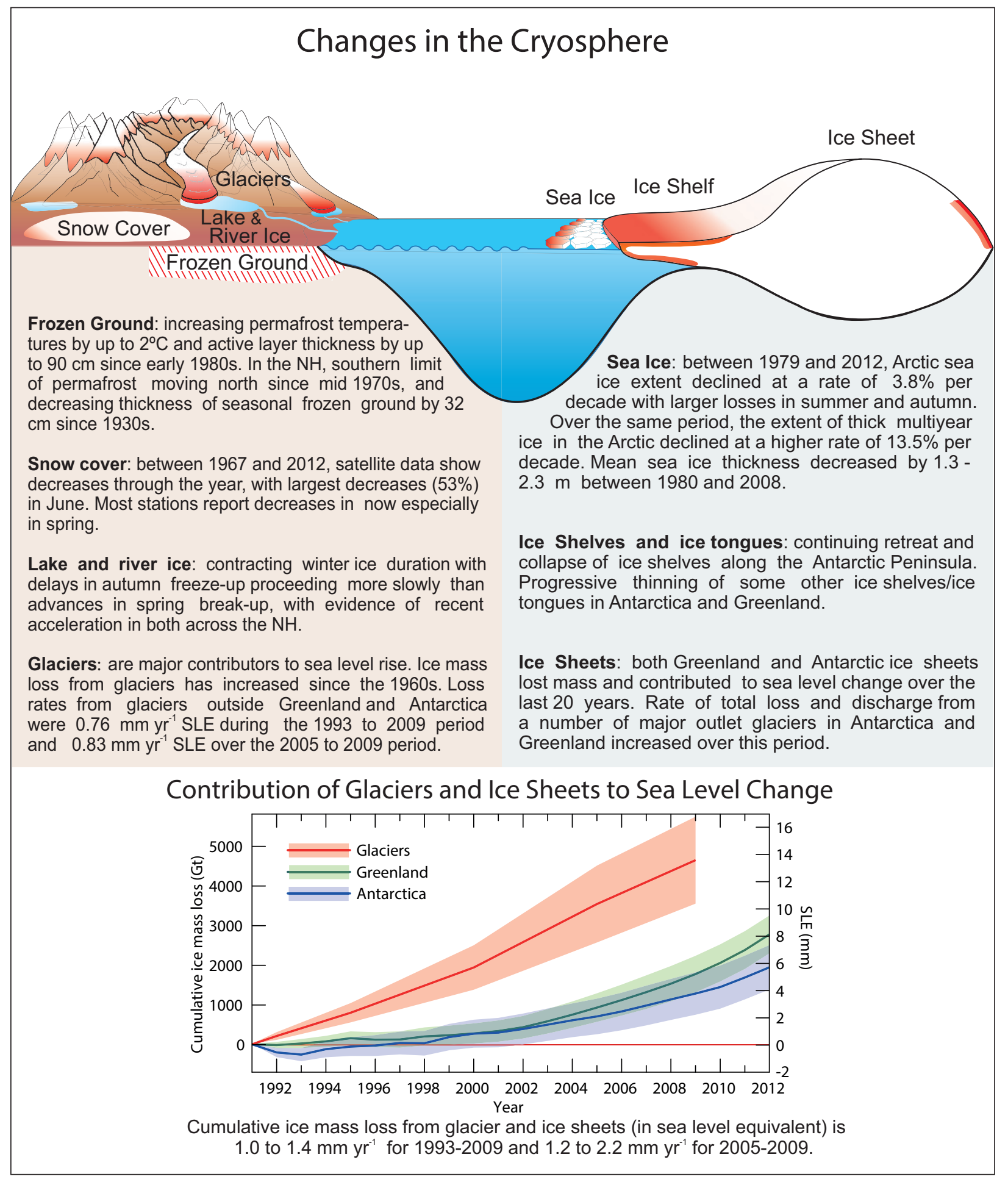

Figure 4.25 | Schematic summary of the dominant observed variations in the cryosphere. The inset figure summarises the assessment of the sea level equivalent of ice loss from the ice sheets of Greenland and Antarctica, together with the contribution from all glaciers except those in the periphery of the ice sheets (Section 4.3.3 and 4.4.2). 
Some of the observed changes since AR4 have been considerable and unexpected. One of the most visible was the dramatic decline in the September minimum sea ice cover in the Arctic in 2007, which was followed by a record low value in 2012, supporting observations that the thicker components of the Arctic sea ice cover are decreasing. The trend in extent for Arctic sea ice is $-3.8 \pm 0.3 \%$ per decade (very likely) while that for multi-year ice is $-13.5 \pm 2.5 \%$ per decade (very likely). Observations also show marked decreases in Arctic ice thickness and volume. The pattern of melt on the surface of the Greenland ice sheet has also changed radically, with melt occurring in 2012 over almost the entire surface of the ice sheet for the first time during the satellite era. The ice mass loss in Greenland has been observed to have increased from 34 [-6 to 74] Gt yr ${ }^{-1}$ for the period 1992-2001 to 215 [157 to

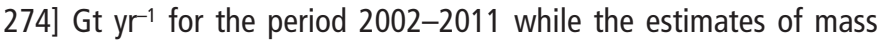
loss in Antarctica have increased from 30 [-37 to 97] $\mathrm{Gt} \mathrm{yr}^{-1}$ during the 1992-2001 period to 147 [72 to 221] Gt $\mathrm{yr}^{-1}$ during the 2002-2011 period. Observed mass loss from glaciers has also increased, with the global mass loss (excluding the glaciers peripheral to the ice sheets) estimated to be 226 [91 to 361] Gt $\mathrm{yr}^{-1}$ during the 1971-2009 period, 275 [140 to 410] Gt yr-1 over the 1993-2009 period, and 301 [166 to 436] over the 2005-2009 period. A large majority of observing stations report decreasing trends in snow depth, snow duration, or snow water equivalent, and the largest decreases are typically observed at locations with temperatures close to freezing. Most lakes and rivers with long-term records have exhibited declines in ice duration and average seasonal ice cover. Permafrost has also been degrading and retreating to the north while permafrost temperatures have increased in most regions since the 1980 s.

The observed positive trend of sea ice extent in the Antarctic that was regarded as small and insignificant in AR4, has persisted, and increased slightly to about $1.5 \pm 0.2 \%$ per decade. The higher-than-average Antarctic sea ice extent in recent years has been mainly due to increases in the Ross Sea region, which more than offset the declines in the Bellingshausen Sea and Amundsen Sea. Ice production in coastal polynyas (regarded as 'sea ice factories') along the Ross Sea ice shelves have been observed to be increasing. Recent work suggests strengthening of the zonal (east-west) winds and accompanying ice drift accounts for some of the increasing sea ice extent.

Satellite data have provided the ability to observe large-scale changes in the cryosphere at relatively good temporal and spatial resolution throughout the globe. Largely because of the availability of high resolution satellite data, the first near-complete global glacial inventory has been generated, leading to a more precise determination of the past, current and future contribution of glaciers to sea level rise. As more data accumulate, and as more capable sensors are launched, the data become more valuable for studies related to change assessment. The advent of new satellites and airborne missions has provided powerful tools that have enabled breakthroughs in the capability to measure some parameters and enhance our ability to interpret results. However, a longer record of measurements of the cryosphere will help increase confidence in the results, reduce uncertainties in the long-term trends, and bring more critical insights into the physical processes controlling the changes. There is thus a need for the continuation of the satellite records, and a requirement for longer and more reliable historical data from in situ measurements and proxies.
The sea level equivalent of mass loss from the Greenland and Antarctic ice sheets over the period 1993-2010, has been about $5.9 \mathrm{~mm}$ (including $1.7 \mathrm{~mm}$ from glaciers around Greenland) and $4.8 \mathrm{~mm}$, respectively. The reliability of observations of ice loss from the ice sheets has been enhanced with the introduction of advanced satellite observation techniques. The ice loss from glaciers between 1993 and 2009 measured in terms of sea level equivalent (excluding those peripheral to the ice sheets) is estimated to be $13 \mathrm{~mm}$. The inset to Figure 4.25 shows the cumulative sea level equivalent from glaciers and the ice sheets in Greenland and Antarctica. These have been contributing dominantly to sea level rise in recent decades. The contribution of the cryosphere to sea level change is discussed more fully in Chapter 13.

The overall consistency in the negative changes observed in the various components of the cryosphere (Figure 4.25), and the acceleration of these changes in recent decades, provides a strong signal of climate change. Regional differences in the magnitude and direction of the signals are apparent, but these are not unexpected considering the large variability and complexity of atmospheric and oceanic circulations. It is very likely, however, that the Arctic has changed substantially since 1979.

\section{Acknowledgements}

We acknowledge the kind contributions of C. Starr (NASA Visualization Group), U. Blumthaler, S. Galos (University of Innsbruck) and P. Fretwell (British Antarctic Survey), who assisted in drafting figures. M. Mahrer R. Graber (University of Zurich) and G. Hiess (BAS) undertook valuable literature reviews, and N. E. Barrand (BAS) assisted with collation of references. 


\section{References}

Abdalati, W., et al., 2004: Elevation changes of ice caps in the Canadian Arctic Archipelago. J. Geophys. Res. Earth Surf., 109, 11 (F04007).

Abdalati, W., et al., 2010: The ICESat-2 Laser Altimetry Mission. Proc. IEEE, 98, 735-751.

Akerman, H. J., and M. Johansson, 2008: Thawing permafrost and thicker active layers in sub-Arctic Sweden. Permafr. Process., 19, 279-292.

Allard, M., B. L. Wang, and J. A. Pilon, 1995: Recent cooling along the southern shore of the Hudson Strait, Quebec, Canada, documented from permafrost temperatuure-measurements. Arct. Alp. Res., 27, 157-166.

Alley, R. B., and S. Anandakrishnan, 1995: Variations in melt-layer frequency in the GISP2 ice core: Implications for Holocene summer temperatures central Greenland. Ann. Glaciol., 21, 64-70.

Alley, R. B., et al., 2008: A simple law for ice-shelf calving. Science, 322, 1344-1344.

Amundson, J. M., M. Fahnestock, M. Truffer, J. Brown, M. P. Luthi, and R. J. Motyka, 2010: Ice melange dynamics and implications for terminus stability, Jakobshavn Isbrae Greenland. J. Geophys. Res. Earth Surf., 115, 12

Andresen, C. S., et al., 2012: Rapid response of Helheim Glacier in Greenland to climate variability over the past century. Nature Geosci., 5, 37-41

Arendt, A. A., K. A. Echelmeyer, W. D. Harrison, C. S. Lingle, and V. B. Valentine, 2002: Rapid wastage of Alaska glaciers and their contribution to rising sea level. Science, 297, 382-386.

Arendt, A., et al., 2012: Randolph Glacier Inventory [v2.0]: A Dataset of Global Glacier Outlines. Global Land Ice Measurements from Space, Boulder Colorado, USA. Digital Media 32 pp. [Available online at: http://www.glims.org/RGI/RGI_ Tech_Report_V2.0.pdf]

Arthern, R. J., D. P. Winebrenner, and D. G. Vaughan, 2006: Antarctic snow accumulation mapped using polarization of $4.3-\mathrm{cm}$ wavelength microwave emission. J. Geophys. Res. Atmos., 111, D06107.

Arthern, R. J., D. G. Vaughan, A. M. Rankin, R. Mulvaney, and E. R. Thomas, 2010: In-situ measurements of Antarctic snow compaction, compared with predictions of models. J. Geophys. Res., 115, F03011.

Azam, M. F., et al., 2012: From balance to imbalance: a shift in the dynamic behaviour of Chhota Shigri glacier, western Himalaya, India. J. Glaciol., 58, 315-324.

Bahr, D. B., M. F. Meier, and S. D. Peckham, 1997: The physical basis of glacier volumearea scaling. J. Geophys. Res. Sol. Ea., 102, 20355-20362.

Bahr, D. B., M. Dyurgerov, and M. F. Meier, 2009: Sea-level rise from glaciers and ice caps: A lower bound. Geophys. Res. Lett., 36, 4 (L03501).

Bales, R. C., et al., 2009: Annual accumulation for Greenland updated using ice core data developed during 2000-2006 and analysis of daily coastal meteorological data. J. Geophys. Res. Atmos., 114, D06116.

Bamber, J. L., et al., 2013: A new bed elevation dataset for Greenland. Cryosphere, 7, 499-510.

Barrand, N., D. G. Vaughan, N. Steiner, M. Tedesco, P. Kuipers Munneke, M. R. van den Broeke, and J. S. Hosking, 2013: Trends in Antarctic Peninsula surface melting conditions from observations and regional climate modelling. J. Geophys. Res., 118, 1-16.

Barrett, P. J., 2013: Resolving views on Antarctic Neogene glacial history-the Sirius debate. Earth Environ. Sci. Trans. R. Soc. Edinburgh, 104, $29-51$.

Barry, R., and T. Y. Gran, 2011: The Global Cryosphere: Past, Present and Future. Cambridge University Press, Cambridge, UK, and New York, NY, USA, 498 pp.

Barry, R. G., R. E. Moritz, and J. C. Rogers, 1979: Fast ice regimes of the Beaufort and Chukchi sea coasts, Alaska. Cold Reg. Sci. Technol., 1, 129-152.

Bartholomew, I. D., P. Nienow, A. Sole, D. Mair, T. Cowton, M. A. King, and S. Palmer, 2011: Seasonal variations in Greenland Ice Sheet motion: Inland extent and behaviour at higher elevations. Earth Planet. Sci. Lett., 307, 271-278.

Baur, 0., M. Kuhn, and W. E. Featherstone, 2009: GRACE-derived ice-mass variations over Greenland by accounting for leakage effects. J. Geophys. Res. Sol. Ea., 114, 13 (B06407).

Belchansky, G. I., D. C. Douglas, and N. G. Platonov, 2004: Duration of the Arctic Sea ice melt season: Regional and interannual variability, 1979-2001. J. Clim., 17, 67-80.

Beltaos, S., and T. Prowse, 2009: River-ice hydrology in a shrinking cryosphere. Hydrol. Process., 23, 122-144.

Benn, D. I., C. R. Warren, and R. H. Mottram, 2007: Calving processes and the dynamics of calving glaciers. Earth Sci. Rev., 82, 143-179.
Benson, B. J., et al., 2012: Extreme events, trends, and variability in Northern Hemisphere lake-ice phenology (1855-2005). Clim. Change, 112, 299-323.

Berthier, E., E. Schiefer, G. K. C. Clarke, B. Menounos, and F. Remy, 2010: Contribution of Alaskan glaciers to sea-level rise derived from satellite imagery. Nature Geosci., 3, 92-95.

Bindschadler, R., et al., 2011: Getting around Antarctica: new high-resolution mappings of the grounded and freely-floating boundaries of the Antarctic ice sheet created for the International Polar Year. Cryosphere, 5, 569-588.

Bjørk, A. A., et al., 2012: An aerial view of 80 years of climate-related glacier fluctuations in southeast Greenland. Nature Geosci., 5, 427-432.

Björnsson, H., et al., 2013: Contribution of Icelandic ice caps to sea level rise: trends and variability since the Little Ice Age. Geophys. Res. Lett., 40, 1546-1550

Blaszczyk, M., J. A. Jania, and J. 0. Hagen, 2009: Tidewater glaciers of Svalbard: Recent changes and estimates of calving fluxes. Pol. Polar Res., 30, 85-142.

Bliss, A., R. Hock, and J. G. Cogley, 2013: A new inventory of mountain glaciers and ice caps for the Antarctic periphery. Ann. Glaciol., 54, 191-199.

Bodin, X., F. Rojas, and A. Brenning, 2010: Status and evolution of the cryosphere in the Andes of Santiago (Chile, 33.5 degrees S.). Geomorphology, 118, 453-464.

Bodin, X., et al., 2009: Two Decades of Responses (1986-2006) to Climate by the Laurichard Rock Glacier, French Alps. Permafr. Periglac. Process., 20, 331-344.

Boening, C., M. Lebsock, F. Landerer, and G. Stephens, 2012: Snowfall-driven mass change on the East Antarctic ice sheet. Geophys. Res. Lett., 39, L21501.

Boening, C. W., A. Dispert, M. Visbeck, S. R. Rintoul, and F. U. Schwarzkopf, 2008: The response of the Antarctic Circumpolar Current to recent climate change. Nature Geosci., 1, 864-869.

Bolch, T., B. Menounos, and R. Wheate, 2010: Landsat-based inventory of glaciers in western Canada, 1985-2005. Remote Sens. Environ., 114, 127-137.

Bolch, T., L. Sandberg Sørensen, S. B. Simonsen, N. Moelg, H. Machguth, P. Rastner, and F. Paul, 2013: Mass loss of Greenland's glaciers and ice caps 2003-2008 revealed from ICESat data. Geophys. Res. Lett., 40, 875-881.

Bolch, T., et al., 2012: The state and fate of Himalayan glaciers. Science, 336, 310 314.

Bown, F., A. Rivera, and C. Acuna, 2008: Recent glacier variations at the Aconcagua basin, central Chilean Andes. Ann. Glaciol., 48, 43-48.

Box, J. E., L. Yang, D. H. Bromwich, and L. S. Bai, 2009: Greenland ice sheet surface air temperature variability: 1840-2007. J. Clim., 22, 4029-4049.

Box, J. E., X. Fettweis, J. C. Stroeve, M. Tedesco, D. K. Hall, and K. Steffen, 2012: Greenland ice sheet albedo feedback: Thermodynamics and atmospheric drivers. Cryosphere, 6, 821-839.

Brewer, M. C., 1958: Some results of geothermal investigations of permafrost. Am. Geophys. Union Trans. 39, 19-26.

Bromwich, D. H., J. P. Nicolas, and A. J. Monaghan, 2011: An assessment of precipitation changes over Antarctica and the Southern Ocean since 1989 in contemporary global reanalyses. J. Clim., 24, 4189-4209.

Bromwich, D. H., J. P. Nicolas, A. J. Monaghan, M. A. Lazzara, L. M. Keller, G. A. Weidner, and A. B. Wilson, 2013: Central West Antarctica among the most rapidly warming regions on Earth. Nature Geosci, 6, 139-145.

Brooks, R. N., T. D. Prowse, and I. J. O'Connell, 2012: Quantifying Northern Hemisphere freshwater ice. Geophys. Res. Lett., 40, 1128-1131.

Brown, R., C. Derksen, and L. B. Wang, 2010: A multi-data set analysis of variability and change in Arctic spring snow cover extent, 1967-2008. J. Geophys. Res. Atmos., 115, D16111.

Brown, R. D., and P. Coté, 1992: Interannual variability of landfast ice thickness in the Canadian High Arctic, 1950-89. Arctic, 45, 273-284.

Brown, R. D., and P. W. Mote, 2009: The response of Northern Hemisphere snow cover to a changing climate. J. Clim., 22, 2124-2145.

Brown, R. D., and D. A. Robinson, 2011: Northern Hemisphere spring snow cover variability and change over 1922-2010 including an assessment of uncertainty. Cryosphere, 5, 219-229.

Brunt, K. M., E. A. Okal, and D. R. MacAyeal, 2011: Antarctic ice-shelf calving triggered by the Honshu (Japan) earthquake and tsunami, March 2011. J. Glaciol., 57, 785-788.

Buchardt, S. L., H. B. Clausen, B. M. Vinther, and D. Dahl-Jensen, 2012: Investigating the past and recent delta180-accumulation relationship seen in Greenland ice cores. Clim. Past, 8, 2053-2059. 
Bulygina, O. N., V. N. Razuvaev, and N. N. Korshunova, 2009: Changes in snow cover over Northern Eurasia in the last few decades. Environ. Res. Lett., 4, 045026.

Bulygina, O. N., P. Y. Groisman, V. N. Razuvaev, and N. N. Korshunova, 2011: Changes in snow cover characteristics over Northern Eurasia since 1966. Environ. Res. Lett., 6, 045204.

Burn, C. R., and S. V. Kokelj, 2009: The environment and permafrost of the Mackenzie Delta Area. Permafr. Periglac. Process., 20, 83-105.

Burn, C. R., and Y. Zhang, 2009: Permafrost and climate change at Herschel Island (Qikiqtaruq), Yukon Territory, Canada. J. Geophys. Res., 114, F02001.

Callaghan, T. V., F. Bergholm, T. R. Christensen, C. Jonasson, U. Kokfelt, and M. Johansson, 2010: A new climate era in the sub-Arctic: Accelerating climate changes and multiple impacts. Geophys. Res. Lett., 37, L14705.

Callaghan, T. V., M. Johansson, O. Anisimov, H. H. Christiansen, A. Instanes, V. Romanovsky, and S. Smith, 2011: Changing permafrost and its impacts. In: Snow, Water, Ice and Permafrost in the Arctic (SWIPA). Arctic Monitoring and Assessment Program (AMAP).

Carrivick, J. L., B. J. Davies, N. F. Glasser, D. Nyvlt, and M. J. Hambrey, 2012: LateHolocene changes in character and behaviour of land-terminating glaciers on James Ross Island, Antarctica. J. Glaciol., 58, 1176-1190.

Carturan, L., and R. Seppi, 2007: Recent mass balance results and morphological evolution of Careser glacier (Central Alps). Geograf. Fis. Dinam. Quat., 30, 33-42.

Cavalieri, D. J., and C. L. Parkinson, 2012: Arctic sea ice variability and trends, 19792010. Cryosphere, 6, 957-979.

Cavalieri, D. J., P. Gloersen, and W. J. Campbell, 1984: Determination of sea ice parameters with the Nimbus-7 SMMR. J. Geophys. Res. Atmos., 89, 5355-5369.

Cazenave, A., et al., 2009: Sea level budget over 2003-2008: A reevaluation from GRACE space gravimetry, satellite altimetry and Argo. Global Planet. Change, $65,83-88$.

Chapman, W. L., and J. E. Walsh, 2007: A synthesis of Antarctic temperatures. J. Clim., 20, 4096-4117.

Charrassin, J. B., et al., 2008: Southern Ocean frontal structure and sea-ice formation rates revealed by elephant seals. Proc. Natl. Acad. Sci. U.S.A., 105, 11634-11639.

Chen, J. L., C. R. Wilson, and B. D. Tapley, 2006: Satellite gravity measurements confirm accelerated melting of Greenland ice sheet. Science, 313, 1958-1960.

Chen, J. L., C. R. Wilson, and B. D. Tapley, 2011: Interannual variability of Greenland ice losses from satellite gravimetry. J. Geophys. Res. Sol. Ea., 116, 11 ( B07406).

Chen, J. L., C. R. Wilson, D. Blankenship, and B. D. Tapley, 2009: Accelerated Antarctic ice loss from satellite gravity measurements. Nature Geosci., 2, 859-862.

Chen, J. L., C. R. Wilson, B. D. Tapley, D. D. Blankenship, and E. R. Ivins, 2007: Patagonia icefield melting observed by gravity recovery and climate experiment (GRACE). Geophys. Res. Lett., 34, 6 (L22501).

Cheng, G. D., and T. H. Wu, 2007: Responses of permafrost to climate change and their environmental significance, Qinghai-Tibet Plateau. J. Geophys. Res., 112, F02S03.

Chinn, T., S. Winkler, M. J. Salinger, and N. Haakensen, 2005: Srecent glacier advances in Norway and New Zealand: A comparison of their glaciological and meteorological causes. Geograf. Annal. A, 87A, 141-157.

Choi, G., D. A. Robinson, and S. Kang, 2010: Changing Northern Hemisphere snow seasons. J. Clim., 23, 5305-5310.

Christiansen, H. H., M. Guglielmin, J. Noetzli, V. Romanovsky, N. Shiklomanov, S. Smith, and L. Zhao, 2012: Cryopsphere, Permafrost thermal state. Special Suppl. to Bull. Am. Meteorol. Soc., 93 ( July) [J. Blunden and D. S. Arndt (eds.)], S19-S21.

Christiansen, H. H., et al., 2010: The thermal state of permafrost in the Nordic area during the International Polar Year 2007-2009. Permafr. Periglac. Process., 21, 156-181.

Christoffersen, P., et al., 2011: Warming of waters in an East Greenland fjord prior to glacier retreat: Mechanisms and connection to large-scale atmospheric conditions. Cryosphere, 5, 701-714.

Christy, J. R., 2012: Searching for information in 133 years of California snowfall observations. J. Hydrometeorol., 13, 895-912.

Citterio, M., F. Paul, A. P. Ahlstrom, H. F. Jepsen, and A. Weidick, 2009: Remote sensing of glacier change in West Greenland: accounting for the occurrence of surgetype glaciers. Ann. Glaciol., 50, 70-80.

Citterio, M., G. Diolaiuti, C. Smiraglia, C. D'Agata, T. Carnielli, G. Stella, and G. B. Siletto, 2007: The fluctuations of Italian glaciers during the last century: A contribution to knowledge about Alpine glacier changes. Geograf. Annal. A, 89A, 167-184.

Cogley, J. G., 2009a: A more complete version of the World Glacier Inventory. Ann. Glaciol., 50, 32-38.
Cogley, J. G., 2009b: Geodetic and direct mass-balance measurements: comparison and joint analysis. Ann. Glaciol., 50, 96-100.

Cogley, J. G., 2012: Area of the ocean. Mar. Geodesy, 35, 379-388.

Cogley, J. G., et al., 2011: Glossary of Glacier Mass Balance and Related Terms. IHP-VII Technical Documents in Hydrology No. 86, International Association of Cryospheric Sciences, Contribution No. 2, UNESCO-IHP. 114 pp.

Comiso, J. C., 2002: A rapidly declining perennial sea ice cover in the Arctic. Geophys. Res. Lett., 29, 1956.

Comiso, J. C., 2010: Polar Oceans from Space. Springer Science+Business Media, New York, NY, USA and Heidelberg, Germany.

Comiso, J. C., 2012: Large decadal decline in the Arctic multiyear ice cover. J. Clim., 25, 1176-1193.

Comiso, J. C., and F. Nishio, 2008: Trends in the sea ice cover using enhanced and compatible AMSR-E, SSM/I, and SMMR data. J. Geophys. Res. Oceans, 113, $\mathrm{CO2S07.}$

Comiso, J. C., C. L. Parkinson, R. Gersten, and L. Stock, 2008: Accelerated decline in the Arctic Sea ice cover. Geophys. Res. Lett., 35, L01703.

Comiso, J. C., R. Kwok, S. Martin, and A. L. Gordon, 2011: Variability and trends in sea ice extent and ice production in the Ross Sea. J. Geophys. Res. Oceans, 116, C04021.

Cook, A. J., and D. G. Vaughan, 2010: Overview of areal changes of the ice shelves on the Antarctic Peninsula over the past 50 years. Cryosphere, 4, 77-98.

Costa, D. P., J. M. Klinck, E. E. Hofmann, M. S. Dinniman, and J. M. Burns, 2008: Upper ocean variability in west Antarctic Peninsula continental shelf waters as measured using instrumented seals. Deep-Sea Res. Pt. Ii, 55, 323-337.

Coudrain, A., B. Francou, and Z. W. Kundzewicz, 2005: Glacier shrinkage in the Andes and consequences for water resources. Hydrol. Sci. J. -J. Sci. Hydrol., 50, 925-932.

Cullen, N. J., P. Sirguey, T. Moelg, G. Kaser, M. Winkler, and S. J. Fitzsimons, 2013: A century of ice retreat on Kilimanjaro: The mapping reloaded. Cryosphere, 7, 419-431.

Daniault, N., H. Mercier, and P. Lherminier, 2011: The 1992-2009 transport variability of the East Greenland-Irminger Current at 60 degrees N. Geophys. Res. Lett., 38, 4 (L07601).

Das, S. B., I. Joughin, M. D. Behn, I. M. Howat, M. A. King, D. Lizarralde, and M. P. Bhatia, 2008: Fracture propagation to the base of the Greenland Ice Sheet during supraglacial lake drainage. Science, 320, 778-781.

Davies, B. J., and N. F. Glasser, 2012: Accelerating shrinkage of Patagonian glaciers from the "Little Ice Age" (c. AD 1870) to 2011. J. Glaciol., 58, 1063-1084.

De Angelis, H., and P. Skvarca, 2003: Glacier surge after ice shelf collapse. Science, $299,1560-1562$.

Delaloye, R., et al., cited 2011: Recent interannual variations of rock glacier creep in the European Alps. [Available online at http://www.zora.uzh.ch/7031/.]

DeLiberty, T. L., C. A. Geiger, S. F. Ackley, A. P. Worby, and M. L. Van Woert, 2011: Estimating the annual cycle of sea-ice thickness and volume in the Ross Sea. Deep-Sea Res. Pt. li, 58, 1250-1260.

Derksen, C., and R. Brown, 2012: Spring snow cover extent reductions in the 2008-2012 period exceeding climate model projections. Geophys. Res. Lett., 39, L19504.

Derksen, C., et al., 2012: Variability and change in the Canadian cryosphere. Clim. Change, 115, 59-88.

Déry, S. J., and R. D. Brown, 2007: Recent Northern Hemisphere snow cover extent trends and implications for the snow-albedo feedback. Geophys. Res. Lett., 34, 6 (L22504).

Ding, Q. H., E. J. Steig, D. S. Battisti, and M. Kuttel, 2011: Winter warming in West Antarctica caused by central tropical Pacific warming. Nature Geosci., 4, 398403.

Dinniman, M. S., J. M. Klinck, and E. E. Hofmann, 2012: Sensitivity of circumpolar deep water transport and ice shelf basal melt along the West Antarctic Peninsula to changes in the winds. J. Clim., 25, 4799-4816.

Diolaiuti, G., D. Bocchiola, C. D'Agata, and C. Smiraglia, 2012: Evidence of climate change impact upon glaciers' recession within the Italian Alps-The case of Lombardy glaciers. Theor. Appl. Climatol., 109, 429-445.

Dmitrenko, I. A., et al., 2011: Recent changes in shelf hydrography in the Siberian Arctic: Potential for subsea permafrost instability. J. Geophys. Res. Oceans, 116, 10 (C10027).

Doake, C. S. M., and D. G. Vaughan, 1991: Rapid disintegration of the wordie ice shelf in response to atmospheric warming. Nature, 350, 328-330. 
Doake, C. S. M., H. F. J. Corr, H. Rott, P. Skvarca, and N. W. Young, 1998: Breakup and conditions for stability of the northern Larsen Ice Shelf, Antarctica. Nature, 391, 778-780.

Doherty, S. J., S. G. Warren, T. C. Grenfell, A. D. Clarke, and R. E. Brandt, 2010: Lightabsorbing impurities in Arctic snow. Atmos. Chem. Phys., 10, 11647-11680.

Drobot, S. D., and M. R. Anderson, 2001: An improved method for determining snowmelt onset dates over Arctic sea ice using scanning multichannel microwave radiometer and Special Sensor Microwave/Imager data. J. Geophys. Res. Atmos., 106, 24033-24049.

Drozdov, D. S., N. G. Ukraintseva, A. M. Tsarev, and S. N. Chekrygina, 2010: Changes in the temperature field and in the state of the geosystems within the territory of the Urengoy field during the last 35 years (1974-2008). Earth Cryosphere, 14, 22-31.

Druckenmiller, M. L., H. Eicken, M. A. Johnson, D. J. Pringle, and C. C. Williams, 2009: Toward an integrated coastal sea-ice observatory: System components and a case study at Barrow, Alaska. Cold Reg. Sci. Technol., 56, 61-72.

Drucker, R., S. Martin, and R. Kwok, 2011: Sea ice production and export from coastal polynyas in the Weddell and Ross Seas. Geophys. Res. Lett., 38, 4 (L17502).

Ducklow, H., et al., 2011: The marine system of the Western Antarctic Peninsula In: Antarctica: An Extreme Environment in a Changing World [A. D. Rogers (ed.)]. New York, NY, USA, John Wiley \& Sons. 121-159.

E, D.-C., Y.-D. Yang, and D.-B. Chao, 2009: The sea level change from the Antarctic ice sheet based on GRACE. Chin. J. Geophys.-Chin. Ed., 52, 2222-2228.

Ettema, J., M. R. van den Broeke, E. van Meijgaard, W. J. van de Berg, J. L. Bamber, J. E. Box, and R. C. Bales, 2009: Higher surface mass balance of the Greenland ice sheet revealed by high-resolution climate modeling. Geophys. Res. Lett., 36, L12501.

Ewert, H., A. Groh, and R. Dietrich, 2012:Volume and mass changes of the Greenland ice sheet inferred from ICESat and GRACE. J. Geodyn., 59, 111-123.

Fedorov, A. N., and P. Y. Konstantinov, 2008: Recent changes in ground temperature and the effect on permafrost landscapes in Central Yakutia. In: Proceeding of the 9th International Conference on Permafrost, 29 June-3 July 2008, Institute of Northern Engineering, University of Alaska, Fairbanks [D. L. Kane, and K. M. Hinkel (eds.)], pp. 433-438.

Fernandes, R., H. X. Zhao, X. J. Wang, J. Key, X. Qu, and A. Hall, 2009: Controls on Northern Hemisphere snow albedo feedback quantified using satellite Earth observations. Geophys. Res. Lett., 36, L21702.

Fettweis, X., M. Tedesco, M. R. van den Broeke, and J. Ettema, 2011: Melting trends over the Greenland ice sheet (1958-2009) from spaceborne microwave data and regional climate models. Cryosphere, 5, 359-375.

Flament, T., and F. Remy, 2012: Dynamic thinning of Antarctic glaciers from alongtrack repeat radar altimetry. J. Glaciol., 58, 830-840.

Flanner, M. G., C. S. Zender, J. T. Randerson, and P. J. Rasch, 2007: Present-day climate forcing and response from black carbon in snow. J. Geophys. Res., 112, D11202.

Flanner, M. G., K. M. Shell, M. Barlage, D. K. Perovich, and M. A. Tschudi, 2011: Radiative forcing and albedo feedback from the Northern Hemisphere cryosphere between 1979 and 2008. Nature Geosci., 4, 151-155.

Fleming, K., and K. Lambeck, 2004: Constraints on the Greenland Ice Sheet since the Last Glacial Maximum from sea-level observations and glacial-rebound models. Quat. Sci. Rev., 23, 1053-1077.

Foster, J. L., D. K. Hall, R. E. J. Kelly, and L. Chiu, 2009: Seasonal snow extent and snow mass in South America using SMMR and SSM/I passive microwave data (1979-2006). Remote Sens. Environ., 113, 291-305.

Fraser, A. D., R. A. Massom, K. J. Michael, B. K. Galton-Fenzi, and J. L. Lieser, 2012: East Antarctic landfast sea ice distribution and variability, 2000-2008. J. Clim., 25, 1137-1156.

Frauenfeld, O. W., and T. J. Zhang, 2011: An observational 71-year history of seasonally frozen ground changes in the Eurasian high latitudes. Environ. Res. Lett., 6, 044024.

Frauenfeld, O. W., T. J. Zhang, R. G. Barry, and D. Gilichinsky, 2004: Interdecadal changes in seasonal freeze and thaw depths in Russia. J. Geophys. Res., 109, D05101.

Fretwell, P. T., et al., 2013: Bedmap2: improved ice bed, surface and thickness datasets for Antarctica. Cryosphere, 7, 375-393.

Frezzotti, M., C. Scarchilli, S. Becagli, M. Proposito, and S. Urbini, 2012: A synthesis of the Antarctic Surface Mass Balance during the last eight centuries. Cryosphere, 7, 303-319.
Fricker, H. A., and L. Padman, 2012: Thirty years of elevation change on Antarctic Peninsula ice shelves from multimission satellite radar altimetry. J. Geophys. Res. Oceans, 117, C02026.

Fyodorov-Davydov, D. G., A. L. Kholodov, V. E. Ostroumov, G. N. Kraev, V.A. Sorokovikov, S. P. Davudov, and A. A. Merekalova, 2008: Seasonal thaw of soils in the North Yakutian ecosystems. In: Proceedings of the 9th International Conference on Permafrost, 29 June- 3 July 2008, Institute of Northern Engineering, University of Alaska, Fairbanks [D. L. Kane, and K. M. Hinkel (eds.)], pp. 481-486.

Galton-Fenzi, B. K., J. R. Hunter, R. Coleman, and N. Young, 2012: A decade of change in the hydraulic connection between an Antarctic epishelf lake and the ocean. J. Glaciol., 58, 223-228.

Gardelle, J., E. Berthier, and Y. Arnaud, 2012: Slight mass gain of Karakoram glaciers in the early twenty-first century. Nature Geosci., 5, 322-325.

Gardner, A., G. Moholdt, A. Arendt, and B. Wouters, 2012: Accelerated contributions of Canada's Baffin and Bylot Island glaciers to sea level rise over the past half century. Cryosphere, 6, 1103-1125.

Gardner, A. S., et al., 2011: Sharply increased mass loss from glaciers and ice caps in the Canadian Arctic Archipelago. Nature, 473, 357-360.

Gardner, A. S., et al., 2013: A reconciled estimate of glacier contributions to sea level rise: 2003 to 2009. Science, 340, 852-857.

Gerland, S., A. H. H. Renner, F. Godtliebsen, D. Divine, and T. B. Loyning, 2008: Decrease of sea ice thickness at Hopen, Barents Sea, during 1966-2007. Geophys. Res. Lett., 35, L06501.

Gilbert, A., P. Wagnon, C. Vincent, P. Ginot, and M. Funk, 2010: Atmospheric warming at a high-elevation tropical site revealed by englacial temperatures at Illimani, Bolivia (6340 m above sea level, 16 degrees S, 67 degrees W). J. Geophys. Res., 115, D10109.

Giles, A. B., R. A. Massom, and V. I. Lytle, 2008a: Fast-ice distribution in East Antarctica during 1997 and 1999 determined using RADARSAT data. J. Geophys. Res. Oceans, 113, 15 (C02S14).

Giles, K. A., S. W. Laxon, and A. L. Ridout, 2008b: Circumpolar thinning of Arctic sea ice following the 2007 record ice extent minimum. Geophys. Res. Lett., 35 L22502.

Gille, S. T., 2002: Warming of the Southern Ocean since the 1950s. Science, 295, $1275-1277$.

Gille, S. T., 2008: Decadal-scale temperature trends in the Southern Hemisphere Ocean. J. Clim., 21, 4749-4765.

Glazovsky, A., and Y. Macheret, 2006: Eurasian Arctic. In: Glaciation in North and Central Eurasia in Present Time. [V. M. Kotlyakov (ed.)]. Nauka, Saint Petersburg, Russian Federation, pp. 438-445.

Gordon, A. L., M. Visbeck, and J. C. Comiso, 2007: A possible link between the Weddell Polynya and the Southern Annular Mode. J. Clim., 20, 2558-2571.

Grebmeier, J. M., S. E. Moore, J. E. Overland, K. E. Frey, and R. Gradinger, 2010: Biological response to recent Pacific Arctic sea ice retreats. EOS Trans. Am. Geophys. Union, 91, 161-163.

Green, K., 2011: Interannual and seasonal changes in the ice cover of glacial lakes in the Snowy Mountains of Australia. J. Mount. Sci., 8, 655-663.

Gregory, J. M., and J. Oerlemans, 1998: Simulated future sea-level rise due to glacier melt based on regionally and seasonally resolved temperature changes. Nature, 391, 474-476.

Griggs, J., and J. L. Bamber, 2011: Antarctic ice-shelf thickness from satellite radar altimetry. J. Glaciol., 57, 485-498.

Grinsted, A., 2013: An estimate of global glacier volume. Cryosphere, 7, 141-151.

Gruber, S., 2012: Derivation and analysis of a high-resolution estimate of globalpermafrost zonation. Cryosphere, 6, 221-233.

Gruber, S., and W. Haeberli, 2007: Permafrost in steep bedrock slopes and its temperature-related destabilization following climate change. J. Geophys. Res., 112, 10 (F02S18).

Guglielmin, M., and N. Cannone, 2012: A permafrost warming in a cooling Antarctica? Clim. Change, 111, 177-195.

Guglielmin, M., M. R. Balks, L. S. Adlam, and F. Baio, 2011: Permafrost thermal regime from two 30-m deep boreholes in Southern Victoria Land, Antarctica. Permafr. Periglac. Process., 22, 129-139.

Gunter, B., et al., 2009: A comparison of coincident GRACE and ICESat data over Antarctica. J. Geodesy, 83, 1051-1060.

Gusmeroli, A., P. Jansson, R. Pettersson, and T. Murray, 2012: Twenty years of cold surface layer thinning at Storglaciären, sub-Arctic Sweden, 1989-2009. J. Glaciol., 58, 3-10. 
Haas, C., S. Hendricks, H. Eicken, and A. Herber, 2010: Synoptic airborne thickness surveys reveal state of Arctic sea ice cover. Geophys. Res. Lett., 37, L09501.

Haas, C., H. Le Goff, S. Audrain, D. Perovich, and J. Haapala, 2011: Comparison of seasonal sea-ice thickness change in the Transpolar Drift observed by local ice mass-balance observations and floe-scale EM surveys. Ann. Glaciol., 52, 97-102.

Haas, C., A. Pfaffling, S. Hendricks, L. Rabenstein, J. L. Etienne, and I. Rigor, 2008 Reduced ice thickness in Arctic Transpolar Drift favors rapid ice retreat. Geophys. Res. Lett., 35, L17501.

Haeberli, W., M. Hoelzle, F. Paul, and M. Zemp, 2007: Integrated monitoring of mountain glaciers as key indicators of global climate change: the European Alps. Ann. Glaciol., 46, 150-160.

Haeberli, W., et al., 2006: Permafrost creep and rock glacier dynamics. Permafr. Periglac. Process., 17, 189-214.

Haeberli, W., et al., 2010: Mountain permafrost: development and challenges of a young research field. J. Glaciol., 56, 1043-1058.

Hagg, W., C. Mayer, A. Lambrecht, D. Kriegel, and E. Azizov, 2012: Glacier changes in the Big Naryn basin, Central Tian Shan. Global Planet. Change, doi:10.1016/j. gloplacha.2012.07.010.

Hall, D. K., J. C. Comiso, N. E. DiGirolamo, C. A. Shuman, J. E. Box, and L. S. Koenig, 2013: Variability in the surface temperature and melt extent of the Greenland Ice Sheet from MODIS. Geophys. Res. Lett., 10, 2114-2120.

Halsey, L. A., D. H. Vitt, and S. C. Zoltai, 1995: Disequilibrium response of permafrost in boreal continental western Canada to climate-change. Clim. Change, 30, 57-73.

Hanna, E., et al., 2011: Greenland Ice Sheet surface mass balance 1870 to 2010 based on Twentieth Century Reanalysis, and links with global climate forcing. J. Geophys. Res., 116, D24121.

Harig, C., and F. J. Simons, 2012: Mapping Greenland's mass loss in space and time. Proc. Natl. Acad. Sci. U.S.A., 109, 19934-19937.

Heid, T., and A. Kääb, 2012: Repeat optical satellite images reveal widespread and long term decrease in land-terminating glacier speeds. Cryosphere , 6, 467-478

Hirabayashi, Y., S. Kanae, K. Masuda, K. Motoya, and P. Doell, 2008: A 59-year (19482006) global near-surface meteorological data set for land surface models. Part I: Development of daily forcing and assessment of precipitation intensity. Hydrol. Res. Lett., 2, 36-40.

Hirabayashi, Y., Y. Zhang, S. Watanabe, S. Koirala, and S. Kanae, 2013: Projection of glacier mass changes under a high-emission climate scenario using the global glacier model HYOGA2. Hydrol. Res. Lett., 7, 6-11.

Hock, R., M. de Woul, V. Radic, and M. Dyurgerov, 2009: Mountain glaciers and ice caps around Antarctica make a large sea-level rise contribution. Geophys. Res. Lett., 36, L07501.

Hodgkins, A. G., I. C. James, and T. G. Huntington, 2002: Historical changes in lake ice-out dates as indicators of climate change in New England, 1850-2000. Int. J. Clim., 22, 1819-1827.

Hoelzle, M., G. Darms, M. P. Lüthi, and S. Suter, 2011: Evidence of accelerated englacial warming in the Monte Rosa area, Switzerland/Italy. Cryosphere, 5, 231-243.

Hoffman, M. J., G. A. Catania, T. A. Neumann, L. C. Andrews, and J. A. Rumrill, 2011: Links between acceleration, melting, and supraglacial lake drainage of the western Greenland Ice Sheet. J. Geophys. Res. Earth Surf., 116, F04035.

Holland, D. M., and A. Jenkins, 1999: Modeling thermodynamic ice-ocean interactions at the base of an ice shelf. J. Phys. Oceanogr., 29, 1787-1800.

Holland, D. M., R. H. Thomas, B. De Young, M. H. Ribergaard, and B. Lyberth, 2008: Acceleration of Jakobshavn Isbrae triggered by warm subsurface ocean waters. Nature Geosci., 1, 659-664.

Holland, P. R., and R. Kwok, 2012: Wind-driven trends in Antarctic sea ice motion. Nature Geosci., 5, 872-875.

Holland, P. R., A. Jenkins, and D. M. Holland, 2010: Ice and ocean processes in the Bellingshausen Sea, Antarctica. J. Geophys. Res. Oceans, 115, C05020.

Holland, P. R., H. F. J. Corr, H. D. Pritchard, D. G. Vaughan, R. J. Arthern, A. Jenkins, and M. Tedesco, 2011: The air content of Larsen Ice Shelf. Geophys. Res. Lett., 38, L10503.

Holzhauser, H., M. Magny, and H. J. Zumbuhl, 2005: Glacier and lake-level variations in west-central Europe over the last 3500 years. Holocene, 15, 789-801.

Horwath, M., and R. Dietrich, 2009: Signal and error in mass change inferences from GRACE: The case of Antarctica. Geophys. J. Int., 177, 849-864.

Howat, I. M., I. Joughin, and T. A. Scambos, 2007: Rapid changes in ice discharge from Greenland outlet glaciers. Science, 315, 1559-1561.
Howat, I. M., I. Joughin, M. Fahnestock, B. E. Smith, and T. A. Scambos, 2008: Synchronous retreat and acceleration of southeast Greenland outlet glaciers 2000-06: Ice dynamics and coupling to climate. J. Glaciol., 54, 646-660.

Howat, I. M., Y. Ahn, I. Joughin, M. R. van den Broeke, J. T. M. Lenaerts, and B. Smith, 2011: Mass balance of Greenland's three largest outlet glaciers, 2000-2010. Geophys. Res. Lett., 38, 5 (L12501).

Hudson, S. R., 2011: Estimating the global radiative impact of the sea ice-albedo feedback in the Arctic. J. Geophys. Res. Atmos., 116, D16102.

Hughes, T. J., 1973: Is the West Antarctic ice sheet disintegrating? J. Geophys. Res. 78, 7884-7910.

Hulbe, C. L., T. A. Scambos, T. Youngberg, and A. K. Lamb, 2008: Patterns of glacier response to disintegration of the Larsen B ice shelf, Antarctic Peninsula. Global Planet. Change, 63, 1-8.

Humbert, A., et al., 2010: Deformation and failure of the ice bridge on the Wilkins Ice Shelf, Antarctica. Ann. Glaciol., 51, 49-55.

Hurrell, J. W., 1995: Decadal trends in the North-Atlantic oscillation-regiona temperatures and precipitation. Science, 269, 676-679.

Huss, M., 2012: Extrapolating glacier mass balance to the mountain-range scale: The European Alps 1900-2100. Cryosphere, 6, 713-727.

Huss, M., and D. Farinotti, 2012: Distributed ice thickness and volume of 180,000 glaciers around the globe. J. Geophys. Res., 117, F04010.

Isaksen, K., et al., 2011: Degrading mountain permafrost in southern Norway: Spatial and temporal variability of mean ground temperatures, 1999-2009. Permafr. Periglac. Process., 22, 361-377.

Ishikawa, M., N. Sharkhuu, Y. Jambaljav, G. Davaa, K. Yoshikawa, and T. Ohata, 2012: Thermal state of Mongolian permafrost. In: Proceedings of the 10th International Conference on Permafrost, June, 2012, Salekhard, Yamel-nenets Autonomous District, Russian Federation, v1.[K. M. Hinkel (ed)]. The Northern Publisher, Salekhard, Russia, pp. 173-178.

Ishizaka, M., 2004: Climatic response of snow depth to recent warmer winter seasons in heavy-snowfall areas in Japan. Ann. Glaciol., 38, 299-304.

Ivins, E. R., and T. S. James, 2005: Antarctic glacial isostatic adjustment: A new assessment. Antarct. Sci, 17, 541-553.

Ivins, E. R., M. M. Watkins, D. N. Yuan, R. Dietrich, G. Casassa, and A. Rulke, 2011: On-land ice loss and glacial isostatic adjustment at the Drake Passage: 20032009. J. Geophys. Res. Sol. Ea., 116, 24 (B02403).

Jacob, T., J. Wahr, W. T. Pfeffer, and S. Swenson, 2012: Recent contributions of glaciers and ice caps to sea level rise. Nature, 482, 514-518.

Jacobs, S. S., A. Jenkins, C. F. Giulivi, and P. Dutrieux, 2011: Stronger ocean circulation and increased melting under Pine Island Glacier ice shelf. Nature Geosci., 4, 519-523.

Jacobs, S. S., H. H. Helmer, C. S. M. Doake, A. Jenkins, and R. M. Frolich, 1992: Melting of the ice shelves and the mass balance of Antarctica. J. Glaciol., 38, 375-387.

Jenkins, A., 2011: Convection-driven melting near the grounding lines of ice shelves and tidewater glaciers. J. Clim., 41, 2279-2294.

Jenkins, A., and C. S. M. Doake, 1991: Ice-Ocean interaction on Ronne ice shelf, Antarctica J. Geophys. Res. Oceans, 96, 791-813.

Jenkins, A., and S. Jacobs, 2008: Circulation and melting beneath George VI Ice Shelf, Antarctica. J. Geophys. Res. Oceans, 113, C04013.

Jenkins, A., P. Dutrieux, S. S. Jacobs, S. D. McPhail, J. R. Perrett, A. T. Webb, and D. White, 2010: Observations beneath Pine Island Glacier in West Antarctica and implications for its retreat. Nature Geosci, 3, 468-472.

Jensen, O. P., B. J. Benson, J. J. Magnuson, V. M. Card, M. N. Futter, P. A. Soranno, and K. M. Stewart, 2007: Spatial analysis of ice phenology trends across the Laurentian Great Lakes Region during a recent warming period. Limnol. Oceanogr., 52, 2013-2026.

Jia, L. L., H. S. Wang, and L. W. Xiang, 2011: Effect of glacio-static adjustment on the estimate of ice mass balance over Antarctic and uncertainties. Chin. J. Geophys., 54, 1466-1477.

Johannessen, O. M., E. V. Shalina, and M. W. Miles, 1999: Satellite evidence for an Arctic sea ice cover in transformation. Science, 286, 1937-1939.

Johnson, J. S., M. J. Bentley, and K. Gohl, 2008: First exposure ages from the Amundsen Sea embayment, West Antarctica: The late quaternary context for recent thinning of Pine Island, Smith, and Pope Glaciers. Geology, 36, 223-226.

Jones, B. M., C. D. Arp, M. T. Jorgenson, K. M. Hinkel, J. A. Schmutz, and P. L. Flint, 2009: Increase in the rate and uniformity of coastline erosion in Arctic Alaska. Geophys. Res. Lett., 36, 5 (L03503). 
Jones, P. D., D. H. Lister, T. J. Osborn, C. Harpham, M. Salmon, and C. P. Morice, 2012: Hemispheric and large-scale land-surface air temperature variations: An extensive revision and an update to 2010. J. Geophys. Res. Atmos., 117, D05127.

Jorgenson, M. T., Y. L. Shur, and E. R. Pullman, 2006: Abrupt increase in permafrost degradation in Arctic Alaska. Geophys. Res. Lett., 33, 4 (L02503).

Joughin, I., and R. B. Alley, 2011: Stability of the West Antarctic ice sheet in a warming world. Nature Geosci., 4, 506-513.

Joughin, I., W. Abdalati, and M. Fahnestock, 2004: Large fluctuations in speed on Greenland's Jakobshavn Isbrae glacier. Nature, 432, 608-610.

Joughin, I., B. E. Smith, and D. M. Holland, 2010a: Sensitivity of 21st century sea level to ocean-induced thinning of Pine Island Glacier, Antarctica. Geophys. Res. Lett., 37, L20502.

Joughin, I., R. B. Alley, and D. M. Holland, 2012: Ice-sheet response to oceanic forcing. Science, 338, 1172-1176.

Joughin, I., M. Fahnestock, R. Kwok, P. Gogineni, and C. Allen, 1999: Ice flow of Humboldt, Petermann and Ryder Gletscher, northern Greenland. J. Glaciol., 45, 231-241.

Joughin, I., B. E. Smith, I. M. Howat, T. Scambos, and T. Moon, 2010b: Greenland flow variability from ice-sheet-wide velocity mapping. J. Glaciol., 56, 415-430.

Joughin, I., S. B. Das, M. A. King, B. E. Smith, I. M. Howat, and T. Moon, 2008a: Seasonal speedup along the western flank of the Greenland ice sheet. Science, $320,781-783$.

Joughin, l., et al., 2008b: Ice-front variation and tidewater behavior on Helheim and Kangerdlugssuaq Glaciers, Greenland. J. Geophys. Res. Earth Surf., 113, F01004.

Kääb, A., R. Frauenfelder, and I. Roer, 2007: On the response of rockglacier creep to surface temperature increase. Global Planet. Change, 56, 172-187.

Kääb, A., W. Haeberli, and G. H. Gudmundsson, 1997: Analysing the creep of mountain permafrost using high precision aerial photogrammetry: 25 years of monitoring Gruben Rock Glacier, Swiss Alps. Permafr. Periglac. Process., 8, 409-426.

Kääb, A., E. Berthier, C. Nuth, J. Gardelle, and Y. Arnaud, 2012: Contrasting patterns of early twenty-first-century glacier mass change in the Himalayas. Nature, 488, 495-498.

Kargel, J. S., et al., 2012: Greenland's shrinking ice cover: "Fast times" but not that fast. Cryosphere, 6, 533-537.

Kaser, G., J. G. Cogley, M. B. Dyurgerov, M. F. Meier, and A. Ohmura, 2006: Mass balance of glaciers and ice caps: Consensus estimates for 1961-2004. Geophys. Res. Lett., 33, L19501.

Khan, S. A., J. Wahr, M. Bevis, I. Velicogna, and E. Kendrick, 2010a: Spread of ice mass loss into northwest Greenland observed by GRACE and GPS. Geophys. Res. Lett., 37, L06501.

Khan, S. A., L. Liu, J. Wahr, I. Howat, I. Joughin, T. van Dam, and K. Fleming, 2010b: GPS measurements of crustal uplift near Jakobshavn Isbrae due to glacial ice mass loss. J. Geophys. Res. Sol. Ea., 115, 13 (B09405).

King, M. A., R. J. Bingham, P. Moore, P. L. Whitehouse, M. J. Bentley, and G. A. Milne, 2012: Lower satellite-gravimetry estimates of Antarctic sea-level contribution. Nature, 491, 586-589.

King, M. A., et al., 2009: A 4-decade record of elevation change of the Amery Ice Shelf, East Antarctica. J. Geophys. Res. Earth Surf., 114, F01010.

Kinnard, C., C. M. Zdanowicz, D. A. Fisher, E. Isaksson, A. De Vernal, and L. G. Thompson, 2011: Reconstructed changes in Arctic sea ice over the past 1,450 years. Nature, 479, 509-U231.

Kjaer, K. H., et al., 2012: Aerial photographs reveal late-20th-century dynamic ice loss in northwestern Greenland. Science, 337, 569-573.

Klein, A. G., and J. L. Kincaid, 2006: Retreat of glaciers on Puncak Jaya, Irian Jaya, determined from 2000 and 2002 IKONOS satellite images. J. Glaciol., 52, 65-79.

Knoll, C., and H. Kerschner, 2009: A glacier inventory for South Tyrol, Italy, based on airborne laser-scanner data. Ann. Glaciol., 50, 46-52.

Koch, K., C. Knoblauch, and D. Wagner, 2009: Methanogenic community composition and anaerobic carbon turnover in submarine permafrost sediments of the Siberian Laptev Sea. Environ. Microbiol., 11, 657-668.

Kopp, R. E., F. J. Simons, J. X. Mitrovica, A. C. Maloof, and M. Oppenheimer, 2009: Probabilistic assessment of sea level during the last interglacial stage. Nature, 462, 863-867.

Kozlovsky, A. M., Y. L. Nazintsev, V. I. Fedotov, and N. V. Cherepanov, 1977: Fast ice of the Eastern Antarctic (in Russian). Proc. Soviet Antarct. Expedit., 63, 1-129.

Krabill, W., et al., 1999: Rapid thinning of parts of the southern Greenland ice sheet. Science, 283, 1522-1524.

Krabill, W., et al., 2000: Greenland ice sheet: High-elevation balance and peripheral thinning. Science, 289, 428-430.
Krabill, W. B., et al., 2002: Aircraft laser altimetry measurement of elevation changes of the Greenland ice sheet: Technique and accuracy assessment. J. Geodyn., 34, 357-376.

Kuipers Munneke, P., G. Picard, M. R. van den Broeke, J. T. M. Lenaerts, and E. Van Meijgaard, 2012: Insignificant change in Antarctic snowmelt volume since 1979. Geophys. Res. Lett., 39, (L01501).

Kunkel, K. E., M. A. Palecki, K. G. Hubbard, D. A. Robinson, K. T. Redmond, and D. R. Easterling, 2007: Trend identification in twentieth-century US snowfall: The challenges. J. Atmos. Ocean. Technol., 24, 64-73.

Kurtz, N. T., and T. Markus, 2012: Satellite observations of Antarctic sea ice thickness and volume. J. Geophys. Res. Oceans, 117, C08025

Kutuzov, S., and M. Shahgedanova, 2009: Glacier retreat and climatic variability in the eastern Terskey-Alatoo, inner Tien Shan between the middle of the 19th century and beginning of the 21st century. Global Planet. Change, 69, 59-70.

Kwok, R., 2004: Annual cycles of multiyear sea ice coverage of the Arctic Ocean: 1999-2003. J. Geophys. Res.-Oceans, 109, C11004.

Kwok, R., 2005: Variability of Nares Strait ice flux. Geophys. Res. Lett., 32, L24502.

Kwok, R., 2007: Near zero replenishment of the Arctic multiyear sea ice cover at the end of 2005 summer. Geophys. Res. Lett., 34, L05501.

Kwok, R., 2009: Outflow of Arctic Ocean Sea Ice into the Greenland and Barents Seas: 1979-2007. J. Clim., 22, 2438-2457.

Kwok, R., and D. A. Rothrock, 1999: Variability of Fram Strait ice flux and North Atlantic Oscillation. J. Geophys. Res. Oceans, 104, 5177-5189.

Kwok, R., and D. A. Rothrock, 2009: Decline in Arctic sea ice thickness from submarine and ICESat records: 1958-2008. Geophys. Res. Lett., 36, L15501.

Kwok, R., and G. F. Cunningham, 2010: Contribution of melt in the Beaufort Sea to the decline in Arctic multiyear sea ice coverage: 1993-2009. Geophys. Res. Lett., 37, L20501.

Kwok, R., G. F. Cunningham, M. Wensnahan, I. Rigor, H. J. Zwally, and D. Yi, 2009: Thinning and volume loss of the Arctic Ocean sea ice cover: 2003-2008. J. Geophys. Res. Oceans, 114, C07005.

Latifovic, R., and D. Pouliot, 2007: Analysis of climate change impacts on lake ice phenology in Canada using the historical satellite data record. Remote Sens. Environ., 106, 492-507.

Laxon, S., N. Peacock, and D. Smith, 2003: High interannual variability of sea ice thickness in the Arctic region. Nature, 425, 947-950.

Laxon, S. W., et al., 2013: CryoSat-2 estimates of Arctic sea ice thickness and volume. Geophys. Res. Lett., 40, 732-737.

Leclercq, P. W., and J. Oerlemans, 2012: Global and hemispheric temperature reconstruction from glacier length fluctuations. Clim. Dyn., 38, 1065-1079.

Leclercq, P. W., J. Oerlemans, and J. G. Cogley, 2011: Estimating the glacier contribution to sea-level rise for the period 1800-2005. Surv. Geophys., 32, 519-535.

Leclercq, P. W., A. Weidick, F. Paul, T. Bolch, M. Citterio, and Oerlemans.J, 2012: Brief communication-Historical glacier length changes in West Greenland. Cryosphere, 6, 1339-1343.

Lemke, P., et al., 2007: Observations: Changes in snow, ice and frozen ground. In: Climate Change 2007: The Physical Science Basis. Contribution of Working Group I to the Fourth Assessment Report of the Intergovernmental Panel on Climate Change [Solomon, S., D. Qin, M. Manning, Z. Chen, M. Marquis, K. B. Averyt, M. Tignor and H. L. Miller (eds.)] Cambridge University Press, Cambridge, United Kingdom and New York, NY, USA, pp. 337-383.

Lenaerts, J. T. M., M. R. van den Broeke, W. J. van de Berg, E. van Meijgaard, and P. Kuipers Munneke, 2012: A new, high resolution surface mass balance map of Antarctica (1979-2010) based on regional climate modeling. Geophys. Res. Lett., 39, 1-5 (L04501).

Levermann, A., T. Albrecht, R. Winkelmann, M. A. Martin, M. Haseloff, and I. Joughin, 2012: Kinematic first-order calving law implies potential for abrupt ice-shelf retreat. Cryosphere, 6, 273-286.

Lewkowicz, A. G., B. Etzelmuller, and S. L. Smith, 2011: Characteristics of discontinuous permafrost based on ground temperature measurements and electrical resistivity tomography, Southern Yukon, Canada. Permafr. Periglac. Process., 22, 320-342.

Li, J., and H. J. Zwally, 2011: Modeling of firn compaction for estimating ice-sheet mass change from observed ice-sheet elevation change. Ann. Glaciol., 52, 1-7.

Li, R., L. Zhao, and Y. Ding, 2009: The climatic characteristics of the maximum seasonal frozen depth in the Tibetan plateau. J. Glaciol. Geocryol., 31, 1050-1056.

Li, R., et al., 2012a: Temporal and spatial variations of the active layer along the Qinghai-Tibet Highway in a permafrost region. Chin. Sci. Bull., 57, 4609-4616. 
Li, X., R. Jin, X. D. Pan, T. J. Zhang, and J. W. Guo, 2012b: Changes in the near-surface soil freeze-thaw cycle on the Qinghai-Tibetan Plateau. Int. J. Appl. Earth Obs. Geoinf., 17, 33-42.

$\mathrm{Li}, \mathrm{X}$., et al., 2008: Cryospheric change in China. Global Planet. Change, 62, 210-218.

Ling, F., and T. Zhang, 2003: Numerical simulation of permafrost thermal regime and talik development under shallow thaw lakes on the Alaskan Arctic Coastal Plain. J. Geophys. Res. Atmos., 108, 11.

Liu, L., T. Zhang, and J. Wahr, 2010: InSAR measurements of surface deformation over permafrost on the North Slope of Alaska. J. Geophys. Res. Earth Surf., 115, F03023

Lopez, P., P. Chevallier, V. Favier, B. Pouyaud, F. Ordenes, and J. Oerlemans, 2010: A regional view of fluctuations in glacier length in southern South America. Global Planet. Change, 71, 85-108.

Lopez-Moreno, J. I., and S. M. Vicente-Serrano, 2007: Atmospheric circulation influence on the interannual variability of snow pack in the Spanish Pyrenees during the second half of the 20th century. Nordic Hydrol., 38, 33-44.

Luckman, A., and T. Murray, 2005: Seasonal variation in velocity before retreat of Jakobshavn Isbrae, Greenland. Geophys. Res. Lett., 32, 4.

Luethi, M. P., A. Bauder, and M. Funk, 2010: Volume change reconstruction of Swiss glaciers from length change data. J. Geophys. Res. Earth Surf., 115, F04022.

Luthcke, S. B., A. A. Arendt, D. D. Rowlands, J. J. McCarthy, and C. F. Larsen, 2008 Recent glacier mass changes in the Gulf of Alaska region from GRACE mascon solutions. J. Glaciol., 54, 767-777.

Luthcke, S. B., et al., 2006: Recent Greenland ice mass loss by drainage system from satellite gravity observations. Science, 314, 1286-1289.

Ma, L., and D. Qin, 2012: Temporal-spatial characteristics of observed key parameters of snow cover in China during 1957-2009. Sci. Cold Arid Reg. , 4(5), 384-393.

MacAyeal, D. R., et al., 2006: Transoceanic wave propagation links iceberg calving margins of Antarctica with storms in tropics and Northern Hemisphere. Geophys. Res. Lett., 33, 4 (L17502).

MacGregor, J. A., G. A. Catania, M. S. Markowski, and A. G. Andrews, 2012: Widespread rifting and retreat of ice-shelf margins in the eastern Amundsen Sea Embayment between 1972 and 2011. J. Glaciol., 58, 458-466.

Machguth, H., F. Paul, S. Kotlarski, and M. Hoelzle, 2009: Calculating distributed glacier mass balance for the Swiss Alps from regional climate model output: A methodical description and interpretation of the results. J. Geophys. Res. Atmos., 114, D19106.

Mahoney, A., H. Eicken, and L. Shapiro, 2007: How fast is landfast sea ice? A study of the attachment and detachment of nearshore ice at Barrow, Alaska. Cold Reg. Sci. Technol., 47, 233-255.

Macias Fauria, M., et al., 2010: Unprecedented low twentieth century winter sea ice extent in the Western Nordic Seas since AD 1200. Clim. Dyn., 34, 781-795.

Malkova, G. V., 2008: The last twenty-five years of changes in permafrost temperature of the European Russian Arctic. In: Proceedings of the 9th International Conference on Permafrost, 29 June- 3 July 2008, Institute of Northern Engineering, University of Alaska, Fairbanks [D. L. Kane, and K. M. Hinkel (eds.)], pp. 1119-1124.

Marchenko, S. S., A. P. Gorbunov, and V. E. Romanovsky, 2007: Permafrost warming in the Tien Shan Mountains, Central Asia. Global Planet. Change, 56, 311-327.

Markus, T., and D. J. Cavalieri, 2000: An enhancement of the NASA Team sea ice algorithm. IEEE Trans. Geosci. Remote Sens., 38, 1387-1398.

Markus, T., J. C. Stroeve, and J. Miller, 2009: Recent changes in Arctic sea ice melt onset, freezeup, and melt season length. J. Geophys. Res. Oceans, 114, C12024.

Marshall, G. J., A. Orr, N. P. M. van Lipzig, and J. C. King, 2006: The impact of a changing Southern Hemisphere Annular Mode on Antarctic Peninsula summer temperatures. J. Clim., 19, 5388-5404.

Martinson, D. G., S. E. Stammerjohn, R. A. Iannuzzi, R. C. Smith, and M. Vernet, 2008: Western Antarctic Peninsula physical oceanography and spatio-temporal variability. Deep-Sea Res. Pt. li, 55, 1964-1987.

Marty, C., 2008: Regime shift of snow days in Switzerland. Geophys. Res. Lett., 35, L12501.

Marty, C., and R. Meister, 2012: Long-term snow and weather observations at Weissfluhjoch and its relation to other high-altitude observatories in the Alps. Theor. Appl. Climatol., 110, 573-583.

Marushchak, M. E., A. Pitkamaki, H. Koponen, C. Biasi, M. Seppala, and P. J. Martikainen, 2011: Hot spots for nitrous oxide emissions found in different types of permafrost peatlands. Global Change Biol., 17, 2601-2614.

Marzeion, B., A. H. Jarosch, and M. Hofer, 2012: Past and future sea-level change from the surface mass balance of glaciers. Cryosphere, 6, 1295-1322.
Masiokas, M. H., R. Villalba, B. H. Luckman, and S. Mauget, 2010: Intra- to multidecadal variations of snowpack and streamflow records in the Andes of Chile and Argentina between 30 degrees and 37 degrees S. J. Hydrometeorol., $11,822-831$.

Masiokas, M. H., A. Rivera, L. E. Espizua, R. Villalba, S. Delgado, and J. C. Aravena, 2009: Glacier fluctuations in extratropical South America during the past 1000 years. Palaeogeogr. Palaeoclimatol. Palaeoecol., 281, 242-268.

Maslanik, J. A., C. Fowler, J. Stroeve, S. Drobot, J. Zwally, D. Yi, and W. Emery, 2007: A younger, thinner Arctic ice cover: Increased potential for rapid, extensive sea-ice loss. Geophys. Res. Lett., 34, L24501.

Massom, R. A., and S. Stammerjohn, 2010: Antarctic sea ice change and variabilityPhysical and ecological implications. Polar Sci., 149-186.

Massom, R. A., P. Reid, B. Raymond, S. Stammerjohn, A. D. Fraser, and S. Ushio, 2013: Change and variability in East Antarctic Sea Ice Seasonality, 1979/80-2009/10. PLOS ONE, 8, e64756.

Massom, R. A., et al., 2001: Snow on Antarctic Sea ice: A review of physical characteristics. Rev. Geophys., 39, 413-445.

Matsuo, K., and K. Heki, 2010: Time-variable ice loss in Asian high mountains from satellite gravimetry. Earth Planet. Sci. Lett., 290, 30-36.

Mazhitova, G. G., 2008: Soil temperature regimes in the discontinuous permafrost zone in the east European Russian Arctic. Euras. Soil Sci., 41, 48-62.

Mazhitova, G. G., and D. A. Kaverin, 2007: Thaw depth dynamics and soil surface subsidence at a Circumpolar Active Layer Monitoring (CALM) site in the East European Russian Arctic. Kriosfera Zemli, XI, N, 20-30.

McGuire, A. D., et al., 2009: Sensitivity of the carbon cycle in the Arctic to climate change. Ecol. Monogr., 79, 523-555.

Meese, D. A., et al., 1994: The accumulation record from the Gisp2 Core as and indicator of climate change throughout the holocene. Science, 266, 1680-1682.

Meier, M. F., 1984: Contribution of small glaciers to global sea level. Science, 226, 1418-1421.

Meier, W. N., J. Stroeve, A. Barrett, and F. Fetterer, 2012: A simple approach to providing a more consistent Arctic sea ice extent time series from the 1950 s to present. Cryosphere, 6, 1359-1368.

Melling, H., 2012: Sea-Ice Observation: Advances and challenges. In: Arctic Climate Change: The ACSYS Decade and Beyond [P. Lemke and H.-W. Jacobi (eds.)]. Atmospheric and Oceanographic Sciences Library. Springer Science, New York, NY, USA, and Heidelberg, Germany. 27-115.

Mercer, J. H., 1978: West Antarctic ice sheet and CO2 greenhouse effect- threat of disaster. Nature, 271, 321-325.

Micu, D., 2009: Snow pack in the Romanian Carpathians under changing climatic conditions. Meteorol. Atmos. Phys., 105, 1-16.

Mitchell, T. D., and P. D. Jones, 2005: An improved method of constructing a database of monthly climate observations and associated high-resolution grids. Int. J. Climatol., 25, 693-712.

Moholdt, G., B. Wouters, and A. S. Gardner, 2012: Recent contribution to sea-level rise from glaciers and ice caps in the Russian High Arctic. Geophys. Res. Lett., 39, L10502.

Moholdt, G., C. Nuth, J. O. Hagen, and J. Kohler, 2010: Recent elevation changes of Svalbard glaciers derived from ICESat laser altimetry. Remote Sens. Environ., 114, 2756-2767.

Monaghan, A. J., D. H. Bromwich, and S. H. Wang, 2006: Recent trends in Antarctic snow accumulation from Polar MM5 simulations. Philos. Trans. R. Soc. A, 364, 1683-1708.

Montes-Hugo, M., S. C. Doney, H. W. Ducklow, W. Fraser, D. Martinson, S. E. Stammerjohn, and O. Schofield, 2009: Recent changes in phytoplankton communities associated with rapid regional climate change along the western Antarctic Peninsula. Science, 323, 1470-1473.

Moon, T., and I. Joughin, 2008: Changes in ice front position on Greenland's outlet glaciers from 1992 to 2007. J. Geophys. Res. Earth Surf., 113, F02022.

Moon, T., I. Joughin, B. Smith, and I. Howat, 2012: 21st-Century evolution of Greenland outlet glacier velocities. Science, 336, 576-578.

Moore, P., and M. A. King, 2008: Antarctic ice mass balance estimates from GRACE: Tidal aliasing effects. J. Geophys. Res. Earth Surf., 113, F02005.

Morris, E. M., and D. G. Vaughan, 2003: Spatial and temporal variation of surface temperature on the Antarctic Peninsula and the limit of viability of ice shelves. In: Antarctic Peninsula Climate Variability: Historical and Paleoenvironmental Perspectives [E. Domack, A. Leventer, A. Burnett, R. Bindschadler, P. Convey, and M. Kirby (eds.)]. Antarctic Research Series, 79, American Geophysical Union, Washington, DC, pp. 61-68. 
Mote, P. W., 2006: Climate-driven variability and trends in mountain snowpack in western North America. J. Clim., 19, 6209-6220.

Motyka, R. J., L. Hunter, K. A. Echelmeyer, and C. Connor, 2003: Submarine melting at the terminus of a temperate tidewater glacier, LeConte Glacier, Alaska, USA. Ann. Glaciol., 36, 57-65.

Motyka, R. J., M. Truffer, M. Fahnestock, J. Mortensen, S. Rysgaard, and I. Howat, 2011: Submarine melting of the 1985 Jakobshavn Isbrae floating tongue and the triggering of the current retreat. J. Geophys. Res. Earth Surf., 116, F01007.

Murray, T., T. Strozzi, A. Luckman, H. Jiskoot, and P. Christakos, 2003: Is there a single surge mechanism? Contrasts in dynamics between glacier surges in Svalbard and other regions. J. Geophys. Res. Sol. Ea., 108, 2237.

Murray, T., et al., 2010: Ocean regulation hypothesis for glacier dynamics in southeast Greenland and implications for ice sheet mass changes. J. Geophys. Res. Earth Surf., 115, F03026.

Myers, P. G., C. Donnelly, and M. H. Ribergaard, 2009: Structure and variability of the West Greenland Current in Summer derived from 6 repeat standard sections. Prog. Oceanogr., 80, 93-112.

National Snow and Ice Data Center, 2013: http://nsidc.org/data/icesat/correction-toproduct-surface-elevations.html.

Nerem, R. S., and J. Wahr, 2011: Recent changes in the Earth's oblateness driven by Greenland and Antarctic ice mass loss. Geophys. Res. Lett., 38, 6 (L13501).

Nesje, A., O. Lie, and S. O. Dahl, 2000: Is the North Atlantic Oscillation reflected in Scandinavian glacier mass balance records? J. Quat. Sci., 15, 587-601.

Nghiem, S. V., I. G. Rigor, D. K. Perovich, P. Clemente-Colon, J. W. Weatherly, and G. Neumann, 2007: Rapid reduction of Arctic perennial sea ice. Geophys. Res. Lett., 34, 6 (L19504).

Nghiem, S. V., et al., 2012: The extreme melt across the Greenland ice sheet in 2012. Geohys. Res. Lett., 39, L20502.

Nicholls, K. W., K. Makinson, and E. J. Venables, 2012: Ocean circulation beneath Larsen C Ice Shelf, Antarctica from in situ observations. Geophys. Res. Lett., 39, L19608.

Nicholls, N., 2005: Climate variability, climate change and the Australian snow season. Aust. Meteorol. Mag., 54, 177-185.

Nick, F. M., A. Vieli, I. M. Howat, and I. Joughin, 2009: Large-scale changes in Greenland outlet glacier dynamics triggered at the terminus. Nature Geosci., 2, 110-114.

Nick, F. M., C. J. van der Veen, A. Vieli, and D. Benn, 2010: A physically based calving model applied to marine outlet glaciers and implications for their dynamics. $J$. Glaciol., 56, 781-794.

Nick, F. M., et al., 2013: Future sea level rise from Greenland's major outlet glaciers in a warming climate. Nature, 497, 235-238.

Noetzli, J., and D. Vonder Muehll, 2010: Permafrost in Switzerland 2006/2007 and 2007/2008. Glaciological Report (Permafrost) No. 8/9 of the Cryospheric Commission of the Swiss Academy of Sciences. Cryospheric Commission of the Swiss Academy of Sciences, $68 \mathrm{pp}$.

Nussbaumer, S. U., A. Nesje, and H. J. Zumbuhl, 2011: Historical glacier fluctuations of Jostedalsbreen and Folgefonna (southern Norway) reassessed by new pictorial and written evidence. Holocene, 21, 455-471.

Nuth, C., G. Moholdt, J. Kohler, J. O. Hagen, and A. Kaab, 2010: Svalbard glacier elevation changes and contribution to sea level rise. J. Geophys. Res. Earth Surf., 115, 16 (F01008).

Oberman, N. G., 2008: Contemporary permafrost degradation of Northern European Russia. In: Proceedings of the 9th International Conference on Permafrost, 29 June- 3 July 2008, Institute of Northern Engineering, University of Alaska, Fairbanks [D. L. Kane, and K. M. Hinkel (eds.)], pp. 1305-1310.

Oberman, N. G., 2012: Long-term temperature regime of the Northeast European permafrost region during contemporary climate warming. In: Proceedings of the 10th International Conference on Permafrost, June, 2012, Salekhard, Yamel-Nenets Autonomous District, Russian Federation, v2. [V. P. Melnikov, D. S. Drozdov and V. E. Romanovsky (eds)]. The Northern Publisher, Salekhard, Russia. pp. 287-291.

Oerlemans, J., 2001: Glaciers and Climate Change. A. A. Balkema, Lisse, the Netherlands, 160 pp.

Oerlemans, J., M. Dyurgerov, and R. De Wal, 2007: Reconstructing the glacier contribution to sea-level rise back to 1850 . Cryosphere, 1, 59-65.

O'Leary, M., and P. Christoffersen, 2013: Calving on tidewater glaciers amplified by submarine frontal melting. Cryosphere, 7, 119-128.

Osterkamp, T.E., 2005: The recent warming of permafrost in Alaska. Global Planet. Change, 49, 187-202.
Osterkamp, T. E., 2007: Characteristics of the recent warming of permafrost in Alaska. J. Geophys. Res. Earth Surf., 112, 10 (F02S02).

Osterkamp, T. E., 2008: Thermal state of permafrost in Alaska during the fourth quarter of the twentieth century. In: Proceedings of the 9th International Conference on Permafrost, 29 June- 3 July 2008, Institute of Northern Engineering,University of Alaska, Fairbanks, Alaska [D. L. Kane, and K. M. Hinkel (eds.)], pp. 1333-1338.

Overduin, P. P., and D. L. Kane, 2006: Frost boils and soil ice content: Field observations. Permafr. Periglac. Process., 17, 291-307.

Overduin, P. P., H.-W. Hubberten, V. Rachold, N. Romanovskii, M. N. Grigoriev, and M. Kasymskaya, 2007: Evolution and degradation of coastal and offshore permafrost in the Laptev and East Siberian Seas during the last climatic cycle. GSA Special Papers, 426, 97-111.

Overduin, P. P., S. Westermann, K. Yoshikawa, T. Haberlau, V. Romanovsky, and S. Wetterich, 2012: Geoelectric observations of the degradation of nearshore submarine permafrost at Barrow (Alaskan Beaufort Sea). J. Geophys. Res. Earth Surf., 117, F02004.

Padman, L., et al., 2012: Oceanic controls on the mass balance of Wilkins Ice Shelf, Antarctica. J. Geophys. Res. Oceans, 117, C01010

Palmer, S., A. Shepherd, P. Nienow, and I. Joughin, 2011: Seasonal speedup of the Greenland Ice Sheet linked to routing of surface water. Earth Planet. Sci. Lett., 302, 423-428.

Parkinson, C. L., 2002: Trends in the length of the Southern Ocean sea-ice season, 1979-99. Ann. Glaciol., 34, 435-440.

Parkinson, C. L., and D. J. Cavalieri, 2012: Antarctic sea ice variability and trends, 1979-2010. Cryosphere, 6, 871-880.

Parkinson, C. L., and J. C. Comiso, 2013: On the 2012 record low Arctic sea ice cover: Combined impact of preconditioning and an August storm. Geophys. Res. Lett., 40, 1356-1361.

Paul, F., and W. Haeberli, 2008: Spatial variability of glacier elevation changes in the Swiss Alps obtained from two digital elevation models. Geophys. Res. Lett., 35, 5 (L21502).

Paulson, A., S. J. Zhong, and J. Wahr, 2007: Inference of mantle viscosity from GRACE and relative sea level data. Geophys. J. Int., 171, 497-508.

Payne, A. J., A. Vieli, A. P. Shepherd, D. J. Wingham, and E. Rignot, 2004: Recent dramatic thinning of largest West Antarctic ice stream triggered by oceans. Geophys. Res. Lett., 31, L23401.

Peltier, W. R., 2004: Global glacial isostasy and the surface of the ice-age earth: The ice-5G (VM2) model and grace. Annu. Rev. Earth Planet. Sci., 32, 111-149.

Peltier, W. R., 2009: Closure of the budget of global sea level rise over the GRACE era: The importance and magnitudes of the required corrections for global glacial isostatic adjustment. Quat. Sci. Rev., 28, 1658-1674.

Pelto, M. S., 2006: The current disequilibrium of North Cascade glaciers. Hydrol. Process., 20, 769-779.

Perovich, D. K., B. Light, H. Eicken, K. F. Jones, K. Runciman, and S. V. Nghiem, 2007: Increasing solar heating of the Arctic Ocean and adjacent seas, 1979-2005: Attribution and role in the ice-albedo feedback. Geophys. Res. Lett., 34, L19505.

Petkova, N., E. Koleva, and V. Alexandrov, 2004: Snow cover variability and change in mountainous regions of Bulgaria, 1931-2000. Meteorol. Z., 13, 19-23.

Pfeffer, W. T., 2007: A simple mechanism for irreversible tidewater glacier retreat. J. Geophys. Res. Earth Surf., 112, F03S25.

Pfeffer, W. T., 2011: Land ice and sea level rise: A thirty-year perspective. Oceanography, 24, 94-111.

Phillips, T., H. Rajaram, and K. Steffen, 2010: Cryo-hydrologic warming: A potential mechanism for rapid thermal response of ice sheets. Geophys. Res. Lett., 37, L20503.

Pollard, D., and R. M. DeConto, 2009: Modelling West Antarctic ice sheet growth and collapse through the past five million years. Nature, 458, 329-333.

Polyakov, I. V., et al., 2003: Long-term ice variability in Arctic marginal seas. J. Clim., 16, 2078-2085.

Polyakov, I. V., et al., 2010: Arctic Ocean warming contributes to reduced polar ice cap. J. Phys. Oceanogr., 40, 2743-2756

Pritchard, H. D., and D. G. Vaughan, 2007: Widespread acceleration of tidewater glaciers on the Antarctic Peninsula. J. Geophys. Res. Earth Surf., 112, F03S29.

Pritchard, H. D., S. B. Luthcke, and A. H. Fleming, 2010: Understanding ice-sheet mass balance: Progress in satellite altimetry and gravimetry. J. Glaciol., 56, 11511161.

Pritchard, H. D., R. J. Arthern, D. G. Vaughan, and L. A. Edwards, 2009: Extensive dynamic thinning on the margins of the Greenland and Antarctic ice sheets. Nature, 461, 971-975. 
Pritchard, H. D., S. R. M. Ligtenberg, H. A. Fricker, D. G. Vaughan, M. R. van den Broeke, and L. Padman, 2012: Antarctic ice loss driven by ice-shelf melt. Nature, 484 502-505.

Prowse, T., et al., 2011: Arctic freshwater ice and its climatic role. Ambio, 40, 46-52. Quincey, D. J., M. Braun, N. F. Glasser, M. P. Bishop, K. Hewitt, and A. Luckman, 2011: Karakoram glacier surge dynamics. Geophys. Res. Lett., 38, L18504.

Rabatel, A., J. P. Dedieu, and C. Vincent, 2005: Using remote-sensing data to determine equilibrium-line altitude and mass-balance time series: validation on three French glaciers, 1994-2002. J. Glaciol., 51, 539-546.

Rabatel, A., B. Francou, V. Jomelli, P. Naveau, and D. Grancher, 2008: A chronology of the Little Ice Age in the tropical Andes of Bolivia (16 degrees $S$ ) and its implications for climate reconstruction. Q. Res., 70, 198-212.

Rabatel, A., et al., 2013: Current state of glaciers in the tropical Andes: A multicentury perspective on glacier evolution and climate change. Cryosphere, $\mathbf{7}$ 81-102.

Rachold, V., et al., 2007: Near-shore Arctic subsea permafrost in transition. EOS Trans. Am. Geophys. Union, 88, 149-156.

Radić, V., and R. Hock, 2010: Regional and global volumes of glaciers derived from statistical upscaling of glacier inventory data. J. Geophys. Res. Earth Surf., 115 F01010.

Radić, V., A. Bliss, A. C. Beedlow, R. Hock, E. Miles, and J. G. Cogley, 2013: Regional and global projections of $21 \mathrm{st}$ century glacier mass changes in response to climate scenarios from global climate models. Clim. Dyn., doi:10.1007/s00382013-1719-7.

Ramillien, G., A. Lombard, A. Cazenave, E. R. Ivins, M. Llubes, F. Remy, and R. Biancale, 2006: Interannual variations of the mass balance of the Antarctica and Greenland ice sheets from GRACE. Global Planet. Change, 53, 198-208.

Ramirez, E., et al., 2001: Small glaciers disappearing in the tropical Andes: a casestudy in Bolivia: Glaciar Chacaltaya (16 degrees S). J. Glaciol., 47, 187-194.

Rampal, P., J. Weiss, and D. Marsan, 2009: Positive trend in the mean speed and deformation rate of Arctic sea ice, 1979-2007. J. Geophys. Res. Oceans, 114, C05013.

Rastner, P., T. Bolch, N. Mölg, H. Machguth, and F. Paul, 2012: The first complete glacier inventory for entire Greenland. Cryosphere, 6, 1483-1495.

Ravanel, L., F. Allignol, P. Deline, S. Gruber, and M. Ravello, 2010: Rock falls in the Mont Blanc Massif in 2007 and 2008. Landslides, 7, 493-501.

Rayner, N. A., et al., 2003: Global analyses of SST, sea ice and night marine air temperature since the late nineteenth century. J. Geophys. Res., 108, 4407.

Repo, M. E., et al., 2009: Large N20 emissions from cryoturbated peat soil in tundra. Nature Geosci., 2, 189-192.

Ridley, J., J. M. Gregory, P. Huybrechts, and J. Lowe, 2010: Thresholds for irreversible decline of the Greenland ice sheet. Clim. Dyn., 35, 1065-1073.

Rignot, E., 2008: Changes in West Antarctic ice stream dynamics observed with ALOS PALSAR data. Geophys. Res. Lett., 35, L12505.

Rignot, E., and S. S. Jacobs, 2002: Rapid bottom melting widespread near Antarctic ice sheet grounding lines. Science, 296, 2020-2023.

Rignot, E., and R. H. Thomas, 2002: Mass balance of polar ice sheets. Science, 297, 1502-1506.

Rignot, E., and P. Kanagaratnam, 2006: Changes in the velocity structure of the Greenland ice sheet. Science, 311, 986-990.

Rignot, E., and J. Mouginot, 2012: Ice flow in Greenland for the International Polar Year 2008-2009. Geophys. Res. Lett., 39, L11501.

Rignot, E., A. Rivera, and G. Casassa, 2003: Contribution of the Patagonia Icefields of South America to sea level rise. Science, 302, 434-437.

Rignot, E., M. Koppes, and I. Velicogna, 2010: Rapid submarine melting of the calving faces of West Greenland glaciers. Nature Geosci., 3, 187-191.

Rignot, E., J. Mouginot, and B. Scheuchl, 2011a: Ice flow of the Antarctic ice sheet. Science, 333, 1427-1430.

Rignot, E., J. Mouginot, and B. Scheuchl, 2011b: Antarctic grounding line mapping from differential satellite radar interferometry. Geophys. Res. Lett., 38, L10504.

Rignot, E., J. E. Box, E. Burgess, and E. Hanna, 2008a: Mass balance of the Greenland ice sheet from 1958 to 2007. Geophys. Res. Lett., 35, L20502.

Rignot, E., I. Velicogna, M. R. van den Broeke, A. Monaghan, and J. Lenaerts, 2011 c: Acceleration of the contribution of the Greenland and Antarctic ice sheets to sea level rise. Geophys. Res. Lett., 38, 5 (L05503).

Rignot, E., G. Casassa, P. Gogineni, W. Krabill, A. Rivera, and R. Thomas, 2004 Accelerated ice discharge from the Antarctic Peninsula following the collapse of Larsen B ice shelf. Geophys. Res. Lett., 31, 4 (L18401).
Rignot, E., J. L. Bamber, M. R. van den Broeke, C. Davis, Y. H. Li, W. J. van de Berg, and E. Van Meijgaard, 2008b: Recent Antarctic ice mass loss from radar interferometry and regional climate modelling. Nature Geosci., 1, 106-110.

Riva, R. E. M., et al., 2009: Glacial Isostatic Adjustment over Antarctica from combined ICESat and GRACE satellite data. Earth Planet. Sci. Lett., 288, 516-523.

Rivera, A., F. Bown, D. Carrion, and P. Zenteno, 2012: Glacier responses to recent volcanic activity in Southern Chile. Environ. Res. Lett., 7, 014036.

Robinson, D. A., K. F. Dewey, and R. R. Heim, 1993: Global snow cover monitoringAn update. Bull. Am. Meteorol. Soc., 74, 1689-1696.

Roer, I., W. Haeberli, M. Avian, V. Kaufmann, R. Delaloye, C. Lambiel, and A. Kääb, 2008: Observations and considerations on destabilizing active rock glaciers in the European Alps. In: Proceedings of the 9th International Conference on Permafrost, 29 June- 3 July 2008, Institute of Northern Engineering, University of Alaska, Fairbanks [D. L. Kane, and K. M. Hinkel (eds.)], pp. 1505-1510.

Romanovsky, V. E., S. L. Smith, and H. H. Christiansen, 2010a: Permafrost thermal state in the polar Northern Hemisphere during the International Polar Year 2007-2009: A Synthesis. Permafr. Periglac. Process., 21, 106-116.

Romanovsky, V. E., et al., 2010b: Thermal state of permafrost in Russia. Permafr. Periglac. Process., 21, 136-155.

Rosenau, R., E. Schwalbe, H.-G. Maas, M. Baessler, and R. Dietrich, 2013: Grounding line migration and high resolution calving dynamics of Jakobshavn Isbræ, West Greenland. J. Geophys. Res., 118, 382-395.

Ross, N., et al., 2012: Steep reverse bed slope at the grounding line of the Weddell Sea sector in West Antarctica. Nature Geosci, 5, 393-396.

Rothrock, D. A., and M. Wensnahan, 2007: The accuracy of sea ice drafts measured from US Navy submarines. J. Atmos. Ocean. Technol., 24, 1936-1949.

Rothrock, D. A., Y. Yu, and G. A. Maykut, 1999: Thinning of the Arctic sea-ice cover Geophys. Res. Lett., 26, 3469-3472.

Rothrock, D. A., D. B. Percival, and M. Wensnahan, 2008: The decline in arctic sea-ice thickness: Separating the spatial, annual, and interannual variability in a quarter century of submarine data. J. Geophys. Res. Oceans, 113, C05003.

Rott, H., F. Muller, T. Nagler, and D. Floricioiu, 2011: The imbalance of glaciers after disintegration of Larsen-B ice shelf, Antarctic Peninsula. Cryosphere, 5, 125-134.

Sanchez-Bayo, F., and K. Green, 2013: Australian snowpack disappearing under the influence of global warming and solare activity. Arct., Antarct. Alp. Res., 45, 107-118.

Sannel, A. B. K., and P. Kuhry, 2011: Warming-induced destabilization of peat plateau/ thermokarst lake complexes. J. Geophys. Res. Biogeosci., 116, 16 (G03035).

Sasgen, I., et al., 2012: Timing and origin of recent regional ice-mass loss in Greenland. Earth Planet. Sci. Lett., 333, 293-303.

Scambos, T. A., C. Hulbe, M. Fahnestock, and J. Bohlander, 2000: The link between climate warming and break-up of ice shelves in the Antarctic Peninsula. $J$. Glaciol., 46, 516-530.

Scambos, T. A., J. A. Bohlander, C. A. Shuman, and P. Skvarca, 2004: Glacier acceleration and thinning after ice shelf collapse in the Larsen B embayment, Antarctica. Geophys. Res. Lett., 31, 4.

Schaefer, K., T. J. Zhang, L. Bruhwiler, and A. P. Barrett, 2011: Amount and timing of permafrost carbon release in response to climate warming. Tellus $B, 63$, 165-180.

Scherler, D., B. Bookhagen, and M. R. Strecker, 2011: Spatially variable response of Himalayan glaciers to climate change affected by debris cover. Nature Geosci., 4, 156-159

Schiefer, E., B. Menounos, and R. Wheate, 2007: Recent volume loss of British Columbian glaciers, Canada. Geophys. Res. Lett., 34, 6 (L16503).

Schneider, D. P., C. Deser, and Y. Okumura, 2012: An assessment and interpretation of the observed warming of West Antarctica in the austral spring. Clim. Dyn., 38, 323-347.

Schoeneich, P., X. Bodin, J. Krysiecki, P. Deline, and L. Ravanel, 2010: Permafrost in France, 1st Report. Institut de Géographie Alpine, Université Joseph Fourier, Grenoble, France. 68 pp.

Schoof, C., 2007: Ice sheet grounding line dynamics: Steady states, stability, and hysteresis. J. Geophys. Res. Earth Surf., 112, F03S28.

Schoof, C., 2010: Ice-sheet acceleration driven by melt supply variability. Nature, $468,803-806$

Schrama, E. J. O., and B. Wouters, 2011: Revisiting Greenland ice sheet mass loss observed by GRACE. J. Geophys. Res. Sol. Ea., 116, B02407.

Schuur, E. A. G., J. G. Vogel, K. G. Crummer, H. Lee, J. O. Sickman, and T. E. Osterkamp, 2009: The effect of permafrost thaw on old carbon release and net carbon exchange from tundra. Nature, 459, 556-559. 
Schweiger, A., R. Lindsay, J. L. Zhang, M. Steele, H. Stern, and R. Kwok, 2011: Uncertainty in modeled Arctic sea ice volume. J. Geophys. Res. Oceans, 116, CO0D06.

Screen, J. A., 2011: Sudden increase in Antarctic sea ice: Fact or artifact? Geophys. Res. Lett., 38, L13702.

Selmes, N., T. Murray, and T. D. James, 2011: Fast draining lakes on the Greenland Ice Sheet. Geophys. Res. Lett., 38, 5 (L15501).

Shakhova, N., I. Semiletov, A. Salyuk, V. Yusupov, D. Kosmach, and O. Gustafsson, 2010a: Extensive methane venting to the atmosphere from sediments of the East Siberian Arctic Shelf. Science, 327, 1246-1250.

Shakhova, N., I. Semiletov, I. Leifer, A. Salyuk, P. Rekant, and D. Kosmach, 2010b: Geochemical and geophysical evidence of methane release over the East Siberian Arctic Shelf. J. Geophys. Res. Oceans, 115, 14 (C08007).

Shannon, S., et al., 2012: Enhanced basal lubrication and the contribution of the Greenland ice sheet to future sea level rise. Proc. Natl. Acad. Sci. U.S.A. 110 (35), 14156-14161.

Sharkhuu, A., et al., 2007: Permafrost monitoring in the Hovsgol mountain region, Mongolia. J. Geophys. Res. Earth Surf., 112, 11 (F02S06).

Shepherd, A., and D. Wingham, 2007: Recent sea-level contributions of the Antarctic and Greenland ice sheets. Science, 315, 1529-1532.

Shepherd, A., D. Wingham, T. Payne, and P. Skvarca, 2003: Larsen ice shelf has progressively thinned. Science, 302, 856-859.

Shepherd, A., A. Hubbard, P. Nienow, M. King, M. McMillan, and I. Joughin, 2009: Greenland ice sheet motion coupled with daily melting in late summer. Geophys. Res. Lett., 36, L01501.

Shepherd, A., D. Wingham, D. Wallis, K. Giles, S. Laxon, and A. V. Sundal, 2010: Recent loss of floating ice and the consequent sea level contribution. Geophys. Res. Lett., 37, 5 (L13503).

Shepherd, A., et al., 2012: A reconciled estimate of ice-sheet mass balance. Science, 338, 1183-1189.

Shi, H. L., Y. Lu, Z. L. Du, L. L. Jia, Z. Z. Zhang, and C. X. Zhou, 2011: Mass change detection in Antarctic ice sheet using ICESat block analysis techniques from 2003 similar to 2008. Chin. J. Geophys.-Chin. Ed., 54, 958-965.

Shiklomanov, N. I., et al., 2010: Decadal variations of active-layer thickness in moisture-controlled landscapes, Barrow, Alaska. J. Geophys. Res. Biogeosci, 115, G00I04.

Shuman, C. A., E. Berthier, and T. A. Scambos, 2011: 2001-2009 elevation and mass losses in the Larsen A and B embayments, Antarctic Peninsula. J. Glaciol., 57, 737-754.

Siegfried, M. R., R. L. Hawley, and J. F. Burkhart, 2011: High-resolution ground-based GPS measurements show intercampaign bias in ICESat Elevation data near Summit, Greenland. IEEE Trans. Geosci. Remote Sens., 49, 3393-3400.

Simmonds, I., C. Burke, and K. Keay, 2008: Arctic climate change as manifest in cyclone behavior. J. Clim., 21, 5777-5796.

Simpson, M. J. R., G. A. Milne, P. Huybrechts, and A. J. Long, 2009: Calibrating a glaciological model of the Greenland ice sheet from the Last Glacial Maximum to present-day using field observations of relative sea level and ice extent. Quat. Sci. Rev., 28, 1631-1657.

Skaugen, T., H. B. Stranden, and T. Saloranta, 2012: Trends in snow water equivalent in Norway (1931-2009). Hydrol. Res., 43, 489-499.

Slobbe, D. C., P. Ditmar, and R. C. Lindenbergh, 2009: Estimating the rates of mass change, ice volume change and snow volume change in Greenland from ICESat and GRACE data. Geophys. J. Int., 176, 95-106.

Smith, D. M., 1998: Recent increase in the length of the melt season of perennial Arctic sea ice. Geophys. Res. Lett., 25, 655-658.

Smith, S. L., J. Throop, and A. G. Lewkowicz, 2012: Recent changes in climate and permafrost temperatures at forested and polar desert sites in northern Canada. Can. J. Earth Sci., 49, 914-924.

Smith, S. L., S. A. Wolfe, D. W. Riseborough, and F. M. Nixon, 2009: Active-layer characteristics and summer climatic indices, Mackenzie Valley, Northwest Territories, Canada. Permafr. Periglac. Process., 20, 201-220.

Smith, S. L., et al., 2010: Thermal state of permafrost in North America: A contribution to the International Polar Year. Permafr. Periglac. Process., 21, 117-135.

Sole, A. J., D. W. F. Mair, P. W. Nienow, I. D. Bartholomew, M. A. King, M. J. Burke, and I. Joughin, 2011: Seasonal speedup of a Greenland marine-terminating outlet glacier forced by surface melt-induced changes in subglacial hydrology. J. Geophys. Res. Earth Surf., 116, 11 (F03014)
Solomon, S. M., A. E. Taylor, and C. W. Stevens, 2008: Nearshore ground temperatures, seasonal ice bonding and permafrost formation within the bottom-fast ice zone, Mackenzie Delta, NWT. In: Proceedings of the 9th International Conference of Permafrost, 29 June-3 July 2008, Institute of Northern Engineering, University of Alaska, Fairbanks [D. L. Kane, and K. M. Hinkel (eds.)], pp. 1675-1680.

Sorensen, L. S., et al., 2011: Mass balance of the Greenland ice sheet (2003-2008) from ICESat data: The impact of interpolation, sampling and firn density. Cryosphere, 5, 173-186.

Spreen, G., R. Kwok, and D. Menemenlis, 2011: Trends in Arctic sea ice drift and role of wind forcing: 1992-2009. Geophys. Res. Lett., 38, 6 (L19501).

Spreen, G., S. Kern, D. Stammer, and E. Hansen, 2009: Fram Strait sea ice volume export estimated between 2003 and 2008 from satellite data. Geophys. Res. Lett., 36, L19502.

Stammerjohn, S., R. Massom, D. Rind, and D. Martinson, 2012: Regions of rapid sea ice change: An inter-hemispheric seasonal comparison. Geophys. Res. Lett., 39, L06501.

Stammerjohn, S. E., D. G. Martinson, R. C. Smith, X. Yuan, and D. Rind, 2008: Trends in Antarctic annual sea ice retreat and advance and their relation to El NiñoSouthern Oscillation and Southern Annular Mode variability. J. Geophys. Res. Oceans, 113, C03590.

Steig, E. J., Q. Ding, D. S. Battisti, and A. Jenkins, 2012: Tropical forcing of Circumpolar Deep Water Inflow and outlet glacier thinning in the Amundsen Sea Embayment, West Antarctica. Ann. Glaciol., 53, 19-28.

Steig, E. J., D. P. Schneider, S. D. Rutherford, M. E. Mann, J. C. Comiso, and D. T. Shindell, 2009: Warming of the Antarctic ice-sheet surface since the 1957 International Geophysical Year. Nature, 457, 459-462.

Stevens, C. W., B. J. Moorman, and S. M. Solomon, 2010: Modeling ground thermal conditions and the limit of permafrost within the nearshore zone of the Mackenzie Delta, Canada. J. Geophys. Res. Earth Surf., 115, F04027.

Straneo, F., R. G. Curry, D. A. Sutherland, G. S. Hamilton, C. Cenedese, K. Vage, and L. A. Stearns, 2011: Impact of fjord dynamics and glacial runoff on the circulation near Helheim Glacier. Nature Geosci., 4, 322-327.

Straneo, F., et al., 2010: Rapid circulation of warm subtropical waters in a major glacial fjord in East Greenland. Nature Geosci., 3, 182-186.

Straneo, F., et al., 2012: Characteristics of ocean waters reaching Greenland's glaciers. Ann. Glaciol., 53, 202-210.

Streletskiy, D. A., N. I. Shiklomanov, F. E. Nelson, and A. E. Klene, 2008: 13 Years of Observations at Alaskan CALM Sites: Long-term Active Layer and Ground Surface Temperature Trends. In: Proceedings of the 9th International Conference on Permafrost, 29 June-3 July 2008, Institute of Northern Engineering, University of Alaska, Fairbanks [D. L. Kane, and K. M. Hinkel (eds.)], pp. 1727-1732.

Stroeve, J., M. M. Holland, W. Meier, T. Scambos, and M. Serreze, 2007: Arctic sea ice decline: Faster than forecast. Geophys. Res. Lett., 34, L09501.

Sundal, A. V., A. Shepherd, P. Nienow, E. Hanna, S. Palmer, and P. Huybrechts, 2011: Melt-induced speed-up of Greenland ice sheet offset by efficient subglacial drainage. Nature, 469, 522-U583.

Takala, M., J. Pulliainen, S. J. Metsamaki, and J. T. Koskinen, 2009: Detection of snowmelt using spaceborne microwave radiometer data in Eurasia from 1979 to 2007. IEEE Trans. Geosci. Remote Sens., 47, 2996-3007.

Tamura, T., and K. I. Ohshima, 2011: Mapping of sea ice production in the Arctic coastal polynyas. J. Geophys. Res. Oceans, 116, 20 (C07030).

Tang, J. S., H. W. Cheng, and L. Liu, 2012: Using nonlinear programming to correct leakage and estimate mass change from GRACE observation and its application to Antarctica. J. Geophys. Res. Sol. Ea., 117, B11410.

Tarasov, L., and W. R. Peltier, 2002: Greenland glacial history and local geodynamic consequences. Geophys. J. Int., 150, 198-229.

Tarnocai, C., J. G. Canadell, E. A. G. Schuur, P. Kuhry, G. Mazhitova, and S. Zimov, 2009: Soil organic carbon pools in the northern circumpolar permafrost region. Global Biogeochem. Cycles, 23, 11 (GB2023).

Tedesco, M., and A. J. Monaghan, 2009: An updated Antarctic melt record through 2009 and its linkages to high-latitude and tropical climate variability. Geophys. Res. Lett., 36, L18502.

Tedesco, M., M. Brodzik, R. Armstrong, M. Savoie, and J. Ramage, 2009: Pan arctic terrestrial snowmelt trends (1979-2008) from spaceborne passive microwave data and correlation with the Arctic Oscillation. Geophys. Res. Lett., 36, L21402.

Tedesco, M., X. Fettweis, T. Mote, J. Wahr, P. Alexander, J. E. Box, and B. Wouters, 2013: Evidence and analysis of 2012 Greenland records from spaceborne observations, a regional climate model and reanalysis data. Cryosphere, 7, 615-630. 
Tedesco, M., et al., 2011: The role of albedo and accumulation in the 2010 melting record in Greenland. Environ. Res. Lett, , 6, 6 (014005).

Tennant, C., B. Menounos, R. Wheate, and J. J. Clague, 2012: Area change of glaciers in the Canadian Rocky Mountains, 1919 to 2006. Cryosphere, 6, 1541-1552.

Thibert, E., R. Blanc, C. Vincent, and N. Eckert, 2008: Glaciological and volumetric mass-balance measurements: error analysis over 51 years for Glacier de Sarennes, French Alps. J. Glaciol., 54, 522-532.

Thomas, E. R., G. J. Marshall, and J. R. McConnell, 2008a: A doubling in snow accumulation in the western Antarctic Peninsula since 1850. Geophys. Res. Lett., 35, 5 (L01706)

Thomas, I. D., et al., 2011a: Widespread low rates of Antarctic glacial isostatic adjustment revealed by GPS observations. Geophys. Res. Lett., 38, L22302.

Thomas, R., E. Frederick, W. Krabill, S. Manizade, and C. Martin, 2006: Progressive increase in ice loss from Greenland. Geophys. Res. Lett., 33, 4 (L10503).

Thomas, R., E. Frederick, W. Krabill, S. Manizade, and C. Martin, 2009: Recent changes on Greenland outlet glaciers. J. Glaciol., 55, 147-162.

Thomas, R., C. Davis, E. Frederick, W. Krabill, Y. H. Li, S. Manizade, and C. Martin, 2008b: A comparison of Greenland ice-sheet volume changes derived from altimetry measurements. J. Glaciol., 54, 203-212.

Thomas, R., E. Frederick, J. Li, W. Krabill1, S. Manizade, J. Paden, J. Sonntag, R. Swift, J. Yungel., $2011 \mathrm{~b}$ : Accelerating ice loss from the fastest Greenland and Antarctic glaciers. Geophys. Res. Lett., 38, L10502.

Thomas, R. H., and C. R. Bentley, 1978: A model for Holocene retreat of the West Antarctic Ice Sheet. Quat. Res., 10, 150-170.

Thompson, D. W. J., and J. M. Wallace, 1998: The Arctic Oscillation signature in the wintertime geopotential height and temperature fields. Geophys. Res. Lett., 25, 1297-1300.

Thompson, D. W. J., and J. M. Wallace, 2000: Annular modes in the extratropical circulation. Part I: Month-to-month variability. J. Clim., 13, 1000-1016.

Thomson, L. I., G. R. Osinski, and C. S. L. Ommanney, 2011: Glacier change on Axel Heiberg Island, Nunavut, Canada. J. Glaciol., 57, 1079-1086

Throop, J., A. G. Lewkowicz, and S. L. Smith, 2012: Climate and ground temperature relations at sites across the continuous and discontinuous permafrost zones, northern Canada. Can. J. Earth Sci., 49, 865-876.

Turner, J., et al., 2005: Antarctic climate change during the last 50 years. Int. J. Climatol., 25, 279-294.

Valt, M., and P. Cianfarra, 2010: Recent snow cover variability in the Italian Alps. Cold Reg. Sci. Technol., 64, 146-157.

van de Berg, W. J., M. R. van den Broeke, C. H. Reijmer, and E. Van Meijgaard, 2006: Reassessment of the Antarctic surface mass balance using calibrated output of a regional atmospheric climate model. J. Geophys. Res. Atmos., 111, D11104.

van de Wal, R. S. W., W. Boot, M. R. van den Broeke, C. Smeets, C. H. Reijmer, J. J. A. Donker, and J. Oerlemans, 2008: Large and rapid melt-induced velocity changes in the ablation zone of the Greenland Ice Sheet. Science, 321, 111-113.

van den Broeke, M., W. J. van de Berg, and E. Van Meijgaard, 2006: Snowfall in coastal West Antarctica much greater than previously assumed. Geophys. Res. Lett., 33, L02505.

van den Broeke, M., et al., 2009: Partitioning recent Greenland mass loss. Science, 326, 984-986.

Van Everdingen, R. (ed.), 1998: Multi-language Glossary of Permafrost and Related Ground-Ice Terms. National Snow and Ice Data Center /World Data Center for Glaciology.

Van Ommen, T. D., and V. Morgan, 2010: Snowfall increase in coastal East Antarctica linked with southwest Western Australian drought. Nature Geosci., 3, 267-272.

Vasiliev, A. A., M. O. Leibman, and N. G. Moskalenko, 2008: Active layer monitoring in West Siberia under the CALM II Program. In: Proceedings of the 9th International Conference on Permafrost, 29 June-3 July 2008, Institute of Northern Engineering, University of Alaska, Fairbanks, [D. L. Kane, and K. M. Hinkel (eds.)], pp. 1815-1821.

Vaughan, D. G., et al., 2003: Recent rapid regional climate warming on the Antarctic Peninsula. Clim. Change, 60, 243-274.

Velicogna, I., 2009: Increasing rates of ice mass loss from the Greenland and Antarctic ice sheets revealed by GRACE. Geophys. Res. Lett., 36, L19503.

Velicogna, I., and J. Wahr, 2006a: Acceleration of Greenland ice mass loss in spring 2004. Nature, 443, 329-331.

Velicogna, I., and J. Wahr, 2006b: Measurements of time-variable gravity show mass loss in Antarctica. Science, 311, 1754-1756.
Vieira, G., et al., 2010: Thermal state of permafrost and active-layer monitoring in the Antarctic: Advances during the International Polar Year 2007-2009. Permafr. Periglac. Process., 21, 182-197.

Vigdorchik, M. E., 1980: Arctic Pleistocene History and the Development of Submarine Permafrost. Westview Press, Boulder, CO, USA, $286 \mathrm{pp}$.

Vincent, C., E. Le Meur, D. Six, P. Possenti, E. Lefebvre, and M. Funk, 2007: Climate warming revealed by englacial temperatures at Col du Dome ( $4250 \mathrm{~m}$, Mont Blanc area). Geophys. Res. Lett., 34.

Vinje, T., 2001: Fram strait ice fluxes and atmospheric circulation: 1950-2000. J. Clim., 14, 3508-3517.

Wadhams, P., 1990: Evidence for thinning of the Arctic ice cover north of Greenland. Nature, 345, 795-797.

Wadhams, P., and J. C. Comiso, 1992: The ice thickness distribution inferred using remote sensing techniques. In: Microware Remote Sensing of Sea Ice [F. Carsey (ed.)]. American Geophysical Union, Washington, DC, pp. 375-383.

Wadhams, P., and N. R. Davis, 2000: Further evidence of ice thinning in the Arctic Ocean. Geophys. Res. Lett., 27, 3973-3975.

Wadhams, P., N. Hughes, and J. Rodrigues, 2011: Arctic sea ice thickness characteristics in winter 2004 and 2007 from submarine sonar transects. J. Geophys. Res. Oceans, 116, CO0E02.

Wahr, J. M., 2007: Time-variable gravity from satellites. In: Treatise on Geophysics [T. A. Herring (ed.)]. Elsevier, Amsterdam, the Netherlands, and Philadelphia, PA, USA, pp. 213-237.

Walsh, J. E., and W. L. Chapman, 2001: 20th-century sea-ice variations from observational data. Ann. Glaciol., 33, 444-448.

Wang, J., X. Bai, H. Hu, A. Clites, M. Colton, and B. Lofgren, 2012: Temporal and spatial variability of Great Lakes ice cover, 1973-2010. J. Clim., 25, 13181329.

Weeks, W. F., and A. J. Gow, 1978: Preferred crystal orientations in fast ice along margins of Arctic Ocean J. Geophys. Res. Oceans Atmos., 83, 5105-5121.

Weertman, J., 1974: Stability of the junction of an ice sheet and an ice shelf. J. Glaciol., 13, 3-11.

Wendt, J., A. Rivera, A. Wendt, F. Bown, R. Zamora, G. Casassa, and C. Bravo, 2010: Recent ice-surface-elevation changes of Fleming Glacier in response to the removal of the Wordie Ice Shelf, Antarctic Peninsula. Ann. Glaciol., 51, 97-102.

WGMS, 1989: World glacier inventory-Status 1988. IAHS (ICSI)/UNEP/ UNESCO,[Haeberli, W., H. Bösch, K. Scherler, G. Østrem and C. C. Wallén (eds.)] World Glacier Monitoring Service, Zurich, Switzerland, $458 \mathrm{pp}$.

WGMS, 2008: Global Glacier Changes: Facts and Figures. [Zemp, M, I. Roer, A. Kääb, M. Hoelzle, F. Paul, W. G. Haeberli (eds.)] UNEP and World Glacier Monitoring Service, Zurich, Switzerland, $88 \mathrm{pp}$.

WGMS, 2009: Glacier Mass Balance Bulletin No. 10 (2006-2007). ICSU (WDS)/IUGG (IACS) /UNEP/UNESCO/WMO. [Haeberli, W., I. Gärtner-Roer, M. Hoelzle, F. Paul, M.I Zemp (eds.)] World Glacier Monitoring Service, Zurich, Switzerland. 96 pp.

White, D., et al., 2007: The arctic freshwater system: Changes and impacts. J. Geophys. Res. Biogeosci, 112, G04S54.

White, W. B., and R. G. Peterson, 1996: An Antarctic circumpolar wave in surface pressure, wind, temperature and sea-ice extent. Nature, 380, 699-702.

Whitehouse, P. L., M. J. Bentley, G. A. Milne, M. A. King, and I. D. Thomas, 2012: A new glacial isostatic adjustment model for Antarctica: Calibrated and tested using observations of relative sea-level change and present-day uplift rates. Geophys. J. Int., 190, 1464-1482.

Willis, M. J., A. K. Melkonian, M. E. Pritchard, and A. Rivera, 2012: Ice loss from the Southern Patagonian Icefield. Geophys. Res. Lett., 39, L17501.

Wingham, D. J., D. W. Wallis, and A. Shepherd, 2009: Spatial and temporal evolution of Pine Island Glacier thinning, 1995-2006. Geophys. Res. Lett., 36, L17501.

Wingham, D. J., A. Shepherd, A. Muir, and G. J. Marshall, 2006: Mass balance of the Antarctic ice sheet. Philos. Trans. R. Soc. A, 364, 1627-1635.

Wingham, D. J., A. J. Ridout, R. Scharroo, R. J. Arthern, and C. K. Shum, 1998: Antarctic elevation change from 1992 to 1996. Science, 282, 456-458.

Worby, A. P., C. A. Geiger, M. J. Paget, M. L. Van Woert, S. F. Ackley, and T. L. DeLiberty, 2008: Thickness distribution of Antarctic sea ice. J. Geophys. Res. Oceans, 113, C05S92.

Wouters, B., D. Chambers, and E. J. O. Schrama, 2008: GRACE observes small-scale mass loss in Greenland. Geophys. Res. Lett., 35, L20501.

Wu, Q., T. Zhang, and Y. Liu, 2012: Thermal state of the active layer and permafrost along the Qinghai-Xizang (Tibet) Railway from 2006 to 2010. Cryosphere, 6, 607-612. 
Wu, Q. B., and T. J. Zhang, 2008: Recent permafrost warming on the Qinghai-Tibetan plateau. J. Geophys. Res. Atmos., 113, D13108.

Wu, Q. B., and T. J. Zhang, 2010: Changes in active layer thickness over the QinghaiTibetan Plateau from 1995 to 2007. J. Geophys. Res. Atmos., 115, D09107.

Wu, X. P., et al., 2010: Simultaneous estimation of global present-day water transport and glacial isostatic adjustment. Nature Geosci., 3, 642-646.

Xie, H., et al., 2011: Sea-ice thickness distribution of the Bellingshausen Sea from surface measurements and ICESat altimetry. Deep-Sea Res. Pt. Ii, 58, 1039-1051.

Xu, Y., E. Rignot, D. Menemenlis, and M. Koppes, 2012: Numerical experiments on subaqueous melting of Greenland tidewater glaciers in response to ocean warming and enhanced subglacial discharge. Ann. Glaciol., 53, 229-234.

Yao, T., et al., 2012: Different glacier status with atmospheric circulations in Tibetan Plateau and surroundings. Nature Clim. Change, 2, 663-667

Yde, J. C., and N. T. Knudsen, 2007: 20th-century glacier fluctuations on Disko Island (Qeqertarsuaq), Greenland. Ann. Glaciol., 46, 209-214.

Yde, Y. C., and O. Pasche, 2010: Reconstructing climate change: Not all glaciers suitable. EOS, 91, 189-190.

Young, D. A., et al., 2011a: A dynamic early East Antarctic Ice Sheet suggested by ice-covered fjord landscapes. Nature, 474, 72-75.

Young, N. E., J. P. Briner, Y. Axford, B. Csatho, G. S. Babonis, D. H. Rood, and R. C. Finkel, $2011 \mathrm{~b}$ : Response of a marine-terminating Greenland outlet glacier to abrupt cooling 8200 and 9300 years ago. Geophys. Res. Lett., 38, L24701.

Zamolodchikov, D., 2008: Recent climate and active layer changes in northeast Russia: Regional output of Circumpolar Active Layer Monitoring (CALM). In: Proceedings of the 9th International Conference on Permafrost, 29 June-3 July 2008, Institute of Northern Engineering, University of Alaska, Fairbanks [D. L. Kane, and K. M. Hinkel (eds.)], pp. 2021-2027.

Zdanowicz, C., A. Smetny-Sowa, D. Fisher, N. Schaffer, L. Copland, J. Eley, and F. Dupont, 2012: Summer melt rates on Penny Ice Cap, Baffin Island: Past and recent trends and implications for regional climate. J. Geophys. Res., 117, F02006.

Zeeberg, J., and S. L. Forman, 2001: Changes in glacier extent on north Novaya Zemlya in the twentieth century. Holocene, 11, 161-175.

Zemp, M., H. J. Zumbhul, S. U. Nussbaumer, M. H. Masiokas, L. E. Espizua, and P. Pitte, 2011: Extending glacier monitoring into the Little Ice Age and beyond. PAGES News, 19, 67-69.

Zhang, T., R. G. Barry, K. Knowles, J. A. Heginbottom, and J. Brown, 1999: Statistics and characteristics of permafrost and ground ice distribution in the Northern Hemisphere. Polar Geogr., 23, 147-169.

Zhang, T., R. G. Barry, K. Knowles, F. Ling, and R. L. Armstrong, 2003: Distribution of seasonally and perennially frozen ground in the Northern Hemisphere. In: Proceedings of the 8th International Conference on Permafrost, 21-25 July 2003, Zurich, Switerland [Phillips, M., S.M. Springman, and L.U. Arenson (eds)]. A. A. Balkema, Lisse, the Netherlands, pp. 1289-1294.

Zhang, T. J., 2005: Influence of the seasonal snow cover on the ground thermal regime: An overview. Rev. Geophys., 43, RG4002

Zhang, T. J., et al., 2005: Spatial and temporal variability in active layer thickness over the Russian Arctic drainage basin. J. Geophys. Res. Atmos., 110, D16101.

Zhao, L., Q. B. Wu, S. S. Marchenko, and N. Sharkhuu, 2010: Thermal state of permafrost and active layer in central Asia during the International Polar Year. Permafr. Periglac. Process., 21, 198-207.

Zhou, Y., D. Guo, G. Qiu, G. Cheng, and S. Li, 2000: Geocryology in China. Science Press, Beijing, China, 450 pp.

Zimov, S. A., E. A. G. Schuur, and F. S. Chapin, 2006: Permafrost and the global carbon budget. Science, 312, 1612-1613.

Zuo, Z., and J. Oerlemans, 1997: Contribution of glacier melt to sea-level rise since AD 1865: A regionally differentiated calculation. Clim. Dyn., 13, 835-845.

Zwally, H. J., and P. Gloersen, 2008: Arctic sea ice surviving the summer melt: interannual variability and decreasing trend. J. Glaciol., 54, 279-296.

Zwally, H. J., and M. B. Giovinetto, 2011: Overview and assessment of Antarctic IceSheet mass balance estimates: 1992-2009. Surv. Geophys., 32, 351-376.

Zwally, H. J., D. H. Yi, R. Kwok, and Y. H. Zhao, 2008: ICESat measurements of sea ice freeboard and estimates of sea ice thickness in the Weddell Sea. J. Geophys. Res. Oceans, 113, C02S15.

Zwally, H. J., J. C. Comiso, C. L. Parkinson, D. J. Cavalieri, and P. Gloersen, 2002a: Variability of Antarctic sea ice 1979-1998. J. Geophys. Res., 107, 1029-1047.

Zwally, H. J., W. Abdalati, T. Herring, K. Larson, J. Saba, and K. Steffen, 2002b: Surface melt-induced acceleration of Greenland ice-sheet flow. Science, 297, 218-222.
Zwally, H. J., et al., 2005: Mass changes of the Greenland and Antarctic ice sheets and shelves and contributions to sea-level rise: 1992-2002. J. Glaciol., 51, 509-527.

Zwally, H. J., et al., 2011: Greenland ice sheet mass balance: Distribution of increased mass loss with climate warming; 2003-07 versus 1992-2002. J. Glaciol., 57, 88-102. 


\section{Appendix 4.A: Details of Available and Selected Ice Sheet Mass Balance Estimates from 1992 to 2012}

All comprehensive mass balance estimates available for Greenland, and the subset of those selected for this assessment (Section 4.4.2) are listed in Tables 4.A.1 and 4.A.2. Those available for Antarctica are shown in Tables 4.A.3 and 4.A.4. These studies include estimates made from satellite gravimetry (GRACE), satellite altimetry (radar and laser) and the mass balance (flux) method. The studies selected for this assessment are the latest made by different research groups, for each of Greenland and Antarctica. The tables indicate whether smaller glaciers peripheral to the ice sheet are included, or excluded, in the estimate, and explain why some studies were not selected (e.g., earlier estimates from the same researchers have been updated by more recent analyses using extended data).

Table 4.A.1 | Sources used for calculation of ice loss from Greenland.

\begin{tabular}{|c|c|c|c|c|c|c|c|}
\hline Source & Method & Start & End & Gt $y r^{-1}$ & Uncertainty & $\begin{array}{l}\text { Peripheral } \\
\text { Glaciers }\end{array}$ & Comment \\
\hline \multirow{2}{*}{ Ewert et al. (2012) } & Laser alt. & 2003.8 & 2008.2 & -185 & 28 & Excluded & \\
\hline & GRACE & 2002.7 & 2009.5 & -191 & 21 & Included & \\
\hline Harig and Simons (2012) & GRACE & 2003.0 & 2011.0 & -200 & 6 & Included & $\begin{array}{l}\text { Yearly estimates used in compilation. } \\
\text { GIA uncertainty not provided. }\end{array}$ \\
\hline \multirow[t]{3}{*}{ Sasgen et al. (2012) } & GRACE & 2002.7 & 2011.7 & -240 & 18 & Included & Yearly estimates used in compilation. \\
\hline & Flux & 2002.7 & 2011.7 & -244 & 53 & Excluded & Yearly estimates used in compilation. \\
\hline & Laser alt. & 2003.8 & 2009.8 & -245 & 28 & Included & \\
\hline \multirow[t]{2}{*}{ Chen et al. (2011) } & GRACE & 2002.3 & 2005.3 & -144 & 25 & Included & \\
\hline & GRACE & 2005.3 & 2009.9 & -248 & 43 & Included & \\
\hline Rignot et al. (2011c) & Flux & 1992.0 & 2010.0 & -154 & 51 & Excluded & Yearly estimates used in compilation. \\
\hline Schrama and Wouters (2011) & GRACE & 2003.2 & 2010.1 & -201 & 19 & Included & 2 standard deviation $(2 \sigma)$ uncertainty \\
\hline Sorensen et al. (2011) & Laser alt. & 2003.8 & 2008.2 & -221 & 28 & Included & \\
\hline \multirow[t]{2}{*}{ Zwally et al. (2011) } & Radar alt. & 1992.3 & 2002.8 & -7 & 3 & Excluded & \\
\hline & Laser alt. & 2003.8 & 2007.8 & -171 & 4 & Excluded & \\
\hline Pritchard et al. (2010) & GRACE & 2003.6 & 2009.6 & -195 & 30 & Included & \\
\hline Wu et al. (2010) & $\begin{array}{l}\text { GRACE } \\
+ \text { GPS }\end{array}$ & 2002.4 & 2009.0 & -104 & 23 & Included & Global inversion technique. \\
\hline Baur et al. (2009) & GRACE & 2002.6 & 2008.6 & -159 & 11 & Included & No GIA correction. \\
\hline Cazenave et al. (2009) & GRACE & 2003.0 & 2008.0 & -136 & 18 & Included & \\
\hline \multirow[t]{2}{*}{ Slobbe et al. (2009) } & GRACE & 2002.5 & 2007.5 & -178 & 78 & Included & \\
\hline & Laser alt. & 2003.1 & 2007.3 & -139 & 68 & Included & \\
\hline Velicogna (2009) & GRACE & 2002.3 & 2009.1 & -269 & 33 & Included & $\begin{array}{l}\text { Time series extended to } 2012 \text { using } \\
\text { new data and published method. Yearly } \\
\text { estimates derived from cited trend. }\end{array}$ \\
\hline
\end{tabular}


Table 4.A.2 | Sources NOT used for calculation of ice loss from Greenland.

\begin{tabular}{|c|c|c|c|c|c|c|c|}
\hline Source & Method & Start & End & Gt $\mathrm{yr}^{-1}$ & Uncertainty & $\begin{array}{l}\text { Peripheral } \\
\text { Glaciers }\end{array}$ & Comment \\
\hline \multirow[t]{2}{*}{ Shepherd et al. (2012) } & Flux & 1992.0 & 2009.9 & -154 & 51 & Excluded & $\begin{array}{l}\text { This comprehensive inter-comparison rec- } \\
\text { onciles estimates from different techniques. } \\
\text { The "reconciled" value is the best estimate } \\
\text { from all techniques. This source is discussed } \\
\text { separately and not included within the } \\
\text { average assessment presented here. }\end{array}$ \\
\hline & Reconciled & 1992.0 & 2011.0 & -142 & 49 & - & \\
\hline van den Broeke (2009) & Flux & 2003.0 & 2009.0 & -237 & 20 & Excluded & Superseded by Rignot et al. (2011c). \\
\hline \multirow[t]{2}{*}{ Rignot et al. (2008a) } & Flux & 1996.0 & 1997.0 & -97 & 47 & Excluded & Superseded by Rignot et al. (2011c). \\
\hline & Flux & 2000.0 & 2001.0 & -156 & 44 & Excluded & \\
\hline Ramillien et al. (2006) & GRACE & 2002.5 & 2005.2 & -129 & 15 & Included & Superseded by Cazenave et al. (2009). \\
\hline \multirow[t]{3}{*}{ Rignot and Kanagaratnam (2006) } & Flux & 1996.0 & 1997.0 & -83 & 28 & Excluded & Superseded by Rignot et al. (2011c). \\
\hline & Flux & 2000.0 & 2001.0 & -127 & 28 & Excluded & \\
\hline & Flux & 2005.0 & 2006.0 & -205 & 38 & Excluded & \\
\hline \multirow[t]{2}{*}{ Thomas et al. (2006) } & Radar alt. & 1994.0 & 1999.0 & -27 & 23 & Excluded & $\begin{array}{l}\text { Includes only half the ice sheet and } \\
\text { fills in the rest with a melt model. }\end{array}$ \\
\hline & Radar alt. & 1999.0 & 2005.0 & -81 & 24 & Excluded & \\
\hline \multirow[t]{2}{*}{ Velicogna and Wahr (2006a) } & GRACE & 2002.3 & 2004.3 & -95 & 49 & Included & Superseded by Velicogna (2009). \\
\hline & GRACE & 2004.3 & 2006.3 & -313 & 60 & Included & \\
\hline
\end{tabular}

Table 4.A.3 | Sources used for calculation of ice loss from Antarctica.

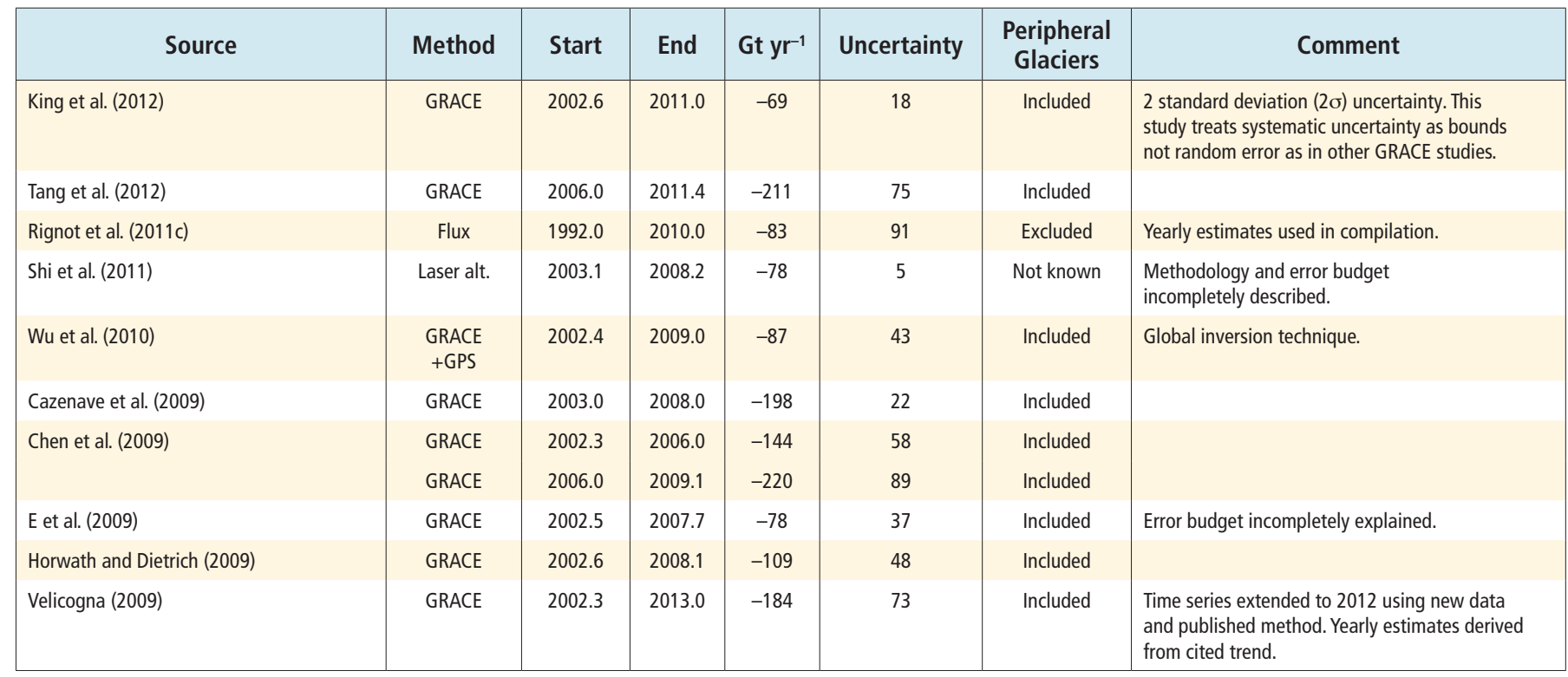


Table 4.A.4 | Sources NOT used for calculation of ice loss from Antarctica.

\begin{tabular}{|c|c|c|c|c|c|c|c|}
\hline Source & Method & Start & End & Gt $\mathrm{yr}^{-1}$ & Uncertainty & $\begin{array}{l}\text { Peripheral } \\
\text { Glaciers }\end{array}$ & Comment \\
\hline \multirow[t]{4}{*}{ Shepherd et al. (2012) } & Flux & 1992.0 & 2010.0 & -110 & 89 & Excluded & $\begin{array}{l}\text { This comprehensive inter-comparison reconciles } \\
\text { estimates from different techniques. Estimates are } \\
\text { made separately for East Antarctica, West Antarctica } \\
\text { and the Antarctic Peninsula. The "reconciled" value is } \\
\text { the best estimate from all techniques. The results from } \\
\text { this study are discussed separately and not included } \\
\text { within the average assessment presented here. }\end{array}$ \\
\hline & GRACE & 2003.0 & 2011.0 & -90 & 44 & Included & \\
\hline & Laser alt. & 2003.8 & 2008.7 & +21 & 76 & Excluded & \\
\hline & Reconciled & 1992.0 & 2011.0 & -71 & 53 & - & \\
\hline Jia et al. (2011) & GRACE & 2002.6 & 2010.0 & -82 & 29 & Included & No consideration of gravity signal leakage. \\
\hline Zwally and Giovinetto (2011) & Radar alt. & 1992.3 & 2001.3 & -31 & 12 & Excluded & $\begin{array}{l}\text { Same data analysis as Zwally et al. (2005). } \\
\text { Excludes Antarctic Peninsula. }\end{array}$ \\
\hline Gunter et al. (2009) & Laser alt. & 2003.1 & 2007.1 & -100 & $?$ & Not known & No error bar and no final estimate. \\
\hline Moore and King (2008) & GRACE & 2002.3 & 2006.0 & -150 & 73 & Included & Superseded by King et al. (2012) \\
\hline \multirow[t]{2}{*}{ Rignot et al. (2008b) } & Flux & 1996.0 & 1997.0 & -112 & 91 & Excluded & Superseded by Rignot et al. (2011c). \\
\hline & Flux & 2006.0 & 2007.0 & -196 & 92 & Excluded & \\
\hline Ramillien et al. (2006) & GRACE & 2002.5 & 2005.2 & -40 & 36 & Included & Superseded by Cazenave et al. (2009). \\
\hline Velicogna and Wahr (2006b) & GRACE & 2002.3 & 2005.8 & -139 & 73 & Included & Superseded by Velicogna (2009). \\
\hline Zwally et al. (2005) & Radar alt. & 1992.3 & 2001.3 & -31 & 52 & Excluded & Antarctic Peninsula excluded. \\
\hline Wingham et al. (2006) & Radar alt. & 1992.8 & 2003.1 & 27 & 29 & Not known & $\begin{array}{l}\text { No data in Antarctic Peninsula; series truncated within } \\
100 \mathrm{~km} \text { of coast. }\end{array}$ \\
\hline Rignot and Thomas (2002) & Flux & Not specific & $\begin{array}{l}\text { Not } \\
\text { specific }\end{array}$ & -26 & 37 & Excluded & Not an ice-sheet wide estimate. \\
\hline Wingham et al. (1998) & Radar alt. & 1992.3 & 1997.0 & -60 & 76 & Not known & Superseded by Wingham et al. (2006). \\
\hline
\end{tabular}

